\title{
Technological change and work
}

The relation between technology implementation within organizations and changes in workers' employment

Jannes ten Berge 


\section{Technological change and work}

The relation between technology implementation within organizations and changes in workers' employment

Jannes ten Berge 


\section{Manuscript committee:}

Prof. dr. P.T. de Beer (University of Amsterdam)

Prof. dr. E. Hamaker (Utrecht University)

Prof. dr. J.C. Vrooman (Sociaal en Cultureel Planbureau, Utrecht University)

Prof. dr. F. van Tubergen (Utrecht University)

Dr. F. Dekker (SEOR, Erasmus University Rotterdam)

Cover design Harriët van Reek and Jannes ten Berge

Printed by Ridderprint | www.ridderprint.nl

ISBN: 978-94-6416-378-0

\section{(C) 2021 Jannes ten Berge}

All rights reserved. No part of this publication may be reproduced or transmitted in any form by any means, electronic or mechanical, including photocopy, recording, or any information storage or retrieval system, without permission in writing from the author. The copyright of the articles that have been accepted for publication or that already have been published, has been transferred to the respective journals. 


\section{Technological change and work}

The relation between technology implementation within organizations and changes in workers' employment

\section{Technologische verandering en werk}

De relatie tussen technologie implementatie binnen organisaties en baanveranderingen van werknemers

(met een samenvatting in het Nederlands)

\section{Proefschrift}

ter verkrijging van de graad van doctor aan de

Universiteit Utrecht

op gezag van de

rector magnificus, prof.dr. H.R.B.M. Kummeling, ingevolge het besluit van het college voor promoties

in het openbaar te verdedigen op

vrijdag 19 februari 2021 des ochtends te 10.30 uur

door

\section{Jan Beer ten Berge}

geboren op 11 oktober 1989

te Rotterdam 


\section{Promotoren:}

Prof. dr. ir. A.G. van der Lippe

Prof. dr. M. Goos

\section{Copromotor:}

Dr. Z. Lippényi 


\section{Contents}

Chapter 1. Synthesis..............................................................................................................................9

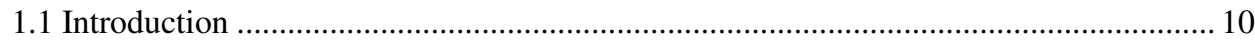

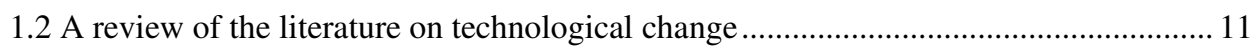

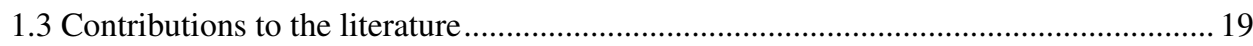

1.4 Institutions and employment protection in the Netherlands .......................................... 23

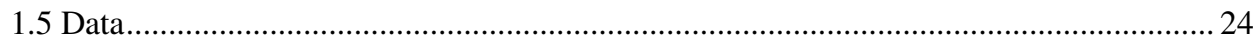

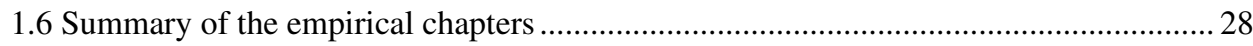

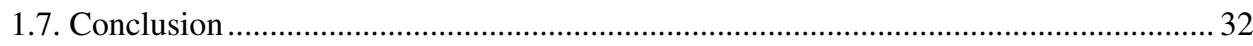

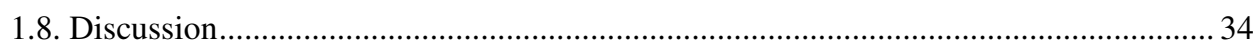

1.9 Limitations of the dissertation and suggestions for further research............................... 37

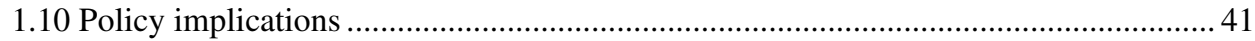

Chapter 2. Technology implementation within enterprises and job ending among employees. A study of the role of educational attainment, organizational tenure, age, and unionization........................................................................................................................................... 45

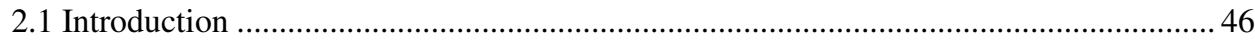

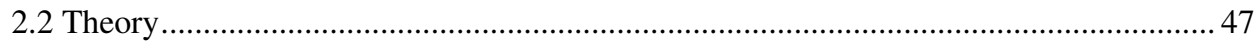

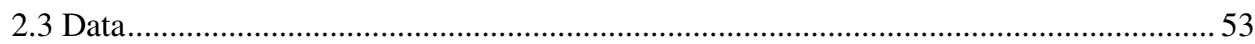

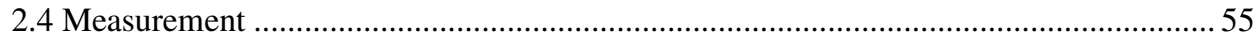

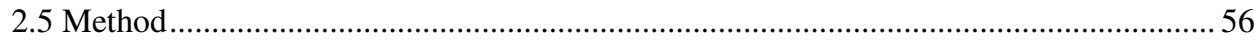

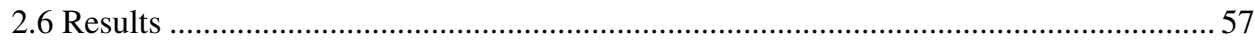

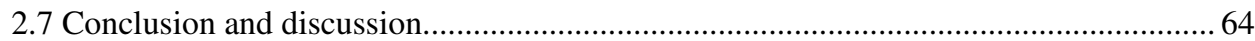

Chapter 3. Does technological change lead to longer job searches for workers who left their jobs?....................................................................................................................................... 69

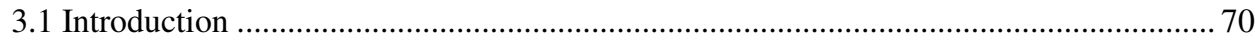

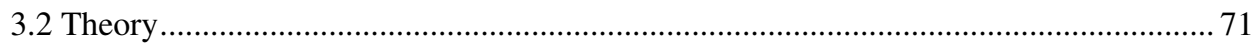

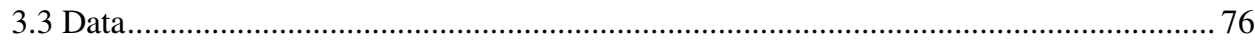

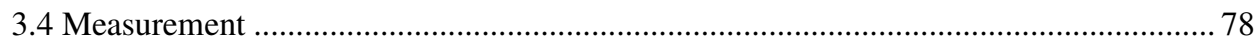

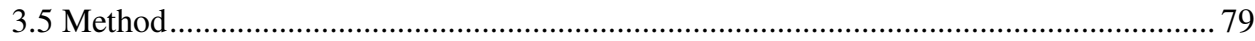

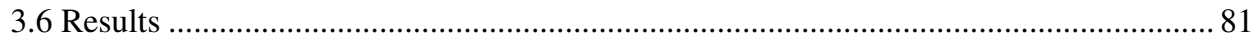

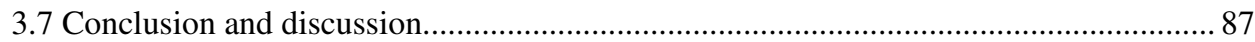

Chapter 4. Immigrant-biased technological change: The effect of technology implementation on employment of native workers and workers with non-Western immigrant backgrounds in the Netherlands..............................................................................93

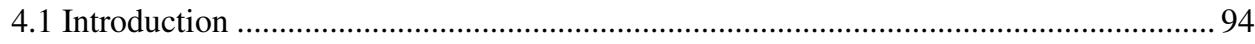




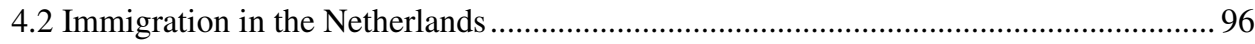

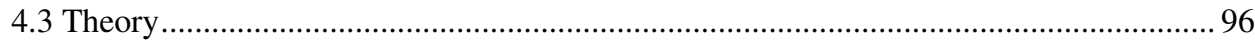

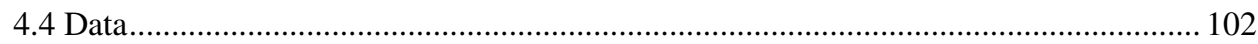

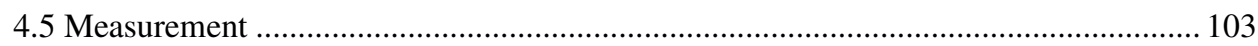

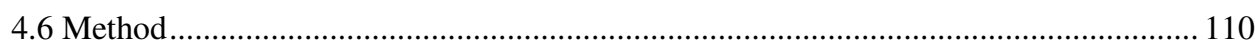

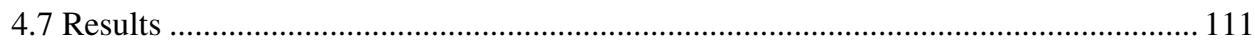

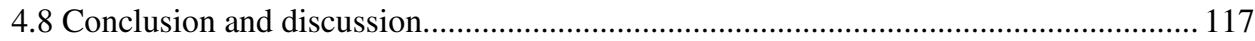

Chapter 5. Technology implementation within enterprises and changes in the educational and age composition of enterprise workforces .......................................... 121

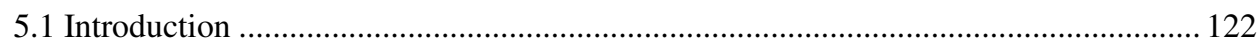

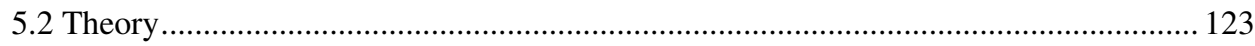

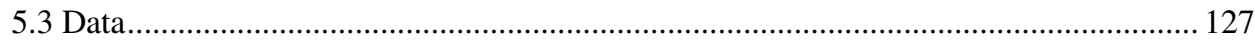

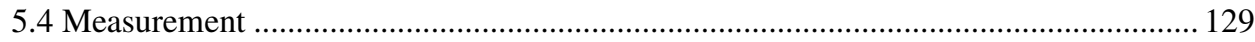

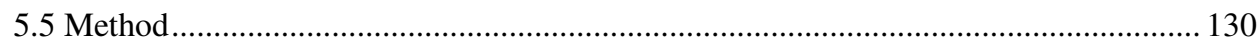

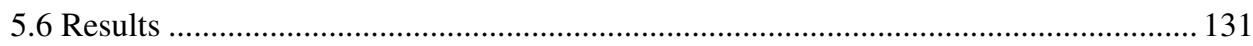

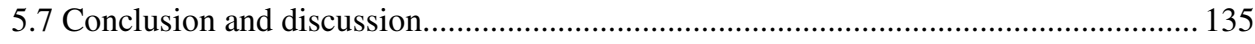

Appendix A .......................................................................................................................................................... 139

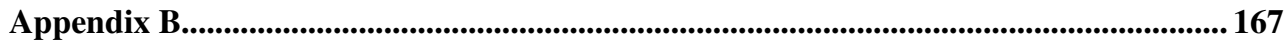

Nederlandse samenvatting (Dutch summary) ........................................................................... 173

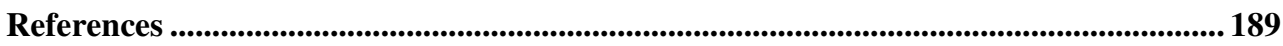

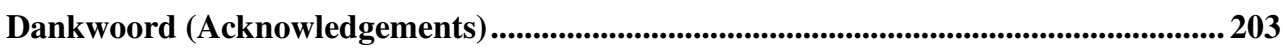

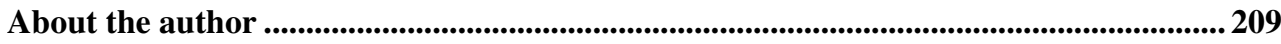

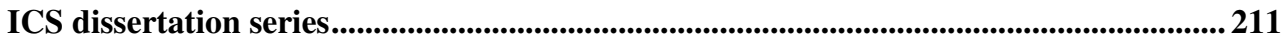






\title{
Chapter 1
}

\author{
Synthesis $^{1}$
}

${ }^{1}$ This chapter has benefited greatly from discussions with Zoltán Lippényi, Tanja van der Lippe and Maarten Goos. 


\subsection{Introduction}

In recent years there has been a surge in concerns about the pressure that technological advancement puts on the sustainability of employment. These concerns are fueled by speculations about an impending 'jobless future' as a result of accelerating advances in robotics and artificial intelligence and strengthened by studies examining the feasibility of replacing human labor by such soon-to-be-realized technological innovations. Predictions from these studies range between one tenth (Arntz, Gregory and Zierahn, 2017) to half of all US jobs (Osborne and Frey, 2017) becoming automatable in the near future.

Most research on technological change focuses on labor markets while little research has been done on how workers are affected by technological change. The question of how workers at the micro level are impacted when new technologies enter organizations is therefore left largely unanswered. This is remarkable, since much of the concerns articulated in media are about the effects of technological changes on people's jobs and employment opportunities, rather than labor markets (BBC, 2015; CNBC, 2019). For example, given the warning signals that technology replaces jobs of workers, do we find that the implementation of new technologies leads to workers leaving organizations? And if so, do these workers easily find new jobs? Automation may replace and displace workers. At the same time, however, technological change may provide employment opportunities for workers, as technology also creates new job tasks. Currently, it largely remains a puzzle how workers' employment is affected by the implementation of new technologies. The aim of this dissertation is to further these questions by studying technology implementation within organizations and its relation to workers' jobs ending and the successfulness of workers' job searches.

A principal question is whether the effects of technology implementation increase existing inequalities between workers. Research emphasizes that technology principally benefits capital owners (Kristal, 2013) and higher educated workers (Goldin and Katz, 2009), while forces of automation primarily impact the work of lower and middle educated workers (Autor, Levy and Murnane, 2003; Goos and Manning, 2007). These two processes are argued to increase labor market job polarization and to contribute to a weakening of the middle class. At the same time, technology arguably increases the need for new skills that complement technologies. This is concerning given that people are working till increasingly older ages (OECD, 2019). For older workers, the acceleration of technological innovation within organizations may provide an additional challenge to remaining productive throughout their already extended working lives. Moreover, fast technological changes may cause the productivity of tech-savvy workers to increase relative to experienced, but less technologically skilled workers. Finally, opportunities and challenges introduced by new technologies may increase competition between workers for jobs, potentially fostering animosity between worker groups as well as opportunity hoarding by dominant worker groups.

All in all, some workers are arguable more able to benefit from technological change, while for other workers securing employment may become increasingly difficult. Importantly, technology seems to be a potential amplifier of existing inequalities between worker groups. Despite these potentially undesirable effects of technology, our knowledge of how the employment of different workers is impacted by technological changes is surprisingly limited. This dissertation aims to improve our understanding of how technology differently impacts workers by investigating whether the relation between technology implementation within 
organizations and employment outcomes of workers differs depending on the education, organizational tenure, age, and migration background of workers. Additionally, we investigate whether the educational and age composition of organizational workforces change with the implementation of technologies.

Furthermore, technological changes are happening in a time in which the power of workers versus employers and capital is more and more tilting towards the latter. Financialization (Kollmeyer and Peters, 2019; Meyer, 2019; Tomaskovic-Devey and Lin, 2011 ), neoliberalization of political landscapes (Baccaro and Howell, 2011), the growth of precarious work (Kalleberg, 2011), and the decline of unionized jobs, union membership and collective bargaining coverage (Kristal, 2013, Kristal and Cohen, 2017; Kalleberg, 2011) are argued to have contributed to a loss of bargaining power among employees. When technological changes take place, the importance of bargaining processes arguably increases. Because of technological change organizational resources such as jobs, wages and training may be redistributed. The distribution of such resources is likely to benefit less powerful worker groups more as their bargaining power vis-a-vis powerful worker groups and employers increases. For example, Fernandez (2001) studying the retooling of a food-processing factory finds that the implementation of new technologies greatly altered work processes, created many new jobs requiring computer skills, and destroyed many old jobs. Importantly, he finds that the distribution of (re-)training and job tasks were greatly influenced by union bargaining as the union agreed to help (re-)train workers in exchange for no-layoff guarantees for the workers employed at the plant.

How bargaining power within organizations is distributed arguably differs between organizational and institutional settings. Within organizations and institutional settings where less powerful workers are better able to organize themselves, their power to bargain for their interests in times of technological change arguably increases. In this dissertation we aim to further this question by investigating whether and how the organizational and institutional context mitigate the effects of technology implementation on employment.

The overarching research question of the dissertation is: How does technology implementation differently impact the employment of workers depending on worker, organizational and institutional characteristics?

\subsection{A review of the literature on technological change}

\section{Skill-biased technological change}

Theory on the labor market effects of technological change is dominated by economical models that focus on the relation between technological advances and the marginal returns to human labor. During the first three quarters of the $20^{\text {th }}$ century, the returns to college education sharply increased, especially in the US. For economists this was puzzling, since the number of workers with college-education also rose sharply during that period, increasing the supply of college educated workers. All things equal, the increase in supply of higher skilled workers should have driven down the wage premia for college-education.

To solve this puzzle, Tinbergen $(1974,1975)$ proposed that technological changes during this period strongly increased the productivity of higher educated workers. The proposition that technology mainly complements the work of higher skilled workers later became famously known as the Skill-Biased Technological Change hypothesis. 
As a scholar interested in labor market inequality, Tinbergen proposed that technology and education are intertwined in a continuous 'race'. When technology spurs ahead of education, the demand for higher educated workers drives up the wages for these workers, increasing wage inequality between higher and lower educated workers. However, when education spurs ahead of technology, the supply of educated workers outgrows the demand for higher educated workers, thereby compressing wage dispersion on the labor market.

This macroeconomic model of labor market inequality focuses on the marginal returns to education and its relation to technological change and it served as an analytical model for volumes of scientific studies since. Overall, research findings seem to confirm the SBTC hypothesis. For example, Autor, Katz and Krueger (1989), studying aggregate changes in the relative supplies and wages of workers by education from 1940 to 1996 in the US find persistent growth in relative demand of college graduates. They also find that this skill upgrading has been greater in more computer-intensive industries. Krueger (1993) finds computer use at work to associate with around 10 to $15 \%$ higher wages than similar workers who do not use a computer. Furthermore, Krueger finds the expansion in computer use during the 1980's to account for between one-third and one-half of the observed increase in the rate of returns to education. Focusing on US manufacturing, Berman, Bound and Griliches (1994) similarly find the use of skilled labor to increase with investment in computers and R\&D. Goldin and Katz (1998) also find this technology-skill complementarity for data focusing on the first half of the $20^{\text {th }}$ century. In addition, Katz (2009), elaborating on Tinbergen's 'race' between technology and education offers evidence in favor of this model. Up until the 1970's, the rise in college education was of such magnitude that it could keep up with the pace of technological change, resulting in decreased wage inequality for the US. However, from the 1970's onward, the education boom started to slow down (Katz, 1999), while technology, mainly computer technology, kept steadily advancing, leading to an increase in wages among higher skilled higher educated relative to lower skilled lower educated workers (also see Acemoglu, 2002). Finally, research testing the SBTC across different countries in the OECD similarly conclude that technological change associates with increased demand for more higher skilled workforces (Berman, Bound and Machin, 1998; Machin and Van Reenen, 1998).

Despite ample studies presenting evidence in favor of the Skill-Biased Technological Change hypothesis, not all researches reach the same conclusions. At the heart of this 'revisionist' literature stand Card and DiNardo (2002), which point to several problems with the SBTC hypothesis. They show that despite continuing advances in computer technology during the 1990's, wage inequality stabilized during this period. Furthermore, they point towards the inability of SBTC to explain the closing of the gender gap, the stability of the racial wage gap, and the dramatic rise in education-related wage gaps for younger versus older workers. Pointing to findings from Lee (1999), Card and DiNardo argue that the fall of the real minimum wage is better able to explain rises in aggregate inequality in the 1980's. Additionally, Katz (1999), investigating the development of wage structures and returns to education across the US and a multitude of countries in the OECD, shows that the supply and demand frameworks and the role of SBTC herein are valuable, but fall short in elaborating on the role of institutional changes. The study proposes that the role of skill-biased technological change, globalization, and changes in demographics and relative skill supplies, industry labor rents, unions and the minimum wage should all be considered if one wants to account for divergent 
patterns in returns to education in equality within and between countries. For example, where the UK and the US saw large increases in wage inequality during the 1980's, the Netherlands saw a moderate fall in wage differentials, and France, Germany and Italy showed no noticeable change in educational wage differentials. As argued in work in the area of political economy, differences in the constraints that institutions put on pure supply and demand labor market mechanisms are sure to play an important role in explaining such differences between countries (Hall and Soskice, 2001).

Another criticism of the SBTC framework is that it is largely unable to explain diverging patterns in the relation between technological change and the returns to skills. For example, Goldin and Katz (1998) argue that during the $19^{\text {th }}$ century technological changes increased the demand for low wage unskilled labor, rather than skilled labor. Advances in textile weaving machinery, for example, replaced skilled artisans with less skilled factory workers. Considered more problematic, however, is the inability of the SBTC framework to explain the polarization of labor markets, i.e. the growth of jobs in the lower skilled and higher skilled job segments relative to jobs in the middle skill segment (Goos and Manning, 2007).

\section{Tasks, technology, and the Routine-Biased Technological Change hypothesis}

At the base of the re-evaluation of the SBTC hypothesis stands a theoretical innovation which emphasizes the relation between work tasks and technology (Autor et al., 2003). According to the authors, in order for us to better understand how technological changes lead to changes in the demand for skills, we should zoom in on what exactly it is that computers do, and compare this with the job tasks that are involved in a job. They propose the following: First, that computers replace a limited, well-defined set of human activities, namely those involving routine, repetitive cognitive and manual tasks. The rationale here is that only repetitive tasks can be codified in computer language or captured in machine sequences. And two, that technology complements activities involving non-routine problem solving and interactive tasks. Computerization herein associates with declines in demand for routine manual and cognitive tasks and increased demand primarily for non-routine cognitive tasks. Finally, the authors translate the observed task shifts into educational demands, showing task-shifts to explain thirty to forty percent of the observed relative shift favoring college versus non-college educated work during 1970 to 1998 .

Taking this novel approach to understanding the effects of technological change, Goos and Manning (2007) complement the approach by showing that actually many low wage jobs involve job tasks that are manual non-routine, and that in fact jobs with routine tasks are more common in the middle wage job segment. For example, truck driving or shelf filling are generally low wage, lower skilled jobs that require much hand-eye coordination and are therefore very hard to replace with technology. At the same time, much work previously done by office clerks, such as book-keeping, generally a middle wage job, is highly routine, making these jobs susceptible to automation. The authors propose that technological change increases demand for workers in both the high and low wage job segments, while decreasing the demand for middle skilled workers in middle wage routine intense jobs. Finally, testing this hypothesis on data on the UK between 1975 and 1999, they conclude routine-biased technological change has led to a polarization of the British labor market between 'lousy', low wage jobs, and 'lovely' high wage jobs. 
The Routine-Biased Technological Change hypothesis, like the SBTC hypothesis has since become a central analytical framework for understanding how technology affects work, particularly in relation to job polarization within modern economies. Studying patterns of labor market inequality for the US, Autor, Katz and Kearney (2006) find that the 1990's saw employment growth at the bottom and top relative to the middle of the skill distribution. Studying the role of computerization, they provide evidence that computers, by complementing non-routine cognitive tasks, substituting routine tasks, and having little impact on non-routine manual tasks, can account for this polarization pattern. Studying polarization of US employment and wages, Autor and Dorn (2013) reach similar conclusions, finding that the adoption of information technology in routine-intense industries associated with a reallocation of low skill labor into service occupations (employment polarization), earnings growth at the tails of the distribution (wage polarization), and an inflow of skilled labor.

Moreover, routine-biased technological change as a complement to the SBTC hypothesis is argued to be able to explain why during the 1990's the demand for college educated workers decreased while the distribution of information technology expanded. This pattern, which earlier mentioned 'revisionists' Card and DiNardo (2002) took as evidence that the SBTC framework falls short in explaining labor market inequality, can be explained by the substitution of routine (middle-education) tasks by technology, according to Autor et al. (2008). (See Acemoglu and Autor (2011) for an analytical model relating technology (but also offshoring) to changes in the allocation of skills to job tasks, an according redistribution of workers across the labor market, and its consequences, based on supply and demand principles, for the wage distribution).

Corroborating findings for the US, Spitz-Oener (2006), studying West-German firms, finds that between 1979 to 1999 the diffusion of computers significantly contributed to increased skill requirements of work tasks within occupations. Moreover, investigating changes in the distribution of workers across occupations of different skill levels over this period, she finds, in accordance with the routinization hypothesis, relative increases in the lower and upper tail of the distribution. High skill occupations, such as engineers, consultants, tax accountants, merchandisers, dealers, and scientists, as well as low skill occupations, such as waiters, blacksmiths, domestic staff, hoteliers, and casters showed employment growth. Employment in middle skill occupations, such as office clerks, machine operators and galvanizers, however, decreased. Aiming to test the pervasiveness of the phenomenon of job polarization, Goos, Manning and Salomons (2009) conclude that routine-biased technological change associates with similar patterns of job polarization across (16) Western European countries (also see Michaels, Natraj and Van Reenen, 2014).

Despite ample evidence in favor of technology being a driver of job polarization, other authors propose that first, the pattern of job polarization is not as pervasive as previously mentioned studies suggest (Fernández-Macías, 2012). And second, that in order to understand divergent patterns in labor market changes, contributing factors other than technology cannot be overlooked. Testing the hypothesis that European countries experienced a polarization in their job quality structures, Fernández-Macías (2012) finds a plurality of patterns rather than uniform job polarization. They find that, conceding with usual institutional categorizations of Europe, Continental Europe saw job polarization, Scandinavia saw structural upgrading, while Southern 
Europe saw a relative expansion of middling jobs. The UK and Ireland being somewhere in between polarization and upgrading. The authors argue that institutions and institutional changes impact the structural change in employment, particularly in the lower end of the job quality structure. They provide evidence showing that the significant expansion of low-paid jobs of Continental Europe is associated with a process of deregulation of employment contracts, whereas union backed wage compression in Scandinavian countries plausibly relates to slower growth of low paid jobs.

Similarly, Kristal and Cohen (2017), comparing the relative contributions of technological change and institutional changes to wage inequality in the US, conclude that declining unions and the fall in the real value of the minimum wage explain about half of rising inequality, while computerization explains about one quarter. Kalleberg (2011) similarly emphasizes the weakening of unions and associated shifts in balance of power from workers to capital, as well as the growth of precarious non-standard work, as central contributors to job polarization. Finally, Dwyer (2013), also studying the US argues that prior research that focuses on technological change and weakening labor market institutions overlooks how growth in care jobs contributed significantly and increasingly to job polarization from 1983 to 2007. Care work, she shows, made up the largest group of jobs at the bottom of the wage structure over this period. While care work also grew at the top, it did not grow at all in the middle.

Further problematizing the routine-biased technological change hypothesis, FernándezMacías and Hurley (2017) assess the link between routine-biased technological change and job polarization using a novel operationalization of tasks. They conclude that routine tasks are not associated with skills in the polarized way proposed by the routinization hypothesis, nor to the observed cases of job polarization in Europe in 1995-2007. Instead, they find routine and cognitive tasks to be related to the skill-expansion of higher-paid jobs in the way predicted by the SBTC hypothesis. As argued in Fernández-Macías (2012), they conclude that polarization observed in some European countries is not primarily the result of technological change. Similarly, Cortes, Jaimovich and Sui (2017) find that automation can account for only a relatively small portion of the joint decline in routine employment.

All in all, many studies point toward technology as a driving factor of labor market polarization and inequality between higher and lower skilled workers within modern economies. Several authors, however, warn us that an overemphasis on technology leaves us blind for other factors that are alternative or complementary explanations to technology. In particular, institutional changes such as deregulation of employment contracts and rises in precarious non-standard work, the fall in real value of minimum wages and the weakening of unions are mentioned as drivers of inequality as well as reasons why the effects of technology vary across institutional contexts.

\section{Technological change and the future of work}

Recently, research focusing on how yet to be realized technological advances are going to change work and labor markets in the (near) future has strongly gained momentum. These studies attempt to gauge the types of technologies that will be developed, in what time spectrum these technologies will enter the labor market, and, importantly, what type of job tasks currently performed by humans these technologies will replace. 
Brynjolfsson and McAfee (2014) point towards the acceleration in advances in artificial intelligence, machine learning and robotics and the consequences that such a technological revolution has on work. Where technology was previously limited to performing a rather limited set of routine cognitive and manual tasks, newly developed technologies are starting to delve into what the RBTC literature calls non-routine manual and cognitive tasks. For example, developments in sensory technology combined with machine learning algorithms make technology increasingly adept at recognizing and reacting to its environment. As a result, selfdriving cars are now almost a reality. Jobs, such as truck driving, or public transport and the taxi branch, which employ millions are likely to be replaced by technology sooner or later. However, also non-routine cognitive tasks in high skilled jobs are potentially at risk. For example, advances in automated financial management and tax preparation, legal e-discovery or cancer diagnosis and treatment, increasingly replace tasks traditionally performed by highly skilled workers (Brynjolfsson and McAfee, 2014).

Osborne and Frey (2017) aim to quantify the effect these technological advances have on the labor market. They take 702 detailed occupations and compare the tasks involved in these occupations with prognoses about the tasks that soon to be realized technological innovations will be able to perform. Next, they assign a label of how 'at risk' of automation the occupation is. They predict that in the coming decades, around $47 \%$ of all US jobs are at high risk of being automated by new technologies. Their prognosis indicates that most workers in transportation and logistics, together with the bulk of office and administrative support and labor in production occupations is at risk. Moreover, they expect a substantial share of employment in service occupations to be highly susceptible to computerization, as a result of the diminishment of the comparative advantage of human labor in tasks involving mobility and dexterity. Finally, they conclude that most of these jobs are located in low-skill low-wage occupations. These workers will have to reallocate to tasks that are less susceptible to computerization, i.e. tasks requiring creative and social intelligence.

Following the methodology of ranking occupations' automation risk, other studies reach similar conclusions for other countries. Pajarinen and Rouvinen (2014) estimate that in Finland the share of automatable jobs is around 35\%, while estimations for Germany are as high as 59\% of jobs (Brzeski and Burk, 2015).

The methodology used by Frey and Osbourne (2017) has, however, been criticized for its focus on measuring the risk of automation for entire occupations, rather than job tasks (Arntz, Gregory and Zierahn, 2017). Autor (2015) argues that many occupations contain some tasks that are prone to automation, but because most occupations consist of a range of different tasks the automation of entire occupations is unlikely. For example, the automation of melanoma examination does not mean the end of dermatologists, since their occupation holds a range of other job tasks that are not as easily automated. Assessing the risk of automation of jobs for 21 OECD countries, taking into account the heterogeneity of workers' tasks within occupations, Arntz, Gregory and Zierahn (2017) find a much lower 9\% of jobs to be automatable. They conclude by underlining that 'risk of automation' should not be equated with actual or expected employment losses from technological advance. They argue that due to economic, legal, and social hurdles the actual utilization of new technologies is slow. Furthermore, even when technologies are implemented, workers can adjust to technological changes by switching tasks, preventing technological unemployment. Finally, technological 
advance also creates additional jobs. They warn, however, that low qualified workers are likely to bear the heaviest burden as automation likely hits them hardest, making the real challenge for the future coping with rising inequality and providing sufficient (re-)training to ensure successful adjustment to technological changes.

\section{Technological change, social categorization, and worker power}

Studying the relation between technological advancement and labor market changes in job structures and inequality most of the previously mentioned studies overlook the organization. Technological change primarily happens within organizations, and to understand how this impacts employment of workers, it is necessary to consider the inequalities in power that exist between organizational actors.

Within organizations workers compete for organizational resources such as jobs and training. How successful workers are in claiming organizational resources depends on how valid such claims are and relatedly on how much power workers have within the organization. Following the dominant human capital framework, we may expect that workers who have skills that accommodate new technologies have the most valid claims for jobs, wages, and training, as their expected growth in productivity due to technology is largest. The human capital model, however, has been criticized for being unable to account for the large and persisting inequalities between workers with similar skill and productivity levels (Tomaskovic-Devey and AventHolt, 2019). The reason why the human capital model falls short in explaining inequality is that it ignores the role of intra-organizational social-relations and the differences in organizational power that lie within these social-relations.

Power refers here to the ability of workers to influence and direct decisions made within the organization. Within organizations, workers who have more power are better able to claim jobs, wages, and training within the organization (Tomaskovic-Devey and Avent-Holt, 2019; Tilly, 1998). An important source of inequality in organizational power between workers is social categorization. Research finds that the unequal division of organizational resources often happens along lines of social categories, such as race (Tomaskovic-Devey, 1993) immigrant background (Melzer, Tomaskovic-Devey, Schunck and Jacobebbinghaus, 2018; TomaskovicDevey, Hällsten and Avent-Holt, 2015), gender (Baron and Bielby, 1986; Tomaskovic-Devey, 1993), educational attainment (Tomaskovic-Devey, Avent-Holt, Zimmer and Harding, 2009) and management-non-management (Hanley, 2014; Tomaskovic-Devey et al., 2009). Status differences between such groups are both created outside the organization, for example in schools (Domina, Penner and Penner, 2017) and imported into organizations, as well as (re)produced within organizations (Tilly, 1998). Within organizations, advantaged groups benefit from or make use of their categorical distinction to extract greater rewards for the positions they hold within organizations. For example, studying reorganizations within manufacturing firms Vallas (2006) finds that high-skilled engineers often referred to their educational credentials to successfully negotiate their allocation to complex analytical tasks at the expense of lower-educated process control engineers and technicians who resisted this allocation. Bielby and Baron (1986) studying Californian establishments find that when enterprises employ men and women in the same occupation, they are usually assigned different job titles, suggesting a structural basis for sex differences in promotion opportunities, occupational status, and earnings trajectories. Tomaskovic-Devey et al. (2015) examined 
Swedish and immigrant-native workplace wage gaps using longitudinal employer-employee panel data. They find that net of workers human capital, there are large immigrant-native wage gaps, which the authors link to social closure of better jobs and exploitation as a result of devaluing the jobs held by immigrant workers.

Social stereotypes and (statistical) discrimination are important causes of inequality in power to claim organizational resources that run along lines of social groups. For example, Roscigno, Garcia and Bobbit-Zeher (2007) studying over 14 thousand cases of filed employment discrimination complaints in Ohio, show that managers use particularistic criteria and subjectivity in evaluating workers. This particularism typically favored majority groups, showing compelling cases of management favoring Caucasian workers for promotion over African American workers, despite superior work experience among the latter group. Investigating wage disparities by race and gender, Huffman and Cohen (2004) and Petersen and Saporta (2004) similarly conclude that racial discrimination in the allocation of workers to positions within organizations are likely to play a part in maintaining US earnings inequalities. Also, Posthuma and Campion (2009) in a review of literature of age stereotypes in the workplace find that ageist stereotypes negatively influence older workers on numerous workrelated outcomes. These effects exist, even when the productivity of older workers contradicts ageist stereotypes.

Inequalities tied to social categorizations are likely to be important when technological changes take place. Technological changes, by re-organizing production processes, creating and destroying jobs, and by introducing promotion and training opportunities, can lead to a redistribution of organizational resources such as jobs and training. More powerful actors within the organization are more able to use technological changes to their own benefit and claim such resources. How categorical distinctions between workers tie into power processes within organizations and how this affects the outcome of technological changes for workers' employment warrants investigation.

\section{Technological change, worker power and the organizational and institutional context}

Besides studying intra-organizational inequality in power between workers, research studying inequality between workers within organizations is increasingly interested in studying the role of the organizational context. This research proposes that the salience of social categorization and its relation to power within organizations is likely to differ between organizations. For example, Tomaskovic-Devey et al. (2015) find that, net of observed and fixed effect controls for individual traits, workplace immigrant-native wage gaps decline with increased workplace immigrant employment and managerial representation and increase when job segregation rises. They argue that the categorical distinction of non-Western immigrant as a subordinate status trait is less salient in workplaces with more immigrants as well as in workplaces in which immigrant workers are represented in management, increasing bargaining power for immigrant workers. At the same time, in workplaces were immigrant and native workers are segregated into lower and higher status jobs, bargaining power of immigrant workers is lower and wage inequality increases. Other research on the role of organizational characteristics argue that increases in the group size of workers can also increase perceptions of threat among dominant groups of workers. Research finds support for increased competition with increasing proportions of women versus men in Japanese organizations (Avent-Holt and Tomaskovic- 
Devey, 2012) and racial competition in the US prior to 1980 (Stainback and TomaskovicDevey, 2012). Melzer et al. (2018), studying German firms, find that in workplaces with very high shares of immigrant workers the wage gap between first generation immigrants and native workers increases. The role of the organizational context and its relation to inequality in power between groups of workers is increasingly studied.

The study of the role of the organizational context in which social relations exist can furthermore be extended to include the institutional context in which organizations are embedded. Institutions can also influence intra-organizational processes of claims making and distribution of organizational resources. Institutions, such as centralized wage setting (Tomaskovic-Devey et al., 2015; Tomaskovic-Devey et al., 2009), formal human resource practices (Tomaskovic-Devey et al., 2009), and collective bargaining (Melzer et al., 2018), influence to what degree the distribution of organizational resources is open to opportunity hoarding and exploitation by powerful worker groups.

The perspective of positional power of groups of workers and the role of the organizational and institutional context is a promising avenue for studying how technology impacts workers. Fernandez (2001) studying the retooling of a food processing plant finds that unions helped workers to bargain for no-layoff and wage-guarantees. The author concludes that absent these policies, technology driven demand shocks would have greatly boasted race, gender, and overall inequality. In this instance, the institutional setting empowered workers to bargain for wage and job guarantees, mediating the effects of technological change. Intraorganizational differences in power between categorically distinct groups likely also direct the distribution of resources such as jobs, wages, and training. Kristal (2013) finds technological changes within US organizations to benefit and empower employers and managers over rankand-file workers (also see King, Reichelt and Huffman, 2017). The question how the impact of technology implementation within organizations varies across groups of works differing in organizational power, and the role of organizational and institutions herein, calls for further scientific investigation.

\subsection{Contributions to the literature}

This overview makes apparent that most studies on technological change concern the relation between technological changes and its consequence on aggregate wage and job distributions. Despite the possibly large consequences for individuals, there is scant attention to how technological change relates to employment outcomes for workers in the literature, and the role of worker, organizational and institutional characteristics herein.

A first contribution to the literature of this dissertation is that we investigate how technological change impact jobs of individual workers, rather than the labor market at large. We study how technological change relates to job ending among workers, how easily these workers can find employment elsewhere, and how organizational workforces change with the implementation of new technology. We complement the scarce literature that investigate the effects of technological change within organizations on employment of workers. Bauer and Bender (2004), studying German firms, find no significant effect of technological change on gross job and worker flows, but question their results due to their vague indicator of technological change. Bessen et al., (2019) studying the effects of automation within Dutch firms find investment in automation technologies to increase the probability of workers 
separating from their employer, to decrease days worked and to decrease wages. We move beyond these studies by paying explicit attention to categorical distinctions between workers that are related to organizational power, such as natives versus immigrants. Furthermore, we take the role of the organizational and institutional context in which the firm operates into account, which we argue are important in mitigating the effects of technological change.

A second contribution of the dissertation is that it provides an empirical and theoretical elaboration of how the impact of technological changes differs between workers. When new technologies are implemented within the organization, workers are likely to be differently able to adapt and respond to these technological changes. Some workers may find it easy to learn, or already have the skills to work with new technologies, while others may have trouble adapting to technological changes within the workplace. There is, however, a lack of research that systematically evaluates how the effects of technological changes on employment differ depending on key individual characteristics, such as education. Studying the adoption of new technology by US manufacturing firms, Siegel (1998) finds technology adoption to lead to a shift in labor composition towards higher educated workers. Similarly, Fernandez (2001), studying the retooling of a food processing plant, finds retooling to increase the skill requirements and overall level of education of the workforce. It remains unclear, however, what happened to individual workers. Did lower educated workers lose their job? And where the workers who lost their job able to easily find a new job? This dissertation contributes to this literature by testing whether the effects of technology implementation within organizations differently relate to chances of job ending and chances of finding re-employment depending on the educational level of workers.

We take a diversified approach of looking at the role of human capital under technological change that goes beyond educational differences. Workers also gain experience and skills working within organizations (Lazear, 2009). Furthermore, workers are differently able to adapt their skills to changing work requirements depending on their age (Bartel and Lichtenberg, 1987). For workers with long organizational tenure, skill depreciation due to technological change may be particularly problematic. Similarly, technology may increase the importance of adaptability and learning new skills, which may impart, for example, older workers or workers with language deficiencies. In this dissertation we disentangle how workers with different characteristics related to human capital dimensions are differently affected by technological changes at work. Specifically, we investigate the role of workers education, organizational tenure, age, and immigrant background.

A third contribution of the dissertation is that we study characteristics of workers and organizations that relate to power inequalities between workers. There is a lack of research on these factors that are distinct from human capital, and we therefore lack insights about the role of social processes associated with workers bargaining power and the role of social stereotypes under technological change. Technological changes within organizations are likely to be associated with a (re)distribution of resources such as jobs and training. This is likely to trigger competition among workers for the opportunities that such changes create, such as promotion, as well as to avoid being negatively affected by such changes, for example layoff. Under circumstances of competition for organizational resources, such as jobs, the salience of group categorization, such as black-white, old-young, male-female, blue collar-white collar, increases 
(Tomaskovic-Devey and Avent-Holt, 2019). Such categorical distinctions influence how organizational resources get distributed. We may expect that more powerful groups of workers are better able to benefit from technological changes. In part, the power to claim resources such as jobs and training depends on whether organizational decision makers see claims as legitimate based on expected productivity and 'worth' of a worker for the company. This expected productivity, when tied to social categories such as age, or ethnicity, is a social stereotype that is shown to influence organizational decision making, for example regarding hiring decisions, or investments in training. Moreover, these stereotypes influence decision making even when the actual productivity of these workers contradict these stereotypes (Posthuma and Campion, 2009, Tomaskovic-Devey and Avent-Holt, 2019).

Importantly, investigating the role of worker power can increase our understanding of how technology differently impacts workers. For example, based on the human capital framework, we may expect workers with longer organizational tenure to be more negatively impacted by technology implementation because skill depreciation may be stronger for these workers than recent hires. However, considering that tenured workers generally also have more power within organizations than new hires, we may formulate the contrasting hypothesis that workers with little tenure are more negatively affected by technological change. Despite the potential value of an approach that considers social relations, there is hardly any theoretical or empirical elaboration of how intra-organizational processes shape the effect of technological change on employment. This dissertation advances this question by studying how technology implementation differently impacts workers employment depending on social group distinctions based on educational levels, organizational tenure, age, and immigrationbackground. Furthermore, we study how the relevance of categorical distinctions differ depending on organizational and institutional characteristics. We do this by investigating how workers with immigrant backgrounds show different patterns of job ending depending on the percentage of immigrant workers and the volatility of jobs within organizations, and on the union density of the industry in which the organization operates.

A fourth contribution of the dissertation to the literature is that we study the role of the institutional context in which technological change occurs. The process of technology implementation is first and foremost an organizational phenomenon. How the implementation of new technologies affect workers is going to differ depending on the institutional context in which this organization operates and how such institutions shape organizational decision making.

Within the literature on the polarization of labor markets several authors have pointed towards the importance of institutions and institutional changes, regarding, among others, minimum-wages, unionization, and regulation of employment contracts, as important contributors of job polarization (Card and DiNardo, 2002; Fernández-Macías, 2012; Kalleberg, 2011; Kristal and Cohen, 2016). This dissertation proposes, however, that institutions are not only a separate factor to technological change for explaining employment outcomes. Rather, institutions are also important in determining the very effect of technological change itself. This dissertation focuses on technological changes within Dutch enterprises. The Dutch political economy is characterized by a high degree of cooperation, coordination and consultation between organizations, union federations, employer federations and the national, regional, and 
local governments. Within this corporatist institutional structure there is a high degree of organized interaction on all issues of social-economic policies, including labor legislation and social protection. This institutional structure gives workers the opportunity and bargaining power to influence decision making of organizational actors.

Much research on the (future) effects of technological changes focus on the US. Within this liberal market economy, workers enjoy much weaker institutional employment protection. The effects of technological changes on employment are likely to be stronger in the US where workers' bargaining power vis-a-vis employers is lower compared to institutional settings where institutions empower employees. Through institutions workers can bargain for measures that increase their opportunities to keep their job or to facilitate work-to-work transitions, for example through (re-)training (Choi, Leiter and Tomaskovic-Devey, 2008; Fernandez, 2001; Kalleberg, Wallace and Althauser, 1981; Kristal, 2013). Despite that institutions are likely to be important in mitigating the effects of technological change, there is little variation in, or attention paid to institutional settings within the literature on technological change.

Studying the Netherlands, we gauge the effects of technological change in an institutional setting that contrasts the US by its high degree of institutionalized employment protection and employee bargaining power. Employers in the Netherlands, when seeking to reorganize their workforce, for example because of the implementation of technology, are obliged to notify employee associations and propose arrangements mitigating negative employment consequences for employees. Although employers are not obliged to consult with collective workers' unions about these arrangements, in practice this is often done because unilateral agreements are considered less valid in case of arbitrage. The cooperation with unions legitimizes the actions of employers for external parties and gives workers the opportunity to influence the content of the arrangements. Such arrangements can, but do not necessarily, include reallocation of employees within the organization, re-training and/or aid in work-towork transitions. Within this institutional arrangement, strong unions arguably increase the bargaining power of workers to shape the effects of technological changes. This dissertation contributes to our understanding of the role of institutions by investigating the extent to which unions mitigate the effects of technological change for workers.

A final contribution of the dissertation concerns the data we use to study technological change. We use large scale survey data on (technological) innovation within Dutch enterprises in the private sector (excluding agriculture). The organizations within the survey are linked to register data from the Dutch Central Bureau of Statistics, creating a matched employer-employee dataset including over 35.000 enterprises, over 4 million employees and close to 7 million jobs over the period 2000-2014. The data contain around 2.5 million working individuals per year on average. This is over half of the working population in the private sector (excluding agriculture), which ranged between 3.5 to 4 million workers over the period 2000-2014. The data thus allow for a test of the effects of technological change using a representative dataset that covers almost all private sectors and spans over a decade. Save Bessen et al., (2019) it is, to our knowledge, the only test of the effects of technological changes using employeremployee data on such a vast range of enterprises and years.

The data contain a measure of technological change at the enterprise level. This means that we observe the impact of technological change on workers directly at its origins, within 
organizations. A limitation of much research on the effects of technological change is that the effect of technological change is often inferred from changes in the educational composition and the share of routine jobs within labor-markets. Consequently, direct empirical evidence on the worker-level impacts of technological change is lacking (Bessen et al., 2019). Technology is just one among many significant factors, such as offshoring and outsourcing (Goos et al., 2014), that influence aggregate labor market changes. Furthermore, testing the assumption that technologies are the main driver of declines in routine jobs, Nedelkoska (2013) finds little evidence that code-based technologies were driving observed declines in codified jobs within Germany. Linking data on the implementation of new technologies within Dutch enterprises with data on individual workers, we are able to directly measure how technological changes within organizations relate to changes in workers' jobs and organizational workforces, as well as the role of worker characteristics and the institutional context of organizations herein. Furthermore, using register data we are able to follow the employment of workers over time, allowing investigation of the successfulness of job searches of workers whose jobs are affected by technological changes.

\subsection{Institutions and employment protection in the Netherlands}

The dissertation focuses on organizations in the Netherlands. It is relevant, so we argue, to have a good understanding of the institutional setting in which technological change is studied. Particularly relevant is the level of employment protection and the ways in which workers can bargain for their interests. How technological changes impact work will be different between contexts where workers are not organized and have little rights and context were workers are well organized and have many rights.

The Netherlands are characterized by relatively high levels of employment protection. Comparing the Netherlands to 70 other countries within OECD data, we find the Netherlands to be among the top ten countries with the strictest regulations and procedures concerning the dismissal of workers with permanent contracts. ${ }^{2}$ Worker representation and bargaining are an integral part of the Dutch institutional model. Since the beginning of the 1980's, the Netherlands have developed an institutional structure with a high degree of organized interaction and consultation between union federations, employer federations, and the government. This corporatist institutional organization involves a high degree of consultation and coordination aimed at cooperatively constructing policies on all socio-economic issues, including labor legislation and employment protection (Hall and Soskice, 2001; Hartog, Leuven and Teulings, 2002). In practice, this means that when employers want to re-organize their workforce, they generally work together with employee associations and unions to look for ways to serve the interests of both employers and employees as much as possible.

Bargaining for collective agreements by unions is mostly done at the industry level. This centralized way of reaching agreements is characteristic of countries with more corporatist institutions such as the Netherlands and Germany. The result of which is that even when actual

\footnotetext{
${ }^{2}$ The OECD also ranks the regulation of fixed-term and temporary work agency contracts. In contrast with regular employment, the Netherlands have relatively mild regulation of fixed-term work; ranking $54^{\text {th }}$ out of 67 countries included in the OECD data (OECD, 2020). The dissertation focusses primarily on regular employment. I reflect on this in the discussion section of this chapter.
} 
union membership is low (17\% in the Netherlands in 2016, which is similar to the OECD average), the percentage of workers covered by a collective agreement is much higher $(79 \%$ in 2016, ranking $9^{\text {th }}$ among 36 countries included in OECD data (OECD, 2018 3$)$ ). This corporatist model contrasts with more liberal institutional settings, such as the US and the UK, where bargaining is much more decentralized resulting in mostly firm level agreements.

How technological change is organized by employers is influenced by the collective agreements that are in place, as well as the bargaining that employers and employee associations and unions do regarding arrangements and conditions under which technological changes take place. It is of interest to study the role of institutions in mitigating the effects of technological changes, since this possibly provides us with better ideas on how to install institutions that organize technological changes in a way that benefits both employers and employees.

\subsection{Data}

The data the dissertation relies on is a combination of large-scale enterprise survey data and social micro-register data. Data on organizational technological change is taken from the Community Innovation Survey (CIS). In this survey, higher managers from organizations are asked about the innovation activities of the organization over the last two years. It is a largescale cross-national survey that is repeated every two years. The survey uses a stratified random sampling design in which the sample is stratified by the size of enterprises and the principal activity in which enterprises are engaged in. The target population of the CIS includes most market activities, including the population of enterprises in: mining and quarrying, manufacturing, electricity, gas, steam and air conditioning supply, water supply, transportation and storage, information and communication, wholesale-trade (except motor vehicles and motorcycles), architectural and engineering activities, financial and insurance activities, scientific research and development, and advertising and market research. On a voluntary basis some countries covered additional "non-core economic" activities. ${ }^{4}$ Three size classes are included in the core target population: 10 to 49 employees, 50 to 249 employees and 250 or more employees. Enterprises smaller than 10 people were excluded from the survey.

CIS surveys differ between countries regarding the sampling strategy. The studies in the current dissertation focus on the Netherlands in which a combination of a sample survey and a census of the enterprises included in the frame population were carried out. A census was more common for larger enterprises within a sector, while smaller enterprises, where the population is particularly large, were sampled. The survey was mandatory and was collected using web and paper questionnaires. The CIS quality reports of the years 2008, 2012 and 2014 show that unit non-response rates are round 25 to 30 percent. Following Eurostat's recommendations, no non-response surveys where employed as non-response rates do not exceed 30 percent. The

\footnotetext{
${ }^{3}$ Layoffs and collective dismissals are regulated at the national level in the Netherlands. Looking at the strictness of legislation around individual dismissal, the Netherlands ranks $10^{\text {th }}$ out of 71 listed countries. Indonesia ranks $1^{\text {st }}$ while the US ranks last among OECD countries, which indicates that the Netherlands may be more of a 'typical' institutional case than the US with its very low levels of protection.

${ }^{4}$ Some deviations in the target population exist when comparing the different CIS surveys over time. However, overall, the core activities remain similar over time.
} 
sampling design makes it so that relative to the population of enterprises in the Netherlands, the CIS contains more larger companies and excludes organizations in the public sector.

To illustrate how enterprises in the CIS sample compare to the population of enterprises in the Netherlands, Table 1.1 and 1.2 provide descriptive statistics on the size and enterprise sector classifications of the CIS of 2014 and the population of enterprises in the $4^{\text {th }}$ quarter of 2014 in the Netherlands. Table 1.1 compares the CIS 2014 for different strata of enterprise sizes with the population of enterprises in the Netherlands. A first thing to note is that that most enterprises in the population have less than 10 employees. The sampling design of the CIS excludes enterprises smaller than 10 employees. Comparing the remaining strata of enterprise sizes, we see that the CIS includes a relatively large share of big enterprises compared to smaller enterprises. While more than $50 \%$ of the population of enterprises that have $200+$ employees is included in the CIS sample, for enterprises that have 10 to 50 employees, this share is less than $10 \%$.

Table 1.1 Enterprise size comparison between enterprises in the CIS 2014 sample and the total of enterprises in the Netherlands* in the 4th quarter of 2014

\begin{tabular}{llll}
\hline Employees: & $\begin{array}{l}\text { Total n enterprises } \\
\text { CIS 2014 }\end{array}$ & Total n enterprises & $\begin{array}{l}\text { CIS 2014 sample } \\
\text { as percentage of } \\
\text { total enterprises }\end{array}$ \\
\hline 0 to 10 & 0 & 981,725 & 0.00 \\
10 to 50 & 3,117 & 40,295 & 7.74 \\
50 to 200 & 1,974 & 7,850 & 25.15 \\
200 to 1000 & 1,024 & 1,810 & 56.57 \\
$1000+$ & 190 & 340 & 55.88 \\
\hline Total & 6,305 & $1,031,680$ & 0.61 \\
\hline for the sample selection of enterprises of the CIS, which correspond to enterprise \\
classifications B to N in Table 1.2.
\end{tabular}

Table 1.2 compares the total number of enterprises in the CIS 2014 sample, with the population of enterprises and the CIS target population of enterprises with 10+ employees. Looking at the sample sizes of enterprises in different sector classifications, we see that the CIS sample contains relatively many enterprises in sectors with smaller numbers of enterprises, such as mining and quarrying, compared to sectors with very large numbers of enterprises, such as wholesale and retail trade. This oversampling of enterprises in smaller sectors is congruent with the goal within the CIS sampling strategy to obtain a representative sample of the different sectors in the target population, including the smaller ones.

For the studies in this dissertation, the sampling selections mean that we cannot generalize the findings of the effects of technology implementation to enterprises smaller than ten employees, nor to organizations in the public sector. It is possible that technology implementation has different effects in very small organizations or in public organizations. For example, in one-man businesses labor saving technologies likely have a different impact on employment than in large organizations. However, we believe that gauging the effect of technology in larger business-oriented organizations is highly relevant, as many of the larger 
investments in labor saving technologies and technological innovations that impact employment of workers are likely to take place in these organizations.

Table 1.2 Total enterprises and enterprises with ten employees or more in the Netherlands in the final quarter of 2014, versus enterprises in the Community Innovation Survey 2014

\begin{tabular}{|c|c|c|c|c|c|}
\hline Enterprise classification & $\begin{array}{l}\text { Total } n \\
\text { enterprises } \\
\text { CIS } 2014\end{array}$ & $\begin{array}{l}\text { Total } \mathrm{n} \\
\text { enterprises }\end{array}$ & $\begin{array}{l}\text { CIS } 2014 \\
\text { sample as } \\
\% \text { of total } \\
\text { enterprises }\end{array}$ & $\begin{array}{l}\text { Total } n \\
\text { enterprises } \\
10+ \\
\text { employees }\end{array}$ & $\begin{array}{l}\text { CIS } 2014 \\
\text { sample as } \\
\% \text { of total } n \\
\text { enterprises } \\
10+ \\
\text { employees }\end{array}$ \\
\hline $\begin{array}{l}\text { A agriculture, forestry } \\
\text { and fishing }\end{array}$ & 37 & 69,275 & 0.05 & 1,875 & 1.97 \\
\hline $\mathrm{B}$ mining and quarrying & 57 & 385 & 14.81 & 70 & 81.43 \\
\hline $\mathrm{C}$ manufacturing & 1,787 & 57,600 & 3.10 & 8,225 & 21.73 \\
\hline $\begin{array}{l}\text { D electricity, gas, steam, } \\
\text { and air conditioning } \\
\text { supply }\end{array}$ & 45 & 955 & 4.71 & 80 & 56.25 \\
\hline $\begin{array}{l}\text { E water supply; sewerage, } \\
\text { waste management and } \\
\text { remediation activities }\end{array}$ & 66 & 1,350 & 4.89 & 300 & 22.00 \\
\hline F construction & 253 & 143,145 & 0.18 & 4,905 & 5.16 \\
\hline $\begin{array}{l}\text { G wholesale and retail } \\
\text { trade }\end{array}$ & 1,591 & 217,290 & 0.73 & 13,610 & 11.69 \\
\hline $\begin{array}{l}\text { H transportation and } \\
\text { storage }\end{array}$ & 487 & 34,865 & 1.40 & 3,450 & 14.12 \\
\hline $\begin{array}{l}\text { I accommodation and food } \\
\text { service activities }\end{array}$ & 89 & 49,420 & 0.18 & 4,295 & 2.07 \\
\hline $\begin{array}{l}\mathrm{J} \text { information and } \\
\text { communication }\end{array}$ & 541 & 76,865 & 0.70 & 2,795 & 19.36 \\
\hline $\mathrm{K}$ financial institutions & 131 & 80,540 & 0.16 & 1,115 & 11.75 \\
\hline $\begin{array}{l}\text { L renting, buying, and } \\
\text { selling of real estate }\end{array}$ & 51 & 23,690 & 0.22 & 710 & 7.18 \\
\hline $\begin{array}{l}\text { M consultancy, research, } \\
\text { and other specialized } \\
\text { business services }\end{array}$ & 896 & 285,320 & 0.31 & 5,890 & 15.21 \\
\hline $\begin{array}{l}\mathrm{N} \text { renting and leasing of } \\
\text { tangible goods and other } \\
\text { business support services }\end{array}$ & 311 & 60,570 & 0.51 & 4,850 & 6.41 \\
\hline $\begin{array}{l}\text { O public administration, } \\
\text { public services, and } \\
\text { compulsory social security }\end{array}$ & $y$ & 770 & 0.00 & 605 & 0.00 \\
\hline $\mathrm{P}$ education & 0 & 60,140 & 0.00 & 2,080 & 0.00 \\
\hline
\end{tabular}




\begin{tabular}{lccccr}
$\begin{array}{l}\text { Q human health and social } \\
\text { work activities }\end{array}$ & 0 & 116,315 & 0.00 & 4,460 & 0.00 \\
$\begin{array}{l}\text { R culture, sports, and } \\
\text { recreation }\end{array}$ & 0 & 87,090 & 0.00 & 1,420 & 0.00 \\
$\begin{array}{l}\text { S other service activities } \\
\text { T activities of households }\end{array}$ & 0 & 88,480 & 0.00 & 1,380 & 0.00 \\
$\begin{array}{l}\text { as employers; } \\
\text { undifferentiated goods-and }\end{array}$ & 15 & 0 & 0 & 0.00 \\
$\begin{array}{l}\text { service- producing } \\
\text { activities of households for } \\
\begin{array}{l}\text { own use } \\
\text { U extraterritorial } \\
\text { organizations and bodies }\end{array}\end{array}$ & & & & & \\
\hline
\end{tabular}

We focus on the period 2000-2014, during which a total of 37,525 enterprises participated in the Dutch CIS. The Netherlands make a relevant case for studying technological change as it is among the top-ranking countries regarding innovation (Cornell University, INSEAD, \& WIPO, 2015). The survey data on enterprises are linked to register data on workers' jobs, job searches, demographic characteristics, and institutional characteristics from the System of Statistics Databases (SSB) from the Dutch Central Bureau of Statistics, creating a longitudinal matched employer-employee dataset. Although the survey does not have a panel design, the large sample size makes that a substantial number of enterprises is surveyed multiple years. Out of 37,525 enterprises, 14,045 enterprises $(37,43 \%)$ are surveyed multiple times. Importantly, combining the survey data with register data allows studying employment relations, i.e. job beginnings and job endings, which are central in the empirical chapters.

In the observation period 2000-2014 the yearly average job ending rate of all jobs in the Netherlands was $35.23 \%$ (S.D. 2.09). ${ }^{5}$ A minor share of these job endings concern layoffs. Looking at the available data covering the period 2010-2013, the yearly average number of jobs in the Netherlands was approximately 7,8 million (excluding self-employed) (Statistics Netherlands, 2020). Out of the approximately 2,8 million jobs that ended annually, the average number of layoffs was approximately 156 thousand $(\sim 5.5 \%)$. Most of these layoffs were due to bankruptcy of the employer ( 70\%). The remaining layoffs, about 45 thousand annually, were due to other reasons such as business economic reasons or disturbed employment relationships (Statistics Netherlands, 2017). In the empirical chapters we rely on tax-register data to identify job beginnings and job endings. This data does not provide information about the reason why a job ends. We therefore do not know whether job endings concern voluntary quits or involuntary layoffs. In the empirical chapters we therefore use the more neutral term job ending.

Finally, information on technological change within enterprises is taken from the Community Innovation Survey. The CIS includes an item indicating whether the enterprise purchased advanced machinery, equipment (including computer hardware) and/or software

\footnotetext{
${ }^{5}$ For the sample of jobs that used in the studies presented in this dissertation the average yearly job ending rate over the period 2000-2014 is lower; $23.27 \%$ (S.D. 3.22). This is because we aggregate consecutive jobs and multiple jobs held by a person within the same enterprise as a single job record.
} 
over the past two to three years (depending on the survey date), with the goal to significantly improve products, services, and/or production processes. While this measure includes many different types of technologies, the wording of the item ensures that only technologies that have a significant impact within the enterprise, and thus likely to trigger changes in the organizational labor force, are included. Out of the 37,525 enterprises that participated in the survey we find 9,782 enterprises to have implemented new technologies between 2000 and 2014.

\subsection{Summary of the empirical chapters}

The following section provides an overview of the main findings and conclusions of the four empirical chapters. Chapter 2 focuses on the effect of technology implementation on job ending among employees, and the role of education, organizational tenure, age, and unions. Chapter 3 builds upon the previous chapter by investigating whether workers who leave the organization when technology is implemented show longer job searches, and whether this relation differs depending on education, organizational tenure and age, and on the union density of the industry in which the organization operates. Chapter 4 again looks at the relation between technology implementation and job ending and focuses on whether this effect differs between workers with a non-Western immigrant background and native Dutch workers. Furthermore, this chapter investigates whether this effect differs depending on the percentage of workers with a nonWestern immigrant background, the volatility of jobs within the organization, and on the union density of the industry. Finally, chapter 5 investigates how organizational workforces change, regarding their education and age composition, when new technologies are implemented, and whether this relation is different in industries with higher and lower union densities. 
Figure 1.1. Overview of chapters, dependent and independent variables

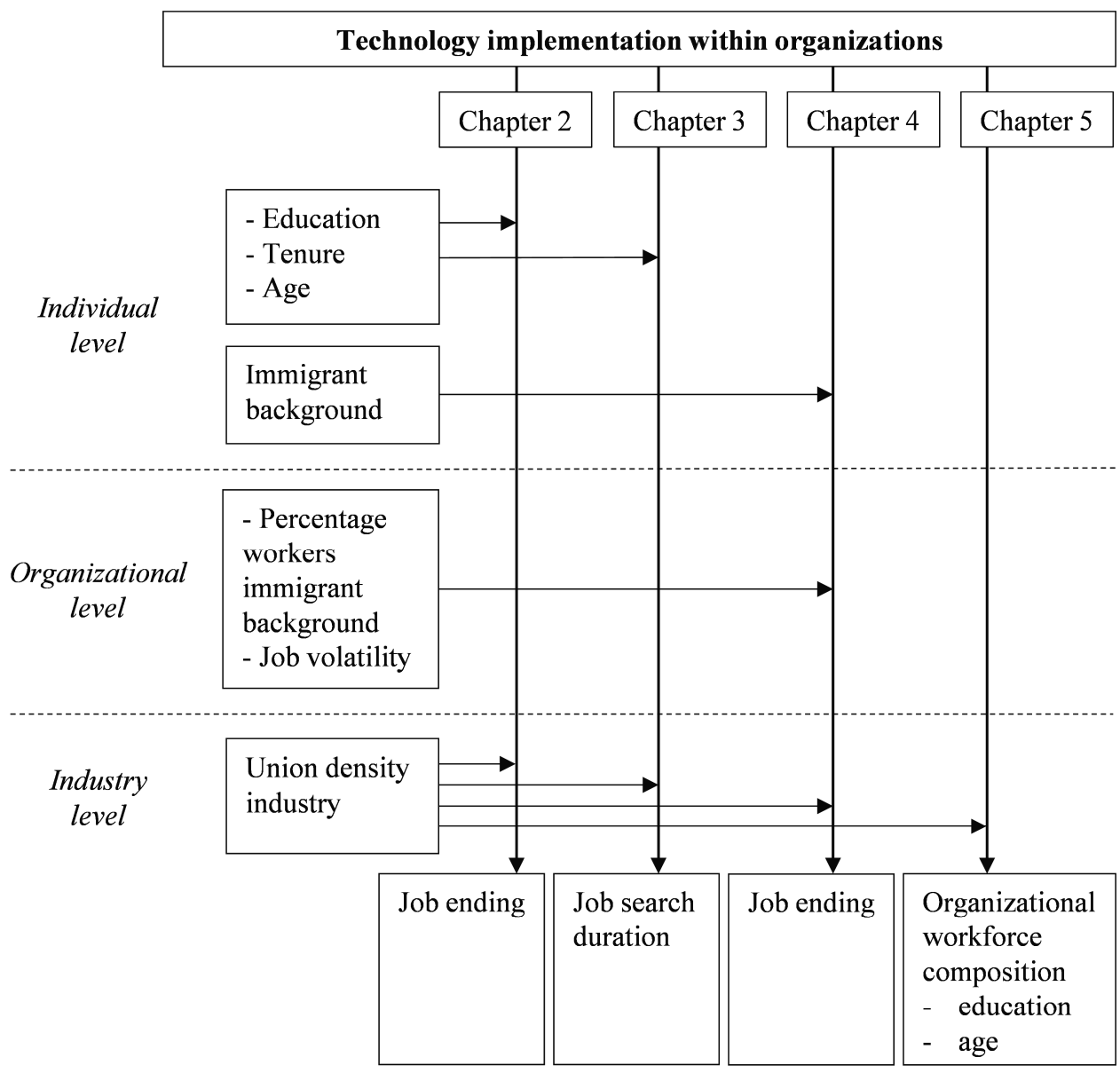

Chapter 2: Technology implementation within enterprises and job ending among employees. A study of the role of educational attainment, organizational tenure, age, and unionization

The second chapter of this dissertation investigates how technology implementation within workplaces impacts job ending among employees. We hypothesize that middle educated workers, workers with longer organizational tenure and older workers possess human capital that is less complementary to technological change, increasing chances of job ending. Partially contrasting these expectations, we furthermore hypothesize that workers with high educational credentials, tenured workers and older workers have more organizational bargaining power, decreasing chances of job ending. Additionally, the study investigates the role of unions in mitigating the effects of technology implementation. Linear probability models with fixed effects at the level of the enterprise and random effects at the worker level are used to analyze large scale longitudinal employer-employee data on technology implementation in Dutch enterprises. 
The findings indicate that technology implementation is associated with an overall decrease in the probability of job ending. Regarding the role of education, we find the chances of job ending for middle and higher educated workers to decrease, relative to lower educated workers, when new technologies are implemented. This finding suggests that workers with higher education are better able to complement technologies and capitalize on technological change. Furthermore, in line with the human capital arguments we find older workers (around $50+$ ) and workers with longer organizational tenure (around 15+ years) to have higher chances of job ending when technology is implemented. Finally, we do not find the effects of technology implementation to differ depending on the union density of the industry in which an enterprise operates.

\section{Chapter 3: Does technological change lead to longer job searches for workers who left their jobs?}

The third chapter explores how technology implementation affects the job search duration of workers leaving organizations. For workers who have jobs at risk of automation the chances of losing their job may increase due to technological changes. However, these workers may additionally have difficulty competing for jobs with other employers, as similar technological changes are likely to spread across organizations. We test the hypothesis that workers leaving enterprises that are in technological transition suffer longer job searches than workers leaving organizations what are not engaged in technological implementation. Furthermore, we investigate whether workers who are at risk of being replaced by technology, as well as workers who are less able to adapt their skills to technological changes -i.e. middle and lower educated, tenured and older workers- are less successful in finding employment after leaving an organization that is implementing new technologies. Finally, we test whether the presence of stronger unions within an industry mitigates the effect of technological change on job search duration of workers.

Using Cox-proportional hazards models we analyze data on over a million job to job transitions of workers in the Netherlands. In line with our expectation, we find the chances of starting a new job to be lower among workers leaving enterprises that are implementing new technologies compared to workers leaving enterprises that are not implementing technology. It appears that workers whose jobs are affected by technological changes are also less successful in finding re-employment. This finding appears to support initiatives that strengthen the employability of workers affected by technological change, such as (re-)training and help with work-to-work transitions.

Another main result is that for older workers who leave enterprises implementing new technologies we find chances of finding re-employment to be smaller than for younger workers. This may be because of lesser training opportunities and adaptive capabilities related to age. Furthermore, older workers seeking employment under technological change may suffer from ageist social stereotypes about their capacity to adapt to technological changes.

Interestingly, we find the negative association between technology implementation and chances of starting a new job to decrease as unionism within an industry increases. What this may mean is that through unions workers are more able to negotiate for more favorable conditions, such as re-training and aid in work transitions, for technology implementation to take place. 
Finally, we do not find educational attainment organizational tenure of workers to be associated with the successfulness of job searches under technological change.

\section{Chapter 4: Immigrant biased technological change: The effect of technology implementation on employment of native workers and workers with non-Western immigrant backgrounds in the Netherlands}

In this chapter we examine whether and how technological change differently impacts native Dutch workers and workers with a non-Western immigrant background. Departing from a human capital perspective we argue that workers with a non-Western immigrant background are likely to be overrepresented in jobs that are prone to automation by technology. We complement this human capital approach with a relational inequality perspective, arguing that workers a with non-Western immigrant background have less intra organizational power than their native Dutch co-workers. Based on both arguments, we hypothesize chances of job ending to increase for non-Western immigrant workers, relative to native Dutch workers.

A second aim of the paper is to study the role of the organizational and institutional context in mitigating the effects of technology implementation. We expect larger proportions of non-Western immigrant workers within an organization to increase presence of perceived threat by dominant worker groups. This perceived threat, known to increase category salience and discrimination, increases social closure, potentially excluding them from job opportunities. Similarly, we expect that in organizations where employment is more volatile, feelings of threat, competition and in-group favoritism are greater. Resultingly, we hypothesize larger shares of non-Western immigrant workers within workplaces and volatile workplaces to increase the chances of job ending for non-Western immigrant workers under technological change. Finally, we expect that in industries with stronger unions the organizational power of minority group workers increases while decreasing particularism and social closure by dominant worker groups, weakening the effects of technological change.

Linear probability models with fixed effects at the level of the enterprise and random effects at the worker level are used to analyze large scale longitudinal employer-employee data on technology implementation in Dutch enterprises. Overall, we find the probability of job ending to decrease when technology is implemented. However, we find this decrease in chances of job ending to be smaller for non-Western immigrant workers relative to native Dutch workers. Furthermore, we find this relation to be particularly salient for first generation immigrant workers from non-Dutch speaking non-Western countries, for whom technology implementation does not relate to any reduction in chances of job ending. More research, however, is needed to untangle whether human capital deficits, selection into automation prone jobs, or mechanisms of social closure and discrimination are principally driving this effect. We do not find the effect of technology implementation to differ depending on the proportion of non-Western immigrant workers within enterprises, the volatility of enterprise jobs or industry unionism. Thus, the effect of technology implementation appears pervasive across workplaces with expectedly low interethnic competition and within institutional contexts offering more protection and bargaining power to workers.

Chapter 5: Technology implementation within enterprises and changes in the educational and age composition of enterprise workforces 
The fifth chapter focuses on how organizations adapt their workforces to technological change. Technological change in organizations alters production processes and the organization of work. These alterations arguably also influence what an optimal organizational workforce looks like. We expect that technology increases employers' demand for higher educated workers that have technology complementary skills. At the same time, we expect a decrease in demand for middle educated workers, and, to a lesser degree, lower educated workers, which are overrepresented in automation prone routine jobs. Furthermore, we expect that organizations engaging in technology implementation seek to attract more tech-savvy younger workers, while letting go older workers whose experience is tied to the old production processes of the organization.

A second aim of the paper is to investigate to what degree the effect of technology implementation is mitigated by the union density of the industry in which an enterprise operates. We expect that stronger unions increase the bargaining power of workers for enterprise resources such as jobs and training while limiting the degree to which employers use churning as a way to adapt the organizations' workforce.

Using seemingly unrelated regression we analyze large scale longitudinal employeremployee data on technology implementation within Dutch enterprises. Contrasting our expectations, we find the proportion of middle educated workers within organizational workforces to increase rather than decrease. Although we do find the proportion of middle educated workers leaving enterprises to increase, the proportion of middle educated workers entering enterprises increases also. Furthermore, we do not find the proportion of higher educated workers to increase. A possible explanation of this finding is that re-training efforts as well as the vocationally oriented Dutch education system effectively enhances middle educated workers with technology complementary skills.

Another main result is that we find the proportion of workers aged 50+ to increase when new technologies are implemented. As expected, we find the proportion of workers aged 50+ leaving enterprises to increase. However, we also, unexpectedly, find the proportion of workers $50+$ entering enterprises to show an increase. These findings may imply that on the one hand adaptation to new technologies becomes trickier with age, but on the other hand that there is also need for experience and knowledge, particularly in times of technological changes.

Findings regarding the role of unions are diverse and do not lend a simple interpretation of uniformly weaker effects in more unionized contexts. We find smaller proportions of lower educated workers leaving and entering enterprises in more strongly unionized industries. Furthermore, we find greater proportions of workers aged 50+ leaving enterprises, which may point to more widespread use of early retirement arrangements.

\subsection{Conclusion}

This dissertation aims to improve our understanding of how technological change impacts employment of workers within organizations. To do this we investigated how the implementation of new technologies associated with workers leaving these organizations, how easily workers who left these organizations in times of technological change were able to find new jobs, and how workforces within these organizations changed. The dissertation emphasizes two perspectives which have not been systematically studied within the literature on technological change. First, the idea that given technology, workers with different 
characteristics will be differently impacted by technological changes. And second, that how technological changes impact work depends on the organizational and institutional context in which technological change take place.

A first main finding of the study is that the effects of technological changes on workers employment within enterprises are present, but relatively small. We do not see technology implementation to lead to mass job loss. Instead, we find technology implementation to associate with an overall decrease in job ending of around 1.7 percent, meaning a slight decrease of the overall rate of job ending, which lies around $23 \%$ within the observed enterprises. For those workers, whose jobs do end with the implementation of new technologies, getting a new job appears to be slightly more difficult. However, this effect is also small, as we find the chances of starting a new job within two years after leaving an organization that is implementing new technologies to only be around 1.18 percent lower compared to when the organization is not implementing new technologies.

Based on these results, concerns about the sustainability of employment in face of technological changes appear to be exaggerated. For a minor subset of workers, technological changes seem to come with adaptation and transition costs that hamper their employability. However, at least in the Dutch context, the vast majority of workers seems to be able to keep their employment or to find new employment elsewhere.

A second main finding of the study is that the effects of technological changes on workers' employment are in part contingent on characteristics of employees. Insofar technology affects employment prospects of workers, it appears to largely exacerbate already existing divisions between worker groups.

First, lower educated workers seem to bear more of the negative consequences than higher educated workers. Chances of job ending increase for lower educated workers relative to middle educated and higher educated workers. Furthermore, the proportion of lower educated workers in organizations decreases with technology implementation. This is in line with the common notion that technology favors higher skilled over lower skilled workers. As such, technological changes contribute to a widening societal gap between higher and lower educated workers.

Second, for older workers technological implementation appears to increase the challenge of finding and keeping employment. Difficulties with learning new (technological) skills and negative ageist stereotypes are likely to contribute to this problem. Furthermore, the finding that workers with higher organizational tenure show higher chances of job ending when technology is implemented seems to support the idea that technology increases skill depreciation, corroborating human capital theory. Efforts in the area of life-long-learning focusing on re-skilling and up-skilling workers during their working lives seem to be justified in light of the finding that technological changes appear to negatively impact employment prospects of longer tenured workers and older workers.

Finally, technology also seems to favor native workers over workers with non-Western immigrant backgrounds. Technological change increases the importance of skills that are hard to replace, such as those needed in occupations requiring face-to-face interaction, soft skills, and service. This shift may particularly pose a challenge for workers suffering from language 
deficiencies and discrimination. Given that workers with non-Western immigrant backgrounds already suffer from these problems more than other groups, technology may worsen the employment prospects of these workers.

A third main finding of the dissertation is that industry union densities mitigate the effects of technological changes on employment only to a very minor degree. A straightforward reading of this result is difficult. On the one hand, this finding appears to corroborate studies indicating that the bargaining power of unions have been on the decline (Lehndorff, Dribbusch and Schulten, 2018). Possibly, unions have only very limited power in mitigating the effects of technological changes. In face of a structural shift in the balance of power in favor employers (Keune, 2016) and capital (Kristal, 2013), the bargaining power of all unions may be in decline, irrespective of existent variations in union densities.

However, among workers whose jobs end, we do find the association between technology implementation and reduced chances of starting a new job to be slightly smaller in more unionized industries. This may mean that unions play a role in helping workers transition from job to job when technological changes take place. Furthermore, the modest overall effects of technology on job loss and chances of finding a new job may be evidence that institutional employment protection in the Netherlands is very effective. Within the Dutch corporatist model many of the ways in which unions bargain for the interests of employees are formalized and coordinated. Resultingly, its influence may be less reliant on actual union memberships compared to countries where the role of unions relies more on activism and local bargaining. The fact that collective agreements cover far more employees $(79 \%)$ than the number of unionized workers $(17 \%)$ is evidence of such representative-channeled union influence. What the findings of this dissertation may tell us is that institutionalizing the bargaining power of employee associations helps to maintain workers' bargaining power despite declining union memberships.

\subsection{Discussion}

The finding of the dissertation that the effects of technology implementation on employment of workers are small are in line with recent studies that almost unanimously find technologies, such as AI/IT, automation and industrial robots to relate to stable or increased total employment (Bessen et al., 2020). Implementation of technology thus does not appear to lead to great loss of employment for workers, or to human workers becoming obsolete. Technology may replace some job tasks, but jobs involve a variety of job tasks, some of which, at this point, cannot be performed by technology. Moreover, the introduction of new technologies within organizations can also bring along new work tasks (Autor, 2015). Thus, although technological changes may mean that the organization needs less workers to produce the same amount of output, the organizations still need workers to perform tasks that are not automated, as well as new tasks that are generated. Moreover, increased productivity due to technological change also increases demand for products and services, which can drive up overall employment. By focusing on organizations, we gained a better understanding of the effects of the implementation of new technologies on workers employment, which is a valuable contribution to the literature which mostly focuses on labor market effects of technological change. 
Despite these results, some authors propose that 'this time it is different' (Ford, 2015) because coming advances in AI and Robotics are unprecedented forms of technological innovation that will be able to replace human labor in vast job segments. According to this view, research results of the past are a bad predictor of what will be happening in the near future. Other authors, however, argue that even when some tasks or job are technically feasible to be automated, economic, legal, and social hurdles slow down the actual implementation of such technologies (Arntz, Gregory and Zierahn, 2017). Studying technology adoption by German firms, Arntz, Gregory and Zierahn (2017) conclude that adoption of advanced technologies is very slow because of the challenges that relate to technology investments. They identify that large expenditures for data security and cyber security, larger skill demands of employees, changes in education and training content, high investment costs and stronger dependencies on external services are among the main challenges for firms. What this means is that technological change is heavily dependent on contextual factors. Although it may be true that this time technological change is different, the pace at which these technologies are introduced is likely to be a lot slower than projected, softening its consequences on employment. The findings from this dissertation seem to align with a more evolutionary rather than revolutionary trajectory of technological change.

To understand how the process of technological advancement affects workers the literature puts great emphasis on the role of educational attainment. In the dissertation we applied the SBTC and RBTC frameworks, commonly used to explain structural labor market changes, to technological change within organizations. We find these frameworks to be partially reflected in our organizational studies. In line with expectations derived from the RBTC hypothesis, the proportion of middle educated workers, who are argued to be more likely to work in routine occupations, leaving enterprises increased. However, the overall proportion of middle educated workers within enterprises increases, as a result of increases in the proportion of middle educated workers entering enterprises. A possible explanation for this finding is that while there are many tasks performed by workers with intermediate levels of education, many newly generated tasks are performed by middle skilled workers trained to work with new technologies (Holzer, 2015).

Speculating on this finding, a point to note is that technological change can be cyclical in nature. What this means is that in the more exploratory and early stages of a new technology, the development and management of such technologies requires higher skilled workers. However, when the technology matures, much effort is put in making the technology accessible for workers who are less skilled. For example, where initially the creation of websites required a fair degree of computer programming knowledge, much effort has been put in making the creation of websites as user friendly and accessible as possible. In preparing workers for coming technological innovations, it may be helpful to try and think in advance how technologies that initially require a high level of technical knowledge may later become more user friendly, thereby creating and altering jobs in less technologically skilled job segments as well.

The finding that technological change increases both the proportion of middle educated workers leaving and entering organizations may in part be particular to the Dutch institutional context. The Netherlands are characterized by a vocational education system in which skills are arguably more prone to skill depreciation than more general education (Weber, 2014). When 
workers are trained to perform specific tasks or jobs tied to 'old' technologies, the usefulness of their training may be particularly negatively affected when new technologies are introduced. What this may mean is that the educational system is not efficient at preparing workers for events that lead their skills to become obsolete, such as technological change. At the same time, the close links between the Dutch vocationally oriented educational system and the labor market may be especially efficient in training workers who enter the labor market to work within technologically advanced workplaces. Together, these characteristics may translate into a high turnover of middle educated workers when Dutch enterprises implement new technologies. Identifying which educational tracks provide specific training in areas where technological changes are projected to lead to the strongest skill depreciation is possibly helpful in anticipating negative effects of technological change on workers' employability.

One of the key challenges surrounding technological advancement is how workers can best acquire new skills and adapt to new technologies. For some types of workers, bridging technology induced skill gaps may be particularly challenging. For workers whose productivity relies heavily on experience skill depreciation due to technology may be particularly problematic. For older workers, learning to work with new technologies and transitioning from old to new ways of working may be more taxing than for younger workers. Furthermore, language deficiencies among immigrant workers may prove to become more problematic as technology favors interactive, service oriented and cognitive work tasks over manual work.

There is, however, a tension here because although human capital deficits undoubtedly play an important role, these groups have the additional challenge of overcoming negative stereotypes and social closure that may intensify with technological change. For example, the idea that older workers are less able to adapt and be productive with new technology is shown to be a stubborn social stereotype that hampers older workers even when actual performance contradicts these stereotypes (Posthuma and Campion, 2009). Such stereotypes have the danger of becoming a self-fulfilling prophecy as they influence the allocation of organizational resources by organizational decision makers. For example, ageist stereotypes negatively contribute to the propensity of older workers to receive or invest in (re-)training. Furthermore, when, due to managerial preferencing, tech-savvy jobs are mainly occupied by young workers, the stereotype that older workers are less fitted to do these jobs solidifies. Furthermore, while the risk of technological change for older workers is widely recognized, the relation between immigration and technological change is hardly ever problematized, making tackling this problem even harder.

Policies fostering the sustainable employability of workers, such as life-long-learning, re-training and aid in work-to-work transitions undoubtedly improve the employability of workers. However, with respect to technological change, the success of such policies may be limited when negative stereotypes discount the skills and productivity of workers. Given that technological changes are argued to become of increasing importance in shaping labor markets, further integration of the discourses and research on technological change and social categorization is warranted.

Finally, we did not find union densities within industries to strongly mitigate the effects of technological change on employment. Possibly, their influence on the effects of technological 
change is channeled through collective labor agreements, as union-based bargaining has overtime entered and shaped collective labor agreements. Furthermore, employee associations such as unions potentially play an important role in ensuring that workers can adapt and benefit from technological change. The finding in chapter 3 that the negative effect of technology implementation on chances of starting a new job becomes weaker as the union density of an industry increases seems to indicate that unions play a role in helping workers transition between jobs in times of technological change. In order to up-skill and re-skill workers investments in workers are necessary. The challenge here is that some of these investments will have to come from organizations, even when such investments are not the most attractive option for employers. Employer associations and unions may foster investments in training of workers by coordinating investments across organizations. Such coordination decreases the possibilities for free riding by organizations that otherwise would poach on the training efforts of competing organizations (Hall and Soskice, 2001; Hall and Lansbury, 2006).

Declines in union power (Lehndorff et al., 2018) have led some authors to question the sustainability of the corporatist model, arguing that the balance of power of employers vis-avis employees is tilting more and more towards employers (Keune, 2016). Moreover, Kristal (2013) argues that technological changes itself contribute to this imbalance, as technology mainly benefits management and capital, and weakens workers bargaining position and unionism. However, a successfully coordinated approach to help workers adapt to technological change is likely to benefit from informed and well-maintained employer associations, as this, and other studies (Fernandez, 2001) seem to indicate.

\subsection{Limitations of the dissertation and suggestions for further research}

The dissertation knows several limitations. A first limitation of the studies presented is that we are largely unable to tease out the different theoretical mechanisms occurring within organizations. In the dissertation we combined the common human capital narrative in this field and theory that focuses on intra-organizational relational inequality. We argue that disentangling these mechanisms is important because it may mean that human capital deficiencies are only part of the problem, and therefore that investments in human capital are only part of the solution.

Disentangling these mechanisms would require a qualitative research design or targeted surveys. This, however, would make it a lot harder to follow workers over time and would strongly limit the scope of the research, which is valuable when gauging the overall effects of technological change. A next step is teasing out the relative importance of the different mechanisms and is an important avenue for future research. Research methods used to study intra-organizational power processes and discrimination may be helpful in empirically distinguishing these different mechanisms.

Furthermore, we could not address the impact of national variation in labor market institutions and policies. The scope of the dissertation is limited to the Netherlands. Workers in the Netherlands enjoy a relatively high degree of employment protection. In institutional settings where employers' decisions about employment are less constrained by institutions, technological changes are likely to have stronger effects on employment. In institutional contexts with less employment protection the effects found in this dissertation may be 
amplified. We therefore encourage further research that compares the effects of technological change between institutional contexts to get a better understanding of the role of institutions such as laws, unions, and collective bargaining.

Another limitation comes from our inability to establish to what degree the effects of technology are endogenous. It is possible that unobserved factors both determine whether technology implementation takes place, as well as changes in employment of workers within organizations. What this means is that we possibly overstate the effect of technology, and that the relations found are to a greater or lesser degree spurious. For example, Bonfiglioli, Crinò, Fadinger and Gancia (2020) studying imports of industrial robots find that robot import occurs after periods of expansion in firm size. Moreover, the authors show that positive demand shocks are associated with both robot imports and employment dynamics. Thus, it may be that exogenous demand shocks both impact employment within organizations as well as the likelihood of organizations implementing new technologies.

Furthermore, the likelihood of enterprises implementing technology may differ depending on organizational and workforce characteristics. Studying robot adoption in Spanish manufacturing firms, Koch, Manuylov and Smolka (2020) show that better performing firms, measured through output and labor productivity, are more likely to adopt robots. Bonfiglioli et al. (2020) also find more productive firms, as well as larger firms and firms employing a higher share of managers and engineers to be more likely to adopt robots. This selection effect possibly points to reversed causality in which enterprises engage in technology implementation because of having particular types of employees, rather than these workers being attracted because of these technologies being implemented.

For the studies presented in this dissertation there is a possibility that the effects of technology are in part endogenous. Consequently, we may overstate the effects of technology as unobserved exogenous factors, such as demand shocks, may be at the root of both changes in employment as well as technologies being implemented. Furthermore, there is the danger of reversed causality, in which changes in employment cause technology to take place, rather than the other way around. In the studies presented we do, however, employ several measures to decrease the problem of endogeneity.

First, in chapters 2, 4 and 5, we control for time invariant characteristics of enterprises by employing fixed effects at the enterprise level. This means we take into account that for example larger, or more productive enterprises may both be more likely to implement technology and to have workforces with higher educated workers. Although this may in part solve the problem of selectivity, the possibility that exogenous events, such as demand shocks both affect technology implementation as well as employment dynamics remains. In chapter 2, 3 and 4 his problem is likely to be partly solved by focusing on workers with permanent employment contracts, since the employment of these workers is less impacted by demand shocks compared to for example temporary and on-call workers. Endogeneity may be more problematic in chapter 5 , in which we study the relation between technology implementation and enterprise entrants. First, the endogeneity problem is arguably more salient when studying the relation between enterprise entrants and technological change, as positive demand shocks have been shown to both increase employment and the likelihood to adopt robots (Bonfiglioli et al., 2020). Furthermore, in chapter 5 we include both fixed-term, on-call, and permanent 
contracts. Because turnover among fixed-term workers and on-call workers is likely to be more strongly dependent on labor demand and demand shocks, the possibility of finding a spurious relationship between employment dynamics and technology implementation may be higher here.

Despite our inability to fully account for endogeneity in our studies, results from recent studies isolating the effect of technology from demand shocks and selection effects seem to be in line with the findings of this dissertation that technological change increases employment. Koch et al., (2020) find robot adoption to increase job creation while Aghion, Antonin, Bunel and Jaravel (2020) find automation to increase firm employment. Bonfiglioli et al. (2020) find that while demand shocks generate a positive relation between robot imports and employment, exogenous changes in automation lead to job losses. Although the results are not unambiguous, the present evidence seems to show positive effects of technology on employment within organizations. Nevertheless, we should be cautious, as our inability to fully account for endogeneity may mean we overstate the effects of technological change.

Another limitation of the studies is that we have not been able to investigate the impact of different types of technology. The indicator of technological change involves all technologies that significantly change work processes, products, or services within the enterprise. Some of these technologies will have more impact on labor than others. For example, manually controlled machines, such as motor vehicles, involve a high degree of human work, whereas self-controlled production systems, such as Smart Factories and Internet of Things, are largely performed automatically (Arntz, Gregory, Lehmer, Matthes and Zierahn, 2017). The measure for technological change we used is likely to show a weaker relationship with workers' employment compared to measures focusing explicitly on automation technology. Indeed, Bessen et al. (2019) also using Dutch data, focusing on investments in automation rather than technology in general reach similar conclusions, but find somewhat stronger effects than the studies in this dissertation.

The advantage of a more general measure is that the findings give an indication of the overall effects of technological change. However, data collection efforts allowing us to disentangle the employment effects of specific and highly advanced technologies are desirable and are a focus of current research (Arntz, Gregory, Lehmer et al., 2017).

The studies are also limited by data constraints, such as having very limited information about the occupations held by workers. Much of the literature on technological change is concerned with how certain jobs are more prone to automation than others. Our aim was to complement this approach by looking at the characteristics of workers, rather than that of jobs, in relation to technological changes. Ideally, however, we would be able to study both simultaneously. For example, in chapter 5 we find the composition of enterprise workforces to show an increase in the proportion of middle educated workers and older workers despite the increases in proportion of these workers leaving enterprises. It is possible that the jobs of enterprise leavers are very different from the jobs of enterprise entrants. Thus, although some occupations held by middle educated and older workers may disappear because of technology, it may also create new jobs for middle educated and older workers. Having data on occupations could provide insight into how worker characteristics and job characteristics interact under technological change. Such 
data could lead to more detailed identification of organizational positions that are most adversely affected by technological changes. In turn, such data, combined with prognoses about jobs that are going to be affected by coming technologies, could help anticipate who are going to need most help in adapting to technological changes.

Another avenue for future research concerns the role of organizational policy in mitigating the effects of technological change for workers. Organizations are central actors in preparing workers for future challenges and changes. Aiming to make their workforces sustainable and productive, organizations make numerous investments in the area of life-long-learning, training and re-training and work-to-work transitions. Many of these investments are not mandated by national policies. Such efforts are likely to be of great importance as technological changes impact the way we work. Sociological research has started to systematically evaluate the effectiveness of different organizational policies in this area (Van der Lippe and Lippényi, 2019). However, there is a lack of research that specifically investigates organizational policies concerned with the employment prospects of workers affected by technological changes. Such knowledge, however, would benefit both workers as well as employers and institutions who must decide which investments in workers have the greatest returns. We therefore encourage research that takes up this challenge.

Another limitation of the studies is that we do not have information about the reasons why a job ends. Using register data, we can see when workers leave an organization and when they enter a new organization. The data lack information as to why a worker left and in what way employment was ended. The consequences for workers' employment, however, may differ depending on whether someone chose to leave the organization, or whether the employer forced the separation. Nevertheless, due to employment protection, non-voluntary layoffs in the Netherlands involve a high degree of coordination between employee associations and the national Employee Insurance Agency. Job separation, even when it is non-voluntary, is based on a 'mutual agreement' by employers and employees that clarifies the conditions under which the employee accepts job termination. The exact content of such an agreement may, however, vary. Furthermore, employers may informally have exerted pressure on employees to accept an agreement, which makes it hard to know exactly how 'mutual' the agreement is.

In institutional settings where laying off workers is easier for employers it may be more feasible and important to distinguish between different types of job separation. We encourage research that investigates how different types of job separation bare different consequences for workers when technological changes occur.

Finally, chapters 2 and 3 focus exclusively on standard forms of employment. We excluded shareholders-directors who are on payroll, trainees, social employment, on-call, and fixed-term employees. The dynamic between technological change and such non-standard forms of employment is likely to differ from standard employment. Especially workers with on-call and fixed-term employment enjoy less institutional protection and have less intra-organizational bargaining power. Employers do not need to negotiate layoffs as they can opt for not extending such contracts. Furthermore, there are self-employed workers, who enjoy even less protection (Kalleberg, 2011). The Netherlands rank 6th in strictness of dismissal of workers with 
standard/permanent contracts out of 71 countries in OECD data. However, when looking at the strictness of dismissal of workers with non-standard/temporary contracts, the Netherlands rank 54 out of 67 countries in OECD data. This suggest that there may be strong differences in the amount of institutional protection between contract types, even within countries.

As a result, these workers may be particularly affected by technological changes. Moreover, for employers who want to be able to adjust their workforces quickly to technological changes, non-standard employment is attractive precisely because these workers enjoy less institutional employment protection. Thus, in anticipation to technological changes, employers' strategy may be to hire workers who are easier to lay-off than better protected workers with standard contracts. The rise in non-standard employment is in part caused by serving as a way for employers to circumvent the otherwise strict rules that apply to hires with permanent contracts. For these workers, technological changes may be particularly detrimental as they have less possibilities to bargain for resources such as training or work-to-work transition arrangements. We strongly encourage research that helps investigating ways in which workers in more precarious employment can prepare and adapt to technological changes.

\subsection{Policy implications}

The results of the studies point out that, at least so far, technological change associates with adaptation costs for some workers, but that overall effects on employment of workers are small. In line with these findings Goos et al., (2019) argue that restructuring of jobs due to technology is currently a greater challenge than decreases in overall employment. Evaluating the impact of technology for the future of work, they underscore that European policies supporting life-longlearning and work-to-work transitions are pivotal in face of coming technological changes, particularly for lower educated and older workers. Our findings corroborate this policy strategy. In addition, current policy directed at investments in human capital could benefit from ideas on how to tackle inequalities between workers that associate with differences in positional power and social categorization. Investment in training of older workers is likely to be helpful, but if employees are unable to overcome negative stereotypes and convince employers of their updated technological skills, policy effectiveness may be limited. A possible way forward is for governments, education institutions and organizations to work towards standardizing credentials and certificates obtained in training/education in later life such that the signaling function of such credentials to employers is more comparable to that of formal education. Overall, organizational policy on technology and the future of work may benefit from some cross-pollination with organizational policy on inclusivity within labor markets and organizations, such as inclusive job advertisement, selection of workers based on knowledge and competences, diversification of selection committees and the creation and communication of a company policy promoting equal treatment and opportunity (Dutch Ministry of Social Affairs and Employment, 2020; Diversiteit in Bedrijf, 2018).

Another focus area of European policies concerns the match between education and business practice (Goos et al., 2019). Monitoring and forecasting the skills needed by business helps education systems to timely prepare workers for changes in skill requirements due to technological change. A key strategy to improve the relation between education and business is the development of vocational education and training through apprenticeships and dual training. Although there is great value in matching the needs of companies with educational 


\section{Chapter $1 \mid$}

programs, there is a potential pitfall in tailoring education to technologies. Technological innovations generally replace old technologies. Arguably, experience and skills tailored to old technologies suffer the strongest depreciation when new technologies enter organizations. Consequently, it may be that in the short run, tailoring to the demand for specific technological skills of employers improves flow of workers onto the labor market. However, in the long run, a second cycle of technological innovation may be particularly challenging for those workers, warranting continuous investments in up-skilling and re-skilling by employers and employees. 




\title{
Chapter 2
}

\section{Technology implementation within enterprises and job ending among employees. A study of the role of educational attainment, organizational tenure, age, and unionization $^{6}$}

\begin{abstract}
This study examines how technology implementation within workplaces impacts job ending among employees. We advance the literature on the labor market consequences of new technologies by focusing on their impact within workplaces where they are implemented, rather than inferring from aggregate labor structural changes. We also address how the impact of technology differs depending on workers' education, organizational tenure, and age. Using large-scale Dutch matched employer-employee longitudinal data directly measuring technology implementation, we find that technology implementation is associated with an overall decrease in the probability of job ending. In line with the Skill-Biased Technological Change hypothesis, higher educational attainment is associated with lower probabilities of job ending. Furthermore, we find older workers (around 50+) and workers with longer organizational tenure (around 12+ years) to have a higher probability of job ending when technology is implemented. Finally, we do not find the effects of technology implementation to differ depending on the union density of the industry in which an enterprise operates.
\end{abstract}

\footnotetext{
${ }^{6}$ A slightly different version of this chapter has been published as: Ten Berge, J., Lippényi, Z., Van der Lippe, T., \& Goos, M. (2020) Technology implementation within enterprises and job ending among employees. A study of the role of educational attainment, organizational tenure, age and unionization. Research in Social Stratification and Mobility, 100548. Jannes ten Berge wrote the main part of the chapter and conducted the analyses. Zoltán Lippényi, Tanja van der Lippe and Maarten Goos provided valuable feedback on earlier versions of this chapter.
} 


\subsection{Introduction}

Concerns about technological advancement and the future of work greatly increased in the past decades. Such worries have been strengthened by studies examining the feasibility of replacing human jobs by soon-to-be realized technologies in robotics, machine learning and artificial intelligence. Frey and Osbourne (2017) estimate that, in the coming decades, $47 \%$ of all jobs in the US are at risk of being automated. Manyika et al. (2017) argue that about $60 \%$ of US occupations have at least $30 \%$ work tasks that will be automatable by 2055 . The World Bank (2016) comes to a similar estimate: almost $60 \%$ of jobs in the OECD are susceptible to automation in the near future. Labor economic theorizing reiterates this labor replacing potential of technological advancement (Acemoglu and Autor, 2011; Autor, Levy and Murnane, 2003; Goos and Manning, 2007; Goos, Manning and Salomons, 2009, 2014).

The current literature on technological change focuses predominantly on labor market structure and inequalities. The macro view, however, overlooks work organizations. Organizations are highly important because organizations are the sites where new technologies are implemented and where economic rewards, such as jobs, are being created and distributed (Baron and Bielby, 1980). Our paper contributes in a number of ways to the small, but emerging literature investigating the consequences of technology implementation in organizations for workers' jobs (Bauer and Bender, 2004; Beckmann, 2007; Bessen, 2016; Fernandez, 2001; King, Reichelt and Huffman, 2017; Nedelkoska, 2013; Siegel, 1998). First, within the current literature, technological change is argued to have differential impact depending on the human capital of workers, which most papers capture with education (Acemoglu and Autor, 2011; Autor et al., 2003). Very few studies incorporate a broader concept of human capital, even though technological change has direct implications for the value of firm and technologyspecific knowledge accumulated over time, as well as for the value of older workers whose adaptive capabilities may decline with age (Bartel and Sicherman, 1993; Becker, 1993; Beckmann, 2007). In this paper we fill this gap by studying the impact of technology on job endings of workers and how this effect differs by education, age, and organizational tenure.

Second, we incorporate the institutional context of organizations which is surprisingly rare in studies on the consequences of technology on labor outcomes. The process of technology implementation and reorganization in organizations does not occur in an institutional vacuum. In fact, several studies have shown that institutions, such as labor unions, fundamentally impact the wage determination process by increasing workers' bargaining power (Fernandez, 2001; Kalleberg, Wallace and Althauser, 1981; Kristal, 2013). In line with this literature, we argue that the likelihood of job loss and differences by education, tenure and age depend on the industrial context of the organizations in which workers are employed. Specifically, we address to what extent industry union strength weakens the relation between technology implementation and job ending for workers with different educational attainment, tenure, and age.

Finally, macro-level studies imply, rather than directly measure, technological change. The few studies that employ direct measures of technological change within enterprises, however, find mixed results which do not align with macro-level outcomes. Corroborating findings of skill-biased technological change, Siegel (1998) and Fernandez (2001) find that the implementation of technologies within firms is associated with increased employment in skilldemanding jobs. Bauer and Bender (2004) studying German firms, however, find that technology implementation is associated with increased churning rates among high skilled 
professionals and engineers. Furthermore, Nedelkoska (2013), studying German manufacturing firms, finds that routine-intensive occupations declined between 1975 and 2004. She finds little evidence, however, that technology implementation was the main driver of these changes. In line with this finding, Bessen (2016), studying computerization within US occupations, does not find computerization to decrease employment in routine-intensive occupations. This evidenced heterogeneity in how technology affects workers calls for research that considers factors at the organizational and institutional level (Fernandez, 2001), and research that empirically tests, rather than assumes, that employment changes are the result of technological change (Nedelkoska, 2013). Adhering to these suggestions we use a large-scale survey of (technological) innovation within Dutch enterprises which we match with register data about their employees. ${ }^{7}$ Our study employs a direct measure of technology at the level of enterprises which indicates whether enterprises have invested in advanced machinery, equipment (including computer hardware) or software specifically purchased to implement new or significantly improved products (goods/services) and/or processes. ${ }^{8}$ The linked employeremployee dataset allows us to follow over three million employees within over 30,000 enterprises over a period of fourteen years (2001-2014).

\subsection{Theory}

Educational attainment, tenure, and age are indicators of human capital on the one hand (Becker, 1993), and distinctive, meaningful, and power-enhancing social categories on the other hand (Tilly, 1998). To study the role of human capital characteristics of workers we rely on supply and demand frameworks as articulated in assignment models (Acemoglu and Autor, 2011) and complement this with relational inequality theory which addresses the role of organizational power (Avent-Holt and Tomaskovic-Devey, 2014). Within relational inequality theory it is argued that appealing to categorical distinctions, such as education or tenure, workers within organizations validate making claims to scarce resources within the enterprise, such as wages or jobs (Avent-Holt and Tomaskovic-Devey, 2010; Tilly, 1998). As we will show, the two interpretations of worker characteristics partly lead to opposing hypotheses. In the final section we elaborate on how institutional contexts shape the relation between technological change and job ending among workers.

Theories of technology-related labor market changes agree that technological developments do not universally replace human labor. In fact, certain groups of workers will be valued more as a result of technological change. Therefore, there is little rationale to theorize on an absolute effect of technological change that applies to all workers. Instead, it is more informative to examine how relative differences in the likelihood of job ending shift between groups of workers as a consequence of technological change.

\section{Education as a human capital dimension}

\footnotetext{
7 The Dutch register data about employees does not provide information on the type of job ending, such as voluntary quits, layoffs, or ending contracts. We therefore use job ending as a definition capturing all different forms of ending work relationships between an employee and the employer.

${ }^{8}$ The Netherlands make a relevant case for conducting the study, as it is among the top-ranking countries regarding innovation (Cornell University, INSEAD and WIPO, 2015).
} 
A core proposition within economic literature on technology is the Skill-Biased Technological Change hypothesis (SBTC) which argues that technological progress increases the relative productivity of higher skilled workers, such as programmers, scientists, analysts, consultants, and engineers (Autor, Katz and Krueger, 1998; Berman, Bound and Griliches, 1994; Card and DiNardo, 2002; Katz and Murphy, 1992; Krueger, 1993; Michaels, Natraj and Van Reenen, 2014). Increased productivity leads to higher demand for skills these workers possess. Examples of skills with increasing demand due to technological change are problem-solving capabilities, analytical capabilities, intuition, creativity, inductive reasoning, and communication skills (Acemoglu and Autor, 2011; Autor et al., 2003; Fernandez, 2001; SpitzOener, 2006).

The level of education of workers is indicative for the accumulation of such skills (Becker, 1993). By virtue of attainment of such skills as inductive reasoning, problem-solving and analysis, the demand for higher educated workers likely increases with the implementation of technology (Spitz-Oener, 2006). Regarding chances of job ending, we expect the increase in demand for skilled labor resulting from the implementation of technology within an enterprise to result in smaller chances of job ending for higher educated workers relative to middle and lower educated workers.

The SBTC framework has been criticized for falling short in explaining the relative decrease of workers in middle skill jobs, such as clerical and production jobs, observed in recent labor market developments (Acemoglu and Autor, 2011; Autor et al., 2003; Goos and Manning, 2007; Goos et al., 2009, 2014). Assignment models argue that technology not only increases the demand for skilled workers, but also decreases the relative demand for workers in middle skilled jobs. Technology mainly replaces manual and cognitive routine tasks, such as record keeping or repetitive assembly, because these tasks are codifiable in computer language (Autor et al., 2003). As middle skilled workers are overrepresented in jobs with routine tasks, automation arguably impacts middle-skilled workers most strongly, possibly displacing their jobs.

We expect that the chances of job ending for workers with intermediate levels of education increase relative to the chances of job ending of lower educated workers. We hereby make the plausible assumption that workers with intermediate levels of education will not be reallocated to do the job tasks performed by lower educated workers, because it is more costefficient to keep lower-earning lower educated workers rather than reallocating more expensive middle-educated workers into low skill jobs. Second, an argument to retain and reallocate middle-educated workers to low-skilled job tasks could be that middle skilled workers are more productive performing these jobs. However, since low-skilled job tasks are simplified and less autonomous, it is debatable whether significant productivity gains can be realized (Acemoglu and Autor, 2011). Based on these arguments, we hypothesize that:

\section{Hla: Technology implementation increases the likelihood of job ending for middle educated workers relative to lower educated workers.}

\section{Education as a source of worker power}

While human capital theory sees education relating primarily to worker productivity, relational theory argues that educational credentials serve as a categorical distinction legitimating claims 
for organizational resources (Tholen, 2017; Weeden; 2002)(cf. Tilly, 1998). The process of any organizational change, such as adopting new technologies, involves organizational politics, conflicting interest, and power dynamics (Buchanan and Badham, 2008). When there are competing claims for organizational resources, such as jobs, promotions or wages, workers can use their educational credentials to distinguish themselves and legitimate their claims. Vallas (2006), studying reorganizations within manufacturing firms, noted that high-skilled engineers often referred to their educational credentials to successfully negotiate their allocation to complex analytical tasks, even when lower-educated process control engineers and technicians resisted such allocation. In a similar vein, Hanley (2014) in a historical case study of automation in General Electric, finds that managers actively constructed a new conception of productivity which valorized themselves as the firm's core productive workers, thereby legitimating increasingly unequal rewards at the expense of clerical and production workers. We expect that during the process of technological change, workers with higher education are more able to claim a (redefined) role within the organizational production process and justify their position.

Based on relational inequality theory and the Skill-Biased Technological Change hypothesis we formulate the following hypothesis:

H1b: Technology implementation decreases the likelihood of job ending for higher educated workers relative to lower educated workers.

\section{Organizational tenure as a human capital dimension}

A large share of a workers' productivity stems from experience gained within the enterprise. As a result, tenured workers are generally more valuable for an enterprise (Crook, Todd, Combs, Woehr and Ketchen, 2011; Gathmann and Schönberg, 2010; Jovanovic, 1979; Lazear, 2009; Topel, 1991). The impact of tenure on job endings, as a source of human capital, likely differs from that of formal education under technology implementation. Workers who have been working within the enterprise for a longer time accumulate experience with technologies linked to their job tasks. However, while generic skills, such as analytical capabilities or problem solving, are transferable across different technologies, experience is a skill specific to current and past technologies within the enterprise (Lazear, 2009; Topel, 1991). When technology does not change, accumulating experience translates to higher productivity (Dearden, Reed and Van Reenen; 2006), which is rewarded with higher wages (Brown, 1989). When the enterprise adopts a new technology, however, skills stemming from experience with past technology may partially become obsolete and cease to support productivity (Beckmann, 2007). Employers are willing to pay higher wages as long as it can be justified by high productivity of an employee. When new technology is implemented, however, the "productivity premium" of tenure resulting from experience with past technology decreases, resulting in wage-costs that are out-of-balance with the productivity of tenured workers. As demotion of tenured workers and lowering their wages is often not preferred, ${ }^{9}$ organizations are more likely

\footnotetext{
${ }^{9}$ Demotions are relatively rare in organizations because of managerial concerns with worker morale and functioning after demotion, as well as reputational problems (Josten and Schalk, 2010)
} 
to recover the balance between wage costs and productivity by laying off tenured workers or incentivizing them to leave the enterprise. We expect that:

H2a: Technology implementation increases the likelihood of job ending for workers with longer organizational tenure relative to workers with shorter tenure.

\section{Organizational tenure as source of worker power}

Relational inequality theory argues that workers' power to make claims for organizational resources increases with organizational tenure (Avent-Holt and Tomaskovic-Devey, 2012). Enterprises often use internal promotions to fill higher-level positions, which usually favor tenured workers, partly because they better know and influence decision makers and they are better informed about opportunities (Althauser and Kalleberg, 1981; Pfeffer and Cohen, 1984). Tenure is also a categorical distinction; workers who have been working within the organization for a long time versus workers who recently entered the organization, which represents valuable knowledge and experience that may justify claims for organizational resources. Tenured workers are likely to secure or even improve their position within the organization in the process of technology implementation. These arguments lead to a prediction about the relationship between tenure and job loss that contradicts the prediction derived from human capital theory: We hypothesize that:

H2b: Technology implementation decreases the likelihood of job ending for workers with longer organizational tenure relative to workers with shorter tenure.

\section{Age, skill accumulation over the life course and adaptability}

The capability of employees to adapt to new technologies is a salient matter when organizations implement new technologies (Bartel and Lichtenberg, 1987). Adaptive capabilities are skills that especially older workers seem to possess less than younger workers. Older workers are accustomed to certain routines and less able and willing to accommodate organizational and technological change, compared to younger workers (De Koning and Gelderblom, 2006; Meyer, 2009; Weinberg, 2004). Older workers may also find it cognitively more difficult to learn new (technological) skills (Desjardins and Warnke, 2012; Slegers, Van Boxtel and Jolles, 2009; Westerman and Davies, 2000). Finally, the implementation of new technologies often requires workers to learn new skills, and younger workers, due to their more recent education, are more likely to have partially acquired these skills (Beckmann, 2007). Due to lower adaptability, older workers may become less attractive to employers when technology is implemented. Numerous studies found that aged workers are less likely to receive re-training (Arulampalam, Booth and Bryan, 2004; Bartel and Sicherman 1993; Beckmann, 2007; Carmichael and Ercolani, 2014; Guerrazzi, 2014; Taylor and Urwin, 2001), indicating the reluctance of employers to invest in workers whose expected productivity is low. ${ }^{10}$ When new

\footnotetext{
${ }^{10}$ It could also be that not participating in re-training explains lower productivity of older workers. However, findings of Behaghel and Greenan (2005) in France indicate that a decrease in productivity due to technology among older workers is causally prior to training investments. They document a decrease in productivity among
} 
technology is implemented, we expect that lower ability, training possibilities, and willingness to adapt to technological change increases the odds of both quits and layoffs. We hypothesize that:

H3: Technology implementation increases the likelihood of job ending for older workers relative to younger workers.

\section{Age stereotyping and discrimination}

From a relational inequality perspective, the low capability of older workers -and seniors in general- to adapt to new technologies is a powerful social stereotype that influences managerial expectations and decisions, even when actual work performance contradicts this stereotype (see Posthuma and Campion, 2009, and Shore and Goldberg, 2005 for overviews of studies on performance stereotypes and actual performance of older workers). Consequently, negative stereotypes and discriminatory practices among managers decrease older employees' claimsmaking power, leading to lower training participation among older workers as well as early retirement arrangements (Posthuma and Campion, 2009; Shore and Goldberg, 2005). From the older employee's perspective, experiencing discrimination and managerial favoritism towards younger workers may incentivize them to leave an enterprise. Human capital and relational inequality theories both point towards greater likelihood of job ending among older workers relative to younger ones under technological change.

\section{Technological change and the role of institutions}

Contemporary organizational theories argue that the institutional context exerts a powerful influence on the behavior of organizational actors (Scott, 2014). How technological change impacts jobs is likely to depend on the institutional context in which the enterprise operates (Avent-Holt and Tomaskovic-Devey, 2014; Orlikowski and Barley, 2001). Employers' actions are constrained by labor laws, unions, and collective agreements that can at the same time also empower workers. Fernandez (2001) studying the consequences of the retooling of a food processing plant for workers' jobs and wages, finds that the outcome of technology implementation is strongly shaped by the bargaining process between the union and the employer. In return for no-layoff and wage guarantees, the union agreed on relaxing seniority and work rule requirements and supporting retraining efforts by the enterprise. When workers are organized in strong unions their power to bargain for favorable agreements that mitigate negative effects on their employment arguably increases.

In the current study we focus on industrial contexts in the Netherlands, differentiating between industries with stronger and weaker unions. Overall, union coverage in the Netherlands is similar to the average of OECD countries (OECD, 2018). In 2016, 17\% of wage-earning workers in the Netherlands was union member. The country ranks $20^{\text {th }}$, while the US ranks $32^{\text {nd }}$ with a union density of $10 \%$. In the Netherlands, however, unions are more influential than their membership suggests because they bargain at the company or industry level over collective

older workers under circumstances of technological change is not explained by the presence or absence of retraining. 
labor agreements, thereby also affecting workers who are themselves not a member of a union. Within the Netherlands, $79 \%$ of wage earners is covered by collective bargaining agreements, ranking $9^{\text {th }}$ among 36 countries included in OECD data. ${ }^{11}$

There is substantial variation in union coverage between industries and sectors in the Netherlands. In manufacturing, union coverage was $31 \%$ in 2011, whereas in business services only $11 \%$ of workers was covered by unions (Statistics Netherlands, 2012). Procedures concerning the dismissal of workers in the Netherlands usually requires employers to find agreement with unions (Dismissal, 2011). In general, weaker unions increases the power of employers to influence labor agreements (Kristal, 2013). Organizations operating in such contexts are therefore more able to develop policies that conform to demand and supply principles. Therefore, workers in industries with stronger unions have better means to achieve favorable agreements with employers, and this improves the bargaining position of workers who otherwise would face a layoff due to technology.

Institutional contexts also influence how certain categorical distinctions are recognized within the process of relational claims-making (Avent-Holt and Tomaskovic-Devey, 2014). Workers of organizations operating in sectors that formalize labor arrangements are likely to use these institutional arrangements to legitimize their claims (Tomaskovic-Devey, Avent-Holt, Zimmer and Harding, 2009). For example, seniority rules can limit the ability of employers to specifically target older workers for layoffs (Lindbeck, 1994), and increase the bargaining power of senior workers for wage benefits (Böckerman, Skedinger and Uusitalo, 2018). More generally, we expect that the more labor arrangements protect the interest of a categorical group, the stronger such categories become as a resource for claims-making. In union dense industries, older and tenured workers are more protected than in industries where unions are weak (De Hek and Van Vuuren, 2011; Tracy, 1986). Consequently, workers in more union dense industries are more likely to use tenure and age to legitimize claims (Bidwell, 2013). As a result, organizational policies, such as early retirement arrangements or wages, are likely to be developed conform such formalizations. When institutionalization is less strong, the degree to which workers can use categorical distinctions to legitimize claims decreases.

Regarding our hypotheses, we expect that in industries with weaker unions the role of human capital in the relation between technology implementation and job ending is stronger. Furthermore, we expect that in industries with weaker unions the role of claims-making based on categorical group distinctions in mitigating the relation between technology implementation and job ending is less salient than in industries with stronger unions. We therefore expect that:

\begin{abstract}
H4: In industries with lower union densities the relation between technology implementation and increases in the likelihood of job ending for middle educated workers relative to lower educated workers is stronger than in industries with higher union densities.
\end{abstract}

\footnotetext{
${ }^{11}$ Layoffs and collective dismissals are regulated at the national level in the Netherlands. Looking at the strictness of legislation around individual dismissal, the Netherlands, ranks $10^{\text {th }}$ out of 71 listed countries. Indonesia ranks $1^{\text {st }}$ while the US ranks last among OECD countries, which indicates that the Netherlands may be more of a 'typical' institutional case than the US with its very low levels of protection.
} 
H5: In industries with lower union densities the relation between technology implementation and increases in the likelihood of job ending for workers with longer organizational tenure relative to workers with shorter organizational tenure is stronger than in industries with higher union densities.

H6: In industries with lower union densities the relation between technology implementation and increases in the likelihood of job ending for older workers relative to younger workers is stronger than in industries with higher union densities.

\subsection{Data}

Our study makes use of the combination of a large-scale enterprise survey and social microregister data. Data on company investment in technology is taken from the Community Innovation Survey (CIS). The CIS is a large-scale cross-national survey of innovation activity in enterprises, repeated every two years. In the Dutch survey used by this study, the sample is stratified by sector and establishment size, excluding enterprises smaller than ten workers (Mortensen and Bloch, 2005). Due to the longitudinal design, we are able to study changes in technology implementation within enterprises over time. We focus on the period 2001-2014, during which a total of 37,520 enterprises participated in the Dutch CIS survey. We linked these enterprises to register data on workers' jobs and demographic characteristics from the System of Social Statistics Databases (SSB) of the Dutch Central Bureau of Statistics, creating a longitudinal matched employer-employee dataset. ${ }^{12}$ The data is characterized by a four-level hierarchical structure in which years are nested in jobs (40,586,509 observations in 15,057,672 jobs), jobs are nested in individuals $(7,015,717)$ and individuals are nested in enterprises $(37,520)$. A job is defined as a contractual employment relation between an individual and an enterprise. If an individual had more employment contracts with the same enterprise, we aggregated them as one record. We restrict the data to include only standard forms of employment, i.e. jobs with a permanent work contract. We excluded shareholders, trainees, social employment, fixed-term, and on-call employees (4,837,025 jobs, 32.12\%). The largest group among those that are excluded, fixed-term employees, were excluded because specific rules and regulations pertain to the ending and renewal of these contracts, making job endings incomparable to those of regular, permanent employees. We exclude jobs for which no information was available on type of employment (889,216 jobs, $5.91 \%)$. Finally, we exclude workers whose level of education was not registered (1,611,724 individuals, $22.97 \%),{ }^{13}$ as well as 207 enterprises with missing data on organizational innovation and 1,089 enterprises with

\footnotetext{
${ }^{12}$ Results are based on calculations by Utrecht University using non-public microdata from Statistics Netherlands. Under certain conditions, these microdata are accessible for statistical and scientific research. For further information: microdata@cbs.nl.

${ }^{13}$ Information on individuals' level of education is gathered from registers of educational institutions and selfreported data from the Dutch Labor Force Surveys (EBB) integrated into the SSB. Educational registers contain all graduates in the Netherlands, but integration of digital records with the SSB is recent, and the data do not include all workers. The register coverage for younger cohorts is very high, about three-fourth of workers under the age of 30 but drops below 50 percent for workers older than 50. Missing information is filled up from the labor force surveys, which include around 10 percent of the population above the age of 50 .
} 
missing data on union density. The remaining dataset consists of 35,814 enterprises with 4,050,217 employees holding 6,879,613 jobs. ${ }^{14}$ The total number of cases is 16,347,201 (jobs $\mathrm{x}$ years). Table 2.1 provides descriptive statistics before and after deletion of missing cases and selections.

Table 2.1 Descriptive statistics before and after selections and deletion of missing cases

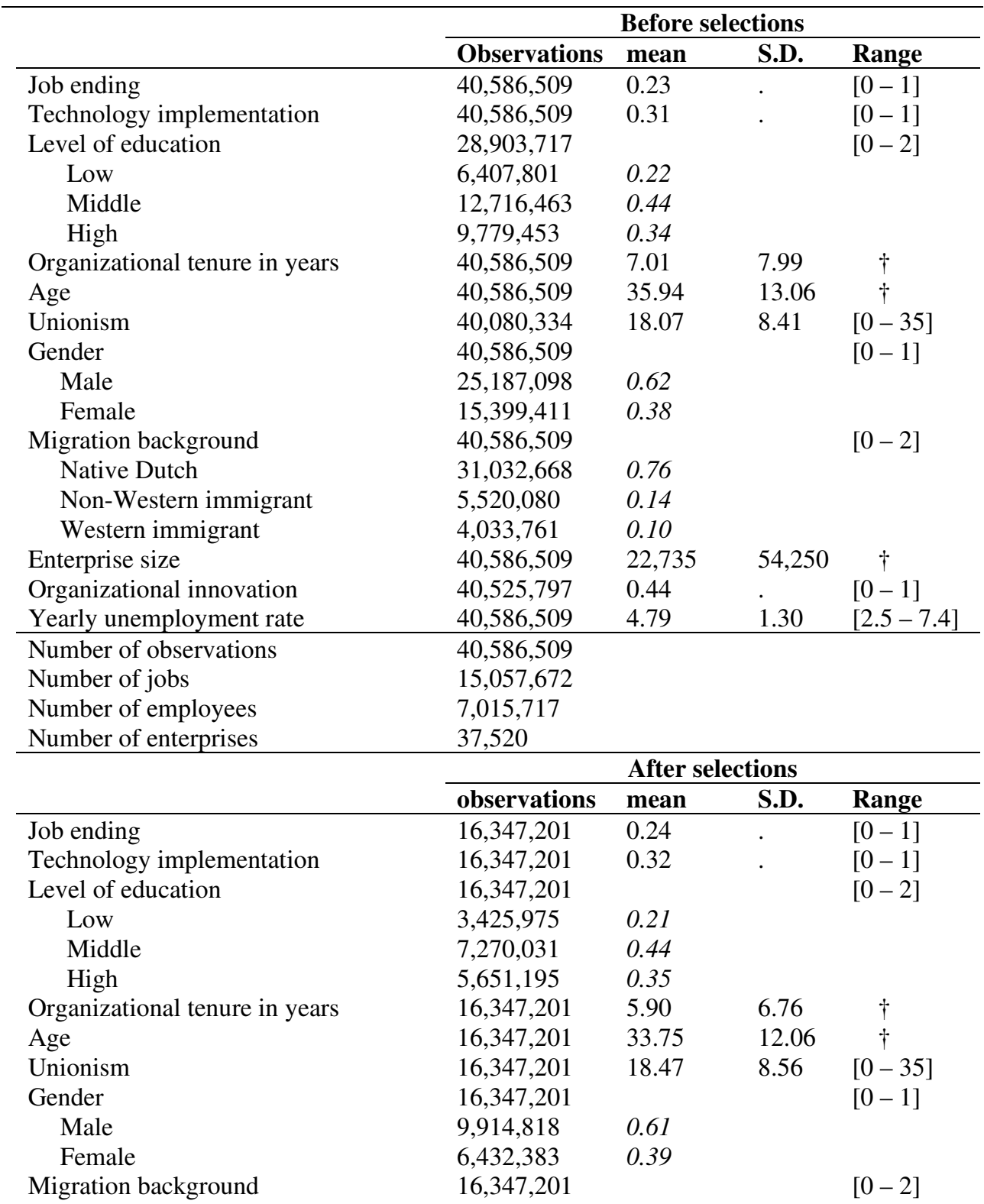

\footnotetext{
${ }^{14}$ In a robustness check we analyze whether these selections may have influenced our results.
} 


\begin{tabular}{|c|c|c|c|c|}
\hline Native Dutch & $12,805,270$ & 0.78 & & \\
\hline Non-Western immigrant & $2,110,541$ & 0.13 & & \\
\hline Western immigrant & $1,431,390$ & 0.09 & & \\
\hline Enterprise size & $16,347,201$ & 6,693 & 18,027 & $\dagger$ \\
\hline Organizational innovation & $16,347,201$ & 0.41 & & {$[0-1]$} \\
\hline Yearly unemployment rate & $16,347,201$ & 4.91 & 1.32 & {$[2.5-7.4]$} \\
\hline Number of observations & $16,347,201$ & & & \\
\hline Number of jobs & $6,879,613$ & & & \\
\hline Number of employees & $4,050,217$ & & & \\
\hline Number of enterprises: & 35,814 & & & \\
\hline
\end{tabular}

\subsection{Measurement}

\section{Dependent variable}

Job ending is a dummy variable measured as the end of a person's contractual employment relation within an enterprise. Having information about the beginning and end of employment relations between individuals and enterprises of all workers from the register data we can reliably document beginnings and endings of worker's jobs. Out of the total of $6,879,613$ jobs, $4,002,743(58.18 \%)^{15}$ end during the period of observation. The data does not provide information on why a job-relation ends. Thus, job ending indicates both layoffs and quits.

\section{Independent variables}

Implementation of technology is measured using an item from the Community Innovation Survey. A higher manager from the enterprise was asked to indicate whether, over the past two to three years (depending on the survey date), the enterprise purchased advanced machinery, equipment (including computer hardware) and/or software with the goal to significantly improve products, services, and/or production processes. Out of the total of 35,814 enterprises in the data, 9,507 enterprises (26.55\%) implemented new technologies to significantly improve their products, services and/or production processes in the period 20012014.

Educational attainment is measured according to the International Standard Classification of Education (ISCED). Eight educational levels are distinguished. We recoded the levels into three broad categories following guidelines from the ISCED 2011 manual (OECD/Eurostat/UNESCO Institute for Statistics, 2015). Low education, including those who attained less than primary education, primary education, and lower secondary education (20.96\%). Medium education, including employees who attained upper secondary education and post-secondary non-tertiary education (44.47\%). And high education, including employees

\footnotetext{
${ }^{15}$ We have linked employer-employee data for the period 2014-2016. For $58.18 \%$ of the jobs (employer x employee) in the data we observe job ending at some point during the period 2001-2014. The remaining jobs $(41.82 \%)$ have not ended by the end of the observation period (end of 2014). The descriptive statistics of job ending in Table 2.1 deviate from these percentages because they indicate the number of job endings as a percentage of all observations (employer x employee x year).
} 
who attained short cycle tertiary, bachelors, a master, or doctoral equivalent education $(34.57 \%)$.

Organizational tenure is measured as the duration of the employment relation within the enterprise in years. The average number of years worked within the enterprise is 5.90 years. For the analyses we mean center the variable.

Age is measured in years since birth. The average age of workers over the years of observation is 33.75 years old. For the analyses we mean center the variable.

Union density is measured as the number of unionized employees younger than 65 years old with paid work for at least 12 hours a week, as a percentage of the total number of employees with paid work for at least 12 hours per week within a sector. Data on union density are taken from Labor Force Surveys, which are available for the years 2001-2005, and 2007-2011 (Statistics Netherlands, 2012). The available surveys show very little variation in union densities within sectors over time, and we therefore take the average union density over the available years per sector to arrive at a measure for comparing union densities between sectors.

We control for the gender of the respondent. Male is the reference category.

Native-(Non-)Western immigrant background is measured using information on the birthplace of a person and the birthplace of the parents. For the definition of native and (non)Western immigrant workers we follow the definition of Statistics Netherlands. Native is defined as those who are born in the Netherlands and whose parents are also born in the Netherlands. (Non-)Western immigrant is measured as those workers whose mother is born in a (Non-)Western country, or in case the mother is born in the Netherlands, as those workers whose father is born in a (Non-)Western country.

Enterprise size. To control for unobserved time varying events that influence chances of job ending for workers within an enterprise we include enterprise size. Because the distribution of enterprise size is strongly right skewed, indicating the presence of several very large enterprises, we use the log of enterprise size in the analyses.

We control for unemployment rate in all models to capture labor market fluctuation, measured as the national yearly unemployment rate of the Netherlands. On average, the unemployment rate is $4.91 \%$ over the period $2001-2014$.

Furthermore, we control for organizational innovations to capture changes in the organization of the enterprise which can be related to job ending (Bauer and Bender, 2004; Bresnahan, Brynjolfsson and Hitt, 2002). A higher manager from the enterprise was asked to indicate whether, over the past two to three years (depending on the survey date), the organization introduced new business procedures, new methods for the organization of professional responsibilities and decision making, or new methods to organize external relations with other companies or institutes. Among the enterprises $34.17 \%$ engaged in organizational innovations at least once in the period 2001-2014.

\subsection{Method}

To investigate the relation between technological change and job ending we estimate linear probability models with fixed effects at the level of the enterprise and random effects at the individual level. By including fixed effects for enterprises, we control for time invariant unobserved heterogeneity at the enterprise level. Random effects at the individual level take into account that our yearly job observations are nested within individuals, as well as model 
individual-level unobserved heterogeneity. We opted not to include individual fixed effects for three reasons. First, we would not be able to identify the effect of education since it is virtually time-invariant. Second, due to the within-person over-time collinearity of age and tenure, the effects of these two variables would only be identifiable for a select group of workers who hold multiple jobs. Third, due to right censoring and the fixed effects specification, cases that do not experience job ending are excluded from the analytical sample for estimation, which could overrepresent "unstable" jobs in the sample.

To the baseline models including the main effect of technology implementation we, oneby-one, add the interaction effects with education, tenure, and age. Finally, a full model including all three interactions is presented. To investigate the effect sizes, we calculate predicted probabilities at meaningful values of the variables. These predicted probabilities are calculated with the other variables set at the mean. ${ }^{16}$

We tested differences in the relation between technology implementation and job ending depending on union strength within the industry by including three-way interactions of unionism, technology implementation and consecutively, educational attainment, organizational tenure, and age.

\subsection{Results}

In Table 2.2 we present the multilevel random effects models which include organization fixed effects. Looking at the effects of technology implementation on the likelihood of job ending in the baseline model 1, we find that technology implementation is associated with a significantly lower probability of job ending in both models. Estimating the overall probability of job ending between the two conditions, we find that under technology implementation the chances of job ending are $23.26 \%$, which is $1.72 \%$ lower than in times without technological innovation $(24.98 \%)$.

In model 2 the main and interaction effects of educational attainment are added to the baseline model. We find that middle and higher educated workers have a higher probability of job ending compared to lower educated workers. Due to the negative correlation of age and level of education, these effects reverse in the full model when we include age and tenure and their interaction effects with technology implementation. Looking at the interaction effects between technology implementation and education, we find that technology implementation is associated with lower probabilities of job ending among middle educated workers. We therefore reject hypothesis 1a. For higher educated workers we find that technology implementation is associated with a decreased probability of job ending, which supports hypothesis $1 \mathrm{~b}$. Figure 1 shows the predicted probabilities of job ending by educational attainment and technology implementation. Overall, the figure shows that under technology implementation the probability of job ending decreases for workers of all educational groups. For higher educated

\footnotetext{
16 The predicted probabilities are based on an alternative model that includes fixed effects at the enterprise level but does not include a multilevel structure. In the multilevel random effects model the effects of enterprises are fixed by hand through demeaning. The alternative method; including dummies for enterprises, is computationally unfeasible with 36,000+ enterprises. The manually computed demeaned interaction variables, however, complicate standard calculations of marginal effects. We therefore calculated a slightly more parsimonious model that generates near identical results to calculate marginal effects. The results of this model are presented in Table 2.A1 in the appendix.
} 
workers, the decrease is greatest; from a $25.16 \%$ chance of job ending when technological innovation is absent, to a $23.03 \%$ chance of job ending when technology is being implemented $(-2.13 \%)$. Relative to lower educated workers the chance of job ending decreases with $0.43 \%$ for middle educated workers, and with $0.91 \%$ for higher educated workers.

Table 2.2 Multilevel random effects models of technology implementation on the likelihood of job ending, with fixed effects for enterprises

\begin{tabular}{|c|c|c|c|c|c|}
\hline & $\begin{array}{c}\text { Model } 1 \\
\text { Baseline } \\
\text { model }\end{array}$ & $\begin{array}{c}\text { Model } 2 \\
\text { Education }\end{array}$ & $\begin{array}{c}\text { Model } 3 \\
\text { Org. } \\
\text { Tenure }\end{array}$ & $\begin{array}{c}\text { Model } 4 \\
\text { Age }\end{array}$ & $\begin{array}{c}\text { Model 5 } \\
\text { Full model }\end{array}$ \\
\hline Technology & $\begin{array}{l}-0.015^{* * *} \\
(0.000)\end{array}$ & $\begin{array}{l}-0.007^{* * *} \\
(0.001)\end{array}$ & $\begin{array}{c}-0.014^{* * *} \\
(0.000)\end{array}$ & $\begin{array}{l}-0.013^{* * * *} \\
(0.000)\end{array}$ & $\begin{array}{l}-0.009^{* * *} \\
(0.001)\end{array}$ \\
\hline (Ref: lower education) & & $0.018^{* * *}$ & & & $-0.003^{* * * *}$ \\
\hline Middle education & & $(0.000)$ & & & $(0.000)$ \\
\hline Middle education* & & $-0.007^{* * *}$ & & & $-0.004^{* * *}$ \\
\hline Technology & & $(0.001)$ & & & $(0.001)$ \\
\hline Higher education & & $\begin{array}{c}0.031^{* * *} \\
(0.000)\end{array}$ & & & $\begin{array}{c}-0.003^{* * *} \\
(0.000)\end{array}$ \\
\hline Higher education* & & $-0.011^{* * *}$ & & & $-0.007^{* * * *}$ \\
\hline Technology & & $(0.001)$ & & & $(0.001)$ \\
\hline Organizational tenure & & & $\begin{array}{c}-0.008^{* * *} \\
(0.000)\end{array}$ & & $\begin{array}{l}-0.004^{* * *} \\
(0.000)\end{array}$ \\
\hline $\begin{array}{l}\text { Organizational } \\
\text { tenure* Technology }\end{array}$ & & & $\begin{array}{l}0.003^{* * * *} \\
(0.000)\end{array}$ & & $\begin{array}{c}0.002^{* * *} \\
(0.000)\end{array}$ \\
\hline Age & & & & $\begin{array}{c}-0.005^{* * *} \\
(0.000)\end{array}$ & $\begin{array}{l}-0.004^{* * *} \\
(0.000)\end{array}$ \\
\hline Age* Technology & & & & $\begin{array}{l}0.001^{* * * *} \\
(0.000)\end{array}$ & $\begin{array}{l}0.001^{* * *} \\
(0.000)\end{array}$ \\
\hline (Ref: male) Gender & $\begin{array}{l}0.008^{* * *} \\
(0.000)\end{array}$ & $\begin{array}{l}0.008^{* * * *} \\
(0.000)\end{array}$ & $\begin{array}{l}0.002^{* * *} \\
(0.000)\end{array}$ & $\begin{array}{l}0.004^{* * * *} \\
(0.000)\end{array}$ & $\begin{array}{l}0.002^{* * *} \\
(0.000)\end{array}$ \\
\hline (Ref: native Dutch) & $0.057^{* * * *}$ & $0.060^{* * * *}$ & $0.046^{* * * *}$ & $0.045^{* * *}$ & $0.041^{* * * *}$ \\
\hline $\begin{array}{l}\text { Non-Western } \\
\text { immigrant background }\end{array}$ & $(0.000)$ & $(0.000)$ & $(0.000)$ & $(0.000)$ & $(0.000)$ \\
\hline $\begin{array}{l}\text { Western immigrant } \\
\text { background }\end{array}$ & $\begin{array}{l}0.023^{* * *} \\
(0.000)\end{array}$ & $\begin{array}{c}0.023^{* * *} \\
(0.000)\end{array}$ & $\begin{array}{l}0.018^{* * *} \\
(0.000)\end{array}$ & $\begin{array}{c}0.027^{* * *} \\
(0.000)\end{array}$ & $\begin{array}{c}0.024^{* * *} \\
(0.000)\end{array}$ \\
\hline Log enterprise size & $\begin{array}{l}0.002^{* * *} \\
(0.000)\end{array}$ & $\begin{array}{c}0.002 \\
(0.000)\end{array}$ & $\begin{array}{l}0.002^{* * * *} \\
(0.000)\end{array}$ & $\begin{array}{l}0.002^{* * * *} \\
(0.000)\end{array}$ & $\begin{array}{l}0.002^{* * *} \\
(0.000)\end{array}$ \\
\hline $\begin{array}{l}\text { Organizational } \\
\text { innovation }\end{array}$ & $\begin{array}{l}0.001^{* * * *} \\
(0.000)\end{array}$ & $\begin{array}{l}0.001^{\text {***** }} \\
(0.000)\end{array}$ & $\begin{array}{l}0.002^{* * * *} \\
(0.000)\end{array}$ & $\begin{array}{l}0.002^{* * * *} \\
(0.000)\end{array}$ & $\begin{array}{l}0.002^{* * *} \\
(0.000)\end{array}$ \\
\hline $\begin{array}{l}\text { Yearly unemployment } \\
\text { rate }\end{array}$ & $\begin{array}{l}0.004^{* * *} \\
(0.000)\end{array}$ & $\begin{array}{l}0.004^{* * * *} \\
(0.000)\end{array}$ & $\begin{array}{l}0.006^{* * * *} \\
(0.000)\end{array}$ & $\begin{array}{l}0.006^{* * * *} \\
(0.000)\end{array}$ & $\begin{array}{l}0.006^{* * *} \\
(0.000)\end{array}$ \\
\hline Constant & $\begin{array}{l}0.045^{* * *} \\
(0.000)\end{array}$ & $\begin{array}{l}0.046^{* * *} \\
(0.000)\end{array}$ & $\begin{array}{l}0.031^{* * *} \\
(0.000)\end{array}$ & $\begin{array}{l}0.029^{* * *} \\
(0.000)\end{array}$ & $\begin{array}{l}0.024^{* * *} \\
(0.000)\end{array}$ \\
\hline $\begin{array}{l}\text { Constant individual } \\
\text { level }\end{array}$ & $\begin{array}{c}0.015 \\
(0.000)\end{array}$ & $\begin{array}{c}0.014 \\
(0.000)\end{array}$ & $\begin{array}{c}0.009 \\
(0.000)\end{array}$ & $\begin{array}{c}0.010 \\
(0.000)\end{array}$ & $\begin{array}{c}0.009 \\
(0.000)\end{array}$ \\
\hline Residual variance & $\begin{array}{c}0.155 \\
(0.000)\end{array}$ & $\begin{array}{c}0.155 \\
(0.000) \\
\end{array}$ & $\begin{array}{c}0.157 \\
(0.000)\end{array}$ & $\begin{array}{c}0.156 \\
(0.000)\end{array}$ & $\begin{array}{c}0.157 \\
(0.000)\end{array}$ \\
\hline Observations & $16,347,201$ & $16,347,201$ & $16,347,201$ & $16,347,201$ & $16,347,201$ \\
\hline Individuals & $4,050,217$ & $4,050,217$ & $4,050,217$ & $4,050,217$ & $4,050,217$ \\
\hline
\end{tabular}


Enterprises

35,814

35,814

35,814

35,814

35,814

Standard errors in parentheses

${ }^{*} p<0.05,{ }^{* *} p<0.01,{ }^{* * *} p<0.001$

Figure 2.1 Predicted probabilities of job ending by education and technology implementation

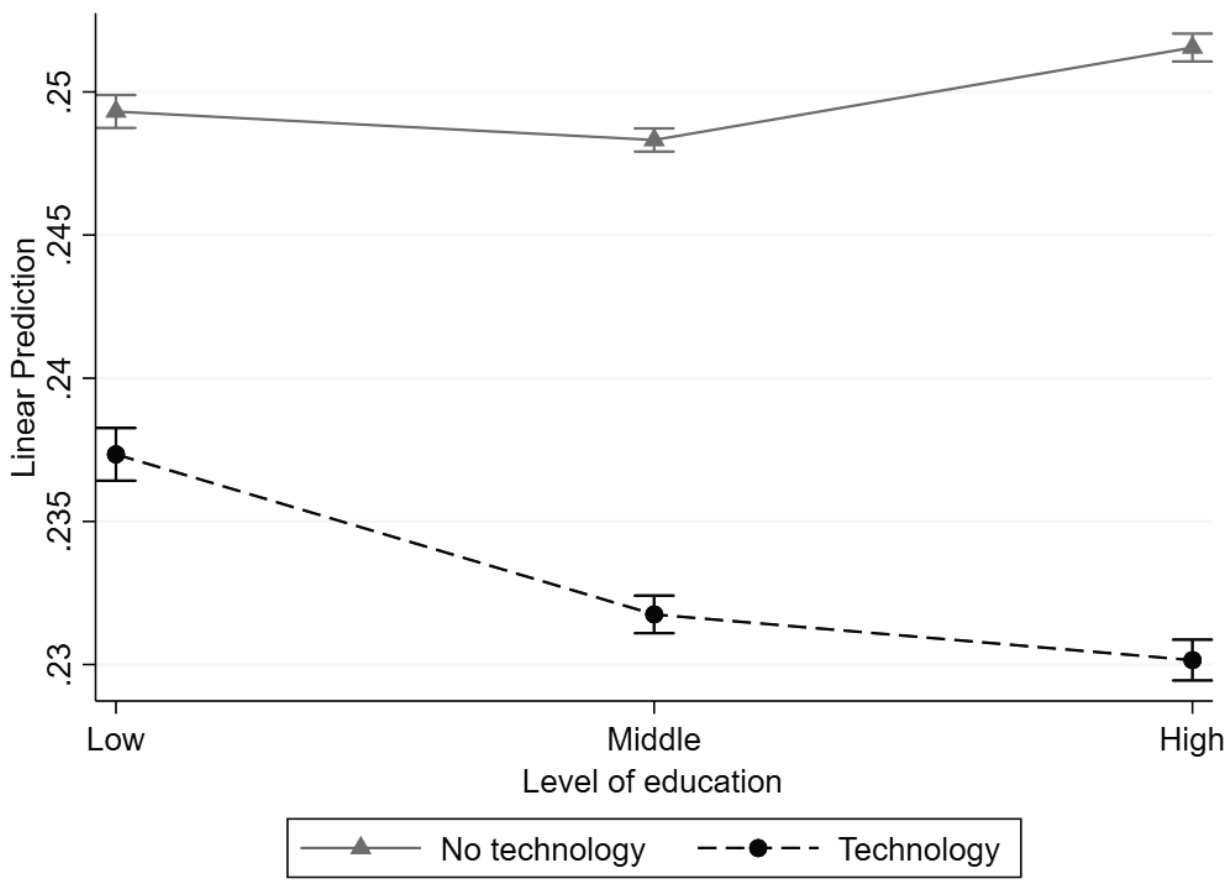

Looking at the effect of organizational tenure in model 3 we find that more senior workers have lower probabilities of job ending. However, technology implementation decreases this effect, which is in line with our second hypothesis. Figure 2 shows the predicted probabilities of job ending by organizational tenure and technology implementation. When we look at workers who have just started their jobs, at zero years of organizational tenure, we find that in times without technological innovation the chance of job ending is $27.42 \%$. When technology is being implemented, the chance of job ending for new hires is slightly lower; $24.84 \%$. Thus, for new hires technology implementation associates with lower probabilities of job ending. At around ten years of organizational tenure the predicted chances of job ending are very similar; $22.44 \%$ in times without technological innovation, and $21.60 \%$ in times of technological change. Among workers with relatively long organizational tenure we find technology implementation to be associated with relatively higher chances of job ending, although the difference is small. At 20 years of organizational tenure, slightly less than two standard deviations from the mean organizational tenure, the predicted chance of job ending is $0.92 \%$ higher $(18.37 \%)$ in times of technology implementation compared to times of no technological innovation (17.45\%). All in all, we find technology implementation to be associated with relative increases in the probability of job ending at higher levels of job tenure compared to lower levels of 
organizational tenure. Concluding, we find support for hypothesis $2 \mathrm{a}$ and no support for hypothesis $2 \mathrm{~b}$.

Figure 2.2 Predicted probabilities of job ending by organizational tenure and technology implementation

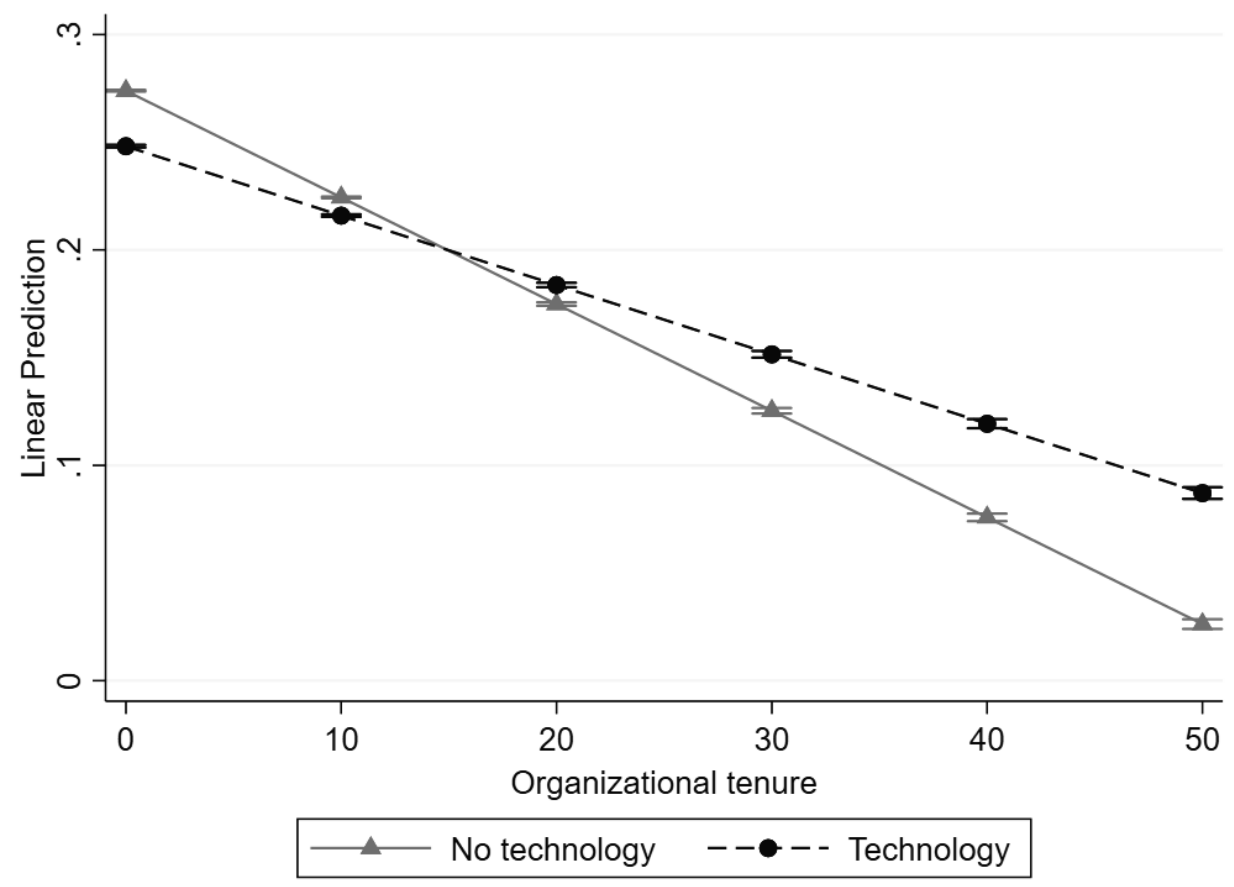

Finally, looking at the effect of age in model 4, we find a similar pattern. Higher age is associated with lower probabilities of job ending. However, this effect decreases slightly when new technologies are implemented within the organization. This finding is in line with the arguments underlying our third hypothesis, that technology increases the likelihood of job ending among older workers relative to younger workers. However, since here too the main effect of age is greater than the interaction effect, older workers still show lower probabilities of job ending under technological change, only slightly less so compared to when the enterprise is not implementing technologies. Interestingly, the results show greater predicted probabilities of job ending from around age 50+ under technology implementation. At sixty years of age, the predicted probability of job ending under technological change is $15.27 \%$, which is $0.81 \%$ higher than the predicted probability of job ending in times without technological innovation $(14.46 \%)$. All in all, the pattern supports hypothesis 3. 
Figure 2.3 Predicted probabilities of job ending by age and technology implementation

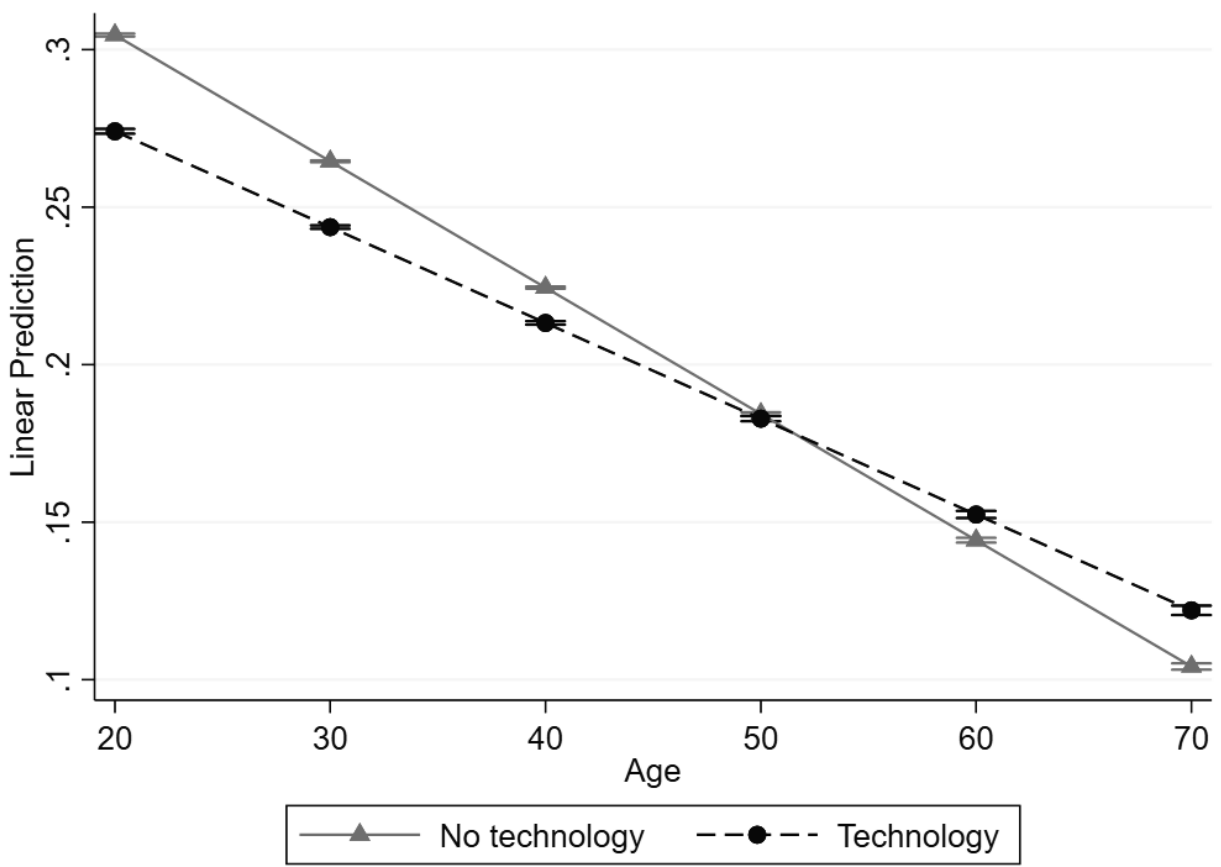

Table 2.3 reports the random effects models testing the effects of unionism. Model 6 shows that there is a statistically significant difference in the likelihood of job ending under technology implementation in unionized and non-unionized industries. The effect, however, is practically zero, meaning that the difference is not substantial. In subsequent models, educational attainment, organizational tenure, and age are added to the model. We find that all three-way interactions are statistically significant. We do not find technology implementation to increase the probabilities of job ending among middle educated more strongly in industries with lower unionization. However, in line with our expectations we do find that in more strongly unionized industries workers age and tenure associate with slightly smaller increases in the probability of job ending when technology is implemented. The effect sizes, however, are all nearly zero, indicating that the interaction effects between worker characteristics and technology implementation are highly similar across industries with different union densities. We therefore reject hypothesis 4,5 and 6.

Table 2.3 Multilevel random effects model of technology implementation on job ending, and the role of education, tenure, age, and unionism

\begin{tabular}{lccccc}
\hline & $\begin{array}{c}\text { Model 6 } \\
\text { Unionism }\end{array}$ & $\begin{array}{c}\text { Model 7 } \\
\text { Education }\end{array}$ & $\begin{array}{c}\text { Model 8 } \\
\text { Org. } \\
\text { Tenure }\end{array}$ & $\begin{array}{c}\text { Model 9 } \\
\text { Age }\end{array}$ & $\begin{array}{c}\text { Model 10 } \\
\text { Full model }\end{array}$ \\
\hline Technology & $-0.015^{* * *}$ & $-0.006^{* * *}$ & $-0.012^{* * *}$ & $-0.011^{* * *}$ & $-0.004^{* * *}$ \\
Technology* Unionism & $(0.000)$ & $(0.001)$ & $(0.000)$ & $(0.000)$ & $(0.001)$ \\
& $0.000^{* * *}$ & $0.000^{* *}$ & $-0.000^{* * *}$ & $-0.000^{* *}$ & $-0.000^{* * *}$ \\
& $(0.000)$ & $(0.000)$ & $(0.000)$ & $(0.000)$ & $(0.000)$
\end{tabular}




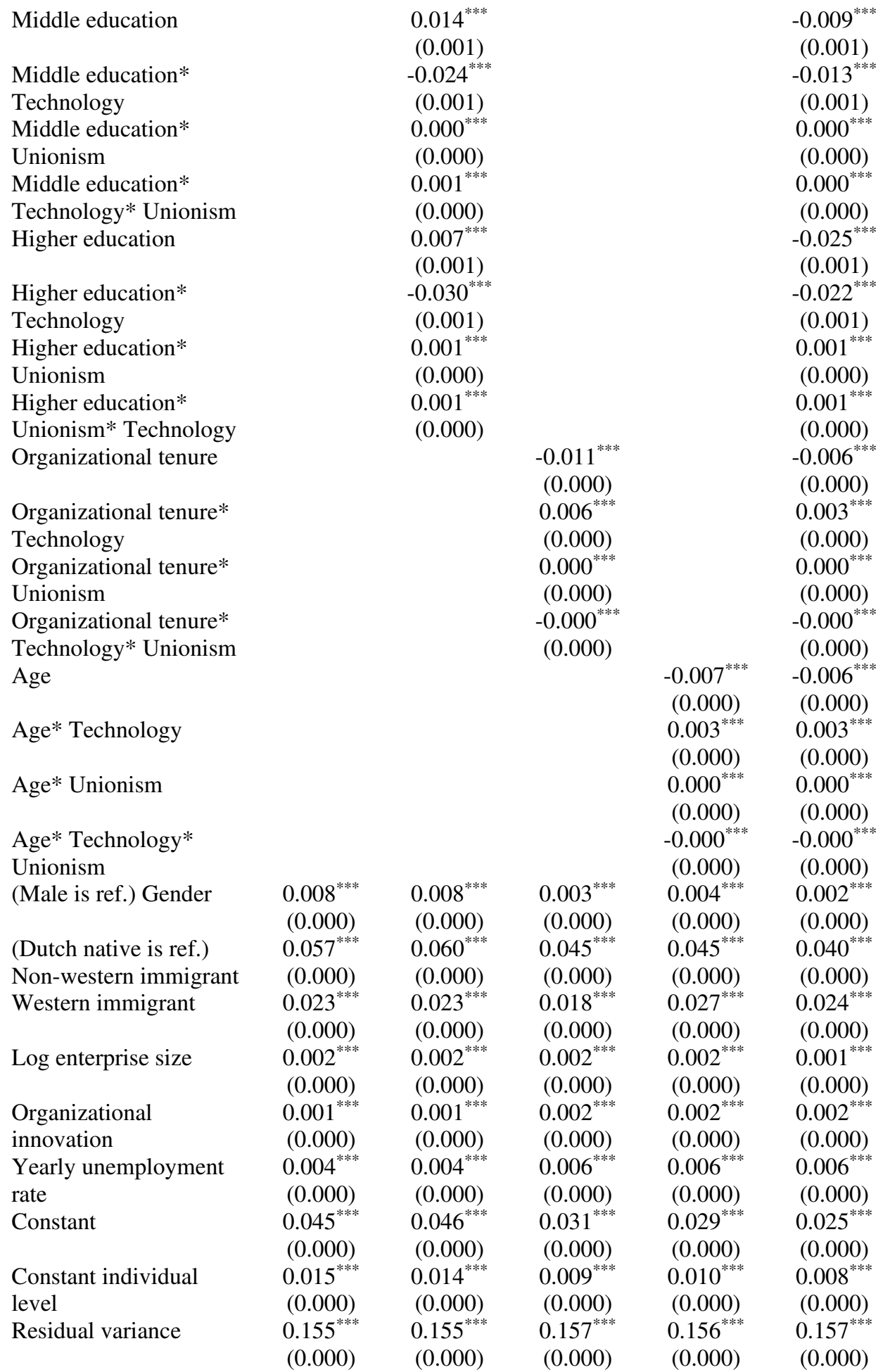




\begin{tabular}{lccccc}
\hline Observations & $16,347,201$ & $16,347,201$ & $16,347,201$ & $16,347,201$ & $16,347,201$ \\
Individuals & $4,050,217$ & $4,050,217$ & $4,050,217$ & $4,050,217$ & $4,050,217$ \\
Enterprises & 35,814 & 35,814 & 35,814 & 35,814 & 35,814 \\
\hline
\end{tabular}

Standard errors in parentheses

${ }^{*} p<0.05,{ }^{* *} p<0.01,{ }^{* * *} p<0.001$

\section{Additional analyses and testing for selection effects}

We performed additional analyses to test whether there is a lagged effect of technological change on job ending (See Table 2.A2 in the appendix). Lagging the effects of technology implementation for one, two and three years after implementation, we find that the negative effect of technology implementation on chances of job ending is lasting. However, the effect sizes are smaller, which may indicate that the apparent increase in demand of human labor found in the main analyses does decrease over time.

We also tested whether task routineness, which is a central concept in task-based models of technological change (Autor et al., 2003), similarly relates to job ending as educational attainment (See Table 2.A3 in the appendix). ${ }^{17} \mathrm{We}$ do not find a statistically significant association between the routineness of occupations and technology implementation and job ending. This result is in line with earlier research that does not find technology implementation in enterprises to relate to destruction of routine-jobs (Bessen, 2016; Nedelkoska, 2013). The absence of a relation between job routineness and technological change may explain why we do not find the probability of job ending to increase for middle educated workers, who are argued to be overrepresented in 'automation prone' routine jobs (Acemoglu and Autor, 2011).

Finally, as indicated in the data section, we made several sample restrictions for our analyses. We select only jobs with permanent work contracts. Furthermore, we exclude cases for which we do not have information on educational attainment, as well as jobs with missing data on contract type. To assess whether these selections and restrictions due to missing data bias the results we investigated the age and technology interaction effect, which can be measured in all data subsets, in models with and without sample restrictions. The results are presented in Table 2.A4 in the appendix. The substantive conclusions and effect sizes regarding the interaction are identical, so we are confident that the sample restrictions do not influence our results. There is, however, a noticeable increase in the main effect of job ending under technological change when we exclude non-permanent contracts from the sample. This finding can be related to the fact that non-standard jobs have a much higher natural turnover rate, decreasing the predictive power of shocks such as technological or organizational changes. Furthermore, it is possible that innovation temporarily increases the demand for flexible workers to accompany the process of technology implementation within enterprises. Considering these dynamics, we believe that restricting the analyses to the stable workforce reflects more robust changes in employment within organizations.

\footnotetext{
${ }^{17}$ Following the strategy of Goos et al., 2014, we measured routineness by attaching routineness scores to occupational measures (ISCO scores). These scores are taken from the Dutch Labor Force Surveys (EBB). Occupation is only available for a small portion of the data, but based on the available data, neither routineness of occupations nor educational attainment appear to be significant predictors of job ending under technological change.
} 


\subsection{Conclusion and discussion}

The current study investigates the relation between technology implementation within enterprises and job endings among employees. We address how the impact of technology implementation on job ending differs depending on human capital characteristics and categorical differences between workers. Furthermore, we investigate whether the effects of technology implementation differ depending on the union strength of the industry in which the enterprise operates. We combine Dutch register data with a large-scale survey on enterprise innovation, creating a matched employer-employee dataset including over 30,000 enterprises with over 4 million employees, covering the period 2001 to 2014.

The findings of the study indicate that, overall, technology implementation decreases the probability of job ending among workers with around 1.7 percent. This finding suggests that technological change does not decrease the need for employment within enterprises. Furthermore, the finding also suggests that technology implementation does not lead to a great turnover, and renewal of workforces. Instead, it suggests that enterprises (and workers) are able to adjust to the new technologies without the loss of jobs. Also, the results warn that studies predicting the decline of human labor may be overly pessimistic: employers seem to still be needing human employment following technological change. Furthermore, the findings corroborate notions that while technology alters and automates some job tasks, it is also creates new ones (Autor, 2015). Although it is possible that future technological developments in robotics and artificial intelligence may be more destructive for jobs than current technologies (Brynjolfsson and McAfee, 2014), predictions of a 'jobless future' may be off because predicting job generation is much harder than predicting job destruction (Osbourne and Frey, 2017). The findings of the current study suggest that concerns about the disappearance of human labor due to technology may be overstated.

Our study shows that, as predicted, technology differentially impacts parts of the organizational workforce. The findings are in line with the Skill-Biased Technological Change (SBTC) hypothesis proposed originally for aggregate labor market changes. We find that higher educated workers are less likely to experience job ending when technology is implemented. Furthermore, the findings are line with the argument from relational inequality theory that educational credentials serve as a categorical distinction used to legitimate claims of (redefined) roles within the organizational production process. When new technology is implemented within organization, educational credentials possibly serve as a source of power workers use to secure benefits generated by technological changes for themselves. Based on the Routine Biased-Technological Change (RBTC) hypothesis, we predicted that jobs of middle educated workers are most strongly affected by technological change. We, however, find no such pattern. Earlier studies suggest that technology may not be the primary driver of observed declines in routine jobs (Bessen, 2016; Nedelkoska, 2013), which could explain why we do not find support for this hypothesis. There are, however, other explanations. One explanation could be that jobs of middle-educated workers still consist of many non-automatable job tasks which require human labor (Bessen, 2016). Or, as we argued earlier, new technologies may enhance demand for human labor (Autor, 2015). Consequently, technology implementation may cause changes in job content rather than changes in the number of jobs. If this is the case, the results of the current study suggest that middle educated workers are generally successful in adapting their skills to perform new job tasks. We consider the question of which circumstances lead to more 
and less successful skill adaption by workers an interesting avenue for future research. Another important question elaborated in chapter 3 is how the employment prospects of workers whose jobs end are impacted by technological change.

Our study reports that workers with long organizational tenure (around 15 years and more) and older workers (around 50+) experience higher rates of job ending under technology implementation. These results seem to support the argument that technological change brings along adaptation costs that are greater for workers with more work experience. Furthermore, these results seem to be in line with the argument that older workers have more difficulty learning new skills (Desjardins and Warnke, 2012; Slegers, Van Boxtel and Jolles, 2009; Westerman and Davies, 2000), as well as the argument that older workers face ageist stereotypes at the workplace about their capacity to adapt to technological change (Posthuma and Campion, 2009; Shore and Goldberg, 2005). In light of the current trend of increasing retirement ages, as well as ever advancing technologies, the results of the current study suggests that policies aimed at timely preparing and training older and more experienced workers to stay competitive in a technologically innovate labor market are advisable.

Finally, we find statistically significant, but largely neglectable differences in our findings across industries. We would, however, be ill-advised to disregard unions as an important institution directing the effects of technological change. Collective bargaining in the Netherlands is highly collectivized, with the existence of industry-specific but also general employee unions, meaning that employees in industries with less degrees of union-specific bargaining benefit from across-the-board bargaining efforts. The Netherlands is not a unique case in this regard, but there are several countries, among which the often-studied US-case, where collective bargaining occurs at a lower level. We encourage research using a crosscountry comparative research design, including comparable labor markets and varying degrees of collectivized bargaining institutions to improve our understanding of the interplay between labor institutions and technological change.

Our focus on the individual-level, rather than aggregate, consequences of technological change opens a new avenue to study and further elaborate the interplay of technology with commonly studied dimensions of worker inequality such as, gender, race, and ethnicity. Currently, there is a paucity of studies on how women and minority race-ethnicity workers fare under technological change (exceptions are studies by Black and Spitz-Oener; 2010, and Warman and Worswick, 2015), but since organizational change evokes power processes, this research question is highly important to study. In chapter 4 we elaborate on the relation between technology implementation and job ending and the role of immigration background herein.

Our study uses a direct measure of technology implementation, which is exceptional as most of the literature address technology indirectly through aggregate labor compositional shifts. Some studies nevertheless suggest that is worthwhile to differentiate between technologies, as they arguably affect work tasks differently. For example, studying German manufacturing firms, Nedelkoska (2013) finds that investment in computers replaced routine tasks with less routine ones, while full automation of machine tools and half-automated (CNC) devices replaced routine tasks with similarly routine ones. Arntz, Gregory, Lehmer, Matthes and Zierahn (2017), find that the degree to which firm's work equipment is automated is larger in firms using mainly office and communication equipment, compared to firms using mainly production equipment. Although the measure we used in our study captures technologies that 
'significantly' alter products, production processes, and services, we cannot identify the type of technology. We encourage future data collection efforts to distinguishing between the types of technology that are implemented to better understand its implications for tasks and workers. 




\title{
Chapter 3
}

\section{Does technological change lead to longer job searches for workers who left their jobs? ${ }^{18}$}

\begin{abstract}
This study examines how technological changes within enterprises impact the successfulness of job searches of workers leaving these enterprises. Furthermore, we investigate how the impact of technological change on job search duration differs depending on the level of education, organizational tenure, and age of workers, and on the union density of the industry in which an organization operates. Using large-scale Dutch matched employer-employee data we find job searches to be significantly longer among workers who leave an enterprise that is implementing new technologies. We do not find this effect of technology implementation to differ depending on the level of education or the organizational tenure of a worker. For older workers, however, we do find the probability of starting a new job to be significantly lower when leaving an enterprise that is implementing new technologies. Finally, we find that in industries with stronger unions the association between technology implementation and job search duration weakens.
\end{abstract}

\footnotetext{
${ }^{18}$ The chapter is co-authored by Zoltán Lippényi, Tanja van der Lippe and Maarten Goos. Jannes ten Berge wrote the main part of the chapter and conducted the analyses.
} 


\subsection{Introduction}

Studies forecasting the labor market effects of technological advancement predict that technology will replace much of human labor. Estimates vary from almost half of current US occupations (Frey and Osbourne, 2017) to $9 \%$ in 21 OECD countries that are at risk of automation (Arntz, Gregory and Zierahn, 2017).

Responding to concerns about the job-destroying potential of technological change, research has put great effort into studying which jobs and job tasks are most vulnerable to technological changes. These studies evaluate the replaceability of job tasks by current technologies to arrive at a typology of which jobs are most at risk of (partial) substitution by technology (Autor, Levy and Murnane, 2003). The main conclusion is that technology triggers structural changes in labor markets in modern economies (Acemoglu and Autor, 2011; Autor et al., 2003; Goos and Manning, 2007; Goos, Manning and Salomons, 2009, 2014). It remains unclear, however, what happens to workers who leave their employer in times of technological change, and whether these workers can find new employment. This is an especially important subject in light of growing concerns about the sustainability of employment in modern economies (Van der Lippe and Lippényi, 2019). In this study we aim to increase our understanding of how technological change impacts the employability of workers whose jobs ended in times of technological change within their work organization.

An important reason why the literature falls short in explaining how technological change affects employment prospects of workers is that it largely ignores the organizational process of technology investment and employment decisions. It is not the labor market, but organizational actors that decide to invest in new technology, as well as to lay-off and hire workers. Acknowledging that technological change is an organizational process shifts the attention from labor markets to organizations. Specifically, regarding hiring, employers are likely to focus on the ability of prospective workers to accommodate technologically innovated organizational processes in times of technological change (Baumol and Wolf, 1998). Consequently, employers' expectations about the productivity of workers under technological change are likely to influence which workers will be successful in finding employment and which are not.

In this study we elaborate on how employers' demand for certain human capital characteristics and the social stereotypes associated with these characteristics influence job searches of workers under technological change. Technology increases employers' demand for workers that complement technologies, i.e. workers that are expected to increase productivity working with technology, while the demand of workers that 'compete' with technologies, i.e. workers that perform job tasks that technology can also perform, decreases (Autor et al., 2003; Acemoglu and Autor, 2011). Workers who possess human capital that employers who are investing in new technology expect to complement technology arguably have an advantage in getting a new job. We consider educational attainment, organizational tenure, and age as markers of human capital that are particularly relevant in times of technological change. Moreover, we argue that age is tied to particularly strong social stereotypes about the productivity of workers under technological change. Such stereotypes influence who gets hired and who does not, even when actual productivity of workers may contradict these stereotypes (Tomaskovic-Devey and Avent-Holt, 2019). 
The organizational focus of our study allows us, furthermore, to take into account institutions that in most modern economies regulate how employers can terminate jobs. Employers, especially in countries that Hall and Soskice (2001) refer to as coordinated market economies, need to cooperate and bargain with a variety of institutions, such as unions, employer and employee associations and governmental organizations, resulting in organization, industry or even nation-wide agreements. This interplay between institutions and organizations influences the consequences of technological change for the employability of workers. Within the literature focusing on technology and labor markets, however, the role of institutions has so far received surprisingly little attention. Perhaps this is in part because most studies focus on the US where more technological innovations originate from and which happens to be a liberal market economy in which institutional constraints on the labor process are weaker, and lost substantial strength in recent decades.

In the current study we remedy this lacuna in the literature by addressing the role industry-wide collective bargaining institutions for worker's employment chances in the Netherlands. The Netherlands is a coordinated market economy according to Hall and Soskice's framework (2001) with liberalizing tendencies in recent decades. However, regarding two institutional features key for our study's purpose; collective agreements regarding worker protection against and in case of layoffs and the role of labor unions, the country gravitates towards greater market regulation and coordination (Touwen, 2006). Specifically, the Dutch economy follows a corporatist institutional model in which bargaining plays out at the level of industries between industry-wide worker's unions and employer's associations. Unions negotiate about the conditions under which organizational changes, such as downsizing and reshaping of workforces take place (Choi, Leiter and Tomaskovic-Devey, 2008; Fernandez 2001; Kalleberg, Wallace and Althauser, 1981; Kristal, 2013). Such arrangements can include re-training, work transition arrangements, and aid in job searches, which can be of particular importance to workers whose jobs are affected by technological change within the organization. We address to what extent the strength of industry-wide labor unions matters in how technology affects the employment chances of workers whose jobs ended.

To study the effects of technological change we use a large-scale repeated survey of technological innovation within Dutch enterprises in the private sector matched with Dutch taxregister data on employees' jobs. This matched employer-employee dataset allows us to follow over three million employees within over 30,000 enterprises over the period 2001-2014.

\subsection{Theory}

The theory section is organized as follows. First, we theorize on how technological change affects the employment prospects of workers whose jobs are affected by technological change. Second, we elaborate on this effect of technological change by arguing how technological change differently impacts the successfulness of job searches depending on the level of education, organizational tenure, and age of workers. Finally, we theorize on the role of unions within an industry and work-to-work transitions of workers.

\section{Technological change and job searches of workers}

Seeking employment, workers rely on their experience and qualifications (Becker, 2009) as well as social connections (Granovetter, 2018; Holzer, 1988; Mouw, 2003) to find and compete 
for jobs. Ultimately, however, it is employers that make the final decision whether or not to hire a job applicant. Technological changes affect the successfulness of workers' job searches by influencing hiring decisions of employers. The principal mechanism through which it does so is by changing what employers look for in job applicants. As employers are implementing new technologies, the importance of finding employees who can effectively work with new technologies increases (Baumol and Wolf, 1998). For workers who do not possess such skills, finding employment with an employer who seeks to hire workers who are able to perform well in a technologically advanced workplace becomes harder.

A lack of technology complementary skills is likely to be particularly common among the workers who lost their jobs due to technological innovation within their previous workplace. When organizations implement new technologies, this not only affects which workers employers want to attract. It also influences who employers want to let go from the organization (see chapter 2). The problem for these workers is that the inability to effectively adapt to technological changes arguably not only affects their chances of employment within their current organization. Similar technological changes are likely to take place within other organizations. The diffusion of technological innovations across organizations generally follows an s-curved shape (Adner and Kapoor, 2016; Hall and Khan, 2003). This means that initially organizations are reluctant to be the first to experiment with new technologies. However, when technology starts to diffuse across organizations, the rate of adoption accelerates. When the market starts to saturate, the adoption rate decelerates again. For workers this means that technological changes that happened with their old employer likely just happened or are about to happen with potential future employers as well. Consequently, when a particular occupation is affected by technological advancement, this is likely to be happening across organizations. This is potentially problematic for workers who lost their job due to technology, as workers are most successful in applying for jobs that to a large extent involve similar job tasks as their previous job (Goos, Rademakers, Salomons and Willekens, 2019). As a result, technological changes that negatively impact workers' employment with previous employers may also negatively affect their employment chances within other organizations. We therefore expect that:

Hypothesis 1: Workers who separate from their employer while new technologies are being implemented in the organization experience longer job searches than workers who separate from their employer while no new technologies are being implemented in the organization.

\section{Level of education and job searches under technological change}

How technological change affects the job searches of workers is likely to differ depending on the characteristics of workers. From the future employer's perspective, the educational attainment of workers is likely to be particularly relevant.

The two dominant hypotheses in the field of technological change and labor markets are the Skill-Biased Technological Change (SBTC) hypothesis and the Routine-Biased Technological Change (RTBC) hypothesis. Both hypotheses predict that technological progress increases the relative productivity of higher skilled workers, such as programmers, scientists, analysts, consultants, and engineers (Autor et al., 2003; Berman, Bound and Griliches, 1994; 
Card and DiNardo, 2002; Katz and Murphy, 1992; Krueger, 1993; Michaels, Natraj and Van Reenen, 2014). While higher education gives access to such high-skilled jobs, a higher educational attainment -regardless of occupation- is also a visible and reliable marker of productivity readily accessible within the hiring process (Becker, 2009). We therefore expect that under technological change the successfulness of job searches of workers with higher levels of education increases relative to that of lower educated workers, thereby showing shorter job searches on average than lower educated workers.

The RBTC hypothesis adds to the SBTC hypothesis by arguing for a more nuanced understanding of the impact of technological change. It proposes that technology is biased towards replacing human labor in routine tasks, because routine tasks are codifiable in computer language or machine sequences, while non-routine tasks cannot (yet) be replaced by technology (Autor et al., 2003). Importantly, from the RBTC hypothesis it is derived that because many jobs involving routine task, such as calculation and repetitive assembly, are found in the middle skill and wage job segment, automation contributes to a polarization of the labor market (Goos and Manning, 2007).

As technological change happens across organizations, the chances that employers seek workers whose skills can be replaced with technologies decreases. Based on the argument that technology is biased towards replacing routine tasks, and that middle-educated workers are more likely to have jobs involving routine tasks, we propose that middle-educated workers are more likely to be among those workers who can be replaced with technologies. Assuming that workers will seek to find employment with similar stature and pay, finding re-employment is likely to become more difficult for those competing with technology. Considering these arguments, we expect that:

Hypothesis 2: The positive effect of previous employer's implementation of new technology on the duration of job search is stronger for middle and lower educated workers than for higher educated workers.

\section{Organizational tenure and job searches under technological change}

Working within an organization, workers gain experience with and knowledge of the working processes within the organization. This experience and knowledge generally make these tenured employees very valuable to the organization (Crook, Todd, Combs, Woehr and Ketchen, 2011).

However, they are often tailored to specific production processes and technologies that change in times of technological change (Lazear, 2009; Topel, 1991). As a result, the experience and knowledge associated with old technologies become, at least partially, obsolete. The depreciation of experience grounded in working with 'old' technologies, combined with their higher reservation wage, makes these tenured workers less desirable for employers. In line with this argumentation, studies find that automation (Bessen, Goos, Salomons and Van den Berge, 2019) and the implementation of new technology (see chapter 2) is associated with greater odds of job separation for longer tenured workers.

The depreciation of experience arguably affects worker's job searches as well. The value of experience gained predominantly through working with old technologies diminishers in a labor market where hiring employers seek experience with new technology. Under the likely 
assumption that workers primarily look for new jobs that (largely) resemble their previous one (Goos et al., 2019), there is likely to be a mismatch between the knowledge and experience of tenured workers and the knowledge and skills employers seek in employees under new technology (Baumol and Wolff, 1998). As it is likely that tenured workers are not willing to accept job offers with a significantly lower pay, their job searches in times of technological change are likely to be longer than workers with less experience. All in all, we expect that:

\section{Hypothesis 3: The positive effect of previous employer's implementation of new technology on the duration of job search of workers increases with the length of organizational tenure.}

\section{Age and job searches under technological change}

There are two main reasons to expect age variation in the employment chances of workers during times of technological change: 1) reduced capability to adapt to new technologies due to cognitive limitations and employers' reluctance to invest in training, and 2) ageist stereotypes.

Technology implementation within organizations leads to change in the work process, work organization and/or products and services. Workers who have jobs that are affected by such technological changes are likely to have to adapt in some way to accommodate to new technology. This adaptation may involve learning new skills via training or education or learning to function within a new organization of work. Technology thereby increases the importance of adaptation and there are indications that such adaptation is more challenging for older workers. First, older workers are less able to learn new (technological) skills, which has been shown by a number of studies on cognition and ageing (Desjardins and Warnke, 2012; Slegers, Van Boxtel and Jolles, 2009; Westerman and Davies, 2000) and are therefore less likely to have picked up such knowledge with their previous employer. Second, older workers' knowledge acquired during formal education pertains to former technological eras. When older workers seek employment under technological change, they may therefore lack the technological know-how required by prospective employers while younger workers are more likely to have acquired such knowledge (Beckmann, 2007). The age gap in technological skills may further increase due to the often-reported reluctance of employers to invest in re-training of older workers for which returns in productivity are expected to be lower (Arulampalam, Booth and Bryan, 2004; Bartel and Sicherman, 1993; Beckmann, 2007; Carmichael and Ercolani, 2014; Guerrazzi, 2014; Taylor and Urwin, 2001). Consequently, the chance that older workers who seek employment have acquired the necessary technological skills with their previous employer is smaller, making them less attractive job candidates in times technological change.

Even if older workers possess the necessary technological know-how that an employer is looking for, they must convince the hiring organization of their competence. Studies, however, show that the idea that older workers are less able and willing to adapt to technological changes is a persistent social stereotype. Observational and experimental studies have shown that ageist stereotypes are likely to influence managerial decision making regarding hiring and training, even when the work performance and productivity of these workers contradict these stereotypes (Lössbroek, Lancee, Van der Lippe and Schippers, 2019; also see Posthuma and 
Campion, 2009 and Shore and Goldberg, 2005 for overviews of studies on performance stereotypes and actual performance of older workers). Thus, even when older workers have the necessary technological skills or adaptive capabilities, they might face barriers in finding a new job due to negative stereotypes of potential employers.

All in all, we expect that:

Hypothesis 4: The positive effect of previous employer's implementation of new technology on the duration of job search of workers increases with the age of the worker.

\section{Unions and job searches under technological change}

Employment relations within work organizations are strongly influenced by the institutional context. Formal institutions, such as laws, unions, and collective agreements explicate "the rules of the game", constraining employers' decisions regarding the employment of their workers (Scott, 2014). Importantly, for the job search process of employees leaving their previous job, this involves which actions organizations should take to enhance the employability of employees who are laid off. Since the beginning of the 1980's, the Netherlands have developed a highly corporatist institutional model (De Beer and Keune, 2017). This corporatist structure is characterized by a high degree of centralized rather than firm-level interaction and consultation between union federations, employer federations, and the national government on all issues of social economic policies, including labor legislation and social protection (Hall and Soskice, 2001; Hartog, Leuven and Teulings, 2002). For the Netherlands (but also for the case of Germany, for example), this institutional arrangement results in relatively high levels of workers covered by a collective agreement (79\% in 2016, ranking $9^{\text {th }}$ among 36 countries included in OECD data (OECD, 2018). Layoffs and collective dismissals are regulated at the national level in the Netherlands, and considering the strictness of legislation around individual dismissal, the Netherlands ranks $10^{\text {th }}$ out of 71 listed countries (OECD, 2020a). The US ranks last among OECD countries, which indicates that the Netherlands may be more of a 'typical' institutional case than the US with its very low levels of protection.

Collective labor unions are an integral part of the consultation procedures enforced within the corporatist institutional structure of the Netherlands. In case of larger layoffs, employers are obliged to notify employee associations and propose arrangements -in form of a written plan, the so-called "Sociaal Plan"- how to mitigate negative consequences of the layoff for workers' employability. It is not statutory in the Netherlands to consult with collective worker's unions regarding arrangements, but in practice it is often done as unilateral arrangements are seen as less valid in case of arbitrage. While the participation of collective unions in proposing arrangements legitimize the actions of the employer for external parties, the actual content of the "Sociaal Plan" depends on the negations between employers and unions. Arrangements can, but not necessarily, include the (re-)training of employees, aid in work-to-work transitions, salary payments during the period of job search, and severance pay. Under such institutional arrangements, union 'voice' is likely to be an important factor in determining how transitional arrangements are made (Freeman and Medoff, 1984; also see Bryson and White (2006) on unions and the provision of severance pay). As a result, we can 
expect that in industries with stronger collective unions -in terms of union density- employees are more likely to benefit from better transitional arrangements assisting them in finding a job.

We expect that:

\begin{abstract}
Hypothesis 5: The positive effect of previous employer's implementation of new technology on the duration of job search of workers is weaker in industries with higher union densities.
\end{abstract}

\title{
3.3 Data
}

Our study makes use of the combination of a large-scale enterprise survey and social microregister data. Data on enterprise investment in technology is taken from the Community Innovation Survey (CIS). The CIS is a large-scale cross-national survey of innovation activity in enterprises, repeated every two years. In the Dutch survey used by this study, the sample is stratified by sector and establishment size, excluding enterprises smaller than ten workers (Mortensen and Bloch, 2005). We focus on the period 2001-2014, during which a total of 37,520 enterprises participated in the Dutch CIS. We linked these enterprises to register data on workers' jobs and demographic characteristics from the System of Social Statistics Databases (SSB) of the Dutch Central Bureau of Statistics, creating a longitudinal matched employer-employee dataset. ${ }^{19}$ Linking the survey data to register data allows tracking job switches between enterprises, as well as job search duration. For the study we selected all job endings occurring within all surveyed enterprises between 2001-2014. A job is defined as a contractual employment relation between an individual and an enterprise. If an individual had more employment contracts with the same enterprise, we aggregated them as one record.

In the study we focus on workers whose standard (permanent) employment ended with their previous employer, excluding job endings of non-standard employment contracts - fixedterm contracts, on-call contracts, and internships. We chose to exclude endings of non-standard contracts because both workers and employers expect these contracts to end, which influences job termination, transitional arrangements, and search behavior in such ways that the mechanisms become incomparable to those with permanent jobs. In addition, we excluded workers younger than 30 because job matches in early career are likely to be imperfect, leading to a high number of job switches not attributable to the technological process. We provide robustness checks in which we do not make these selections to investigate how the results are impacted by these selections.

To arrive at our analytical dataset, we exclude a number of cases due to missing data. We exclude observations of workers whose level of education was not registered $(634,323$ individuals, $34.52 \%$ of all individuals). ${ }^{20}$ Considering the large number of omissions on education, we provide an additional robustness check to assess whether this selection influenced the results. Furthermore, we exclude observations of workers who are past the legal retirement age; 67 (2,886 observations, $0.12 \%$ of total observations). We also exclude enterprises that

\footnotetext{
${ }^{19}$ Results are based on calculations by Utrecht University using non-public microdata from Statistics Netherlands. Under certain conditions, these microdata are accessible for statistical and scientific research. For further information: microdata@cbs.nl.

${ }^{20}$ (see footnote 9 in section 2.3 for a discussion on missing data on education)
} 
could not be linked to an industry (994 enterprises, $2.79 \%$ of all enterprises), and enterprises for which we have no information on organizational innovation (274 enterprises, $0.77 \%$ of all enterprises). The remaining dataset consists of 33,139 enterprises, 1,181,799 workers, and 1,556,065 observations of job ending. Table 3.1A provides descriptive statistics.

The number of observed job endings is higher than the number of workers, as a substantial proportion of workers (276,259 individuals, $23.38 \%$ of individuals in the analytical dataset) have multiple observed job searches within the data (up to a maximum of 19 for one worker). To investigate to what extent repeated job search events drive the results, we provide a robustness check in which we only analyze the first (observed) job search.

Table 3.1A Descriptive statistics before and after deletion of missing cases

\begin{tabular}{|c|c|c|c|c|c|c|}
\hline & \multicolumn{3}{|c|}{ Before deletion } & \multicolumn{3}{|c|}{ After deletion } \\
\hline & Mean & S.D. & Range & Mean & S.D. & Range \\
\hline $\begin{array}{l}\text { Event: Finding a new job } \\
\text { within } 2 \text { years }\end{array}$ & \multicolumn{2}{|c|}{$71.64 \%$} & {$[0-1]$} & \multicolumn{2}{|c|}{$72.17 \%$} & {$[0-1]$} \\
\hline Job search duration in days & 317 & 623 & $\dagger$ & 308 & 589 & $\dagger$ \\
\hline Technology implementation & 0.29 & . & {$[0-1]$} & 0.29 & . & {$[0-1]$} \\
\hline Level of education & & & {$[0-2]$} & & & {$[0-2]$} \\
\hline Low & \multicolumn{2}{|c|}{$26.04 \%$} & \multicolumn{4}{|c|}{$26.12 \%$} \\
\hline Middle & \multicolumn{2}{|c|}{$41.43 \%$} & \multicolumn{4}{|c|}{$41.54 \%$} \\
\hline High & \multicolumn{2}{|c|}{$32.53 \%$} & \multicolumn{4}{|c|}{$32.34 \%$} \\
\hline Organizational tenure & 6.00 & 8.22 & $\dagger$ & 4.72 & 6.75 & $\dagger$ \\
\hline Age & 43.56 & 10.23 & $\dagger$ & 41.44 & 8.78 & $\dagger$ \\
\hline Union strength & 20.25 & 9.96 & {$[12-35]$} & 20.04 & 9.91 & {$[12-35]$} \\
\hline Part-time work & 0.24 & 0.32 & $\dagger$ & 0.24 & 0.31 & $\dagger$ \\
\hline Having a second job at $\mathrm{t}=0$ & 0.21 & . & {$[0-1]$} & 0.22 & . & {$[0-1]$} \\
\hline Migration background & & & {$[0-2]$} & & & {$[0-2]$} \\
\hline Native Dutch & \multicolumn{2}{|c|}{$74.15 \%$} & & \multicolumn{2}{|c|}{$73.39 \%$} & \\
\hline Non-Western immigrant & \multicolumn{2}{|c|}{$13.85 \%$} & & \multicolumn{2}{|c|}{$15.44 \%$} & \\
\hline Western immigrant & \multicolumn{2}{|c|}{$12.01 \%$} & & \multicolumn{2}{|c|}{$11.17 \%$} & \\
\hline Gender & & & {$[0-1]$} & & & {$[0-1]$} \\
\hline Male & \multicolumn{2}{|c|}{$0.62 \%$} & & \multicolumn{2}{|c|}{$0.60 \%$} & \\
\hline Female & \multicolumn{2}{|c|}{$0.38 \%$} & & \multicolumn{2}{|c|}{$0.40 \%$} & \\
\hline Enterprise size & 5,588 & 16,869 & $\dagger$ & 5,877 & 17,926 & $\dagger$ \\
\hline Organizational innovation & 0.40 & . & {$[0-1]$} & 0.40 & . & {$[0-1]$} \\
\hline Yearly unemployment rate & 4.84 & 1.32 & {$[2.5-7.4]$} & 4.91 & 1.32 & {$[2.5-7.4]$} \\
\hline Number of observations & \multicolumn{2}{|c|}{$2,318,339^{*}$} & \multicolumn{4}{|c|}{$1,556,065 * *$} \\
\hline Number of individuals & \multicolumn{2}{|c|}{$1,837,757$} & \multicolumn{4}{|c|}{$1,181,799$} \\
\hline Number of enterprises & \multicolumn{2}{|c|}{35,641} & \multicolumn{4}{|c|}{33,139} \\
\hline
\end{tabular}

* The $\mathrm{n}$ presented is for the variables with complete data. Variables that have a lower $\mathrm{n}$ due to missing data are education $(n=1,590,259)$, industry unionism $(n=2,276,795)$, organizational innovation $(n=2,313,899)$, and job search duration $(n=1,721,464)$

** The $\mathrm{n}$ presented is for the variables with complete data. The variable job search duration has a lower $\mathrm{n}$ due to missing data $(\mathrm{n}=1,292,170)$ 
$\dagger$ Due to the identifiability protocols of the Dutch Central Bureau of Statistics, minimum and maximum values cannot be included here

\subsection{Measurement}

\section{Dependent variable}

Finding a new job is measured as the point in time at which a person whose contractual employment relation within an enterprise ended engages in a new contractual employment relation within a new enterprise. Having information about the beginning and end of employment relations between individuals and enterprises of all workers from the register data we can reliably document beginnings and endings of worker's jobs.

\section{Independent variables}

Implementation of technology was measured using an item from the Community Innovation Survey. A higher-level manager from the enterprise was asked whether, over the past two to three years (depending on the survey date), the enterprise purchased advanced machinery, equipment (including computer hardware) and/or software with the goal to significantly improve products, services, and/or production processes. Out of the 1,529,334 observations of job ending, 451,110 (29.50\%) occurred in an enterprise implementing new technologies.

Level of education is measured according to the International Standard Classification of Education (ISCED). Eight educational levels are distinguished. We recoded the levels into three broad categories following guidelines from the ISCED 2011 manual (OECD/Eurostat/UNESCO Institute for Statistics, 2015). Low level of education, including those who attained less than primary education, primary education, and lower secondary education. Medium level of education, including employees who attained upper secondary education and post-secondary non-tertiary education. And high level of education, including employees who attained short cycle tertiary, bachelors, a master, or doctoral equivalent education.

Organizational tenure is measured as the duration of the employment relation within the enterprise (where a workers' job ends) in years. The average number of years worked within the enterprise is 4.8 years. For the analyses we mean center the variable.

Age is measured in years since birth. The average age of workers over the years of observation is 41.5 years old. For the analyses we mean center the variable.

Union density is measured as the percentage of unionized employees among the total number of employees with paid work for at least 12 hours per week within an industry (Statistics Netherlands, 2012). The Community Innovation Survey surveyed organizations in eight different private sector industries, excluding agriculture and fisheries.

\section{Controls}

Part-time work refers to the job that ended and is measured as jobs that are less than one Full-Time Equivalent. The Netherlands are among the countries with the highest rates of parttime employment in the world. In 2014 over 38\% of employment was part-time (OECD, 2020 b). The majority of Dutch women, more than two-thirds in 2014, work part-time, and most Dutch households employ a one-and-a-half job dual earner model (Visser, 2002). Part-time 
workers are more likely to make work transitions into unemployment and part-time work than full-time workers. This is in part explained by gender differences (Yerkes, 2009). Because job transitions differ, the duration of job searches possibly also differs between part-time and fulltime workers. We therefore control for part-time work.

Second job at $t=0$. Some of the observed job endings occur while workers hold other jobs at another organization. Since job search duration is likely to depend on whether a worker is unemployed or has other jobs, we control for having a second job.

Migration background is measured using information on the birthplace of a person and the birthplace of the parents. Following the categorization of Statistics Netherlands, we define as native those who are born in the Netherlands and whose parents are also born in the Netherlands. The category workers with a non-Western immigrant background include those workers who were born in a non-Western country, or whose mother or father was born in a nonWestern country. Non-Western countries are, according to the Statistics Netherlands definition, those in Asia, Africa, Latin-America, Asia, and Turkey. Workers with backgrounds in Indonesia (due to colonial population of the former Dutch-Indies) and Japan are categorized as Western. As are workers with backgrounds in Europe, North America, and Oceania. Within the models, native Dutch are the reference category.

Gender is taken from municipal register data. Male is the reference category.

Enterprise size. We control for enterprise size to account for differences in job search durations that may differ for workers who leave larger organizations compared to workers leaving smaller organizations. Furthermore, the effects of technology implementation may be different. For example, when technology leads to mass layoffs at a large organization, this may lead to tightness in a local labor market, affecting chances of finding a job (Goos et al., 2019) Because the distribution of enterprise size is strongly right skewed, indicating the presence of several very large enterprises, we use the log of enterprise size in the analyses.

We control for organizational innovations to capture non-technological changes in the organization of the enterprise that may lead to job ending and subsequent job searches (Bauer and Bender, 2004; Bresnahan, Brynjolfsson and Hitt, 2002). The CIS survey measure indicates whether over the past two to three years the organization introduced new business procedures, new methods for the organization of professional responsibilities and decision making, or new methods to organize external relations with other companies or institutes.

Finally, we control for unemployment rate in all models to capture labor market fluctuation, measured as the national yearly unemployment rate of the Netherlands. On average, the unemployment rate was $4.92 \%$ over the period $2001-2014$.

\subsection{Method}

We estimated Cox proportional hazards models with cluster-robust standard errors (at the enterprise level) to test the relation between technological change and the probability of starting a new job at a new enterprise. ${ }^{21}$ We right censored the data at 730 days (two years after the observation period ends) because we have data until two years after the final survey year (2014).

\footnotetext{
${ }^{21}$ The analyses were performed using the stcox command in Stata 15 which corrects for right-censoring. We used the Breslow method (default) to handle ties.
} 
The final observation day is the 30th of December 2016. Out of the total of 1,556,065 cases of job ending observed in the study, 1,121,893 events of re-employment were observed $(72.10 \%)$ within the observation period of two years. In 170,277 cases (10.94\%) re-employment took place after the two-year observation period. In 263,895 cases $(16.96 \%)$, we did not observe reemployment within the data.

Some workers already have a second job when we observe job ending. Out of the 434,172 cases of job ending for which we do not observe an event of re-employment within two years, $30.84 \%$ of the cases $(133,887)$ were observed in combination with this person having a second job, which likely decreases chances of these people looking for a job. Moreover, in $10.90 \%(47,328)$ of cases the second job had started within the month prior to the observed job ending, which likely means this person had already started a new job before the old one ended. Table 3.1B provides descriptive statistics of the observations for which we do and do not observe the event of re-employment within two years. It shows that workers who were not observed to be re-employed within two years are more likely to be higher educated, longer tenured, older, part-time workers, compared to workers for who we observe job starts within the two-year observation period. This may be expected, as workers who quit the workforce are more likely to be older workers (who are also more likely to be lower educated and to have long organizational tenure), and part-time workers.

We tested the proportional hazards assumption graphically, by using Kaplan-Meier curves for categorical variables, and Schoenfeld residual plots for continuous variables, and by employing Schoenfeld residual tests (based on model 6 in Table 3.2). The Schoenfeld residual global test (see Table 3.A1) indicates that the assumption of proportionality is violated $\left(X^{2}(19)=2.59 \mathrm{e}+06, \mathrm{p}<0,001\right)$. Also, each of the covariates included in the model appear to violate the proportional hazards assumption. Important to note is that the tests are based on a very high number of observations. Within the Schoenfeld residual test the $\mathrm{P}$ value is dependent on the sample size, and large sample sizes can produce high significance even when there is minimal violation of the proportionality assumption (In and Lee, 2019). For example, Figure 3.A1 (appendix) shows a plot of the Kaplan-Meier curves for the variable technology implementation. Visually inspecting the plot, the hazards appear to be proportional despite the statistically significant Schoenfeld residual test shown in Table 3.A1. Further inspection of the Kaplan-Meier curves in Figures 3.A2, 3.A7 to 3.A9 and 3.A11 similarly seem to warrant a visual affirmation of the proportionality of the hazards. To investigate the proportional hazards assumption for the continuous variables we plotted the Schoenfeld residuals in Figures 3.A3 to 3.A6, 3.A10 and 3.A12. The plots present the average deviation of the estimated hazards, in which a slope that deviates from zero indicates a violation of the proportional hazard assumption. ${ }^{22}$ Looking at the Figures, the plotted average deviations of the estimated hazards

\footnotetext{
${ }^{22}$ Originally the plots also showed the estimated residuals which appear as dots in the figure. Because these dots present estimations for individual observations, Statistics Netherlands does not allow presentation of this output due to strict identifiability protocols. The range on the y-axis, however, give an indication of the spread of the residuals. To give some indication as to what the residuals look like; the range on the y-axis is generated automatically in Stata, leaving a little space above and below the highest and lowest estimated residuals. Furthermore, because of the very large sample size, the residuals form a cloud of dots that have no outliers that separate from the other dots. Also, the residuals form a rectangular shape around the $\mathrm{x}=0$ axis in which the minimum and maximum values on the $\mathrm{y}$-axis are similar at the start and end of the $\mathrm{x}$-axis.
} 
appear to be very close to zero. Based on these visual inspections, in combination with the sensitiveness of the Schoenfeld residual test to large sample sizes, we decided to interpret the models presented in Table 3.2, thereby assuming that our conclusions are not greatly impacted by the existent violations of strict proportionality of the hazards across time.

In our first model we test the effect of technological change on the likelihood of finding a job. To this model we add, one-by-one, the interaction effects between technological change and education, tenure, age, and union strength. Finally, the full model is presented. Within the models including educational attainment, high educated worker is the reference category.

Table 3.1B Descriptive statistics of workers with observed job starts within the two-year observation period and workers who fall outside the two-year observation period

\begin{tabular}{|c|c|c|c|c|c|c|}
\hline & \multicolumn{3}{|c|}{$\begin{array}{c}\text { Observed job start within } 2 \\
\text { years }\end{array}$} & \multicolumn{3}{|c|}{$\begin{array}{l}\text { No observed job start } \\
\text { within } 2 \text { years }\end{array}$} \\
\hline & Mean & S.D. & Range & Mean & S.D. & Range \\
\hline Job search duration in days & 120 & 172 & $\dagger$ & 1,546 & 822 & $\dagger$ \\
\hline Technology implementation & 0.29 & . & {$[0-1]$} & 0.31 & . & {$[0-1]$} \\
\hline Level of education & & & {$[0-2]$} & & & {$[0-2]$} \\
\hline Low & \multicolumn{2}{|c|}{$23.34 \%$} & & \multicolumn{2}{|c|}{$33.30 \%$} & \\
\hline Middle & \multicolumn{2}{|c|}{$42.91 \%$} & & \multicolumn{2}{|c|}{$38.00 \%$} & \\
\hline High & \multicolumn{2}{|c|}{$33.75 \%$} & & \multicolumn{2}{|c|}{$28.70 \%$} & \\
\hline Organizational tenure & 3.92 & 5.42 & $\dagger$ & 6.81 & 9.03 & $\dagger$ \\
\hline Age & 40.13 & 7.81 & $\dagger$ & 44.83 & 10.15 & $\dagger$ \\
\hline Union strength & 20.08 & 9.91 & [12-35] & 19.94 & 9.94 & [12-35] \\
\hline Part-time work & 0.21 & 0.29 & $\dagger$ & 0.31 & 0.34 & $\dagger$ \\
\hline Having a second job at $\mathrm{t}=0$ & 0.18 & . & {$[0-1]$} & 0.31 & . & {$[0-1]$} \\
\hline Migration background & & & {$[0-2]$} & & & {$[0-2]$} \\
\hline Native Dutch & \multicolumn{2}{|c|}{$73.96 \%$} & & \multicolumn{2}{|c|}{$71.93 \%$} & \\
\hline Non-Western immigrant & \multicolumn{2}{|c|}{$14.83 \%$} & & \multicolumn{2}{|c|}{$17.00 \%$} & \\
\hline Western immigrant & \multicolumn{2}{|c|}{$11.21 \%$} & & \multicolumn{2}{|c|}{$11.06 \%$} & \\
\hline Gender & & & {$[0-1]$} & & & {$[0-1]$} \\
\hline Male & \multicolumn{2}{|c|}{$0.61 \%$} & & \multicolumn{2}{|c|}{$0.57 \%$} & \\
\hline Female & \multicolumn{2}{|c|}{$0.39 \%$} & & \multicolumn{2}{|c|}{$0.43 \%$} & \\
\hline Enterprise size & 5,309 & 17,464 & $\dagger$ & 7,346 & 18,992 & $\dagger$ \\
\hline Organizational innovation & 0.40 & . & {$[0-1]$} & 0.43 & . & {$[0-1]$} \\
\hline Yearly unemployment rate & 4.86 & 1.31 & {$[2.5-7.4]$} & 5.04 & 1.33 & {$[2.5-7.4]$} \\
\hline Number of observations & \multicolumn{2}{|c|}{$1,121,893$} & & \multicolumn{2}{|c|}{434,172} & \\
\hline Number of individuals & \multicolumn{2}{|c|}{852,362} & & \multicolumn{2}{|c|}{416,716} & \\
\hline Number of enterprises & \multicolumn{2}{|c|}{31,990} & & \multicolumn{2}{|c|}{25,594} & \\
\hline
\end{tabular}

$\uparrow$ Due to the identifiability protocols of the Dutch Central Bureau of Statistics, minimum and maximum values cannot be included here

\subsection{Results}

Model 1 in Table 3.2 provides the cox proportional hazards regression estimates for the effect of technology implementation on the hazard ratio of re-employment with only controls 
included. Supporting our first hypothesis, we find the likelihood of re-employment to decrease when job ending occurs during a period of technology implementation at the former employer. Expressed in hazards, we find that (not including interaction terms) workers leaving an enterprise that is implementing new technologies show an $1.18 \%$ decrease in the expected hazard relative to workers leaving an enterprise that is not implementing new technologies.

Looking at the role of workers educational attainment (model 2), we do not find evidence that the likelihood of starting a new job after leaving an enterprise implementing new technologies is smaller for lower educated workers relative to higher educated workers. For middle educated workers, however, we find a significantly smaller likelihood of starting a new job after leaving an enterprise that is implementing new technologies, relative to higher educated workers. However, this effect is no longer significant in the full model. We thus do not find robust support for hypothesis 2 .

Longer organizational tenure is associated with lower likelihood of starting a new job (model 3) but this is no different in periods of technology implementation. We therefore reject hypothesis 3.

Older workers have a lower likelihood of starting a new job and this is even more so in periods of technology implementation (model 4). Estimating the marginal effects, we find that at age 30, leaving an enterprise that is implementing new technologies decreases the chance of starting a new job by $0.11 \%$, compared to workers aged 30 who leave an enterprise that is not implementing new technologies. Comparing the two conditions at age 60 this difference increases to $2.12 \%$. Thus, as age increases, the penalty of leaving an enterprise implementing new technologies slightly increases as well. As this effect is robust in the full model, we find support for hypothesis 4 .

Finally, we tested the proposed differences in the effect of technology implementation by industry union strength. While there are no such differences when assessed in a model only including controls (model 5), ${ }^{23}$ in the full model we do find a small but statistically significant relation between union strength and the effect of technology implementation. Figure 1 shows the estimated marginal effects of technology implementation by union density. It shows that overall, chances of starting a new job are smaller in union dense industries compared to industries with lower union densities. Furthermore, it shows that in industries with a low union density (10\%), technology implementation on average associates with lower chances of starting a new job compared to when enterprises are not implementing new technologies. For example, in the retail and in the business service industry where the average union density is $12 \%$, the predicted chances of starting a new job for workers leaving an enterprise under technological change is $51.53 \%$. Within these industries, for workers leaving an enterprise that is not implementing new technologies the predicted chance of starting a new job is $53.53 \%$, which is $2.00 \%$ higher.

In line with our expectations, we find that this negative association between technology implementation and chances of starting a new job is smaller in industries with higher union

\footnotetext{
${ }^{23}$ The difference between inferences from these two models is quite clear: high union density industries have a different composition regarding the level of education, organizational tenure or age of workers than low union density industries, so the full model gives a more reliable test of differences by union density than the bivariate model without controls.
} 
densities. For example, within industry and mining, and within energy and water management, where the average union density is $35 \%$, workers predicted chances of starting a new job after leaving enterprises implementing and not-implementing new technologies are $50.21 \%$ and $50.00 \%$ respectively. Thus, in an industry with $12 \%$ union density, technology implementation associates with an estimated $1.80 \%$ decrease in chances of starting a new job, whereas in an industry with $35 \%$ union density technology implementation associated with an estimated $0.21 \%$ increase in chances of job ending.

Thus, as union density increases, the expected 'penalty' of leaving an enterprise implementing new technologies decreases. This finding supports hypothesis 5 . In line with what we expected, unionism associates with a decrease of the negative effect of technological change on the probability of starting a new job. 


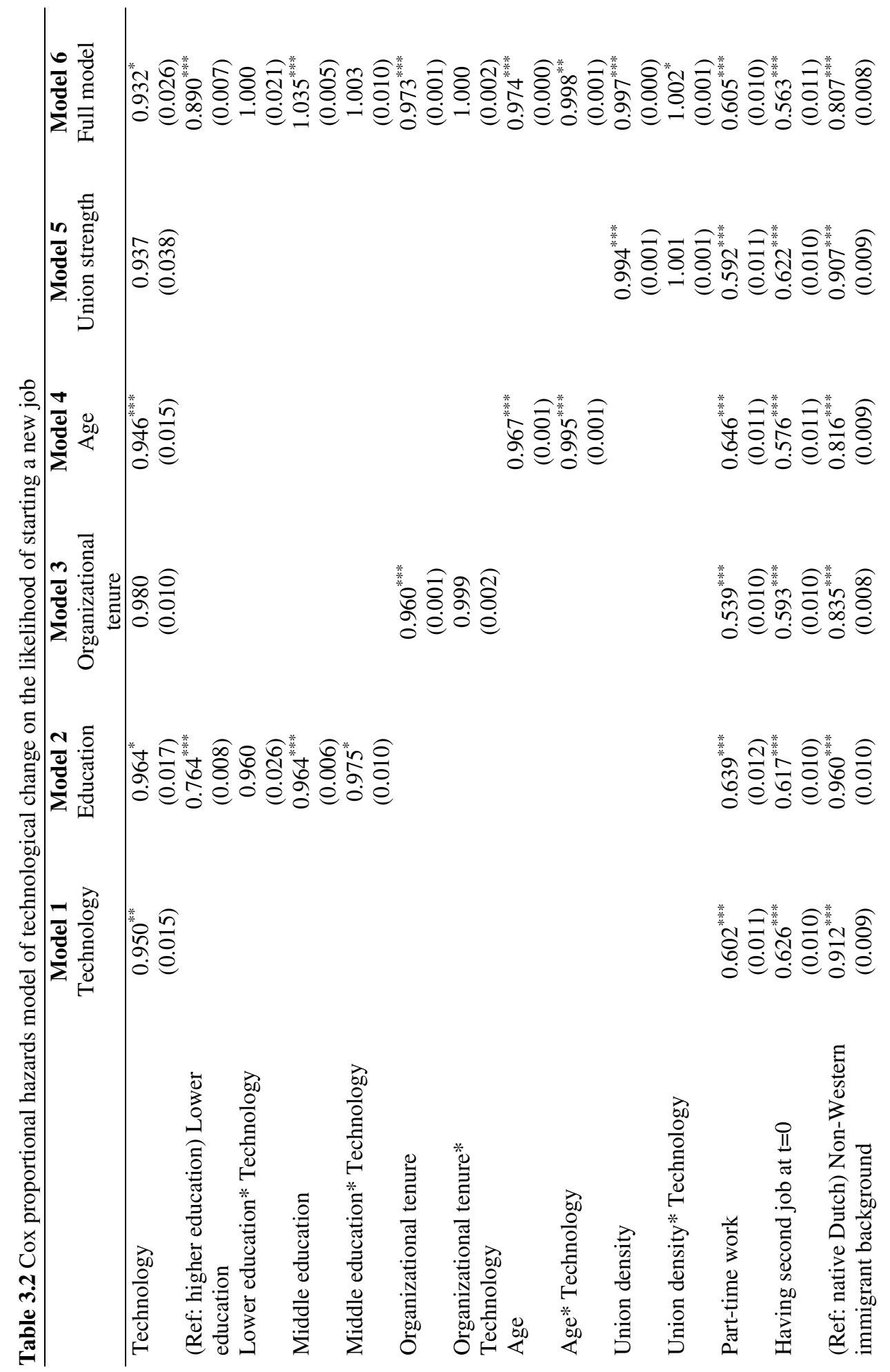




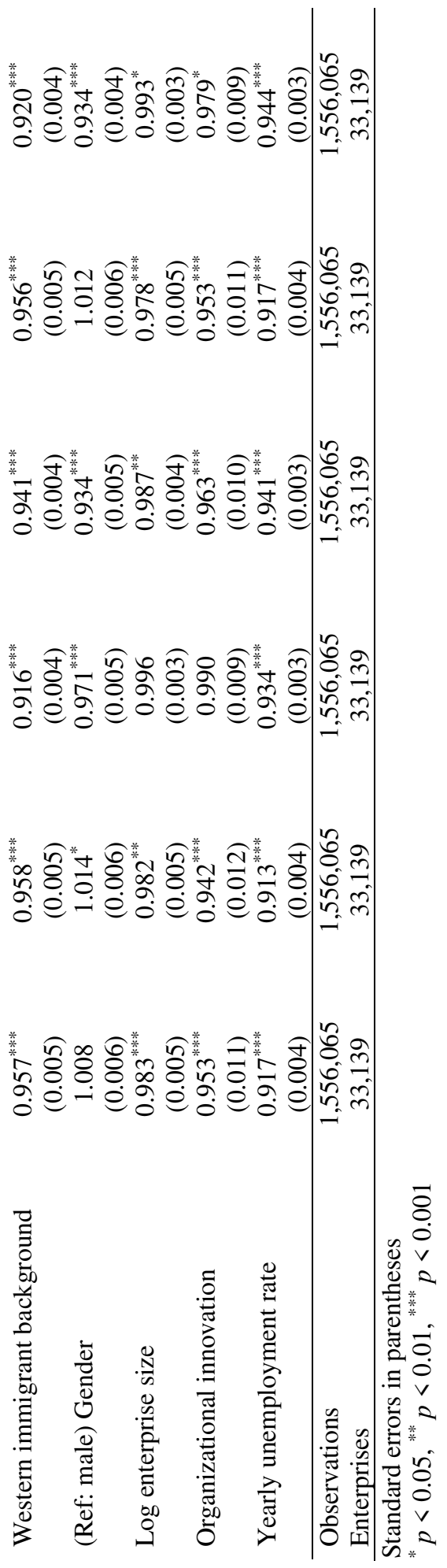


Figure 3.1. Predictive margins of the relative hazard of starting a new job by industry union density and technology implementation

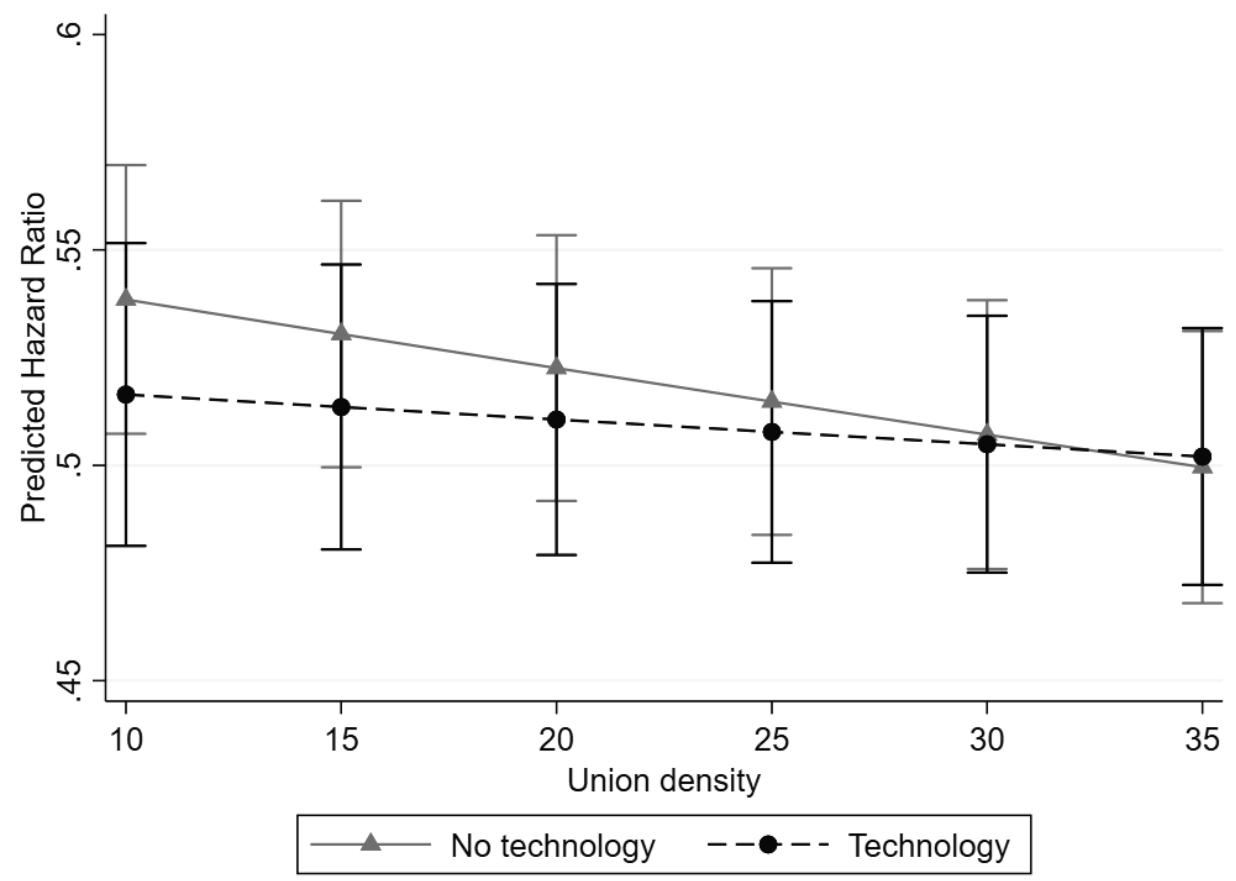

\section{Robustness checks}

To investigate in what way data selections and restrictions affect the results, we compare the estimate of the age and technology interaction effect on the analytical sample, (model 4 in Table 3.2 ), with an estimate on samples where we revert each of the data selections. We chose the age $\mathrm{x}$ technology model specification as the baseline model because all variables can be measured without missing data. We also assess a model excluding repeated observations, keeping only the first observed job that ended per worker. The robustness checks are presented in Table 3.3.

Reintroducing cases with missing data on education does not alter our conclusions (model 7), nor does the exclusion of workers with multiple job searches (model 10). The results do change somewhat when we include non-standard employment contracts (model 8) or reintroduce workers aged below 30 (model 9) to the analytical sample. Compared to the results presented in model 4 , the interaction effect between technology implementation and age is no longer significant.

We do not think that this should be concerning regarding our main findings, since neither our models, nor the data available for us, can account for the many sources of the early career mismatches of younger workers causing frequent job switches. Hence, for the sake of a well-specified and parsimonious model and with a minor loss of generalizability of our findings, excluding these cases is warranted. Furthermore, technological change arguably affects the job searches of workers with fixed-term and on-call contracts differently from that of workers with permanent contracts, as these workers are more likely to be contracted in anticipation of technological changes within the organizations. Although the topic of how technology impacts 
workers with non-standard employment contracts warrants further investigation, we consider this to be beyond the scope of the current study.

Table 3.3 Cox proportional hazards model of technology implementation on the likelihood of starting a new job excluding selections for non-missing data on level of education, standard employment and workers aged below 30, and excluding individuals that have multiple observations within the data

\begin{tabular}{|c|c|c|c|c|}
\hline & $\begin{array}{c}\text { Model } 7 \\
\text { No exclusion } \\
\text { of } \\
\text { workers with } \\
\text { missing data } \\
\text { on educational } \\
\text { attainment }\end{array}$ & $\begin{array}{c}\text { Model 8 } \\
\text { No exclusion } \\
\text { of } \\
\text { non-standard } \\
\text { employment }\end{array}$ & $\begin{array}{c}\text { Model } 9 \\
\text { No exclusion } \\
\text { of } \\
\text { workers aged } \\
\text { below } 30\end{array}$ & $\begin{array}{c}\text { Model 10 } \\
\text { Keeping only a } \\
\text { single (first) } \\
\text { record of job } \\
\text { ending and job } \\
\text { search per } \\
\text { worker }\end{array}$ \\
\hline Technology & $\begin{array}{c}1.015 \\
(0.011)\end{array}$ & $\begin{array}{c}0.983 \\
(0.019)\end{array}$ & $\begin{array}{l}0.954^{* *} \\
(0.015)\end{array}$ & $\begin{array}{c}1.018 \\
(0.011)\end{array}$ \\
\hline Age & $\begin{array}{l}0.958^{* * * *} \\
(0.001)\end{array}$ & $\begin{array}{l}0.972^{* * * *} \\
(0.001)\end{array}$ & $\begin{array}{l}0.976^{* * *} \\
(0.000)\end{array}$ & $\begin{array}{l}0.962^{* * *} \\
(0.001)\end{array}$ \\
\hline Age* Technology & $\begin{array}{c}0.994^{* * * *} \\
(0.001)\end{array}$ & $\begin{array}{c}0.996 \\
(0.002)\end{array}$ & $\begin{array}{c}0.998 \\
(0.002)\end{array}$ & $\begin{array}{c}0.994^{* * *} \\
(0.001)\end{array}$ \\
\hline Part-time & $\begin{array}{c}0.638^{* * * *} \\
(0.012)\end{array}$ & $\begin{array}{l}0.754^{* * * *} \\
(0.018)\end{array}$ & $\begin{array}{c}0.618^{* * *} \\
(0.008)\end{array}$ & $\begin{array}{c}0.598^{* * *} \\
(0.012)\end{array}$ \\
\hline $\begin{array}{l}\text { Having second job at } \\
\mathrm{t}=0\end{array}$ & $\begin{array}{l}0.604^{* * *} \\
(0.011)\end{array}$ & $\begin{array}{l}0.577^{* * *} \\
(0.013)\end{array}$ & $\begin{array}{l}0.619^{* * *} \\
(0.013)\end{array}$ & $\begin{array}{l}0.534^{* * *} \\
(0.011)\end{array}$ \\
\hline $\begin{array}{l}\text { (Ref: native Dutch) } \\
\text { Non-Western } \\
\text { immigrant background }\end{array}$ & $\begin{array}{l}0.791^{* * * *} \\
(0.012)\end{array}$ & $\begin{array}{l}0.866^{* * *} \\
(0.007)\end{array}$ & $\begin{array}{l}0.857^{* * *} \\
(0.011)\end{array}$ & $\begin{array}{l}0.757^{* * *} \\
(0.010)\end{array}$ \\
\hline $\begin{array}{l}\text { Western immigrant } \\
\text { background } \\
\text { (Ref: men) Gender }\end{array}$ & $\begin{array}{c}0.804^{* * *} \\
(0.008) \\
0.964^{* * *} \\
(0.006)\end{array}$ & $\begin{array}{l}0.985^{* * *} \\
(0.004) \\
0.923^{* * *} \\
(0.009)\end{array}$ & $\begin{array}{c}0.925^{* * *} \\
(0.005) \\
1.000 \\
(0.012)\end{array}$ & $\begin{array}{c}0.915^{* * *} \\
(0.005) \\
0.944^{* * *} \\
(0.005)\end{array}$ \\
\hline Log enterprise size & $\begin{array}{l}0.989^{*} \\
(0.004)\end{array}$ & $\begin{array}{l}1.006 \\
(0.004)\end{array}$ & $\begin{array}{l}0.975^{* *} \\
(0.009)\end{array}$ & $\begin{array}{l}0.985^{* * *} \\
(0.004)\end{array}$ \\
\hline $\begin{array}{l}\text { Organizational } \\
\text { innovation }\end{array}$ & $\begin{array}{c}0.962^{* * *} \\
(0.011)\end{array}$ & $\begin{array}{l}0.963^{*} \\
(0.015)\end{array}$ & $\begin{array}{c}1.022 \\
(0.026)\end{array}$ & $\begin{array}{l}0.965^{* *} \\
(0.012)\end{array}$ \\
\hline $\begin{array}{l}\text { Yearly unemployment } \\
\text { rate }\end{array}$ & $\begin{array}{l}0.957^{* * * *} \\
(0.003)\end{array}$ & $\begin{array}{l}0.936^{* * *} \\
(0.004)\end{array}$ & $\begin{array}{l}0.952^{* * * *} \\
(0.003)\end{array}$ & $\begin{array}{c}0.960^{* * *} \\
(0.004)\end{array}$ \\
\hline $\begin{array}{l}\text { Observations } \\
\text { Enterprises }\end{array}$ & $\begin{array}{c}2,253,509 \\
34,485\end{array}$ & $\begin{array}{c}2,647,974 \\
33,627\end{array}$ & $\begin{array}{c}3,983,180 \\
34,914\end{array}$ & $\begin{array}{c}939,970 \\
31,603\end{array}$ \\
\hline
\end{tabular}

Standard errors in parentheses

${ }^{*} p<0.05,{ }^{* *} p<0.01,{ }^{* * *} p<0.001$

\subsection{Conclusion and discussion}

This study investigates the effect of technological change on the job search duration of workers whose jobs end. We examine how the effect of technological change on job search duration differs depending on the education, organizational tenure, age of workers, as well as on the strength of unions within industries. Combining tax-register data with a large-scale survey of (technological) innovation within enterprises, we created a longitudinal (2001-2014) employer- 
employee dataset to study technological change and its relation to job search duration of workers experiencing job ending.

While there are voices that technology implementation -due to increased production capacities- lead to employment growth instead of decline (Bessen and Righi, 2019), our findings regarding those who do not 'survive' the advent of technology lend to somewhat more pessimistic conclusions. First, finding re-employment after job ending is more difficult when the previous employer implemented new technologies. Second, finding a job when technology is changing is even more difficult for older workers and for those who work in less unionized industries. This finding supports institutional efforts aimed at re-education and work-to-work transitions (European Commission, 2016, 2019) which are likely to be especially beneficial to workers weaker employability following technological advances.

Our findings for technology differentials by educational attainment and organizational tenure are not robust enough to warrant conclusions. The former is somewhat unexpected in light of the recent study of Bessen et al. (2019) that finds low-educated workers to have longer unemployment spells following spikes of investment in automation at their former employing companies compared to the high-educated in the Netherlands. A possible explanation in the different findings likely lies in the different operationalization of technology: while Bessen et al. (2019) focuses solely on automation -which arguably impact low- and middle-educated workers' employment chances in a uniformly negative way-, our measure includes all significant technological investments that the enterprise engaged in. Its advantage is that it is a more encompassing assessment of the impact of new technology, but it comes with the downside that skill complementarities are less clear-cut than in case of automation. While the lack of occupational measurement in the Dutch does not make it possible for the current paper, a possible way forward is to evaluate the role of skill more directly through the occupations these workers hold. Also, as Bessen et al. (2019) also mentions, it is pivotal to assess the nature of technologies to understand how they match the existing skill set of workers.

The finding regarding older workers is concerning given an aging labor force and increasing retirement age in modern economies. We highlighted two potential mechanisms explaining this finding, one based on skill development and adaptation and one based on ageist stereotypes but adjudicating between them goes beyond the scope of this study. It is nevertheless important to unravel the mechanisms underlying the reduced employment chances of older workers as it assists in developing effective institutional responses.

A reason to be optimistic about institutional responses lies in our finding that unions in the coordinated economy of the Netherlands seem to have a role in mitigating the impact of technological change. Note, however, that the effect sizes are small, and while unions are an integral part of the Dutch corporatist model, the bargaining power of unions in the Netherlands has declined since the turn of the century (De Beer and Keune, 2017). Waning union memberships are argued to have weakened the legitimacy of unions, undermining the bargaining power of workers relative to employers (Boeri, Brugiavini and Calmfors, 2001; De Beer and Keune, 2017; Keune, 2016). Furthermore, member contributions dry out, reducing unions' capacity to be a meaningful counterforce against employers (De Beer and Berntsen, 2019). In addition, there is a political shift in the Netherlands -and many other European countries- towards neoliberal policies shifting the power balance towards business interests and capital (De Beer and Keune, 2017). It remains to be answered how the corporatist system is to 
be maintained under such circumstances. All in all, our results indicated that coordinated bargaining can potentially reduce the destructive consequences of technological change for labor markets.

Concluding, our study shows that worker characteristics and the institutional setting of workers and organizations both play a role in shaping the effects of technological change for workers' employment. In doing so, the study complements a literature that mainly focuses on job tasks to identify which jobs are affected by technological changes but which pays somewhat limited attention to employers, workers, and instutitions.

A challenge common to studies on the duration of job searches is the possible presence of selection bias (Mueller, Spinnewijn and Topa, 2018). In the paper we conclude that job ending under technological change increases job search duration among workers. However, from this test it remains unclear whether this effect can be explained by the effect of technology, i.e. technology leads to skill depreciation, or whether there is a selection effect in which individuals who ceteris paribus have longer job searches, for example because their job search skills are lower, happen to be more likely to experience job ending under technological change. In that case, longer job search duration coincides with, but is not caused by technological change. Likely, both explanations are valid to some degree. For the results of the current study this possible selection effect is arguably not very problematic. Our aim was to establish whether the hazards of finding a job differ between workers depending on technology implementation. Our aim was not to disentangle the degree to which technology causes longer job searches, for example via skill depreciation, from the degree to which technology is biased to destroying jobs of workers who happen to show longer job searches. Nevertheless, we should be careful in interpreting the relation between technology implementation and the hazards of finding a new job as causal. Recent efforts directed at developing methods that separate 'true' duration dependency from selection effects (Mueller et al., 2018) may be helpful in separating the two effects in future studies.

An interesting avenue for further research is to study the effects of technological change in an international comparative perspective. The context of our study, the Netherlands, is characterized by a high degree of employment protection, which is an integral part of its corporatist institutional system, and it would be informative to draw direct comparisons with liberal market economies.

Another avenue for future research is to directly study how organizations change their policies to deal with the employment consequences of technology implementation. Apart from the coercive forms institutional influence, which we discussed in this paper with respect to the Dutch corporatist system, organizations may also develop and implement policies for different reasons when faced with technological changes in the industry (DiMaggio and Powell, 1983). Organizations, for instance, may mimic other, successful, organizations in how they are dealing with the employability of workers that need to be laid off. In light of recent labor market pressures, notably the ageing of workforces and technological change, organizational policies in the realm of life-long-learning, training and re-training and work-to-work transitions have spread across organizations. Only recently has sociological research begun a systematic evaluation of the effectiveness of different commonplace organizational policies (Van der Lippe and Lippényi, 2019). There is, however, a lack of research that specifically investigates 
Chapter $3 \mid$

organizational policies that are concerned with the employability of workers affected by technological changes. 




\title{
Chapter 4
}

\section{Immigrant-biased technological change: The effect of technology implementation on employment of native workers and workers with non-Western immigrant backgrounds in the Netherlands ${ }^{24}$}

\begin{abstract}
This study examines how technology implementation within enterprises impacts job ending among employees. We advance the literature by studying how the impact of technology differs for native Dutch workers and workers with non-Western immigrant backgrounds. Furthermore, we examine the disparate impact of organizational context, as indexed by the proportion of workers with non-Western immigrant backgrounds and the job volatility within enterprises, as well as industry level unionization. Using large-scale Dutch matched employer-employee longitudinal data for the period 2001-2014 we find technology implementation to decrease chances of job ending, but this decrease is smaller for workers with non-Western immigrant backgrounds than for native Dutch workers. This pattern is most marked for first-generation immigrants. We do not find this effect to differ depending on the proportion of workers with non-Western immigrant background within enterprises, the volatility of enterprise jobs or industry unionism.
\end{abstract}

\footnotetext{
${ }^{24}$ A slightly different version of this chapter has been submitted to an international scientific journal. The chapter is co-authored by Donald Tomaskovic-Devey. Jannes ten Berge wrote the main part of the chapter and conducted the analyses. This chapter has benefited greatly from feedback and suggestions from Zoltán Lippényi, Tanja van der Lippe and Maarten Goos.
} 


\subsection{Introduction}

Recent studies suggesting that large shares of human work tasks may be automated in the near future have sparked scientific research into the effects of technological change on work (Frey and Osbourne, 2017; Manyika, 2017; World Bank, 2016). Advances in robotics, machine learning and artificial intelligence, according to estimates, can automate or partially automate around $47 \%$ of US jobs (Frey and Osbourne, 2017) and almost $60 \%$ of jobs in the OECD in the coming decades (World Bank, 2016).

A key lesson from past studies is that the opportunities and risks of technological change are unequally distributed. Technology is often argued to favor skilled workers over less skilled workers (Autor, Katz and Krueger, 1998; Berman, Bound and Griliches, 1994; Card and DiNardo, 2002; Katz and Murphy, 1992; Krueger, 1993; Spitz-Oener, 2006; Ten Berge, Lippényi, Van der Lippe and Goos, 2020), younger workers over older workers (Beckmann, 2007; Ten Berge et al., 2020), and short-tenured over long-tenured workers (Ten Berge et al., 2020).

While the literature focuses primarily on educational and age groups in the workforce, workers with immigrant background have largely been ignored. Western societies have, and continue to receive sizable groups of immigrant workers, who often face difficulties in labor markets and work organizations (OECD, 2016). Immigrant workers and their offspring often suffer from human capital deficits in the shape of education, work experience, and language skills (Chiswick and Miller, 2006; Esser, 2006), possess less resourceful social ties (Kanas, Van Tubergen and Van der Lippe, 2011) and suffer differential treatment and discrimination in hiring and promotion (Dolfing and Van Tubergen, 2005). As a result, immigrant workers suffer from less successful and longer job search (Dolfing and Van Tubergen, 2005; Fibbi et al., 2006; Heath, Rothon and Kilpi, 2008), lower promotion rates (Roscigno, Garcia and Bobbit-Zeher, 2007), and higher chances of job loss and unemployment (Heath et al., 2008; Reyneri and Fullin, 2011). Arguably, this precarious position makes workers with immigrant background particularly vulnerable to forces that disrupt the labor process in organizations, including, perhaps especially, technological change.

Although rising immigration flows and technological advancement are topics that are central to current political conversations and continue to be important forces shaping societal change, the two topics are hardly ever mentioned in the same breath in the public discourse, let alone in scientific research (an exception is the work of Warman and Worswick, 2015). The aim of this paper is to further the literature by studying how workers with an immigrant background fare in enterprises undergoing technological change. Using Dutch longitudinal matched employer-employee data we investigate how technological changes within enterprises influence job endings among workers with non-Western immigrant background and native workers.

There is increasing an understanding that employment inequality is generated within organizations, rather than in abstract "labor markets" and that the generation and level of inequality differs meaningfully depending on the organizational context (Tomaskovic-Devey and Avent-Holt, 2019). Recent research shows that a considerable share of inequality between immigrant and native workers in Germany and Sweden is generated through selection into workplaces and jobs (Åslund and Skans, 2010; Melzer et al., 2018). Following in this tradition, 
our paper takes an organizational perspective on technological change and inequality. We argue that technological change alters the labor process within the organization through the automation of jobs and jobs tasks, reshaping existing job tasks, and creating new ones. These rearrangements create a window of opportunity for workers to promote their careers and are likely to increase ethnic competition. In-group preferencing, discrimination and social closure can disadvantage immigrant workers, through promotion (Roscigno et al., 2007) and layoff (Elvira and Zatzick, 2002) mechanisms.

Studying the intra-organizational effects of technological change on employment also leads us to engage with the role of the organizational context. Studies of wage inequality indicate that various characteristics of organizations affect the extent of internal wage inequality, such as organizational size (Kalleberg and Van Buren, 1996; Hedstrom, 1991), composition regarding gender (Shin, 2009) and ethnicity (Tomaskovic-Devey, Hällsten and Avent-Holt, 2015), the degree of formalization and bureaucratization (Elvira and Graham, 2002; Kalev, Dobbin and Kelly, 2007; Tomaskovic-Devey and Skaggs, 1999), and the stability of the workforce (Jung, Lippényi and Mun, forthcoming). We expect that, like the generation of wage inequality, inequality in the likelihood of job ending is patterned by organizational context. Specifically, we expect that organizational immigrant-background composition and workforce volatility influence the degree to which technological change, and competition for enterprise jobs and job tasks, induces immigrant-based exclusion.

Organizations do not operate in a vacuum: the institutional context surrounding an organization constrains organizational actors' decisions about the distribution of wages and other organizational resources (Scott, 2014). Previous studies demonstrate the importance of unions in shaping organizational decision-making regarding downsizing and reshaping of enterprise workforces as well as the effects of technological changes (Choi, Leiter and Tomaskovic-Devey, 2008; Fernandez, 2001; Kalleberg, Wallace and Althauser, 1981; Kristal, 2013). Studies indicate, however, that the more strongly unionized native workers can also use union power to represent their own interests first (Marino, Penninx and Roosblad, 2015). This may lead immigrant workers to be less able to protect their jobs under technological change compared to the more strongly unionized native workers. At the same time, in the Netherlands most labor bargaining is done at the industry level, arguably leaving little room for particularism by natives within unions. We aim to clarify whether unions in the Netherlands can indeed mitigate the effects of technological change on jobs of workers with immigrant background by investigating how the relation between technology implementation within enterprises and job ending among native workers and workers with non-Western immigrant background differs depending on the degree of unionization of the industry in which the enterprise operates.

Finally, the literature on technological change contains only a few studies that directly measure the worker-level impact of technological change (Arntz, Gregory, Lehmer, Matthes and Zierahn, 2017; Bessen, Goos, Salomons, and Van den Berge, 2019). We use large-scale panel survey data on technological change within Dutch private sector enterprises. Within the survey, a knowledgeable manager is asked to indicate whether the enterprise has purchased advanced machinery, apparatus, equipment (including computer hardware) or software- with the goal to significantly improve products, services and/or production processes, providing a broad measure of substantively impactful technological change. This organizational survey data is then matched with Dutch tax-register data on employees' jobs. This matched employer- 
employee dataset allows us to follow over three million employees within over 30,000 enterprises over the period 2001-2014. Unfortunately, we are unable to distinguish between voluntary or involuntary job separations. We therefore use the neutral term job ending.

\subsection{Immigration in the Netherlands}

People with an immigrant background -defined in administration as those who were born outside the Netherlands, or those born in the Netherlands from a parent born outside of the Netherlands- make up $22.6 \%$ of the Dutch population, out of which $9.9 \%$ have a Western background, and $12.7 \%$ a non-Western background. These figures approximate the EU28 average, and resemble those from Germany, the UK and France (Vasileva, 2011). Western immigrants are socio-economically, linguistically, visibly, and culturally more similar to natives (Statistics Netherlands, 2016, see also Tomaskovic-Devey et al., 2015 for Sweden), making Western immigrant/native Dutch a less salient and unambiguous categorical distinction. The largest non-Western immigrant groups are Turks, Moroccans, Surinamese and Antilleans.

During the economic boom of the 60's and 70's, the Dutch government carried out organized and large-scale recruitment of guest workers from mostly Turkey and Morroco to fill up industrial labor shortage. The former colonies of the Netherlands are an important immigration origin. The Antillean islands of Aruba, Curaçao and Sint Maarten are currently autonomous regions within the Kingdom of the Netherlands, whereas Suriname is independent country since 1975. Within both the Antilles and Surinam Dutch remains to be the official language. Economic opportunities in the Netherlands, as well as political changes, in Surinam in particular, attracted workers during the 70's and 80's from these countries, occupying mainly low-skilled jobs. During the period of large-scale immigration of Turkish and Moroccan laborers Dutch society invested fairly little in immigrant human capital, since these workers were recruited to fulfill low-skilled manual labor and the expectation at the time was that they would to return to their country of origin (Heath et al., 2008).

This first wave of large-scale immigration of mostly men was followed by a phase of family reunification in the years after. From the 90's onwards the growth of first generation immigrants is primarily due to partners migrating and marriages with partners from the country of origin.

In 2015 about half of the population with a non-Western immigrant background in the Netherlands consisted of second generation immigrants. Despite being born and raised in the Netherlands, they have a disadvantaged position within the Dutch labor market, as data shows that people with non-Western immigrant background are more often unemployed, and overall have lower incomes than natives (Statistics Netherlands, 2016). Although second generation immigrant workers are oficially native Dutch, immigrant background in the second generation is generally treated as a salient status distinction in Dutch society.

\subsection{Theory}

Theories on the effects of technological change on labor market outcomes are dominated by labor market supply and demand frameworks (Acemoglu and Autor, 2011). In this framework, the marginal productivity of workers is determined by the complementarity between the human capital of workers and labor demand generated by technological change. In the current paper we approach the problem with a more sociological perspective, by arguing that beyond human 
capital characteristics, the organizational distribution of jobs and job tasks over workers with immigrant backgrounds and native workers is strongly influenced by intra-organizational social relations. Following arguments from relational inequality theory (Tomaskovic-Devey and Avent-Holt, 2019), the primary mechanism through which we argue jobs are allocated to workers is a process of claims-making, in this case claims for jobs and job tasks. How successful actors are in claiming enterprise resources, such as jobs and job tasks, is determined by their power within the organization. It is through their effect on worker's bargaining-power that we argue categorical distinctions between workers, such as job content or native-immigrant, and organizational characteristics, such as job uncertainty or proportion of workers with immigrant backgrounds, or institutions such as unions, influence job ending of native workers and immigrant workers. Market processes can certainly influence organizational level bargaining power, but so too can collective organization and any culturally salient status distinction.

\section{Immigrant-Biased Technological Change}

A leading hypothesis within the literature on the effects of technological change on work is the Routine-Biased Technological Change hypothesis, which argues that jobs that involve primarily routine tasks have a higher risk of being automated than jobs that are mainly nonroutine (Autor, Levy and Murnane, 2003). The authors make a typology in which they distinguish between manual and non-manual routine job tasks, such as repetitive assembly and customer service, both of which can be substituted for by technology, and manual and nonmanual non-routine tasks, such as truck driving and managing, that are complemented by technology. The Routine-Biased Technological Change hypothesis borrows from earlier accounts of skill-biased technological change that technology increases the relative productivity of, and thus the demand for cognitive skills, such as problem-solving capabilities, analytical capabilities, intuition, creativity and communication skills (Acemoglu and Autor, 2011; Autor et al., 2003; Fernandez, 2001; Spitz-Oener, 2006). As a result, the demand for higher skilled workers such as programmers, scientists, analysts, consultants and engineers also increases as documented by many studies (Autor et al., 1998; Berman et al., 1994; Card and DiNardo, 2002; Katz and Murphy, 1992; Krueger, 1993; Michaels, Natraj and Van Reenen, 2014).

These technology-induced changes in the demand structure of labor are likely to have especially negative consequences for the employment of workers with immigration background. Firstly, because they are more often employed in jobs involving manual tasks and requiring routine skills. Studying the accumulation of skills by immigrants in the US, Bacolod and Rangel (2017) find that immigrant workers from countries whose mother tongue is linguistically distant from English employ more physical skills and fewer communication, math/logic, and socioemotional skills at work. Moreover, they find this relation to increase in strength with increasing age at immigration, which they attribute to difficulties with learning a second language, which in turn hampers the acquisition of other capabilities. In a similar fashion, Imai, Stacey and Warman (2011) studying the transferability of human capital of immigrants coming to Canada and the US find that although male immigrants were employed mainly in cognitive occupations in the country of origin, after immigration they were more likely to be employed in occupations requiring manual skills.

Being employed in routine manual labor puts immigrant workers at a greater risk of being replaced by technology. Nevertheless, based on the task-model of Acemoglu and Autor 
(2011), workers in routine work tasks could be displaced to perform non-routine (cognitive and manual) work. Assuming competition for such jobs, we would expect that, compared to native workers, limited language proficiency and associated focus on physical skills over communication, logic and socioemotional skills make immigrant workers less resourceful in claiming job positions and job tasks involving non-routine work. Following this line of thought leads us to expect that when technology is implemented within enterprises job ending increases among workers with immigrant background relative to native workers.

If the underlying mechanism in the relationship between technological change and job ending is indeed that language linked cultural barriers and resulting bias towards physical skills decreases the power of immigrant workers to claim jobs relative to native workers, we may expect second generation immigrants to suffer less from technological change than first generation immigrant workers. As Bacolod and Rangel (2017) point out, immigrants, especially those arriving after the primary school years, are in occupations that are more physically intensive relative to immigrants arriving at early age or whose country of origin is home to a language more proximate to the hosting country. Studying Dutch immigrants, Van Tubergen and Van de Werfhorst (2007) find that Surinamese and Dutch-Antillean immigrants are more likely than Turkish and Moroccan immigrants (the four largest non-Western immigrant groups) to invest in education after migration. They argue that higher transferability of human capital from Surinam and the Dutch-Antilles, which have more similar education systems, and better Dutch language proficiency, because Dutch is still an official language in both the former colonies, facilitates successful entry and participation in Dutch education.

Based on these arguments we expect that for second generation immigrants, who reportedly have better Dutch language proficiency than the first generation (Van den Broek, Bronneman-Helmers and Veldheer, 2010), and immigrants from countries where Dutch is an official language, the acquisition of skills other than physical skills should be easier. Consequently, technological change should affect their bargaining power less negatively. For the Dutch case we can infer on this mechanism by comparing first and second-generation nonWestern immigrants, and by comparing Surinamese and Dutch-Antillean immigrant workers with other non-Western immigrants.

\section{Discrimination and group-based power}

Thus far we argued that technological change induces a mismatch between the skills demanded by employers and the skills supplied by immigrant workers, resulting in a weakened position of immigrant workers relative to native workers within organizations. However, research on wage inequality provides ample evidence that even when human capital deficits are taken into account, inequalities remain (Cotter, Hermsen and Vanneman, 1999; Marini and Fan, 1997; Tomaskovic-Devey, 1993; Tomaskovic-Devey and Skaggs, 2002). A critique of the human capital view on inequality is that it overlooks the role of inequality in institutional processes, and social closure enforced by dominant groups reifying existing hierarchies and producing group level stratification (Roscigno et al., 2007).

Studying over 14 thousand cases of filed employment discrimination complaints in Ohio, Roscigno et al. (2007) show that managers use particularistic criteria and subjectivity in evaluating workers, which typically works to the disadvantage of minority groups. They show compelling cases of management favoring Caucasian workers for promotion over African 
American workers, despite the latter clearly having superior work experience. Investigating wage disparities by race and gender, Huffman and Cohen (2004) and Petersen and Saporta (2004) similarly conclude that racial discrimination in the allocation of workers to positions within organizations are likely to play a part in maintaining US earnings inequalities.

Such arbitrary decision making may be rooted in discrimination caused by the actual disliking of a person of a group of people. However, within organizations much arbitrary decision-making stems from a subtler process of discrimination, in which employers base their decision making on stereotypes about the attributes and skills of a group of workers. For example, Rosholm, Scott and Husted (2001) find that organizational changes, such as job rotation, team-based work organization and the flattening of management structures, increase the importance of interpersonal communication and cultural capital, favoring natives and disadvantaging more linguistic and culturally distant workers. However, they add to this argument that employers' beliefs about the ability of 'culturally distant' immigrant workers to be productive under organizational change causes negative employment outcomes, rather than cultural and human capital deficits. Illustrating the significance of stereotyping and labor market discrimination in the Netherlands, Andriessen et al. (2012) studying job applications in the Netherlands find that, keeping human capital indicators constant, changing names on job applications between native sounding names and immigrant sounding names associated with significantly smaller chances of being called back for applications with immigrant sounding names.

Technological changes within an enterprise may increase the demand for more cognitive skills needed to work with technology (Fernandez, 2001), increasing the salience of existing stereotypes of employers and managers about the competence of immigrant workers to function well under new skill requirements. Thus, within organizations categorical distinctions such as race, ethnicity and gender are potentially salient distinctions along the lines of which groups of workers and decision makers directly or indirectly favor in-group members over out-group members. Discrimination, through mechanisms of exclusion enables dominant groups of workers to claim greater shares of organizational resources.

We expect that the implementation of new technologies destroys and creates jobs and job tasks within the enterprise, invigorating the process of claims making and opportunity hoarding by dominant groups of workers. For example, Hanley (2014) in a historical case study of automation in General Electric, finds that managers actively constructed a new conception of productivity which valorized themselves as the firm's core productive workers, thereby legitimating increasingly unequal rewards at the expense of clerical and production workers. Similarly, white majority group workers (Roscigno et al., 2007) and white managers (Tomaskovic-Devey, 1993), applying particularistic criteria and through in-group preferencing are found to exclude ethnic minorities from attaining better jobs and promotions within organizations.

We expect that technological change intensifies the claims-making process for existing and newly generated jobs and job tasks. We furthermore expect that non-Western immigrantnative is a highly salient categorical distinction which associates with stereotypes, inter-group prejudice and discrimination (Andriessen et al., 2012), and along the lines of which mechanisms of social closure are enforced. Concluding, based on both the human capital framework and the relational-inequality framework we expect that 
H1: When technology is implemented within enterprises the odds of job ending for nonWestern immigrant workers increases relative to that of native workers.

H2: For first generation immigration workers the increased odds of job ending under technological change relative to native workers, is stronger than for second generation immigrant workers.

H3: For immigrant workers with a Surinamese or Dutch-Antillean background the increased odds of job ending under technological change relative to native workers, is weaker than for immigrant workers with other non-Western immigrant backgrounds.

\section{Organizational characteristics and category salience}

We expect that the creation and destruction of jobs under technological change increases competition between workers. Competitive environments foster feelings of (perceived) threat, as individuals perceive outgroup members as threats to personal and in-group interests (Blalock, 1967), in our case jobs. Furthermore, increased competition increases the salience of group categorizations that define in-and out-groups (Allport, 1954). Protection of personal and ingroup interests results in in-group favoritism, out-group antagonism and social discrimination (Allport, 1954; Bobo, 1988; Brewer, 1979; Coenders and Scheepers, 1998; Scheepers, Gijsberts and Coenders, 2002; Tajfel and Turner, 1979; Schlueter and Scheepers, 2010). Drawing on relational inequality theory we argue that the degree to which native-non-Western immigrant categorical distinction is salient within the competition for jobs and job tasks differs depending on the organizational context (Tomaskovic-Devey et al., 2015; Melzer, Tomaskovic-Devey, Schunck and Jacobebbinghaus, 2018).

Two organizational characteristics that are found to relate to salience of categorization and inequality may be particularly important in the relation between technological change and job ending, namely; the immigrant-native composition of enterprises (Melzer et al., 2018; Tomaskovic-Devey et al., 2015) and the volatility of jobs within enterprises (Jung, Lippényi and Mun, forthcoming).

\section{Enterprise native-immigrant composition}

Assuming that technological change induces competition for jobs and job tasks, competition theory provides a framework to hypothesize on the effects of technological change within organizations with different immigrant-worker shares. Competition theory proposes that increases in minority group sizes increases the perception of group threat by majority groups (Blalock 1967; Quillian 1995; Schlueter and Scheepers 2010). This perceived threat in turn increases category salience and discrimination. Research finds support for increased competition with increasing proportions of women versus men in Japanese organizations (Avent-Holt and Tomaskovic-Devey, 2012) and racial competition in the US prior to 1980 (Stainback and Tomaskovic-Devey, 2012). In line with these findings, Huffman and Cohen (2004) studying the relation between the Black population size within areas and wage inequality in the US, conclude that discrimination against workers, especially through exclusion from better paying jobs, is an important mechanism for the effect of black population size on the 
racial wage gap. It must be noted that previous research has focused on pay inequalities, rather than job loss. In line with this competition model, we expect more job level social closure when organizational workforces have larger shares of immigrant workers, which arguably intensify under pressures resulting from technological change. We therefore expect that:

H4: The higher the share of immigrant workers in an enterprise the larger the technology induced job ending gap between non-Western immigrant workers and native workers.

\section{Enterprise volatility}

Another organizational characteristic that is likely to affect competition between workers is the stability of jobs within the organization. Unstable volatile employment generates higher feelings of uncertainty and insecurity (Kalleberg, 2009; Fullerton and Wallace, 2007; Svensson, 2011). This perceived instability and uncertainty in turn plausibly increases feelings of ethnic threat and competition, strengthening category salience and in-group favoritism. Furthermore, when workers within an organization generally hold their job longer, the time of exposure of workers to one-another increases, as well as the likelihood of intergroup contact to occur. Intergroup contact within organizations associates with less prejudice and lower category salience (Pettigrew and Tropp, 2006). More volatile organizations offer less time to establish strong social relations through a process of interpersonal contact. Consequently, we expect native-immigrant category salience to be higher in more volatile enterprises. As a result of both decreases in ethnic intergroup contact and higher uncertainty and insecurity, we expect that technology implementation evokes stronger feelings of inter-ethnic threat and feelings of competition in enterprises with more volatile employment. We therefore expect that:

H5: Within more volatile enterprises the relation between technology implementation and increased odds of job ending among non-Western immigrant workers relative to native workers is stronger than in enterprises with more stable employment.

\section{Industry union strength and collective bargaining}

The degree to which organizational resources are open to intra-organizational processes of claims-making varies depending on the institutional context in which the organization operates. For example, unions can enforce agreements covering the entire workforce, which constrains the degree to which groups within organizations can hoard opportunities for themselves and influence the allocation of enterprise resources such as jobs. Furthermore, unions increase the potential of subordinate groups of workers to organize, increasing the power of such groups within organizations (Kristal, 2013). Studying Australian organizations, Choi, Leiter, and Tomaskovic-Devey (2008) find that while the use of computer technology within organizations associates with decreased work autonomy for less skilled workers, unionization mutes this tendency. Dekker et al. (2017) find that the fear of robotization is smaller in countries with higher unionization densities. They argue that unionism increases feelings of job-security (Sverke, Hellgren and Näswall, 2006), decreasing fear for the negative effects of robotization. Arguably, unions decrease feelings of threat and competition under technological change. 
Regarding immigration and unionism, one could argue that under circumstances of high competition, such as technological change, the generally more strongly unionized native workers might also use union power to represent their own interests first (Marino, Penninx and Roosblad, 2015). The Dutch case, however, arguably leaves little room for particularism by natives. Dutch labor bargaining takes place typically at the industry level, and only a minority of larger firms (e.g. Phillips, DSM, Shell) have company level agreements between employer and unions. By their collective nature, employers who sign an agreement are obliged to offer the same terms to union and non-union members. Consequently, all employees are covered, including immigrant workers. In addition, since the 1980's Dutch worker unions maintain inclusiveness policies aimed at representing the interest of minority workers (Roosblad, 2002). Therefore, while technological change may generate feelings of threat and ethnic competition, this may be suppressed in unionized contexts. We therefore expect that:

H6: Within enterprises in industries with stronger unions the implementation of technology associates less strongly with increased odds of job ending for non-Western immigrants, relative to native workers.

\subsection{Data}

To study the effects of technological change on jobs we use a large-scale enterprise survey and social micro-register data. Information on enterprise investment in new technology is taken from the Dutch Community Innovation Survey (CIS). The CIS is a large-scale cross-national survey of innovation activity within enterprises, repeated every two years. The sample is stratified by sector and establishment size, excluding enterprises smaller than ten workers (Mortensen and Bloch, 2005). Due to the longitudinal design, we are able to study changes in technology implementation within enterprises over time. We focus on the period 2001-2014, during which a total of 37,520 enterprises participated in the Dutch CIS survey. The survey design is cross-sectional, and we therefore do not observe enterprises for the full period 20012014. However, because the sample covers a large share of Dutch enterprises, there are ample enterprises that appear in the sample multiple years. The average number of years that enterprises are observed in the data is 4.64 years.

Out of the 37,520 enterprises participating in the survey, 27,738 enterprises $(73.93 \%)$ did not implement technologies in the period of observation. 5,210 enterprises (13.89\%) were observed in periods with and without technology implementation. The remaining 4,572 enterprises $(12.18 \%)$ implemented new technologies during all periods of observation.

We linked these enterprises to register data on workers' jobs and demographic characteristics from the System of Social Statistics Databases (SSB) of the Dutch Central Bureau of Statistics, creating a longitudinal matched employer-employee dataset. ${ }^{25}$ The data is characterized by a four-level hierarchical structure in which years are nested in jobs $(40,592,274$

\footnotetext{
${ }^{25}$ Results are based on calculations by Utrecht University using non-public microdata from Statistics Netherlands. Under certain conditions, these microdata are accessible for statistical and scientific research. For further information: microdata@cbs.nl.
} 
observations in 15,061,179 jobs), jobs are nested in individuals $(7,017,990)$ and individuals are nested in enterprises.

A job is defined as a contractual employment relation between an individual and an enterprise. If an individual had more employment contracts with the same enterprise, we aggregated them as one record. Our analyses focus on the 5,210 enterprises for which we observe variation in technology implementation over time. We exclude observations of workers aged below 13 years $(1,826$ observations), which is the legal age of being employed. The models exclude workers with missing data on level of education $(889,242$ individuals $),{ }^{26}$ on working part-time or not $(372,601$ jobs $)$, and missing data on organizational innovation $(12,586$ observations) and union density (64 enterprises). Finally, we delete Western immigrants from the data (292,833 individuals). Table 4.1A and 4.1B provide descriptive statistics for the full sample and the analytical sample.

\subsection{Measurement}

\section{Dependent variable}

Job ending is a dummy variable measured as the end of a person's contractual employment relation within an enterprise. Having information about the beginning and end of employment relations between individuals and enterprises of all workers from the register data we can reliably document beginnings and endings of worker's job(s). The data does not provide information on why a job-relation ended. Thus, job ending may indicate both layoffs and quits. We cannot distinguish between voluntary and involuntary job endings. This means that we observe turnover, but cannot observe direct layoffs, associated with technological change. Thus, we refer to job endings to describe our dependent variable.

\section{Independent variables}

Implementation of technology was measured using an item from the Community Innovation Survey. A higher manager from the enterprise was asked to indicate whether, over the past two to three years (depending on the survey date), the enterprise purchased advanced machinery, apparatus, equipment (including computer hardware) and/or software with the goal to significantly improve products, services, and/or production processes.

Native-non-Western immigrant background is measured using information on the birthplace of a person and the birthplace of the parents. For the definition of native and nonWestern immigrant worker we follow the definition of Statistics Netherlands. Native is defined as those who are born in the Netherlands and whose parents are also born in the Netherlands. non-Western immigrant is measured as those workers whose mother is born in a non-Western country, or in case the mother is born in the Netherlands, as those workers whose father is born in a non-Western country. We follow Statistics Netherlands definition of immigrants from nonWestern countries, namely workers from Asian, African, Latin-American, Asian countries (excluding people from Indonesia and Japan, based on their social-economic and social-cultural position. It includes mainly people from the former Dutch-Indies and employees from Japanese

\footnotetext{
${ }^{26}$ (see footnote 9 in section 2.3 for a discussion on missing data on education).
} 
companies and their families) and Turkey. Within the models, native Dutch is the reference category.

First and second-generation non-Western immigrant is measured as the country of birth of a worker. Workers regarded as first-generation non-Western immigrant are those workers who are themselves born in a non-Western country. Second generation immigrants are those workers who are themselves born in the Netherlands, but whose mother is born in a nonWestern country, or those who have a Dutch mother, but whose father is born in a non-Western country.

Non-Western immigrant workers with Dutch as a primary language are measured as those workers with an immigration background from Surinam and the Dutch Antilles. In both the Dutch Antilles and Surinam Dutch is the official language. For example, in the Dutch Antilles, Dutch is the primary language used in schooling because the Dutch Antilles and the Netherlands use the same central exams, which are in Dutch.

Proportion of non-Western immigrant workers is measured as the percentage of the total enterprise workforce that has a non-Western immigrant background.

Job volatility is measured as the average job duration of workers within an enterprise in years.

Union density is measured as the percentage of unionized employees among the total number of employees with paid work for at least 12 hours per week within an industry (Statistics Netherlands, 2012). The Community Innovation Survey identifies eight different private sector industries, excluding agriculture and fisheries.

\section{Controls}

Educational attainment is measured according to the International standard classification of education (ISCED). Eight educational levels are distinguished. We recoded the levels into three broad categories following guidelines from the ISCED 2011 manual (OECD/Eurostat/UNESCO Institute for Statistics, 2015). Low education, including those who attained less than primary education, primary education, and lower secondary education. Medium education, including employees who attained upper secondary education and postsecondary non-tertiary education. And high education, including employees who attained short cycle tertiary, bachelors, a master, or doctoral equivalent education.

Organizational tenure was measured as the duration of the employment relation within the enterprise in years.

Age is measured in years since birth.

Gender is taken from municipal register data. Male is the reference category.

Part-time work is measured as jobs that are less than one Full Time Equivalent. Parttime work is a nonstandard employment relation that has been associated with lesser training and career opportunities (Kalleberg, 2000; Yerkes and Visser, 2006). The Netherlands are among the countries with the highest rates of part-time employment in the world (Yerkes and Visser, 2006).

Fixed-term contract is measured as temporary jobs and on-call employment. Like parttime work, temporary and on-call jobs enjoy less employment protection.

Percentage Western immigrants. In the period 2001-2014 there were fluctuations in the number of immigrants from Western countries, in particular from Poland, Bulgaria and 
Romania (Statistics Netherlands, 2016). In our models we control for these fluctuations by including a variable indicating the percentage Western immigrants within an organization within a given year. We controll for this influx of Western immigrant workers because this influx may increase feelings of organizational competition and is likely to be non-randomly distributed across enterprises with non-Western immigrant workers.

Enterprise size. To control for unobserved time varying events that influence chances of job ending for workers within an enterprise we include enterprise size. Because the distribution of enterprise size is strongly right skewed, indicating the presence of several very large enterprises, we use the log of enterprise size in the analyses.

We also control for the percentage of part-time workers within an enterprise within a given year. It is measured as the percentage of employment relations within the enterprise that are less than one Full Time Equivalent.

Furthermore, we control for organizational innovations to capture non-technological changes in the organization of the enterprise which might also be related to job ending (Bauer and Bender, 2004; Bresnahan, Brynjolfsson and Hitt, 2002). A higher manager from the enterprise was asked to indicate whether, over the past two to three years (depending on the survey date), the organization introduced new business procedures, new methods for the organization of professional responsibilities and decision making, or new methods to organize external relations with other companies or institutes.

We control for yearly national unemployment rate in all models to capture labor market fluctuations. 


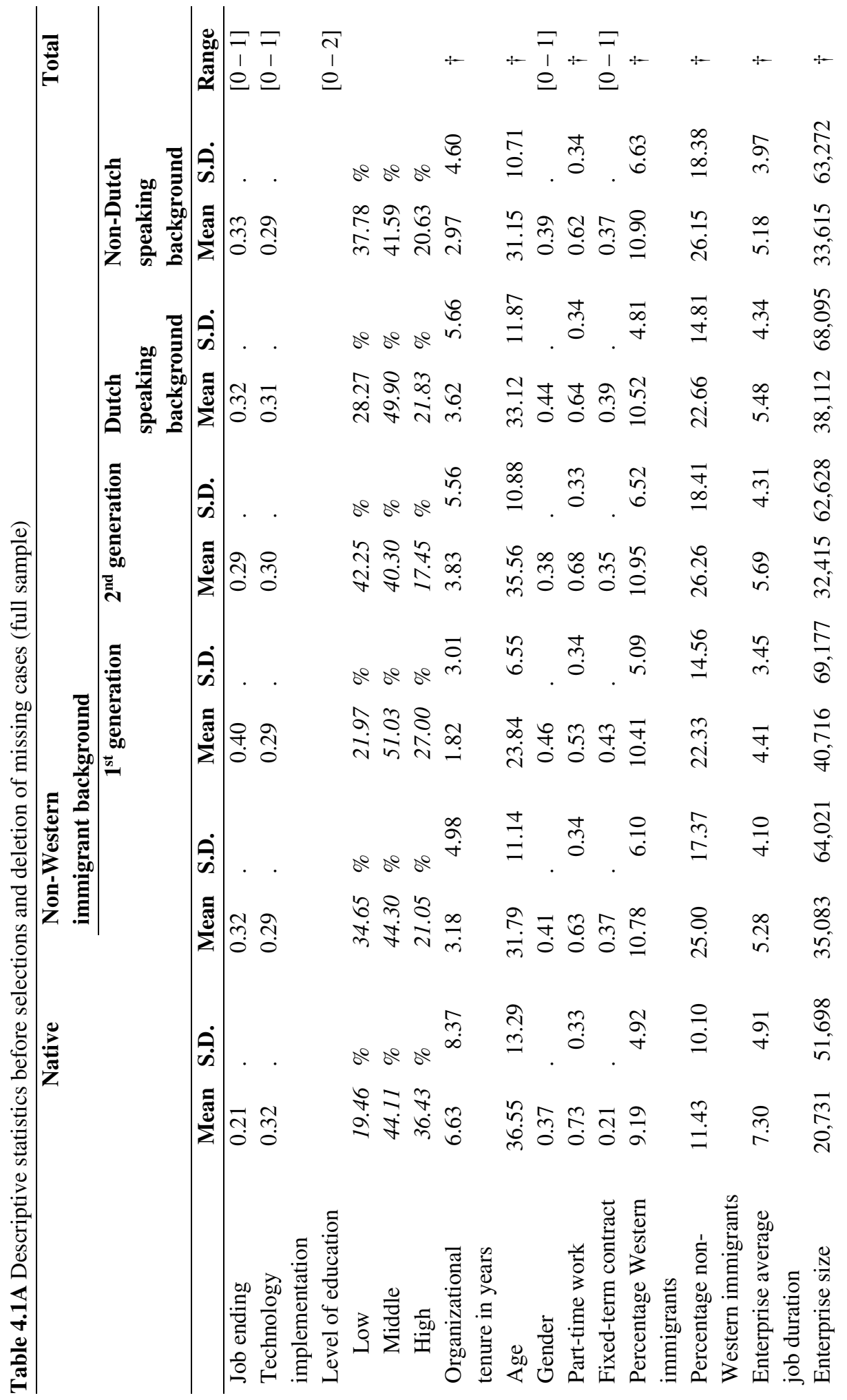




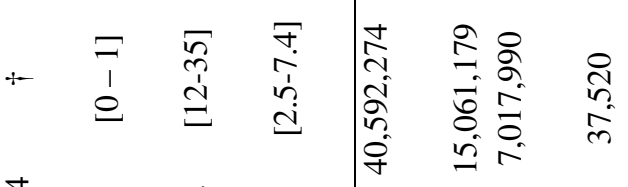

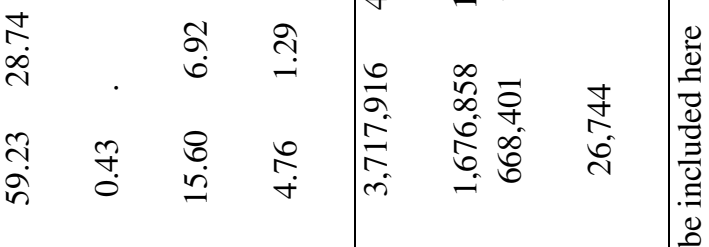

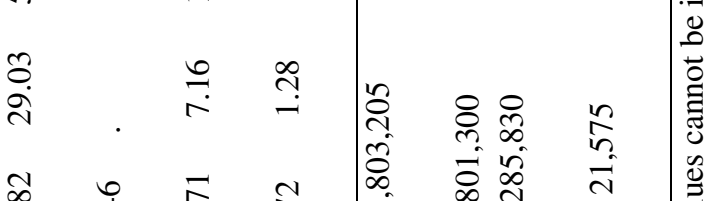

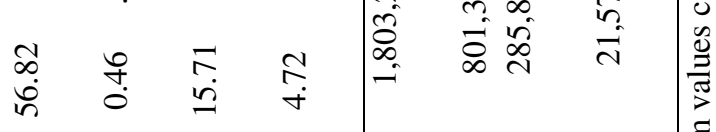

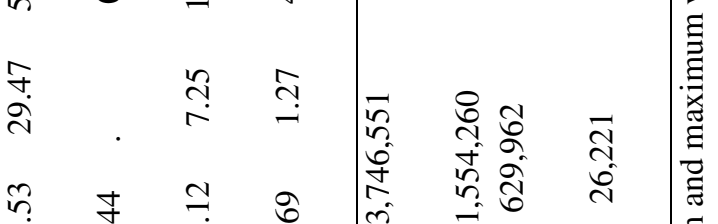

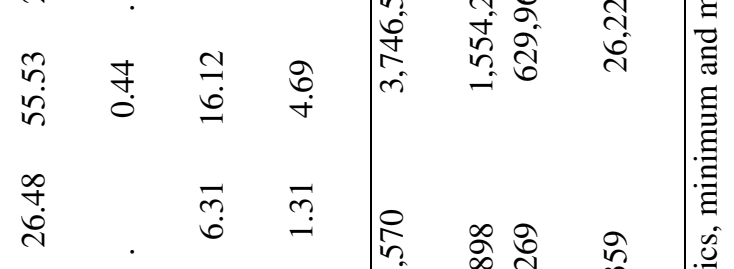

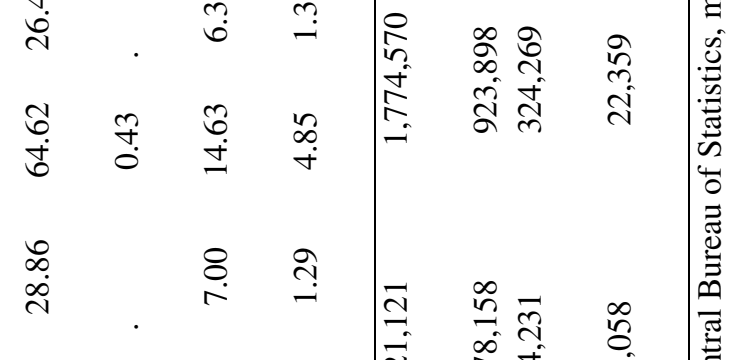

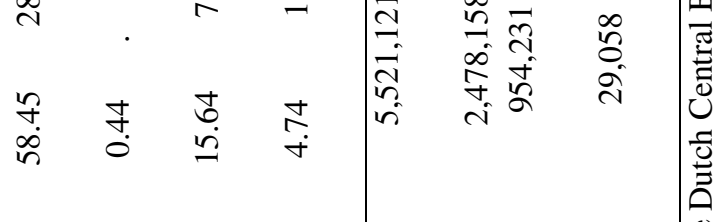

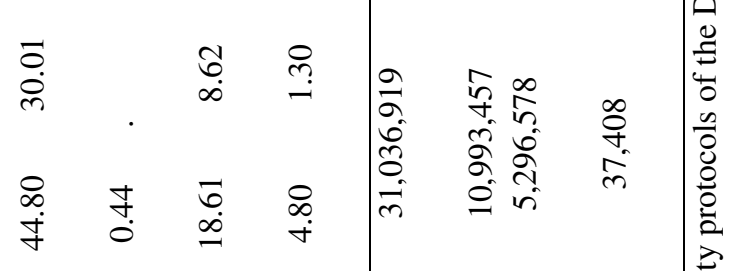

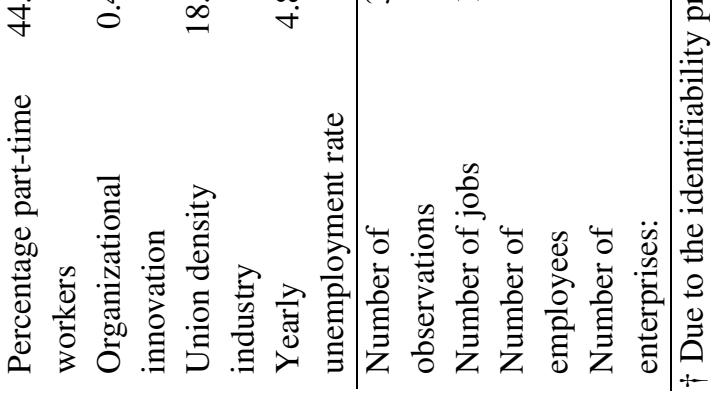




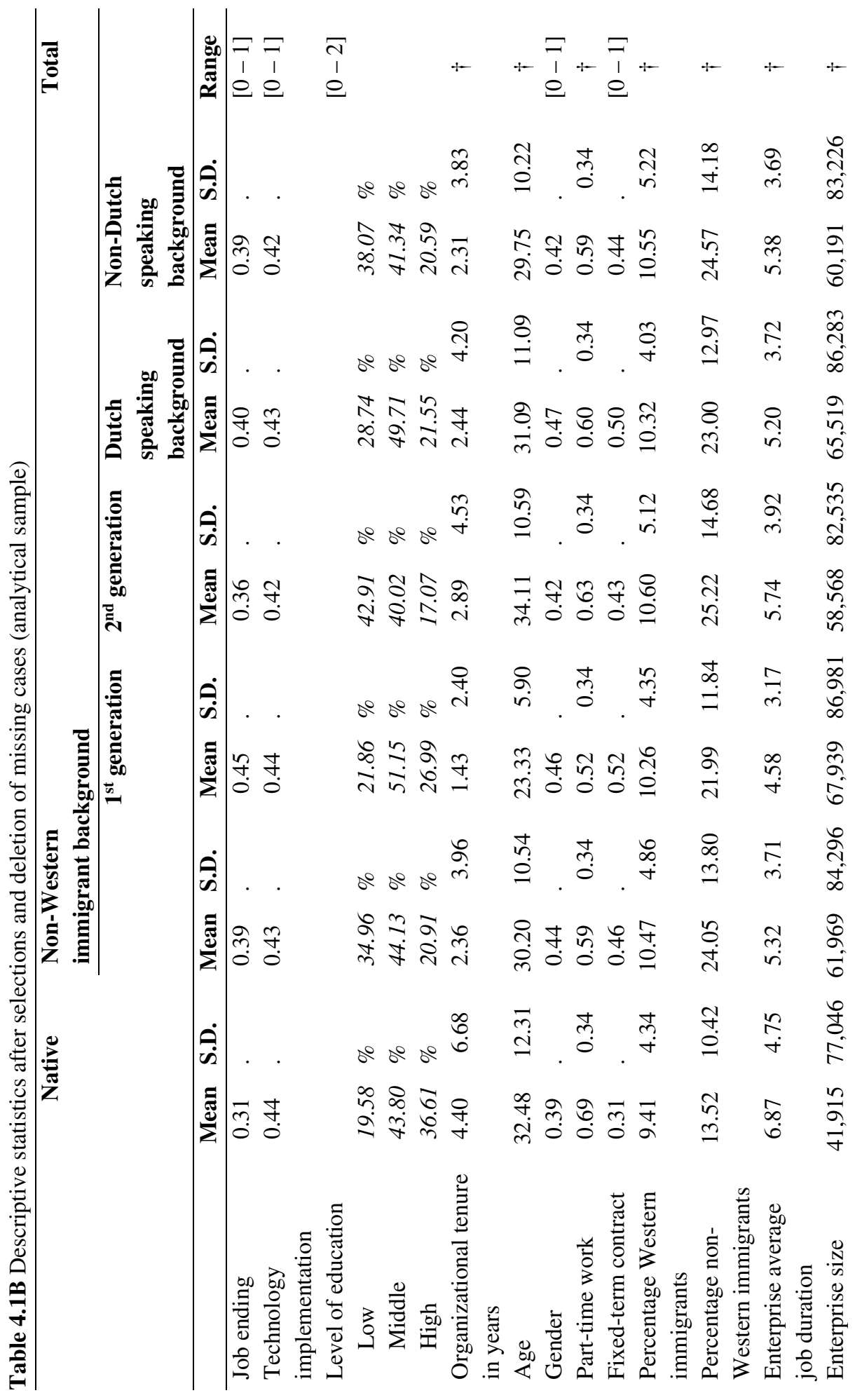




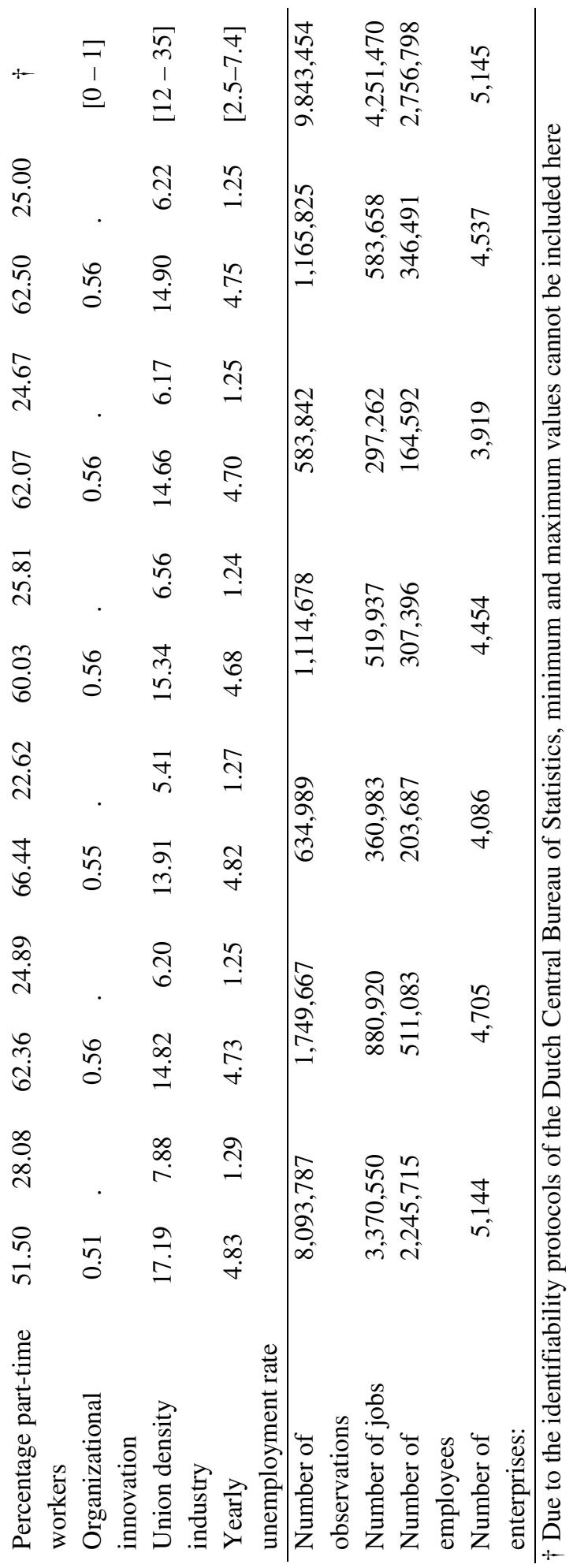




\subsection{Method}

We estimate linear probability models with fixed effects at the level of the enterprise and random effects at the individual level to test the relationship between technology implementation and job ending. By including fixed effects at the enterprise level, we control for enterprise time invariant unobserved heterogeneity. By employing random effects at the individual level, we take into account that our yearly job observations are nested within individuals, as well as model individual-level unobserved heterogeneity. The inclusion of fixed effects at the individual level is not preferable because the fixed effects specification would drop all jobs and individuals that either do not experience job ending (no variation over time) or who do not experience variation in technology implementation over time. This would lead our sample to be bias towards "unstable" jobs. Using fixed effects at the enterprise level means that we include only enterprises that show variation over time in technology implementation. We believe, however, that controlling for unobserved time invariant characteristics of enterprises is preferable for two reasons. First, workers with immigrant backgrounds and native workers are likely to be non-randomly distributed across organizations (Åslund and Skans, 2010). Second, enterprises implementing new technologies are likely to be different from enterprises that do not implement new technologies in other respects as well (King, Reichelt and Huffman, 2017).

All models control for individual characteristics; level of education, organizational tenure, age, gender, and organizational characteristics; the dynamic of the size of the workforce, percentage part-time workers and organizational innovation. Finally, we control for job characteristics; part-time work and fixed-term contracts and we control for unemployment rates to account for labor market fluctuations. Finally, we include a time invariant measure of enterprise average job duration by taking the average job duration of an enterprise over all observed years, instead of yearly. We did this to decrease co-variation with the dependent variable, odds of job ending. We centered the variables age, tenure, percentage non-Western and Western immigrant background and volatility, and we median centered the unionism variable to assure meaningful baseline models. In model 1 in Table 4.2 we test the interaction effect between technological change and workers with non-Western immigrant backgrounds. In model 2 and 3 we dissect this effect by separating non-Western immigrant workers into firstand second-generation immigrants, and into workers with a Dutch and non-Dutch speaking background. Model 4 shows the effects separated between all four sub-groups of workers with a non-Western immigrant background. In Table 4.3 we test organizational and institutional effects.

Finally, our measure of technological change does not allow us to differentiate between different types of technology. However, over the observation period the types of technologies purchased by enterprises are likely to have shifted. We provide robustness checks to investigate whether our measure of technological change does not have contrary impacts on job-ending in different time periods. Furthermore, we investigate whether enterprises with similar characteristics implement technologies at the beginning and at the end of the observation period (see Tables 4.A1 and 4.A2 in the appendix). 


\subsection{Results}

Table 4.2 Multilevel random effects models of technology implementation on the likelihood of job ending with human capital variables and fixed effects for enterprises

\begin{tabular}{|c|c|c|c|c|}
\hline & $\begin{array}{c}\text { Model 1 } \\
\text { Non- } \\
\text { Western } \\
\text { immigrant } \\
\text { background }\end{array}$ & $\begin{array}{l}\text { Model } 2 \\
\text { Non- } \\
\text { Western } \\
\text { immigrant } \\
\text { generation }\end{array}$ & $\begin{array}{l}\text { Model 3 } \\
\text { Non- } \\
\text { Western } \\
\text { Dutch } \\
\text { language }\end{array}$ & $\begin{array}{c}\text { Model 4 } \\
\text { Immigrant } \\
\text { generation* } \\
\text { Dutch } \\
\text { language } \\
\end{array}$ \\
\hline Technology & $\begin{array}{c}-0.015^{* * *} \\
(0.000)\end{array}$ & $\begin{array}{c}-0.014^{* * *} \\
(0.000)\end{array}$ & $\begin{array}{l}-0.015^{* * *} \\
(0.000)\end{array}$ & $\begin{array}{c}-0.014^{* * *} \\
(0.000)\end{array}$ \\
\hline $\begin{array}{l}\text { Non-Western immigrant } \\
\text { background } \\
\text { (Ref: native Dutch) }\end{array}$ & $\begin{array}{l}0.006^{* * * *} \\
(0.001)\end{array}$ & & & \\
\hline $\begin{array}{l}\text { Non-Western immigrant } \\
\text { background* Technology } \\
\text { Non-Western groups decomposed } \\
\text { into: }\end{array}$ & $\begin{array}{l}0.007^{* * * *} \\
(0.001)\end{array}$ & & & \\
\hline Second generation & & $\begin{array}{l}0.021^{* * *} \\
(0.001)\end{array}$ & & \\
\hline Second generation* Technology & & $\begin{array}{l}-0.002 \\
(0.001)\end{array}$ & & \\
\hline First generation & & $\begin{array}{c}-0.003^{* * *} \\
(0.001)\end{array}$ & & \\
\hline First generation* Technology & & $\begin{array}{l}0.011^{* * *} \\
(0.001)\end{array}$ & & \\
\hline $\begin{array}{l}\text { Dutch speaking } \\
\text { (Surinamese/Antillean) }\end{array}$ & & & $\begin{array}{l}0.012^{* * *} \\
(0.001)\end{array}$ & \\
\hline Dutch speaking* Technology & & & $\begin{array}{c}0.002 \\
(0.001)\end{array}$ & \\
\hline Non-Dutch speaking (Rest) & & & $\begin{array}{c}0.002^{* * *} \\
(0.001)\end{array}$ & \\
\hline $\begin{array}{l}\text { Non-Dutch speaking* } \\
\text { Technology }\end{array}$ & & & $\begin{array}{l}0.009^{* * *} \\
(0.001)\end{array}$ & \\
\hline $\begin{array}{l}\text { Second generation \& Dutch } \\
\text { speaking }\end{array}$ & & & & $\begin{array}{l}0.019^{* * *} \\
(0.001)\end{array}$ \\
\hline $\begin{array}{l}\text { Second generation \& Dutch } \\
\text { speaking* Technology }\end{array}$ & & & & $\begin{array}{l}-0.001 \\
(0.002)\end{array}$ \\
\hline $\begin{array}{l}\text { Second generation \& Non-Dutch } \\
\text { speaking }\end{array}$ & & & & $\begin{array}{c}0.021^{* * *} \\
(0.001)\end{array}$ \\
\hline $\begin{array}{l}\text { Second generation \& Non -Dutch } \\
\text { speaking* Technology }\end{array}$ & & & & $\begin{array}{l}-0.002 \\
(0.001)\end{array}$ \\
\hline $\begin{array}{l}\text { First generation \& Dutch } \\
\text { speaking }\end{array}$ & & & & $\begin{array}{l}0.007^{* * * *} \\
(0.001)\end{array}$ \\
\hline $\begin{array}{l}\text { First generation \& Dutch } \\
\text { speaking* Technology }\end{array}$ & & & & $\begin{array}{l}0.003^{*} \\
(0.002)\end{array}$ \\
\hline $\begin{array}{l}\text { First generation \& Non-Dutch } \\
\text { speaking }\end{array}$ & & & & $\begin{array}{c}-0.009^{* * * *} \\
(0.001)\end{array}$ \\
\hline $\begin{array}{l}\text { First generation \& Non-Dutch } \\
\text { speaking* Technology }\end{array}$ & & & & $\begin{array}{l}0.015^{* * * *} \\
(0.001)\end{array}$ \\
\hline
\end{tabular}




\begin{tabular}{|c|c|c|c|c|}
\hline $\begin{array}{l}\text { (Ref: lower education) Middle } \\
\text { education }\end{array}$ & $\begin{array}{l}-0.005^{* * *} \\
(0.000)\end{array}$ & $\begin{array}{c}-0.005^{* * *} \\
(0.000)\end{array}$ & $\begin{array}{c}-0.005^{* * *} \\
(0.000)\end{array}$ & $\begin{array}{c}-0.006^{* * *} \\
(0.000)\end{array}$ \\
\hline Higher education & $\begin{array}{l}-0.003^{* * * *} \\
(0.000)\end{array}$ & $\begin{array}{c}-0.003^{* * * *} \\
(0.000)\end{array}$ & $\begin{array}{c}-0.003^{* * *} \\
(0.000)\end{array}$ & $\begin{array}{c}-0.004^{* * * *} \\
(0.000)\end{array}$ \\
\hline Organizational tenure & $\begin{array}{c}-0.004^{* * *} \\
(0.000)\end{array}$ & $\begin{array}{c}-0.004^{* * * *} \\
(0.000)\end{array}$ & $\begin{array}{c}-0.004^{* * *} \\
(0.000)\end{array}$ & $\begin{array}{c}-0.004^{* * * *} \\
(0.000)\end{array}$ \\
\hline Age & $\begin{array}{c}-0.002^{* * *} \\
(0.000)\end{array}$ & $\begin{array}{c}-0.002^{* * * *} \\
(0.000)\end{array}$ & $\begin{array}{c}-0.002^{* * *} \\
(0.000)\end{array}$ & $\begin{array}{c}-0.002^{* * *} \\
(0.000)\end{array}$ \\
\hline (Ref: male) Gender & $\begin{array}{l}-0.010^{* * *} \\
(0.000)\end{array}$ & $\begin{array}{c}-0.010^{* * *} \\
(0.000)\end{array}$ & $\begin{array}{c}-0.010^{* * *} \\
(0.000)\end{array}$ & $\begin{array}{c}-0.010^{* * *} \\
(0.000)\end{array}$ \\
\hline Part-time work & $\begin{array}{l}0.219^{* * *} \\
(0.001)\end{array}$ & $\begin{array}{l}0.219^{* * *} \\
(0.001)\end{array}$ & $\begin{array}{l}0.219^{* * * *} \\
(0.001)\end{array}$ & $\begin{array}{c}0.219^{* * *} \\
(0.001)\end{array}$ \\
\hline Fixed-term contract & $\begin{array}{c}0.028^{* * *} \\
(0.001)\end{array}$ & $\begin{array}{c}0.028^{* * *} \\
(0.001)\end{array}$ & $\begin{array}{c}0.028^{* * *} \\
(0.001)\end{array}$ & $\begin{array}{c}0.028^{* * *} \\
(0.001)\end{array}$ \\
\hline Percentage Western immigrant & $\begin{array}{l}0.001^{* * *} \\
(0.000)\end{array}$ & $\begin{array}{l}0.001^{* * *} \\
(0.000)\end{array}$ & $\begin{array}{c}0.001^{* * * *} \\
(0.000)\end{array}$ & $\begin{array}{l}0.001^{\text {*** }} \\
(0.000)\end{array}$ \\
\hline Log enterprise size & $\begin{array}{l}-0.001 \\
(0.001)\end{array}$ & $\begin{array}{l}-0.001 \\
(0.001)\end{array}$ & $\begin{array}{l}-0.001 \\
(0.001)\end{array}$ & $\begin{array}{l}-0.001 \\
(0.001)\end{array}$ \\
\hline Percentage part-time workers & $\begin{array}{c}0.001^{* * *} \\
(0.000)\end{array}$ & $\begin{array}{l}0.001^{* * *} \\
(0.000)\end{array}$ & $\begin{array}{l}0.001^{* * * *} \\
(0.000)\end{array}$ & $\begin{array}{c}0.001^{* * *} \\
(0.000)\end{array}$ \\
\hline Organizational innovation & $\begin{array}{c}-0.002^{* * *} \\
(0.000)\end{array}$ & $\begin{array}{c}-0.002^{* * *} \\
(0.000)\end{array}$ & $\begin{array}{c}-0.002^{* * *} \\
(0.000)\end{array}$ & $\begin{array}{c}-0.002^{* * * *} \\
(0.000)\end{array}$ \\
\hline Yearly unemployment rate & $\begin{array}{c}0.007^{* * * *} \\
(0.000)\end{array}$ & $\begin{array}{l}0.007^{* * * *} \\
(0.000)\end{array}$ & $\begin{array}{l}0.007^{* * * *} \\
(0.000)\end{array}$ & $\begin{array}{c}0.007^{* * * *} \\
(0.000)\end{array}$ \\
\hline Constant & $\begin{array}{c}0.059^{* * *} \\
(0.000)\end{array}$ & $\begin{array}{c}0.059^{* * *} \\
(0.000)\end{array}$ & $\begin{array}{c}0.059^{* * *} \\
(0.000)\end{array}$ & $\begin{array}{c}0.059^{* * *} \\
(0.000)\end{array}$ \\
\hline Constant individual level & $\begin{array}{c}0.006 \\
(0.000)\end{array}$ & $\begin{array}{c}0.006 \\
(0.000)\end{array}$ & $\begin{array}{c}0.006 \\
(0.000)\end{array}$ & $\begin{array}{c}0.006 \\
(0.000)\end{array}$ \\
\hline Residual variance & $\begin{array}{c}0.180 \\
(0.000)\end{array}$ & $\begin{array}{c}0.180 \\
(0.000)\end{array}$ & $\begin{array}{c}0.180 \\
(0.000)\end{array}$ & $\begin{array}{c}0.180 \\
(0.000)\end{array}$ \\
\hline $\begin{array}{l}\text { Observations } \\
\text { Enterprises }\end{array}$ & $\begin{array}{c}9,843,454 \\
5,145\end{array}$ & $\begin{array}{c}9,843,454 \\
5,145\end{array}$ & $\begin{array}{c}9,843,454 \\
5,145\end{array}$ & $\begin{array}{c}9,843,454 \\
5,145\end{array}$ \\
\hline
\end{tabular}

Standard errors in parentheses

${ }^{*} p<0.05,{ }^{* *} p<0.01,{ }^{* * *} p<0.001$

Model 1 in Table 4.2 provides the results for the main effect of technology implementation and the interaction effect between technology implementation and native-non-Western immigrant status on job ending. We find that the implementation of new technologies associates with a statistically significant decrease in the probability of workers' jobs ending. ${ }^{27}$ However, we find that the chances of job ending are higher for workers with non-Western immigrant backgrounds. Moreover, we find that the implementation of new technologies further increases the probability of job ending for workers with non-Western immigrant backgrounds relative to native Dutch workers. Estimating marginal effects we find that for both workers with non-Western immigrant backgrounds and native Dutch workers, technology associates with an overall decrease in the chance of job ending from $33.10 \%$ to $32.32 \%(-0.78 \%)$ and from $32.55 \%$ to

\footnotetext{
${ }^{27}$ This effect is slightly different from the result in chapter 2 because of differences in data selections.
} 
$31.11 \%(-1.44 \%)$ respectively. The decreases in chances of job ending associated with technological change are thus $0.66 \%$ greater for Dutch natives. These results support hypothesis 1 .

Model 2 shows the interaction effect between technology implementation and nonWestern immigrant generation. In line with our second hypothesis, we find technology implementation to increase chances of job ending more strongly for first generation $(B=0.011)$ than for second generation non-Western immigrant workers $(B=-0.002)$. We tested for statistical significance using Wald's test $(\mathrm{F}(1,9838292)=89.28$, $\mathrm{p}<0,001)$. Estimating marginal effects, we find that for second generation non-Western immigrant workers technology decreases the probability of job ending with $1.62 \%$, while for first generation non-Western immigrant workers the decrease is $0.32 \%$.

In model 3 we test whether the effects of technology implementation are different for workers with non-Western immigrant workers with backgrounds in Dutch speaking countries (Surinam and the Dutch Antilles), and in non-Dutch speaking countries (rest). Supporting our third hypothesis, we find the effect of technology implementation on job ending to be stronger for workers with backgrounds in non-Dutch speaking non-Western countries than for workers with backgrounds in Dutch-speaking non-Western countries $(\mathrm{F}(1,9838288)=51.09, \mathrm{p}<0,001)$. Marginal effects indicate that for the latter group, technology implementation associates with a decrease in chances of job ending of around $1.33 \%$, whereas for immigrant workers with a background in non-Dutch speaking countries this decrease is slighly lower; $0.50 \%$.

Finally, in model 4 we estimate the effects of technology implementation for all groups separately. Comparing the coeficients for the interaction effects with technology implementation, we find that for second-generation Dutch and non-Dutch speaking immigrant workers we do not find chances of job ending to show a statistically significant difference from that of native Dutch workers. For first generation immigrants, we do find technology implementation to associate with higher chances of job ending relative to native Dutch workers. Moreover, among first generation immigrants, we find that for workers with backgrounds in non-Dutch speaking non-Western countries the coeficient is larger $(B=0.015)$ than for first generation immigrants from Dutch-speaking non-Western countries ( $\mathrm{B}=0.003)$ $(\mathrm{F}(1,9838288)=51.09, \mathrm{p}<0,001)$, which is congruent with our theoretical expectation that employment effects of technological change are concentrated in first generation immigrant workers and workers with backgrounds in non-Dutch speaking countries. Figure 1 shows the marginal effects for the separate groups. ${ }^{28}$ It shows that for first generation immigrants from non-Dutch speaking non-Western countries, technology is not associated with smaller chances of job ending, where we do find such an effect for the other worker groups.

\footnotetext{
${ }^{28}$ The predicted probabilities are based on an alternative model that includes fixed effects at the enterprise level, but does not include a multilevel structure. In the multilevel random effects model the effects of enterprises are fixed by hand through demeaning. The alternative method; including dummies for enterprises, is computationally unfeasible with 5,000+ enterprises. The manually computed demeaned interaction variables, however, complicate standard calculations of marginal effects. We therefore calculated a slightly more parsimonious model that generates near identical results to calculate marginal effects. The results of this model are presented in Table 4.A3 in the appendix.
} 
Figure 4.1 Marginal effects of technology implementation on job ending for different migration backgrounds

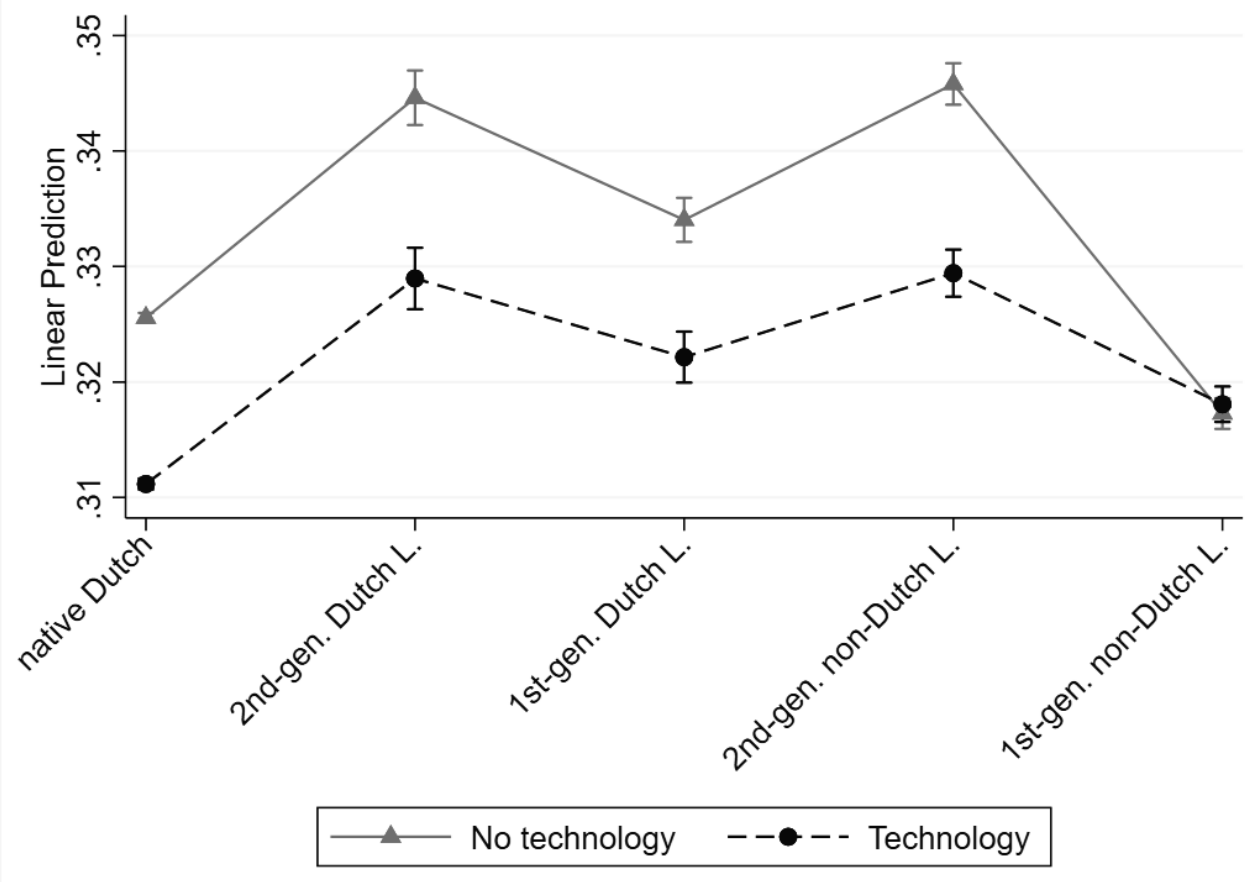

Table 4.3 provides the results for the interaction effects of technological change within enterprises, native- non-Western immigrant status and organizational and institutional characteristics. Model 5 shows the relation between technology implementation, native-nonWestern immigrant status and the percentage of immigrant workers within the enterprise. We find that in enterprises with higher percentages of workers with a non-Western immigrant background chances of job ending overall are higher. The implementation of new technologies is associated with a slight increase of this effect. Furthermore, we find that for non-Western immigrant background workers job endings decrease slightly as the percentage of workers with non-Western immigrant backgrounds increases. Finally, in line with hypothesis 4 we find the effect of technology implementation on job ending to increase for non-Western immigrant background workers employed in organizations with higher percentages of workers with a nonWestern immigrant background. However, contolling for enterprise volatility and union density in model 8 , this effect dissapears. ${ }^{29}$ We therefore reject hypothesis 4.

Turning to model 6 , we find that in organizations with more volatile jobs, technology implementation decreases the chances of job ending. Furthermore, workers with non-Western immigrant backgrounds show lower chances of job ending in more volatile organizations. Finally, we find that in more volatile organizations, technology implementation increases

\footnotetext{
${ }^{29}$ Estimating the effects excluding outlying organizations with exceptionally large percentages of workers with non-Western backgrounds (i.e. with percentages exceeding 23.69\%, 2 standard deviations) yield the same conclusions.
} 
chances of job ending for workers with non-Western immigrant backgrounds relative to native Dutch workers. This effect, however, dissapears in the full model. We therefore reject hypothesis 5 .

Table 4.3 Multilevel random effects models of technology implementation on the likelihood of job ending with organizational variables and fixed effects for enterprises

\begin{tabular}{|c|c|c|c|c|}
\hline & $\begin{array}{c}\text { Model 5 } \\
\text { Percentage } \\
\text { Non- } \\
\text { Western } \\
\text { immigrants }\end{array}$ & $\begin{array}{l}\text { Model 6 } \\
\text { Volatility } \\
\text { enterprise } \\
\text { jobs }\end{array}$ & $\begin{array}{c}\text { Model } 7 \\
\text { Industry } \\
\text { unionization }\end{array}$ & $\begin{array}{l}\text { Model } 8 \\
\text { full model }\end{array}$ \\
\hline Technology & $\begin{array}{l}-0.014^{* * *} \\
(0.000)\end{array}$ & $\begin{array}{c}-0.014^{* * *} \\
(0.000)\end{array}$ & $\begin{array}{c}-0.019^{* * *} \\
(0.000)\end{array}$ & $\begin{array}{c}-0.013^{* * *} \\
(0.000)\end{array}$ \\
\hline $\begin{array}{l}\text { Non-Western immigrant } \\
\text { background }\end{array}$ & $\begin{array}{l}0.021^{* * *} \\
(0.001)\end{array}$ & $\begin{array}{l}0.005^{* * *} \\
(0.001)\end{array}$ & $\begin{array}{c}0.001^{*} \\
(0.001)\end{array}$ & $\begin{array}{l}0.016^{* * *} \\
(0.001)\end{array}$ \\
\hline $\begin{array}{l}\text { Non-Western immigrant } \\
\text { background* Technology }\end{array}$ & $\begin{array}{l}-0.001 \\
(0.001)\end{array}$ & $\begin{array}{c}0.011^{* * *} \\
(0.001)\end{array}$ & $\begin{array}{c}0.009^{* * *} \\
(0.001)\end{array}$ & $\begin{array}{c}0.001 \\
(0.001)\end{array}$ \\
\hline $\begin{array}{l}\text { Percentage non-Western } \\
\text { immigrant }\end{array}$ & $\begin{array}{c}0.003^{* * *} \\
(0.000)\end{array}$ & & & $\begin{array}{l}0.003^{* * * *} \\
(0.000)\end{array}$ \\
\hline $\begin{array}{l}\text { Percentage non-Western } \\
\text { immigrant* Technology }\end{array}$ & $\begin{array}{l}0.000^{* * * *} \\
(0.000)\end{array}$ & & & $\begin{array}{l}0.001^{* * * *} \\
(0.000)\end{array}$ \\
\hline $\begin{array}{l}\text { Non-Western immigrant } \\
\text { background* Percentage non- } \\
\text { Western immigrant }\end{array}$ & $\begin{array}{c}-0.002^{* * *} \\
(0.000)\end{array}$ & & & $\begin{array}{c}-0.002^{\text {**** }} \\
(0.000)\end{array}$ \\
\hline $\begin{array}{l}\text { Percentage non-Western } \\
\text { immigrant* Technology* non- } \\
\text { Western immigrant background }\end{array}$ & $\begin{array}{c}0.001^{* * *} \\
(0.000)\end{array}$ & & & $\begin{array}{c}0.000 \\
(0.000)\end{array}$ \\
\hline Volatility* Technology & & $\begin{array}{c}-0.003^{* * *} \\
(0.000)\end{array}$ & & $\begin{array}{c}-0.004^{* * *} \\
(0.000)\end{array}$ \\
\hline Volatility* Non-Western & & $-0.001^{* * *}$ & & $0.001^{* * * *}$ \\
\hline immigrant background & & $(0.000)$ & & $(0.000)$ \\
\hline Volatility* Technology* Non- & & $0.000^{*}$ & & 0.000 \\
\hline Western immigrant background & & $(0.000)$ & & $(0.000)$ \\
\hline Union density* Technology & & & $\begin{array}{c}0.001^{* * *} \\
(0.000)\end{array}$ & $\begin{array}{c}-0.000^{* * *} \\
(0.000)\end{array}$ \\
\hline Union density* Non-Western & & & $0.001^{* * * *}$ & $0.001^{* * * *}$ \\
\hline immigrant background & & & $(0.000)$ & $(0.000)$ \\
\hline Union density* Technology* & & & $-0.000^{*}$ & -0.000 \\
\hline $\begin{array}{l}\text { Non-Western immigrant } \\
\text { background }\end{array}$ & & & $(0.000)$ & $(0.000)$ \\
\hline $\begin{array}{l}\text { (Ref: lower education) Middle } \\
\text { education }\end{array}$ & $\begin{array}{c}-0.005^{* * *} \\
(0.000)\end{array}$ & $\begin{array}{c}-0.005^{* * *} \\
(0.000)\end{array}$ & $\begin{array}{c}-0.005^{* * *} \\
(0.000)\end{array}$ & $\begin{array}{c}-0.005^{* * *} \\
(0.000)\end{array}$ \\
\hline Higher education & $\begin{array}{l}-0.003^{* * * *} \\
(0.000)\end{array}$ & $\begin{array}{c}-0.003^{* * *} \\
(0.000)\end{array}$ & $\begin{array}{c}-0.003^{* * *} \\
(0.000)\end{array}$ & $\begin{array}{c}-0.003^{* * *} \\
(0.000)\end{array}$ \\
\hline Organizational tenure & $\begin{array}{c}-0.004^{* * * *} \\
(0.000)\end{array}$ & $\begin{array}{c}-0.004^{* * *} \\
(0.000)\end{array}$ & $\begin{array}{c}-0.004^{* * *} \\
(0.000)\end{array}$ & $\begin{array}{c}-0.004^{* * * *} \\
(0.000)\end{array}$ \\
\hline Age & $\begin{array}{c}-0.002^{* * * *} \\
(0.000)\end{array}$ & $\begin{array}{c}-0.002^{* * *} \\
(0.000)\end{array}$ & $\begin{array}{c}-0.002^{* * * *} \\
(0.000)\end{array}$ & $\begin{array}{c}-0.002^{* * *} \\
(0.000)\end{array}$ \\
\hline (Ref: male) Gender & $-0.010^{* * * *}$ & $-0.010^{* * * *}$ & $-0.010^{* * *}$ & $-0.010^{* * * *}$ \\
\hline
\end{tabular}




\begin{tabular}{lcccc} 
& $(0.000)$ & $(0.000)$ & $(0.000)$ & $(0.000)$ \\
Part-time work & $0.219^{* * * *}$ & $0.219^{* * *}$ & $0.219^{* * *}$ & $0.219^{* * * *}$ \\
Fixed-Term contract & $(0.001)$ & $(0.001)$ & $(0.001)$ & $(0.001)$ \\
& $0.030^{* * *}$ & $0.028^{* * *}$ & $0.028^{* * *}$ & $0.030^{* * *}$ \\
Percentage Western immigrant & $(0.001)$ & $(0.001)$ & $(0.001)$ & $(0.001)$ \\
& $0.001^{* * *}$ & $0.000^{* * *}$ & $0.000^{* * *}$ & $0.001^{* * *}$ \\
Log enterprise size & $(0.000)$ & $(0.000)$ & $(0.000)$ & $(0.000)$ \\
& $-0.005^{* * *}$ & 0.001 & -0.001 & $-0.002^{* *}$ \\
Percentage part-time workers & $(0.001)$ & $(0.001)$ & $(0.001)$ & $(0.001)$ \\
& $0.001^{* * *}$ & $0.001^{* * *}$ & $0.001^{* * *}$ & $0.001^{* * *}$ \\
Organizational innovation & $(0.000)$ & $(0.000)$ & $(0.000)$ & $(0.000)$ \\
& $-0.002^{* * *}$ & $-0.001^{* *}$ & $-0.002^{* * * *}$ & $-0.002^{* * *}$ \\
Yearly unemployment rate & $(0.000)$ & $(0.000)$ & $(0.000)$ & $(0.000)$ \\
& $0.007^{* * *}$ & $0.007^{* * *}$ & $0.007^{* * *}$ & $0.006^{* * *}$ \\
Constant & $(0.000)$ & $(0.000)$ & $(0.000)$ & $(0.000)$ \\
& $0.059^{* * *}$ & $0.059^{* * *}$ & $0.059^{* * *}$ & $0.059^{* * * *}$ \\
Constant individual level & $(0.000)$ & $(0.000)$ & $(0.000)$ & $(0.000)$ \\
& $0.006^{* * *}$ & $0.006^{* * *}$ & $0.006^{* * *}$ & $0.006^{* * *}$ \\
Residual variance & $(0.000)$ & $(0.000)$ & $(0.000)$ & $(0.000)$ \\
& $0.180^{* * *}$ & $0.180^{* * *}$ & $0.180^{* * *}$ & $0.180^{* * *}$ \\
& $(0.000)$ & $(0.000)$ & $(0.000)$ & $(0.000)$ \\
\hline Observations & $9,843,454$ & $9,843,454$ & $9,843,454$ & $9,843,454$ \\
Enterprises & 5,145 & 5,145 & 5,145 & 5,145 \\
\hline Standard & & & & \\
\hline
\end{tabular}

Standard errors in parentheses

${ }^{*} p<0.05,{ }^{* *} p<0.01,{ }^{* * *} p<0.001$

Finally, in model 7 we investigate the role of union density within industries. We find that in industries with higher union density, the effect of technology implementation on job ending increases. Furthermore, we find workers with non-Western immigrant backgrounds to show higher chances of job ending when the organization they work in operates in an industry with higher union density. For workers with non-Western immigrant backgrounds the implementation of new technologies within organizations in more highly unionized industries is associated with smaller chances of job ending. However, we do not find this effect to be statistically significant in the full model. We therefore reject hypothesis 6 .

\section{Robustness checks}

To test whether technology does not have contrary impacts on job ending in different time periods we estimate the effect of technology implementation on job ending for three different time periods in the data: 2001-2005/2006-2010/2011-2014 (appendix, Table 4.A1). Results indicate that in all three time periods technology implementation decreases chances of job ending. Although we find the effect to be slightly larger in the period 2001-2005 compared to 2006-2014, the effect of technology implementation on job ending is robust across time periods.

Furthermore, Table 4.A2 compares several enterprise characteristics of enterprises implementing technologies across the three separate time periods. Overall, enterprises implementing technologies at the early observation period appear to be largely similar to enterprises implementing technologies at the end of the observation period. The average enterprise size appears to be smaller in the latter period, however, this is likely due to some 
very large enterprise(s) not being present in the sample in this period. Other enterprise characteristics appear to be largely comparable.

\subsection{Conclusion and discussion}

In the current study we investigate how the implementation of new technology within enterprises affect the chances of job ending for workers with a non-Western immigrant background relative to native Dutch workers. Furthermore, we explore whether this effect differs depending on organizational characteristics, namely, the percentage of non-Western immigrant workers and the volatility of jobs. Finally, we investigate whether the effect of technology differs between enterprises in industries with stronger and weaker unions. Using a large-scale survey of (technological) innovation within Dutch enterprises, linked with register data, we created a longitudinal (2001-2014) employer-employee dataset to study the effects of technology implementation on the chances of job ending for workers.

A main finding of the study is that overall technology implementation decreases chances of job ending, but this decrease is smaller for workers with non-Western immigrant backgrounds compared to native Dutch workers. Furthermore, we find this relation to be particularly salient for first generation immigrant workers from non-Dutch speaking nonWestern countries, for whom technology implementation does not relate to any reduction in chances of job ending.

This finding seems to support the argument that human capital deficits, whether real or perceived, among first generation immigrants may hamper their employment opportunities when technologies are implemented. Possibly contributing to this effect is the selection of firstgeneration immigrant workers into jobs employing more physical skills and fewer communication, math/logic, and socioemotional skills (Bacolod and Rangel, 2017). This may weaken their claims for new job tasks when technology is implemented because technology may increase demand for communication skills, problem-solving capabilities, and analytical capabilities rather than physical skills (Fernandez, 2001; Spitz-Oener, 2006).

Furthermore, immigrant workers from non-Dutch countries arguably face the challenge of transferring their acquired human capital as well as to overcome language barriers. Research has shown that non-Western immigrants have a disadvantage because human capital acquired in the country of origin is not fully transferable to the country of destination. Moreover, foreign degrees are shown to be weaker signals to employers impeding access to occupations, indicating that next to human capital, foreign degrees also suffer from limited transferability (Lancee and Bol, 2017). This may explain why we do find immigrants from Dutch speaking non-Western countries (Surinam and the Dutch-Antilles), whose human capital and educational credentials are more transferrable (Kanas and van Tubergen, 2009) and are already proficient in the Dutch language (Tubergen and Van de Werfhorst, 2007), tend to show some decrease in chances of job ending when technology is implemented and immigrants from non-Dutch speaking countries do not.

The finding that the implementation of technology similarly impacts job ending among native Dutch and second generation non-Western immigrant workers appears to show that within one generation immigrants are able to overcome many of the 'challenges' tied to technological change that their parents face(d). What is likely to play a role here is that returns 
to host-country schooling are much higher than origin-country schooling (Kanas and van Tubergen, 2009) as is growing up learning the host-country language.

Considering prospects of continuing technological advancement and international migration, the findings may tell us that for first generation immigrants' integration into technologically advanced host countries becomes harder. As technology shifts demand away from routine labor requiring manual skills towards non-routine labor requiring skills such as problem-solving capabilities, analytical capabilities, intuition, creativity and communication skills, disadvantages tied to language skills and the transferability of human capital and educational degrees possibly become more salient.

The finding that chances of job ending tied to technological change among secondgeneration and Dutch speaking immigrants from non-Western countries are similar to native Dutch workers seems to underline that investments in human capital of immigrants benefit employment prospects of immigrants in face of technological advances. Policies directed at providing immigrants with opportunities to learn the host-country language as well as access to education will arguably become increasingly important as new technologies enter the labor market.

A limitation of the study is that we rely on register data to measure job endings, meaning that we cannot differentiate between voluntary and involuntary job endings. We interpret a decrease in the probability of job ending as indicating that these workers are better able to claim job opportunities within the technologically innovated organization. For example, Fernandez (2001) studying the retooling of a food-processing factory finds that workers with skills that complemented the new technologies and remained within the enterprise had significantly higher earnings than workers who turned over. Furthermore, Bessen et al. (2019) studying the effects of investments in automation technologies in Dutch firms find a 5-year cumulative wage income loss of about $8 \%$ of one year's earnings for workers who experience job ending. These findings seem to corroborate our assumption that lower chances of job ending point to 'desirable' employment opportunities within the organization. Nevertheless, lacking representative data on workers' jobs or reasons for jobs ending, we are unable to say with certainty that job ending is involuntary and undesirable and remaining employed in the organization points to a successful claim of job opportunity. Assessing whether job ending is voluntary or involuntary is furthermore complicated because in the Netherlands layoffs are based on a 'mutual agreement', coordinated by employee associations and the national Employee Insurance Agency, which clarifies the conditions under which the employee accepts job termination. The content of such agreements may, however, vary. Additionally, employers may informally exert pressure on employees to accept an agreement, which may obscure involuntary job separations.

We do not find the relation between technology implementation and chances of job ending to differ depending on the proportion of non-Western immigrants or the volatility of enterprise jobs, nor on industry union density. A possible reason why we do not find these contextual factors to be of great importance is that we initially assumed technology would be associated with increased chances of job ending rather than decreased chances of job ending. Arguably, the risk of losing one's job evokes more competition and stronger feelings of intergroup-threat and category salience than the risk of not being able to move to a better job. Consequently, our assumption that in contexts where the salience of ethnic categories and 
feelings of threat are arguably greater technology increases relational inequalities between workers with immigrant backgrounds and natives, may be wrong. This may also tie into our measure of technological change, which holds no information on the type of technologies implemented or the degree of disruptiveness to organizational divisions of labor. The dynamics of competition between groups may be very different in instances where technology is strongly labor replacing compared to instances where technology changes process or products without affecting employment. Importantly, the study focuses on employment dynamics in the Netherlands where workers enjoy a high degree of employment protection. Arguably, both the types of technologies that enterprises acquire as well as its effects on work are different when employers cannot easily adjust their workforce to accommodate technological changes compared to contexts where employers can lay-off workers at will. We believe that studies that allow differentiation between the types of technologies being implemented as well as studies comparing countries with lesser and stronger employment protection may further this discussion. 



\title{
Chapter 5
}

\section{Technology implementation within enterprises and changes in the educational and age composition of enterprise workforces ${ }^{30}$}

\begin{abstract}
This study examines how technology implementation within enterprises impacts the education and age composition of workforces, enterprise entrants, and enterprise leavers. We advance the literature on the labor market consequences of technological change by focusing on their impact within workplaces where they are implemented, rather than inferring from aggregate labor structural changes. We use large-scale Dutch matched employer-employee data directly measuring technology implementation within over 37,000 enterprises in the period 2000-2014. We find that the implementation of technology associates with a decrease in the proportion of lower educated workers, and an increase in the proportion of middle educated workers in enterprise workforces. Interestingly, we find the proportion of workers aged 50+ to increase with the implementation of technology, while the proportion of workers aged below 30 decreases. These changes seem to result from changes in the educational and age composition of enterprise entrants, rather than changes in enterprise leavers.
\end{abstract}

\footnotetext{
${ }^{30}$ A slightly different version of this chapter has been published as: Ten Berge, J. B. \& Goos, M. (2019) Technology implementation within enterprises and changes in the educational and age composition of enterprise workforces. In Van der Lippe, T. and Lippényi, Z. (Eds.), Investments in a sustainable workforce in Europe. Jannes ten Berge wrote the main part of the chapter and conducted the analyses. This chapter has benefited greatly from feedback from Zoltán Lippényi and Tanja van der Lippe.
} 


\subsection{Introduction}

Recent studies indicating that large numbers of human work tasks could be automated in the near future have sparked scientific research into the effects of technological change on work (Frey and Osbourne, 2017; Manyika et al., 2017; World Bank, 2016). Feasibility studies estimate that advances in robotics, machine learning and artificial intelligence can automate or partially automate around 47\% of US jobs in the coming decades (Frey and Osbourne, 2017), and almost $60 \%$ of jobs in the OECD (World Bank, 2016). As technology advances, it poses a challenge to the creation of sustainable workforces: technological change can destroy a large number of job tasks (Acemoglu and Autor, 2011). More specifically, recent empirical labor market studies show that technology is associated with decreased employment in middle-skill jobs and increased employment in high- and low-skilled jobs, leading to a polarization of labor markets (Acemoglu and Autor, 2011; Autor, Levy and Murnane, 2003; Goos and Manning, 2007; Goos, Manning and Salomons, 2009, 2014).

What is underexposed in these studies is how organizations, in which the process of technological advancement plays out, adapt their workforces to technological changes. There are four major advantages of taking an organizational perspective on how technological change impacts jobs that macro-level studies which focus on aggregate labor flows are unable to recognize.

First, organizations are the sites where workers' jobs are created and distributed (Baron and Bielby, 1980). What remains unclear is for which workers technological changes within enterprises create job opportunities, and which workers face increasing difficulties in finding and maintaining employment within enterprises when technology is implemented. In the current chapter we contribute to the small but emerging literature on how technological change impacts work within organizations (Bauer and Bender, 2004; Beckmann, 2007; Cortes and Salvatori, 2016; Fernandez, 2001; King, Reichelt and Huffman, 2017; Nedelkoska, 2013; Siegel, 1998).

Second, for the sustainability of workforces, the relation in organizations between technology implementation, education and age is highly important. Previous literature has shown that technology is skill-biased, meaning that it provides opportunities for higher educated workers in particular, while posing challenges for middle and lower educated workers (Autor et al., 2003). In addition, technology is found to lead to a growing pace of skill depreciation and to increase the importance of adaptability of workers and organizations (Beckmann, 2007; Fernandez, 2001; Siegel, 1998). In the current study we contribute to the literature by studying whether workforces change with regard to the level of education and age, and how technology implementation relates to changes in the education and age composition of workers entering and leaving enterprises.

Third, an advantage of investigating organizations is that it allows a closer inspection of how institutional contexts influence the impact of technological change (Fernandez, 2001; Kalleberg, Wallace and Althauser, 1981; Kristal, 2013). As shown in previous studies, organizational decision making is strongly influenced by institutional context, such as unionization and collective bargaining (Fernandez, 2001; Kalleberg et al., 1981; Kristal, 2013). To clarify how the institutional contexts of enterprises shape the effects of technological change, we compare changes in the education and age composition of the workforce and worker 
flows as a consequence of technological change across industries varying in the degree of unionization.

Finally, macro-level studies imply, rather than directly measure, technological change. Previous research has mainly used a proxy measure of technology, namely the level of routineness of a job (Autor et al., 2003; Goos and Manning, 2007; Goos et al., 2009, 2014; Spitz-Oener, 2006). It is argued that only job tasks that follow an exact routine can be effectively codified and computerized. When a decline in routine jobs is observed, it is assumed that technology is the main driver of this change. However, testing this assumption, Nedelkoska (2013) finds little evidence that higher occupational change among routine workers and wage losses for those leaving routine jobs were the result of the implementation of code-based technologies, thus stressing the importance of employing direct measures of technology. Using a large-scale survey of (technological) innovation within Dutch enterprises, we measure technology implementation as the investment of enterprises in advanced machinery, equipment or computer hardware/software specifically purchased to implement new or significantly improved products (goods/services) and/or processes. ${ }^{31}$ To examine the relationship between technology implementation, the flow of workers in and out of enterprises and changes in workforce composition, we match this firm-level data to Dutch register data on employees. This allows us to follow over three million employees within over 30,000 enterprises over a period of fourteen years (2000-2014).

\subsection{Theory}

\section{Technology implementation and the educational composition of workers entering enterprises}

A leading hypothesis within the literature on the effects of technology is the Skill-Biased Technological Change (SBTC) hypothesis, which proposes that technology increases the marginal productivity of highly skilled workers, such as engineers, scientists and consultants (Autor, Katz and Krueger, 1998; Berman, Bound and Griliches, 1994; Card and DiNardo, 2002; Katz and Murphy, 1992; Krueger, 1993; Michaels, Natraj and Van Reenen, 2014). This increased marginal productivity increases the demand for highly skilled workers (Acemoglu and Autor, 2011; Autor et al., 2003; Fernandez, 2001; Spitz-Oener, 2006). Education increases problem-solving capability, analytical capacity, inductive reasoning, and communication skills (Becker, 1964), which are central to high-skill work tasks (Acemoglu and Autor, 2011; Autor et al., 2003; Spitz-Oener, 2006). It can therefore be expected that as the demand for more highly skilled workers increases with technological change in enterprises, it also increases the demand for higher educated workers (Autor et al., 2003). Thus, we expect that:

Hypothesis 1: When technology is implemented, the proportion of higher educated workers entering the enterprise increases while the proportion of lower educated workers entering the enterprise decreases.

\footnotetext{
${ }^{31}$ The Netherlands is a relevant case for conducting the study as it is among the top-ranking countries regarding innovation (Cornell University, INSEAD, \& WIPO, 2015).
} 
A critique of the SBTC framework is that it falls short in explaining the relative decrease of workers in middle-skill jobs, such as clerical and production, evident in recent labor market developments (Acemoglu and Autor, 2011; Autor et al., 2003; Goos and Manning, 2007; Goos et al., 2009, 2014). This relative decline in middle-skill work is explained as resulting from the automation of work, particularly of middle-skilled tasks such as record-keeping or repetitive assembly. Technology mainly substitutes work tasks that are routine intensive, such as repetitive assembly, because these tasks are codifiable in programming language (Autor et al., 2003). Because technology reduces the demand for middle-skilled workers performing routine tasks within organizations we expect that:

Hypothesis 2: When technology is implemented, the proportion of middle educated workers entering the enterprise decreases relative to the proportion of lower educated workers and higher educated workers entering the enterprise.

\section{Technology implementation and the educational composition of workers exiting enterprises}

With the automation of middle-skilled work tasks, the demand for middle-skilled workers already working in the enterprise also decreases. Within assignment models of technological change, the automation of work tasks is argued to lead to a reallocation of middle-skilled workers to high- or low-skill work tasks depending on the comparative advantage of workers in performing either high- or low-skilled tasks, as well as the relative demand and supply of workers' skills (Acemoglu and Autor, 2011). Based on the SBTC hypothesis, we expect that the demand for higher-skilled workers increases. However, assuming that in most cases middleskilled workers are unable to perform high-skill work tasks, we do not expect middle-skilled workers to reallocate to perform high-skill job tasks. Furthermore, we have little reason to suspect that middle-skilled workers get reallocated to perform low-skill job tasks. There are two reasons for this. First, employers cannot easily lower wages, and since middle educated workers on average have higher earnings than lower educated ones, it is more cost-efficient to keep lower educated workers and have them perform tasks that require lower skills rather than reallocating middle educated workers into low-skill jobs. Furthermore, assuming that skills are to some degree transferrable, middle-skilled workers may choose to find work in another enterprise with similar skill requirements and pay, rather than switching to a low-skill job. Second, a reason to retain and reallocate middle educated workers would be their higher productivity in low-skilled job tasks, but it is not clear whether these workers are in fact more productive in performing low-skilled job tasks than low-skilled workers (Acemoglu and Autor, 2011). In conclusion, we expect that the implementation of technology decreases both the demand for middle-skilled work tasks as well as for middle-skilled workers. We therefore expect that:

Hypothesis 3: When technology is implemented the proportion of middle educated workers leaving the enterprise increases. 


\section{Technology implementation and the educational composition of enterprise workforces}

Thus, on the one hand, we predict that under circumstances of technological change the proportion of higher educated workers entering an enterprise increases. On the other hand, we predict that the proportion of middle educated workers entering an enterprise decreases and the proportion of middle educated workers leaving it increases. Based on these predictions we expect that:

Hypothesis 4: When technology is implemented the proportion of higher educated workers in enterprise workforces increases relative to the proportion of middle and lower educated workers.

\section{Technology implementation and the age of workers entering enterprises}

From the human capital literature, we know that within enterprises a large amount of a worker's productivity stems from experience gained within their current and previous jobs. As a result, for an enterprise, experienced workers are generally the more valuable workers (Crook, Todd, Combs, Woehr and Ketchen, 2011; Gathmann and Schönberg, 2010; Jovanovic, 1979; Lazear, 2009; Topel, 1991). Technological change, however, alters skill requirements and increases the pace at which certain skills and knowledge become outdated. New technologies often require adaption - for example, in how to organize a new production process, or how to use new technology. Consequently, experience with the old process, or knowledge about the old product (unless a prerequisite of the new product) decreases in importance with the implementation of new products or processes (Beckmann, 2007).

Skill obsolescence and human capital depreciation is likely to affect younger and older workers differently. The depreciation of existing human capital and the increase in demand for new types of skills are likely to increase the appeal of employing younger workers for two reasons. First, because younger workers have attained their education more recently, they are more likely to offer the necessary state-of-the art skills than older workers (Beckmann, 2007). Second, even if retraining can help workers to attain the necessary skills, enterprises are more likely to invest in retraining younger rather than older workers (Arulampalam, Booth and Bryan, 2004; Bartell and Sicherman, 1993; Beckmann, 2007; Carmichael and Ercolani, 2014; Guerrazzi, 2014; Taylor and Urwin, 2001). The reason for this is that retraining younger workers is more profitable because there is more time for training costs to be recouped. Furthermore, older workers have a shorter time horizon in the labor market, making them reluctant to invest in training themselves (Beckmann, 2007). We therefore expect that:

Hypothesis 5: When technology is implemented the proportion of younger workers entering an enterprise increases.

\section{Technology implementation and the age of workers leaving enterprises}

As workers gain experience within the firm - for example, via job training about current production processes - their productivity increases (Dearden, Reed and Van Reenen, 2006), resulting in higher wages (Brown, 1989). For employers, wages are a cost that is worth paying as long as this cost is compensated for by the high productivity of an employee. When 
technology implementation changes a production process, however, the productivity premium resulting from experience decreases. Thus, technology implementation negatively affects the productivity premium of having on-the-job experience, resulting in wage costs that are out of balance with the productivity of tenured workers. One way to recover the balance between costs and worker productivity is to reduce wages, but in the European context this is often unfeasible as wages are subject to wage regulation by the state, unions or through collective labor agreements. Another way to recover the balance between wage costs and productivity is to layoff or incentivize tenured workers to leave the enterprise.

Some studies argue that rather than facing actual problems with work performance, older workers suffer from negative stereotyping and discrimination, which influences managerial expectations and decision making (Posthuma and Campion, 2009). The stereotype that older workers are less adaptable than younger workers leads to lower training participation among older workers as well as early retirement arrangements (Posthuma and Campion, 2009; Shore and Goldberg, 2005). We expect that discriminatory practices and experiencing managerial favouritism, on the one hand, and actual difficulties with skill adaption and lack of retraining, on the other, will lead to increases in both workers leaving and layoffs. We therefore expect that:

Hypothesis 6: When technology is implemented the proportion of older workers leaving an enterprise increases.

\section{Technology implementation and the age composition of enterprise workforces}

As a result of increases in both the proportion of younger workers entering and the proportion of older workers leaving enterprises under circumstances of technological change, we expect that:

Hypothesis 7: When technology is implemented the proportion of younger workers in enterprise workforces increases while the proportion of older workers decreases.

\section{Technology implementation and the role of institutions}

The behaviour of organizational actors is strongly influenced by the institutional context of the organization (Scott, 2014). How organizations adapt their workforces is likely to depend on how they enable and constrain the actions of both employers and employees (Avent-Holt and Tomaskovic-Devey, 2014; Orlikowski and Barley, 2001). Employers are constrained by laws, unions, and collective agreements that, at the same time, 'empower' employees in negotiation with the employer. Studying the adaption process to technological innovation of a food processing plant, Fernandez (2001) finds that the effects of technology implementation are strongly shaped by bargaining processes between the employer and the workers' union. In return for no-lay-off and wage guarantees, the union agreed to relax seniority and work rule requirements and to support retraining efforts by the enterprise (Fernandez, 2001). While the supply and demand framework aids us in hypothesizing how the implementation of new technologies changes employers demands for skills, the decisions that employers make to adapt to these changing skill demands are constrained by regulative institutions (Avent-Holt and Tomaskovic-Devey, 2014). More specifically, the degree to which employers can use churning 
as a way of adapting an enterprise's workforce to new technologies seems to be less when workers can rely on institutions to bargain for enterprise resources such as jobs, training and wages.

To study the role of institutions we compared more and less unionized industries. In 2016, out of all wage-earning workers in the Netherlands, $17 \%$ were union members - similar to the average for OECD countries (OECD, 2018). In the Netherlands, however, unions are more influential than their membership suggests because they bargain at the company or industry level concerning collective labor agreements, which thereby also includes workers who are not members of a union. In the Netherlands, $79 \%$ of wage earners are covered by collective bargaining agreements, ranking $9^{\text {th }}$ among 36 countries included in OECD data.

Looking at different industries we find substantial variation in union coverage. In manufacturing, union coverage was $31 \%$ (in 2011), whereas in business services only $11 \%$ of workers were covered by unions (Statistics Netherlands, 2012). We expect that in unionized industries, employers are less able to use worker churning to adapt their workforces to technology. We therefore expect that:

\section{Hypothesis 8: The effects of technology implementation on the age and educational composition of workforces, and on workers entering-leaving enterprises, are less in unionized industries.}

\subsection{Data}

Our study makes use of the combination of a large-scale enterprise survey and social microregister data. Data on company investment in technology is taken from the Community Innovation Survey (CIS). The CIS is a large-scale cross-national survey of innovation activity in enterprises, repeated every two years. In the Dutch survey used in this study, the sample is stratified by sector and establishment size, excluding enterprises with less than ten workers (Mortensen and Bloch, 2005). We linked the survey data from the CIS with register data providing information on job beginnings and job endings. Due to the longitudinal design, we are able to study changes in technology implementation within enterprises over time. We focus on the period 2000-2014. Because enterprises do not always participate in the survey followups, we generally did not observe enterprises for the full period 2000-2014. The average number of years that enterprises are observed in the data is 4.64 years. Of the total 36,230 enterprises that we linked to the register data, 26,273 (72.52\%) did not implement technologies during the period of observation, while 5,820 (16.06\%) were observed during periods both with and without technology implementation. The remaining 4,137 enterprises $(11.42 \%)$ implemented new technologies during all periods of observation. We linked these enterprises to register data on workers' jobs and demographic characteristics from the System of Social Statistics Databases (SSB) of the Dutch Central Bureau of Statistics, creating a longitudinal matched employer-employee dataset. Having linked information about workers' jobs, educational attainment and age with the enterprises in the CIS, we were able to track how many workers entered and left the enterprise and what the composition of job entrants, job leavers and workforces looked like, with regard to educational attainment and age.

To study how the implementation of technologies within enterprises affects the composition of entrants, leavers, and workforces with regard to educational attainment and age, 
we selected only the 5,820 enterprises that were observed in contexts both with and without technology being implemented. Furthermore, we exclusively analysed enterprises in which we, over time, observed a shift from a period without technology implementation (0) to a period with technology implementation (1). Because the effects of technology implementation on the age and education composition of workforces are likely to last after the technology has been implemented, we did not include observations of time periods without technology implementation that follow time periods with technology implementation. This selection of observations excluded 2,243 enterprises $(38.54 \%$ ) in which we only observed a shift from technology being implemented (1) to technology no longer being implemented (0). Furthermore, this means that we excluded the observations that came after the observed periods of no technology implementation (0) to technology implementation (1). The remaining analytical sample consists of 3,577 enterprises and 23,156 observations. Table 5.1 provides descriptive statistics for enterprises when implementing and not implementing technologies.

Table 5.1. Descriptive statistics of enterprises and dependent variables differentiated by contexts of technology implementation

\begin{tabular}{lcccccc}
\hline & \multicolumn{2}{l}{$\begin{array}{l}\text { No technology } \\
\text { implementation }\end{array}$} & $\begin{array}{l}\text { Technology } \\
\text { implementation }\end{array}$ & \multicolumn{2}{c}{ All enterprises } \\
& Mean & S.D. & Mean & S.D. & Mean & S.D. \\
\hline $\begin{array}{l}\text { Education of workers entering } \\
\text { (\%) }\end{array}$ & & & & & & \\
Low & 19.76 & 18.00 & 17.50 & 16.49 & 18.55 & 14.98 \\
Middle & 43.00 & 19.08 & 45.87 & 19.99 & 44.45 & 16.73 \\
High & 37.24 & 24.58 & 36.63 & 25.38 & 37.00 & 23.09 \\
& & & & & & \\
Education of workers leaving (\%) & & & & & & \\
Low & 20.48 & 17.96 & 19.34 & 17.05 & 19.87 & 15.49 \\
Middle & 42.59 & 18.84 & 45.16 & 19.41 & 44.09 & 16.39 \\
High & 36.93 & 24.65 & 35.50 & 24.60 & 36.04 & 22.87 \\
Education of workforce (\%) & & & & & & \\
Low & & & & & & \\
Middle & 24.53 & 17.38 & 23.11 & 16.40 & 23.76 & 16.44 \\
High & 44.26 & 15.60 & 45.32 & 15.54 & 44.77 & 14.95 \\
Age of workers entering (\%) & 31.20 & 22.38 & 31.57 & 22.17 & 31.47 & 21.91 \\
Below 30 & & & & & & \\
Between 30 and 50 & 51.61 & 20.24 & 53.17 & 21.33 & 52.64 & 17.88 \\
Above 50 & 41.34 & 18.57 & 39.06 & 19.01 & 40.03 & 15.80 \\
Age of workers leaving (\%) & 7.05 & 8.96 & 7.77 & 9.78 & 7.33 & 7.52 \\
Below 30 & & & & & & \\
Between 30 and 50 & 44.68 & 21.55 & 42.05 & 21.67 & 43.24 & 19.60 \\
& 41.51 & 18.75 & 39.85 & 18.43 & 40.53 & 16.11
\end{tabular}




\begin{tabular}{lcccccc} 
Above 50 & 13.81 & 13.90 & 18.10 & 15.37 & 16.22 & 12.80 \\
Age of workforce (\%) & & & & & & \\
Below 30 & 25.43 & 16.32 & 21.69 & 15.65 & 23.54 & 15.43 \\
Between 30 and 50 & 55.81 & 13.13 & 55.23 & 13.05 & 55.52 & 12.28 \\
Above 50 & 18.75 & 11.37 & 23.08 & 12.44 & 20.94 & 11.41 \\
& & & & & & \\
Organizational innovation & 33.60 & 43.78 & 46.26 & 44.27 & 40.18 & 44.48 \\
Industry union density & 56.00 & 49.65 & 56.00 & 49.65 & 56.00 & 49.64 \\
Enterprise size & 240 & 887 & 287 & 1528 & 263 & 1250 \\
\hline
\end{tabular}

$\mathrm{N}$ enterprises $=3,577$.

\subsection{Measurement}

\section{Dependent variables}

Educational composition of enterprise workforces was measured as the proportion of the workforce with low, high, and middle educational attainment within an enterprise, at the end of a year. Level of education was measured according to the International Standard Classification of Education (ISCED). Eight educational levels are distinguished. We recoded the levels into low, middle and high education following guidelines in the ISCED 2011 manual (OECD/Eurostat/UNESCO Institute for Statistics, 2015): low education, including those who attained less than primary education, primary education and lower secondary education; medium education, including employees who attained upper secondary education and postsecondary non-tertiary education; and high education, including employees who attained shortcycle tertiary, bachelor's, a master's or doctoral equivalent education.

Educational composition of enterprise entrants was measured as the proportion of low, middle, and high educated entrants within the enterprise in a given year.

Educational composition of workers leaving an enterprise was measured as the proportion of low, middle, and high educated employees who left the enterprise in a given year.

Age composition of the workforce was measured as the proportion of younger, middleaged, and older employees within an enterprise, at the end of the year. Following Beckmann's (2007) study on the age composition of workforces, we differentiated between three age categories: workers aged below 30, workers aged between 30 and 50 and workers aged above 50.

Age composition of workers entering the enterprise was measured as the proportion of workers aged below 30, between 30 and 50 and above 50, entering the enterprise in a given year.

Age composition of workers leaving the enterprise was measured as the proportion of workers aged below 30, between 30 and 50 and above 50, leaving the enterprise in a given year.

\section{Independent variables}

Implementation of technology was measured using an item from the CIS. A higher manager from the enterprise was asked to indicate whether, over the past two to three years (depending on the survey date), the enterprise had purchased machinery, equipment and/or software with the aim of significantly improving products, services and/or production processes. 
Industry unionization was captured by differentiating between industries with higher and lower union densities. Union density is defined as the share of unionized employees younger than 65 years of age with paid work for at least 12 hours a week, out of the total number of employees with paid work for at least 12 hours per week. We treated industries where union density is over $25 \%$ as more unionized. Industry and mining, energy and water management, manufacturing, transport, and communication fall in this category: their union densities range from $26 \%$ (industry and mining) to $37 \%$ (manufacturing). Trade, retail, financial services, and business services are less unionized: their union densities range from $12 \%$ in trade to $14 \%$ in financial services (Statistics Netherlands, 2012).

We controlled for organizational innovations to capture changes in the organization of an enterprise which can be related to worker flows in and out of enterprises (Bauer and Bender, 2004; Bresnahan, Brynjolfsson and Hitt, 2002). A higher manager from the enterprise was asked to indicate whether, over the past two to three years (depending on the survey date), the organization had introduced new business procedures, new methods for the organization of professional responsibilities and decision making or new methods for external relations with other companies or institutes.

Furthermore, we controlled for enterprise size, which is measured as the number of employees that worked in the enterprise at the beginning of the year. Because the distribution of enterprise size is strongly right skewed, indicating the presence of several very large enterprises, we use the log of enterprise size in the analyses.

\subsection{Method}

To test the relationship between technology implementation within enterprises and changes in the composition of enterprise workforces and worker flows in and out of enterprises with regard to educational attainment and age, we took the following steps. First, we calculated the proportions of workers, with regard to educational attainment and age, entering and leaving an enterprise, on the one hand, and the workforce total, on the other, for the years 2000-2014. Second, we identified periods in which a change from no technology implementation to technology implementation could be observed - for example, the selected period 2002-2010, during which, between 2002 and 2008 the enterprise did not implement technology, while between 2008 and 2010 it did. Third, having selected periods of change we took the average of the proportions of workers, with regard to education and age, entering, working in and leaving the enterprise. These averages were subtracted from the observed proportions per year, such that observed proportions per year then represented deviations from the enterprise-period specific mean. The advantage of using these deviations from the enterprise-period mean is that when analysing the data we only analysed within-enterprise variation, allowing us to control for time-invariant unobserved heterogeneity.

As the dependent variables are compositions that together always add up to 1 , there is covariation between the variables. We used seemingly unrelated regression (SUR) estimation to account for the correlation between error terms that arose when analysing the proportions of entrants, leavers, and workforces, with regard to education and age. Furthermore, we included dummies for years to control for over time trends in the composition of workers with regard to education and age. Finally, we added weights to the analyses. The measurement of educational attainment was taken from a combination of surveys. Consequently, the coverage of educational 
attainment varied per enterprise. To partially account for the error this missing data incurred, we added weights indicating the percentage of entrants, leavers, and enterprise workforces with data on educational attainment. Furthermore, we added weights for the log of enterprise size to allow larger enterprises to influence the results more strongly than small enterprises, leading to more generalizable results. To test whether technology implementation continues to affect the education and age composition of enterprise entrants, leavers and workforces after periods of technology implementation we performed an additional analysis in which we included one-, two- and three-year lagged effects of technology implementation to the model (Table 5.A1 and 5.A2 in the appendix). We found the directions of the effects of technology implementation to remain the same for all models including one-, two- or three-year effects.

\subsection{Results}

Table 5.2 provides the results for the seemingly unrelated regression of technology implementation on the educational composition of workers. We find that the implementation of technology is associated with an increase in the proportion of middle educated workers entering enterprises, relative to higher and lower educated workers. These results are only partly in line with our first hypothesis. Corroborating Hypothesis 1, we find the relative inflow of lower educated workers to decrease. However, contradicting Hypothesis 1 we find the relative proportion of higher educated workers to decrease, rather than increase. We find that the relative proportion of middle educated workers entering enterprises increases, rather than decreases, when technology is implemented; we therefore reject Hypothesis 2. With respect to the educational composition of workers leaving enterprises, we find support for Hypothesis 3: the proportion of middle educated workers leaving enterprises increased relative to the proportions of higher and lower educated workers. The results on the effect of technology implementation on the educational composition of the enterprise do not correspond with our expectations: we do not find the proportion of higher educated workers to increase. Instead, we find that the proportion of middle educated workers increases, primarily at the expense of lower educated workers. Nevertheless, this relative increase in middle educated workers is in line with the hypothesis that technology is associated with educational upgrading of the workforce. However, we expected this upgrading to occur through an increase in the proportion of high educated workers; we therefore reject Hypothesis 4.

Table 5.3 shows the effects of technology implementation on the age composition of workers. Contrary to our expectations, we find that the proportion of workers aged 50+ entering the enterprise increases relative to the proportion of workers aged between 30 and 50 . We therefore reject Hypothesis 5. Turning to the effects of technology implementation on the age composition of workers leaving enterprises, we find that, in accordance with Hypothesis 6, technology implementation is associated with an increased proportion of workers aged 50+ leaving the enterprise. Finally, changes in the age composition of enterprise workforces do not support our expectations: we find technology implementation to be associated with an increase, instead of a decrease, in the proportion of workers aged $50+$. 


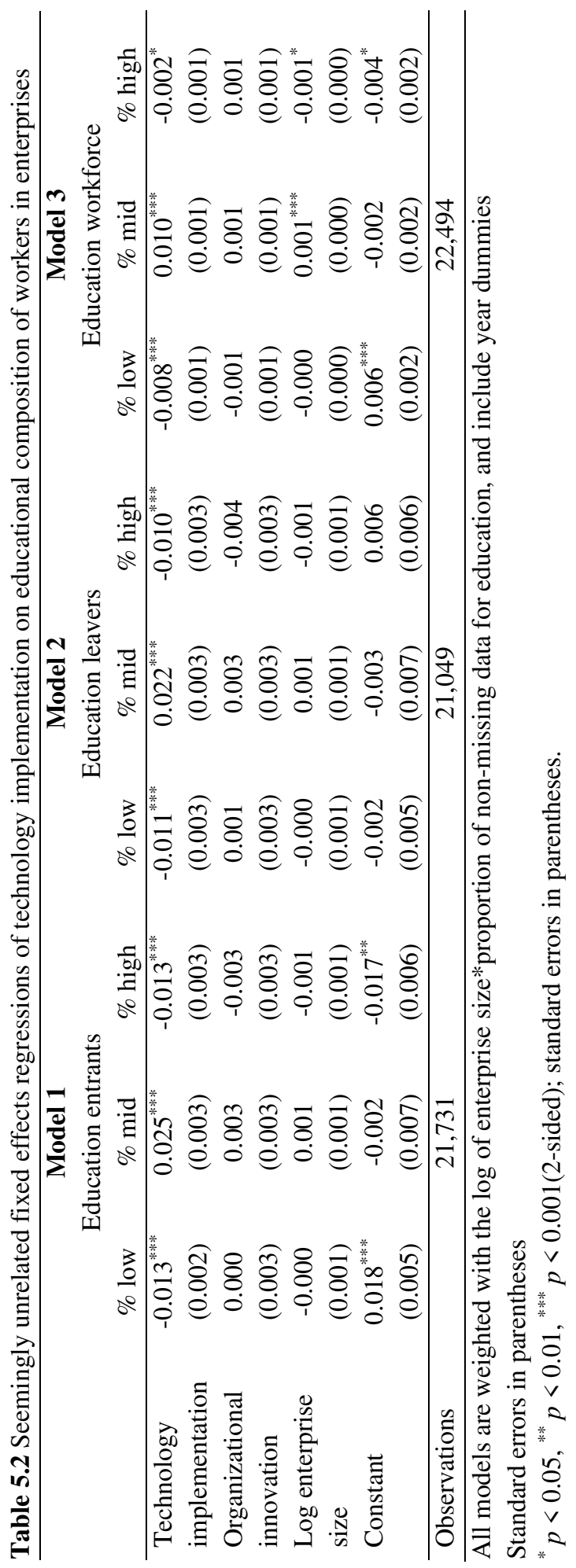




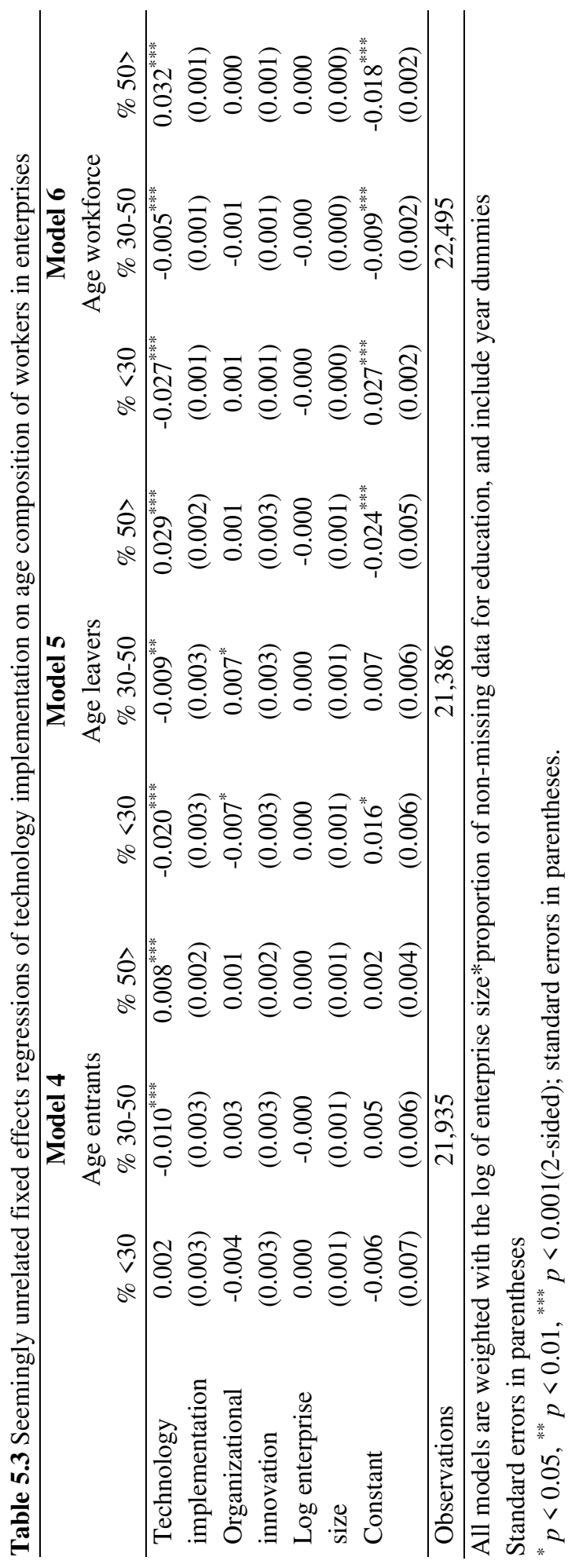




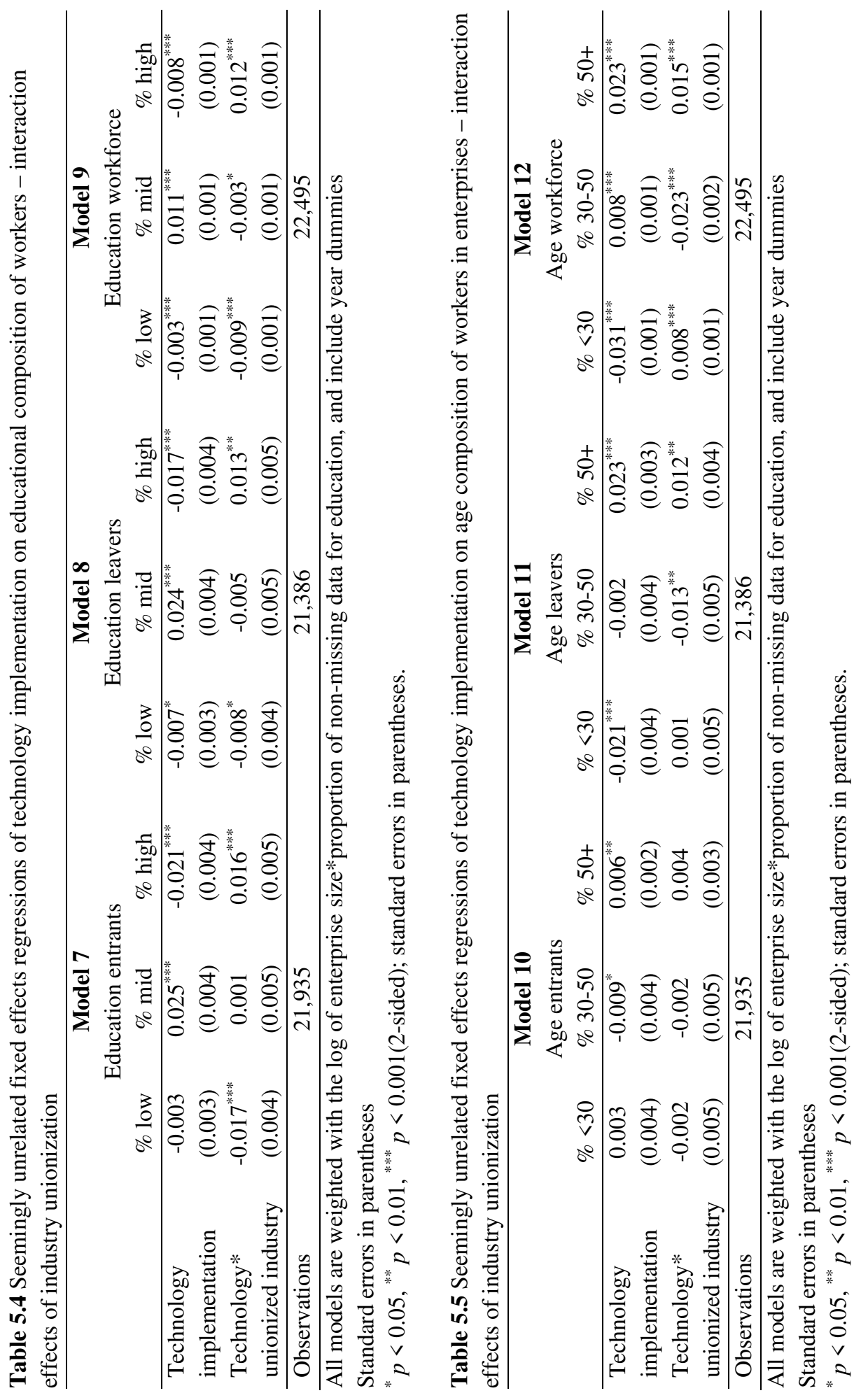


To investigate the role of the institutional context, we included interaction effects between technology implementation and unionization within an industry. We do not find unionization to unequivocally be associated with weaker effects of technology on the education composition of enterprise workforces, entrants, and leavers (see Table 5.4). Changes in the composition of high educated workers entering, leaving, and working in enterprises do appear to be significantly smaller in unionized industries. However, the decrease in the proportions of lower educated workers entering, leaving, and working in enterprises appear to be more pronounced in unionized industries. With respect to changes in age composition, we find a mixed pattern of weaker and stronger associations in unionized industries (see Table 5.5). In summary, although the effects of technology differ significantly between industries, the pattern of findings do not support our expectation of weaker associations in unionized contexts. We therefore reject Hypothesis 8.

\subsection{Conclusion and discussion}

In this study we investigated how the implementation of new technologies affects the education and age composition of workers entering, leaving, and working in enterprises. Using a largescale survey of (technological) innovation within Dutch enterprises, linked with register data, we created a longitudinal (2000-2014) employer-employee dataset to study the effect of technology implementation on enterprise workforces.

We did not witness an increase in the proportion of higher skilled workers, as expected, based on the Skill-Biased Technological Change hypothesis. Recent empirical work, however, documents a decrease in demand for high-skilled, cognitive work tasks from the 2000s onwards (Beaudry, Green and Sand, 2016; Mishel, Schmitt and Shierholz, 2013). Beaudry et al. (2016) argue that during the key investment stage in technology there is high and growing demand for skilled cognitive tasks to build up new technological capital. However, they expect a reduction in demand for these tasks relative to the peak investment stage and argue that the turn of the $21^{\text {st }}$ century marked a turning point from peak investment to a stage of maturity. Although this argument may explain why we see decreased demand for cognitive skills, it is less clear how this dynamic may affect the demand for labor in enterprises that are implementing new technologies. One possible scenario is that when technologies enter a 'phase of maturation,' their applicability to standardized tasks increases, complementing the skills of middle educated workers (Autor, 2015; Holzer, 2015). At the same time, when technologies are in their 'revolutionary stage', there may be a higher demand for the cognitive skills of high educated workers. If the advancement of technology indeed shows such cyclical trends, this may imply that advances in artificial intelligence (AI), machine learning and robotics will lead to a surge of technology investments, increasing the demand for high educated workers, followed by a maturation of these technologies, complementing middle educated workers.

Our findings lend mixed support for the Routine-Biased Technological Change hypothesis (Acemoglu and Autor, 2011; Autor et al., 2003). While the proportion of middle educated workers leaving enterprises increased as predicted by the theory, we also find the relative number of middle educated entrants as well as the proportion of middle educated workers to increase following technology implementation. The organizational-level patterns in our study do not correspond with labor market findings of polarization in earlier research (see Acemoglu and Autor, 2011; Autor et al., 2003; Goos and Manning, 2007; Goos et al., 2009, 
2014). An explanation may be that technology increases demand for workers who are qualified to work with the new technology (Autor, 2015); middle educated workers that are less qualified are replaced by those who possess the knowledge and skills to work with and alongside new technologies (Holzer, 2015). Such replacement processes require a steady supply of workers trained to work with the new technology. The Dutch labor context is likely to create the prerequisites: the Netherlands has a vocationally oriented educational system characterized by close links between educational programs and the labor market (Van de Werfhorst, 2004). This system improves the match between the skill demands of employers and the skill supply of employees through, for instance, internships and company placements embedded in vocational training, as well as the higher possibility of information exchange between educational institutions and employers about skill requirements (Holzer, 2015). This explanation raises a more fundamental question: the extent to which the technology-labor composition relationship depends on the institutionalized features of skill creation (e.g., the existence of formal ties between organizations and educational institutions). We leave this interesting avenue for future studies that use a cross-country comparative design.

Our main finding regarding age compositional change is an unexpected increase in the proportion of workers aged 50+ in the workforces. This finding suggests that organizations may value older workers' experience and skills in times of technological investment more than skillbased theories might imply. For instance, organizations may consider older, experienced workers more suitable for tasks such as change management or consultancy, which are highly valued during periods of organizational change. Future research could investigate the relationship between the type of jobs created during periods of technological change and the age of their incumbents, to gain more insight into which types of older workers are attracted to enterprises in times of technological change. Nevertheless, some findings also support the notion that technology favors younger workers (see Bartell and Sicherman, 1993; Beckmann, 2007), as the proportion of older workers leaving enterprises increases, while the proportion of younger workers leaving enterprises decreases following technological change.

Our results regarding institutional variation are puzzling and, in any case, do not lend a simple interpretation of uniformly weaker effects in more unionized contexts. Remarkably, within unionized industries, technology implementation leads to lower percentages of less educated workers entering and leaving. This pattern may support rather than refute the influence of institutions: in unionized contexts, one way for employers to circumvent protection against layoff is to decrease the hiring of lower educated workers (Fernandez, 2001). Findings regarding age seem to point to institutional influences, albeit through different mechanisms. Within more unionized industries, we find the proportion of 50+ workers leaving enterprises under technological change to be significantly greater. Favourable early retirement schemes agreed by unions and employers are one possible explanation (see Raymo, Warren, Sweeney, Hauser and Ho, 2011), but one may need to follow the destination of leavers - whether retirement, unemployment or a new job - to corroborate this.

Based on our results, the signs for workforce sustainability are generally positive, although there are also reasons to be concerned about the advance of new technologies. Lower educated workers seem to fare worse during technological change, and the extent to which unionism still provides protection to these workers, given the declining power of unions and increasing liberalization of labor markets, is questionable (Thelen, 2014). National policy 
efforts should in any case focus on the employment opportunities of these workers. Another source of concern is the labor market position of middle educated and older groups of workers after leaving jobs, a question we did not touch upon in this study. This topic warrants attention, as the skills these groups bring to the labor market may prove unfitting in an environment where technologies keep advancing (Weber, 2014). On a positive note, the general pattern of our findings does not suggest that experienced, older workers and middle educated workers lose much ground in organizations. A careful consideration of organizational and labor market mechanisms is needed to identify the groups that are at risk during the process of technological change. 

Appendix A 
Table 2.A1 Fixed effects regression model of technology implementation on job ending, and the role of education, tenure, and age

\begin{tabular}{|c|c|c|c|c|c|}
\hline & $\begin{array}{r}\text { Model 11 } \\
\text { Technology }\end{array}$ & $\begin{array}{l}\text { Model } 12 \\
\text { Education }\end{array}$ & $\begin{array}{l}\text { Model } 13 \\
\text { Org. tenure }\end{array}$ & $\begin{array}{l}\text { Model } 14 \\
\text { Age }\end{array}$ & $\begin{array}{c}\text { Model 15 } \\
\text { Full model }\end{array}$ \\
\hline Technology & $-0.015^{* * *}$ & $-0.007^{* * *}$ & $-0.015^{* * *}$ & $-0.014^{* * *}$ & $-0.008^{* * * *}$ \\
\hline & $(0.000)$ & $(0.001)$ & $(0.000)$ & $(0.000)$ & $(0.001)$ \\
\hline (Ref: lower education) & & $0.020^{* * * *}$ & & & $-0.001^{* *}$ \\
\hline Middle education & & $(0.000)$ & & & $(0.000)$ \\
\hline Middle education* & & $-0.008^{* * * *}$ & & & $-0.005^{\text {**** }}$ \\
\hline Technology & & $(0.001)$ & & & $(0.001)$ \\
\hline Higher education & & $0.037^{* * *}$ & & & $0.002^{* * *}$ \\
\hline & & $(0.000)$ & & & $(0.000)$ \\
\hline Higher education* & & $-0.013^{* * * *}$ & & & $-0.009^{* * * *}$ \\
\hline Technology & & $(0.001)$ & & & $(0.001)$ \\
\hline Organizational tenure & & & $\begin{array}{l}-0.008^{* * *} \\
(0.000)\end{array}$ & & $\begin{array}{l}-0.005^{* * *} \\
(0.000)\end{array}$ \\
\hline $\begin{array}{l}\text { Organizational } \\
\text { tenure* Technology }\end{array}$ & & & $\begin{array}{l}0.003^{* * * *} \\
(0.000)\end{array}$ & & $\begin{array}{l}0.002^{* * *} \\
(0.000)\end{array}$ \\
\hline Age & & & & $\begin{array}{c}-0.005^{* * *} \\
(0.000)\end{array}$ & $\begin{array}{c}-0.004^{* * *} \\
(0.000)\end{array}$ \\
\hline Age* Technology & & & & $\begin{array}{l}0.001^{* * * *} \\
(0.000)\end{array}$ & $\begin{array}{l}0.001^{* * * *} \\
(0.000)\end{array}$ \\
\hline (Ref: male) Gender & $\begin{array}{c}0.009^{* * *} \\
(0.000)\end{array}$ & $\begin{array}{l}0.010^{* * *} \\
(0.000)\end{array}$ & $\begin{array}{l}0.004^{* * *} \\
(0.000)\end{array}$ & $\begin{array}{l}0.005^{* * *} \\
(0.000)\end{array}$ & $\begin{array}{l}0.003^{* * *} \\
(0.000)\end{array}$ \\
\hline (Ref: native Dutch & $0.046^{* * * *}$ & $0.049^{* * * *}$ & $0.036^{* * * *}$ & $0.036^{* * * *}$ & $0.032^{* * * *}$ \\
\hline $\begin{array}{l}\text { Non-Western } \\
\text { immigrant background }\end{array}$ & $(0.000)$ & $(0.000)$ & $(0.000)$ & $(0.000)$ & $(0.000)$ \\
\hline $\begin{array}{l}\text { Western immigrant } \\
\text { background }\end{array}$ & $\begin{array}{c}0.017^{* * *} \\
(0.000)\end{array}$ & $\begin{array}{l}0.017^{* * *} \\
(0.000)\end{array}$ & $\begin{array}{l}0.013^{* * *} \\
(0.000)\end{array}$ & $\begin{array}{l}0.022^{* * *} \\
(0.000)\end{array}$ & $\begin{array}{c}0.018^{* * *} \\
(0.000)\end{array}$ \\
\hline Log enterprise size & $\begin{array}{l}0.072^{* * * *} \\
(0.001)\end{array}$ & $\begin{array}{l}0.073^{* * * *} \\
(0.001)\end{array}$ & $\begin{array}{l}0.061^{* * * *} \\
(0.001)\end{array}$ & $\begin{array}{l}0.061^{* * * *} \\
(0.001)\end{array}$ & $\begin{array}{l}0.058^{* * *} \\
(0.001)\end{array}$ \\
\hline $\begin{array}{l}\text { Organizational } \\
\text { innovation }\end{array}$ & $\begin{array}{l}0.002^{* * *} \\
(0.000)\end{array}$ & $\begin{array}{l}0.002^{* * * *} \\
(0.000)\end{array}$ & $\begin{array}{l}0.002^{* * * *} \\
(0.000)\end{array}$ & $\begin{array}{l}0.002^{* * * *} \\
(0.000)\end{array}$ & $\begin{array}{l}0.003^{* * *} \\
(0.000)\end{array}$ \\
\hline $\begin{array}{l}\text { Yearly unemployment } \\
\text { rate }\end{array}$ & $\begin{array}{l}-0.000^{* *} \\
(0.000)\end{array}$ & $\begin{array}{l}-0.000^{*} \\
(0.000)\end{array}$ & $\begin{array}{l}0.003^{* * * *} \\
(0.000)\end{array}$ & $\begin{array}{l}0.002^{* * * *} \\
(0.000)\end{array}$ & $\begin{array}{l}0.003^{* * * *} \\
(0.000)\end{array}$ \\
\hline Constant & $\begin{array}{c}-0.255^{* * *} \\
(0.004)\end{array}$ & $\begin{array}{c}-0.287^{* * *} \\
(0.004)\end{array}$ & $\begin{array}{c}-0.198^{* * *} \\
(0.004)\end{array}$ & $\begin{array}{c}-0.203^{* * *} \\
(0.004)\end{array}$ & $\begin{array}{c}-0.184^{* * *} \\
(0.004)\end{array}$ \\
\hline Observations & $16,347,201$ & $16,347,201$ & $16,347,201$ & $16,347,201$ & $16,347,201$ \\
\hline Enterprises & 35,814 & 35,814 & 35,814 & 35,814 & 35,814 \\
\hline
\end{tabular}

Standard errors in parentheses ${ }^{*} p<0.05,{ }^{* *} p<0.01,{ }^{* * *} p<0.001$ 
Table 2.A2 Lagged fixed effects linear probability model of technology implementation on job ending

Model 16

Lagged effects

\begin{tabular}{lc}
\hline Technology lagged 1 year & $-0.002^{*}$ \\
& $(0.001)$ \\
Technology lagged 2 years & -0.001 \\
& $(0.001)$ \\
Technology lagged 3 years & $-0.002^{* * *}$ \\
& $(0.001)$ \\
(Ref: male) Gender & $0.007^{* * *}$ \\
& $(0.000)$ \\
(Ref: native Dutch) Non- & $0.006^{* * *}$ \\
Western immigrant & $(0.001)$ \\
background & \\
Western immigrant & $0.009^{* * *}$ \\
background & $(0.001)$ \\
Log enterprise size & $0.033^{* * * *}$ \\
& $(0.001)$ \\
Organizational innovation & $0.001^{*}$ \\
& $(0.001)$ \\
Yearly unemployment rate & $0.001^{* * *}$ \\
& $(0.000)$ \\
Constant & $-0.096^{* * *}$ \\
& $(0.009)$ \\
\hline Observations & $3,443,178$ \\
Enterprises & 13,085 \\
\hline
\end{tabular}

Standard errors in parentheses

${ }^{*} p<0.05,{ }^{* *} p<0.01,{ }^{* * *} p<0.001$ 
Table 2.A3 Fixed effects linear probability model of technology implementation on job ending, with routineness of jobs

\begin{tabular}{lc}
\hline & $\begin{array}{c}\text { Model 17 } \\
\text { Routineness of } \\
\text { occupation }\end{array}$ \\
\hline Technology & $-0.055^{* * *}$ \\
& $(0.007)$ \\
Routineness occupation & $-0.004^{* * *}$ \\
Routineness occupation* & $(0.001)$ \\
Technology & 0.002 \\
Organizational tenure & $(0.002)$ \\
& $-0.003^{* * *}$ \\
Organizational tenure* & $(0.000)$ \\
Technology & $0.001^{* *}$ \\
Age & $(0.000)$ \\
Age* Technology & $-0.003^{* * *}$ \\
(Ref: male) Gender & $(0.000)$ \\
(Ref: native Dutch) Non- & $0.001^{* * *}$ \\
Western immigrant & $(0.000)$ \\
background & -0.003 \\
Western immigrant & $(0.002)$ \\
background & 0.005 \\
Yearly unemployment rate & $(0.004)$ \\
Organizational innovation & \\
Enterprises & $0.008^{* *}$ \\
\hline Stanstant & $(0.003)$ \\
& $0.002^{*}$ \\
& $(0.001)$ \\
& -0.001 \\
& $(0.003)$ \\
& $0.278^{* * *}$ \\
& $(0.006)$ \\
\hline & 174,314 \\
& 20,642 \\
\hline
\end{tabular}

Standard errors in parentheses

${ }^{*} p<0.05,{ }^{* *} p<0.01,{ }^{* * *} p<0.001$ 
Table 2.A4 Fixed effects linear probability model of technology implementation on job ending with selections

\begin{tabular}{|c|c|c|c|c|}
\hline & $\begin{array}{c}\text { Model } 18 \\
\text { No selection }\end{array}$ & $\begin{array}{l}\text { Model } 19 \\
\text { Selection } \\
\text { education } \\
\end{array}$ & $\begin{array}{c}\text { Model } 20 \\
\text { Selection job } \\
\text { type }\end{array}$ & $\begin{array}{c}\text { Model 21 } \\
\text { All selections }\end{array}$ \\
\hline Technology & $\begin{array}{l}-0.003^{* * *} \\
(0.000)\end{array}$ & $\begin{array}{l}-0.003^{* * *} \\
(0.000)\end{array}$ & $\begin{array}{c}-0.014^{* * *} \\
(0.000)\end{array}$ & $\begin{array}{l}-0.014^{* * *} \\
(0.000)\end{array}$ \\
\hline Age & $\begin{array}{c}-0.004^{* * *} \\
(0.000)\end{array}$ & $\begin{array}{c}-0.005^{* * * *} \\
(0.000)\end{array}$ & $\begin{array}{c}-0.005^{* * *} \\
(0.000)\end{array}$ & $\begin{array}{c}-0.005^{* * *} \\
(0.000)\end{array}$ \\
\hline Age* Technology & $\begin{array}{l}0.000^{* * *} \\
(0.000)\end{array}$ & $\begin{array}{l}0.000^{* * *} \\
(0.000)\end{array}$ & $\begin{array}{l}0.001^{* * *} \\
(0.000)\end{array}$ & $\begin{array}{l}0.001^{* * *} \\
(0.000)\end{array}$ \\
\hline (Ref: male) Gender & $\begin{array}{l}0.006^{* * *} \\
(0.000)\end{array}$ & $\begin{array}{l}0.011^{* * *} \\
(0.000)\end{array}$ & $\begin{array}{l}0.000^{*} \\
(0.000)\end{array}$ & $\begin{array}{l}0.005^{* * *} \\
(0.000)\end{array}$ \\
\hline (Ref: native Dutch) & $0.020^{* * * *}$ & $0.018^{* * *}$ & $0.035^{* * *}$ & $0.036^{* * *}$ \\
\hline $\begin{array}{l}\text { Non-Western } \\
\text { immigrant background }\end{array}$ & $(0.000)$ & $(0.000)$ & $(0.000)$ & $(0.000)$ \\
\hline $\begin{array}{l}\text { Western immigrant } \\
\text { background }\end{array}$ & $\begin{array}{l}0.016^{* * *} \\
(0.000)\end{array}$ & $\begin{array}{l}0.013^{* * *} \\
(0.000)\end{array}$ & $\begin{array}{l}0.023^{* * *} \\
(0.000)\end{array}$ & $\begin{array}{l}0.022^{* * *} \\
(0.000)\end{array}$ \\
\hline $\begin{array}{l}\text { Yearly unemployment } \\
\text { rate }\end{array}$ & $\begin{array}{l}-0.001^{* * *} \\
(0.000)\end{array}$ & $\begin{array}{l}-0.000 \\
(0.000)\end{array}$ & $\begin{array}{l}0.000^{* *} \\
(0.000)\end{array}$ & $\begin{array}{l}0.002^{* * *} \\
(0.000)\end{array}$ \\
\hline $\begin{array}{l}\text { Organizational } \\
\text { innovation }\end{array}$ & $\begin{array}{l}-0.006^{* * *} \\
(0.000)\end{array}$ & $\begin{array}{c}-0.007^{* * *} \\
(0.000)\end{array}$ & $\begin{array}{l}0.003^{* * *} \\
(0.000)\end{array}$ & $\begin{array}{l}0.003^{* * *} \\
(0.000)\end{array}$ \\
\hline Constant & $\begin{array}{l}0.241^{* * * *} \\
(0.000)\end{array}$ & $\begin{array}{l}0.264^{* * *} \\
(0.000)\end{array}$ & $\begin{array}{l}0.203^{* * *} \\
(0.000)\end{array}$ & $\begin{array}{l}0.220^{* * *} \\
(0.001)\end{array}$ \\
\hline Observations & $43,505,187$ & $30,845,478$ & $24,778,508$ & $16,614,116$ \\
\hline Enterprises & 37,303 & 37,220 & 36,990 & 36,903 \\
\hline
\end{tabular}

Standard errors in parentheses

${ }^{*} p<0.05,{ }^{* *} p<0.01,{ }^{* * *} p<0.001$ 
Table 3.A1 Test of proportional hazard assumption using Schoenfeld residual test

\begin{tabular}{|c|c|c|c|c|c|}
\hline & rho & Chi2 & df & Prob $>$ chi 2 & observations \\
\hline Technology & 0.023 & 22978.90 & 1 & 0.000 & $1,556,065$ \\
\hline (Ref: higher education) & & & 1 & 0.000 & $1,556,065$ \\
\hline Lower education & 0.092 & 151501.29 & & & \\
\hline Lower education* & 0.064 & 141508.09 & 1 & 0.000 & $1,556,065$ \\
\hline \multicolumn{6}{|l|}{ Technology } \\
\hline Middle education & 0.039 & 10581.32 & 1 & 0.000 & $1,556,065$ \\
\hline Middle education* & 0.029 & 10142.13 & 1 & 0.000 & $1,556,065$ \\
\hline \multicolumn{6}{|l|}{ Technology } \\
\hline Organizational tenure & -0.058 & 113126.22 & 1 & 0.000 & $1,556,065$ \\
\hline Organizational tenure* & -0.004 & 392.38 & 1 & 0.000 & $1,556,065$ \\
\hline \multicolumn{6}{|l|}{ Technology } \\
\hline Age & 0.127 & 732133.71 & 1 & 0.000 & $1,556,065$ \\
\hline Age* Technology & 0.037 & 44273.50 & 1 & 0.000 & $1,556,065$ \\
\hline Union density & -0.039 & 36565.51 & 1 & 0.000 & $1,556,065$ \\
\hline Union density* & -0.027 & 31449.49 & 1 & 0.000 & $1,556,065$ \\
\hline \multicolumn{6}{|l|}{ Technology } \\
\hline Part-time work & 0.055 & 105479.37 & 1 & 0.000 & $1,556,065$ \\
\hline $\begin{array}{l}\text { Having second job at } \\
\mathrm{t}=0\end{array}$ & 0.156 & $1.99 \mathrm{e}+06$ & 1 & 0.000 & $1,556,065$ \\
\hline (Ref: native Dutch) & & & 1 & 0.000 & $1,556,065$ \\
\hline $\begin{array}{l}\text { Non-Western } \\
\text { immigrant background }\end{array}$ & 0.132 & $1.12 \mathrm{e}+06$ & & & \\
\hline $\begin{array}{l}\text { Western immigrant } \\
\text { background }\end{array}$ & 0.116 & 220018.22 & 1 & 0.000 & $1,556,065$ \\
\hline (Ref: male) Gender & 0.101 & 141827.61 & 1 & 0.000 & $1,556,065$ \\
\hline Log enterprise size & 0.051 & 187446.13 & 1 & 0.000 & $1,556,065$ \\
\hline $\begin{array}{l}\text { Organizational } \\
\text { innovation }\end{array}$ & 0.021 & 11454.03 & 1 & 0.000 & $1,556,065$ \\
\hline $\begin{array}{l}\text { Yearly unemployment } \\
\text { rate }\end{array}$ & 0.053 & 74867.50 & 1 & 0.000 & $1,556,065$ \\
\hline Global test & & $2.59 \mathrm{e}+06$ & 19 & 0.000 & $1,556,065$ \\
\hline
\end{tabular}

With robust variance-covariance matrix 
Figure 3.A1 Kaplan-Meier survival curve of starting a new job by technology implementation within organizations

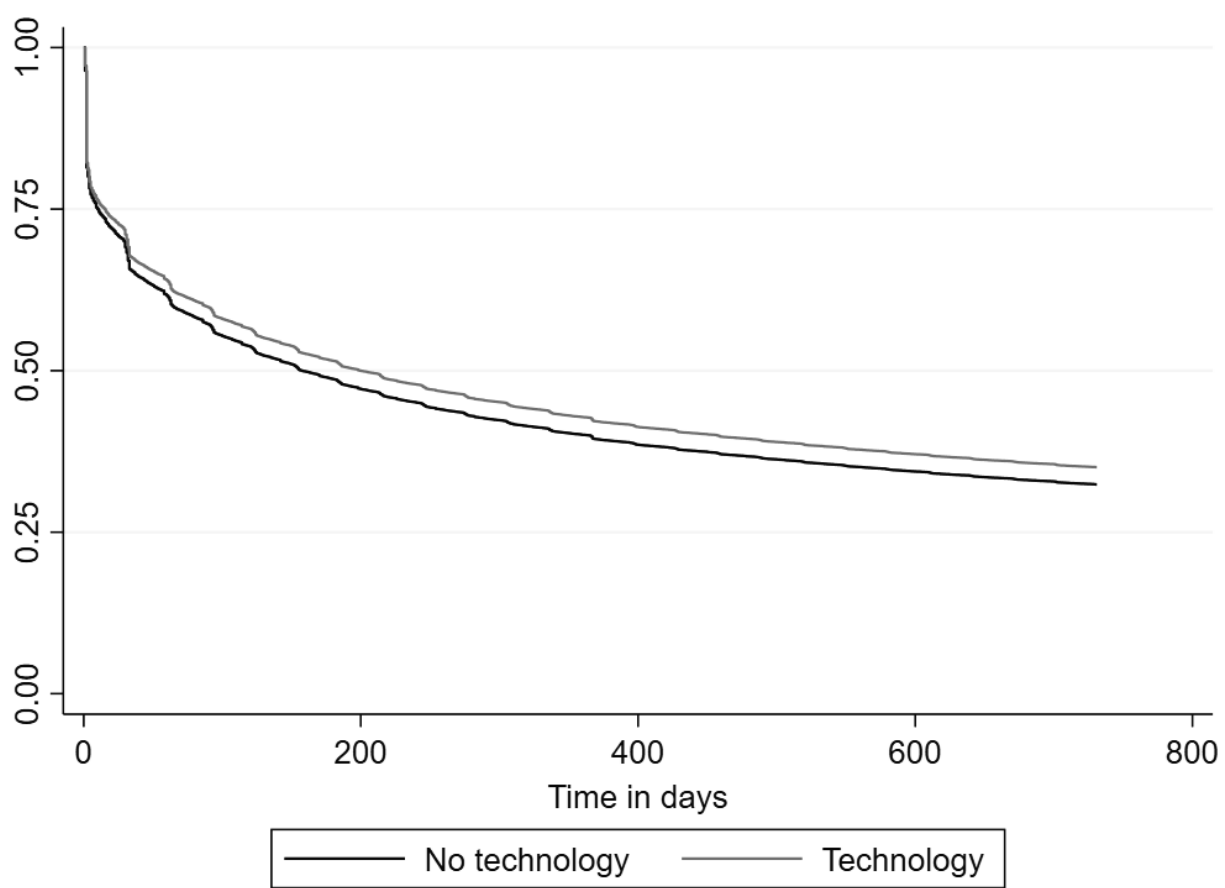


Appendix A |

Figure 3.A2 Kaplan-Meier survival curve of starting a new job by level of education

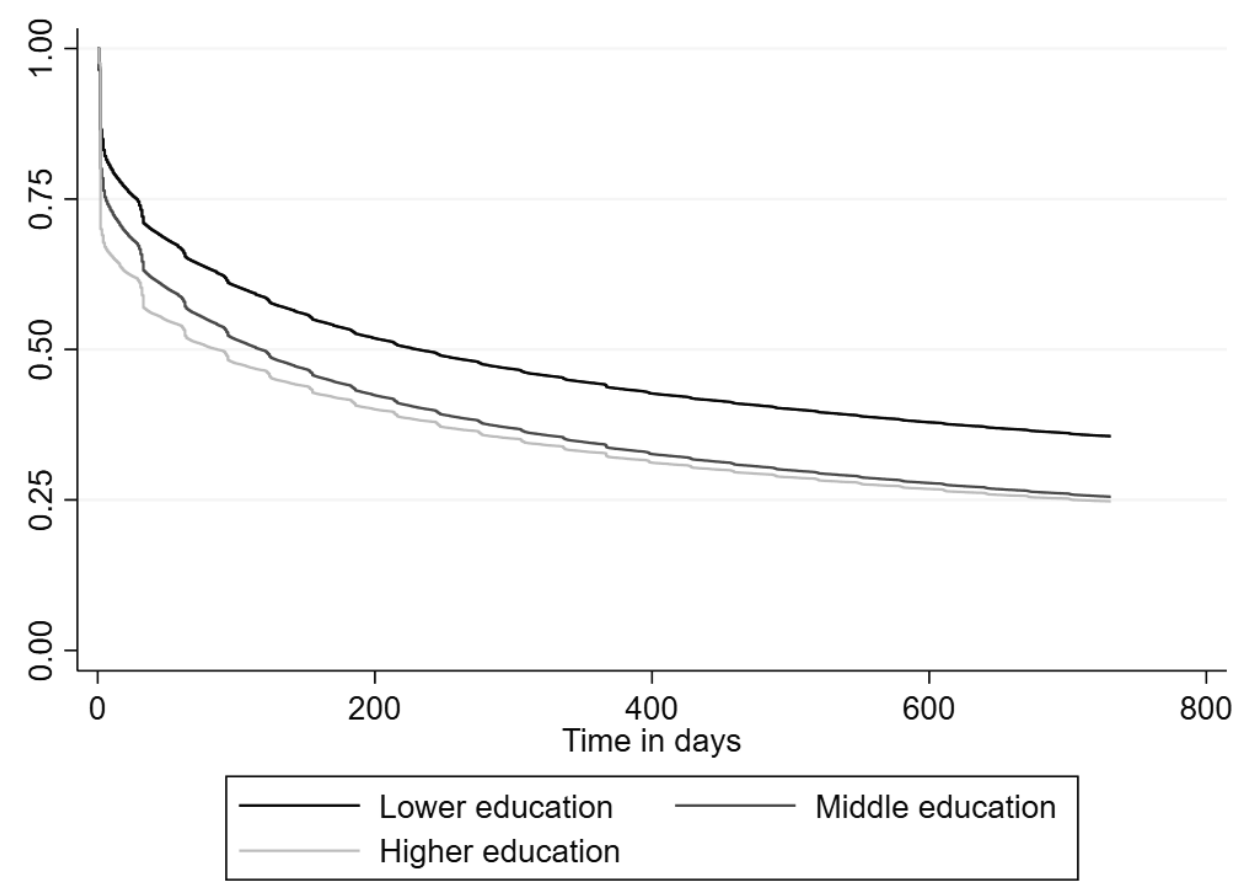


Figure 3.A3 Scaled Schoenfeld residual plot showing the deviation of the average Schoenfeld residuals from zero for the variable organizational tenure

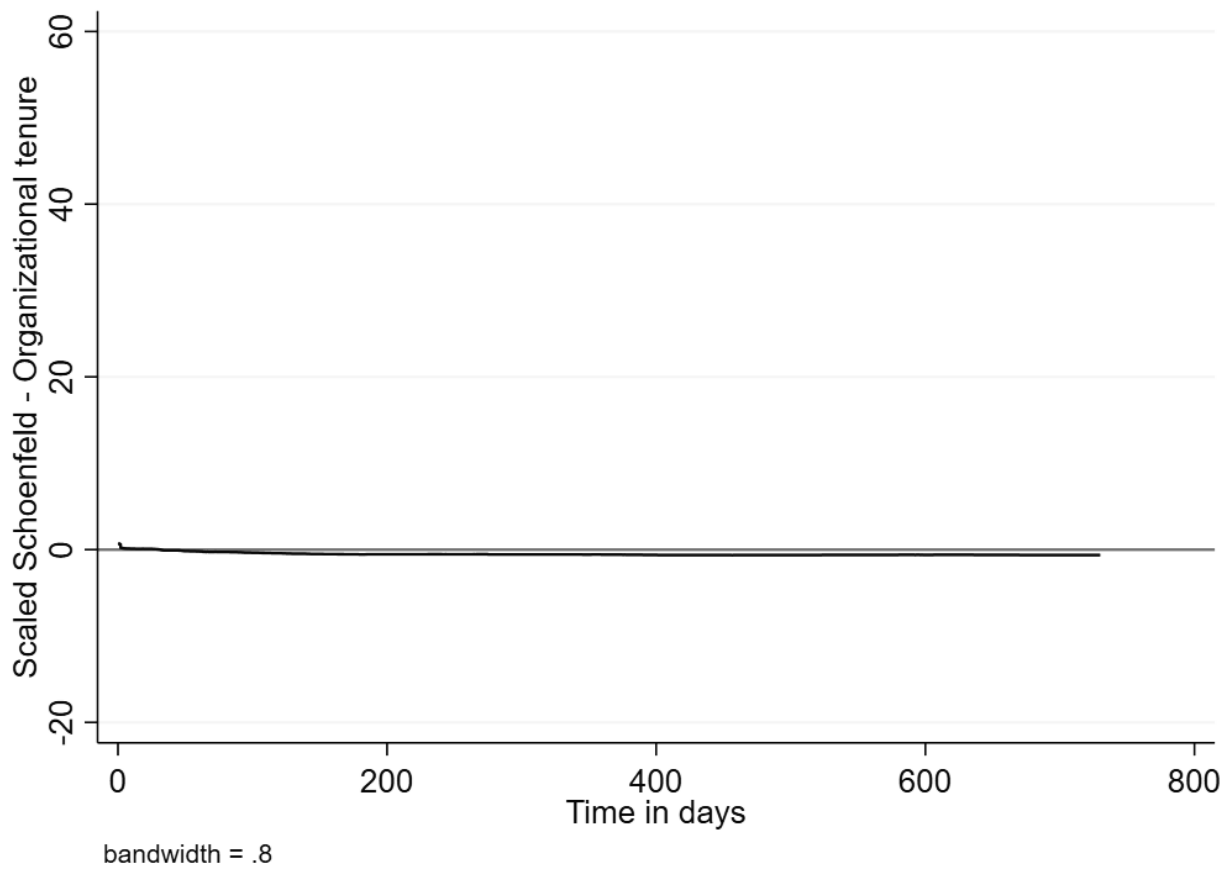

Due to the identifiability protocols of the Dutch Central Bureau of Statistics the plotted residuals cannot be shown 
Appendix A |

Figure 3.A4 Scaled Schoenfeld residual plot showing the deviation of the average Schoenfeld residuals from zero for the variable age

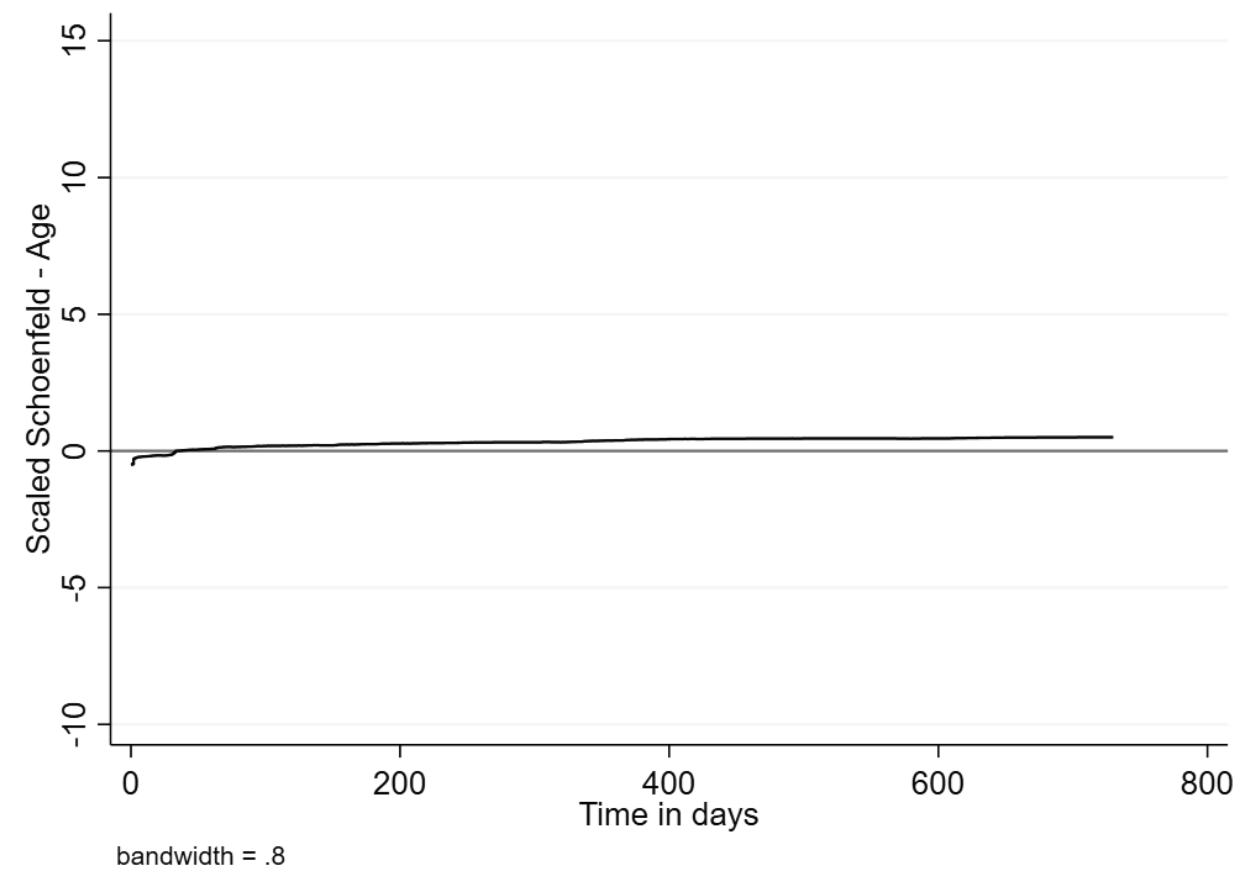

Due to the identifiability protocols of the Dutch Central Bureau of Statistics the plotted residuals cannot be shown 
Figure 3.A5 Scaled Schoenfeld residual plot showing the deviation of the average Schoenfeld residuals from zero for the variable union density

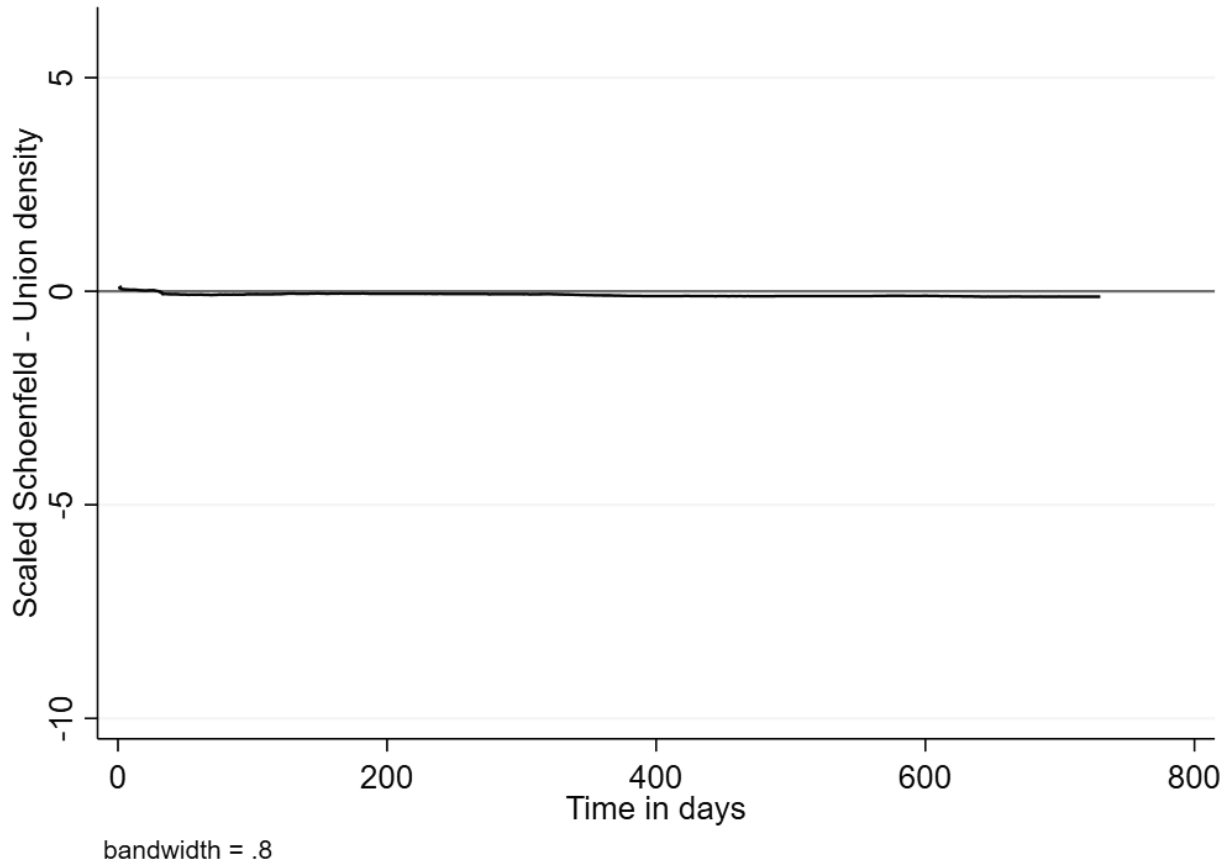

Due to the identifiability protocols of the Dutch Central Bureau of Statistics the plotted residuals cannot be shown 
Figure 3.A6 Scaled Schoenfeld residual plot showing the deviation of the average Schoenfeld residuals from zero for the variable part-time work

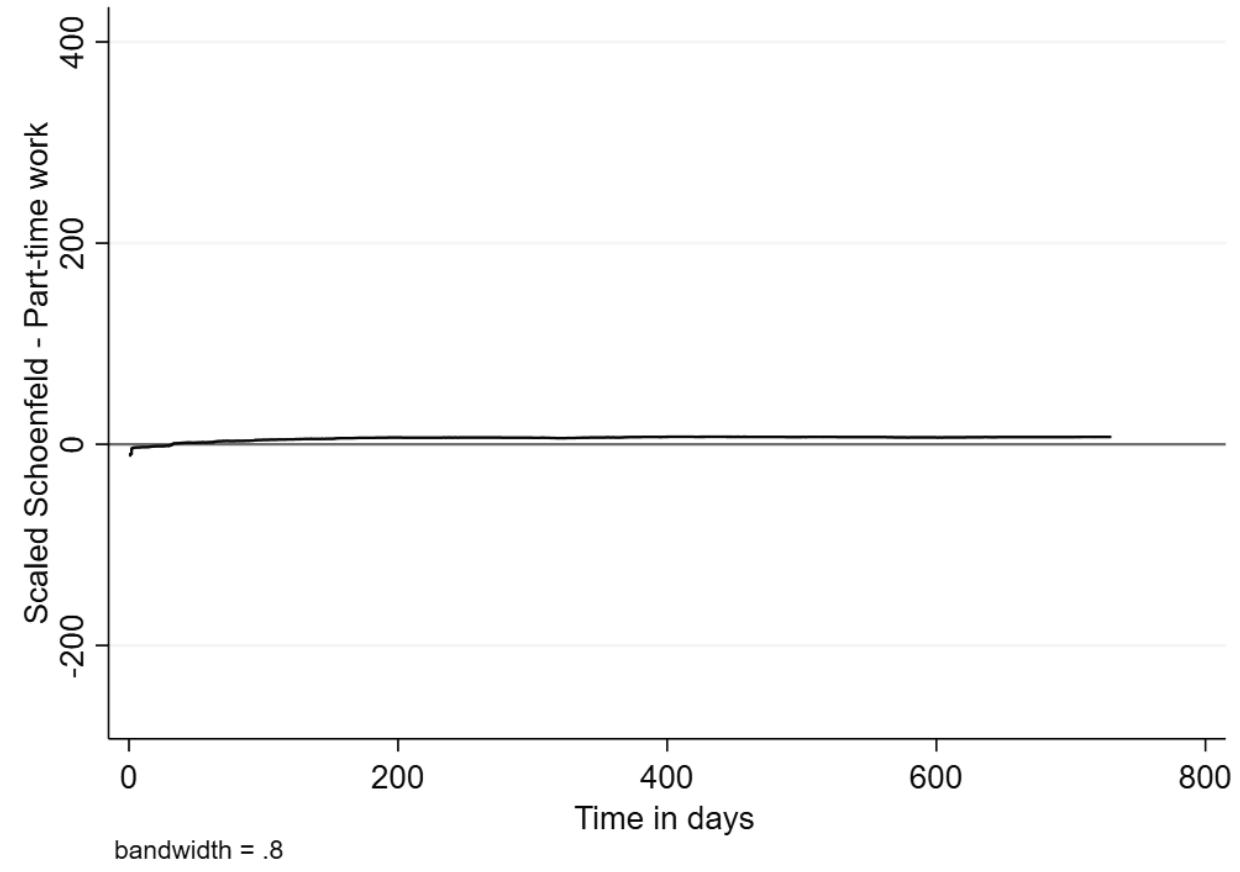

Due to the identifiability protocols of the Dutch Central Bureau of Statistics the plotted residuals cannot be shown 
Figure 3.A7 Kaplan-Meier survival curve of starting a new job by having a second job at $\mathrm{t}=0$

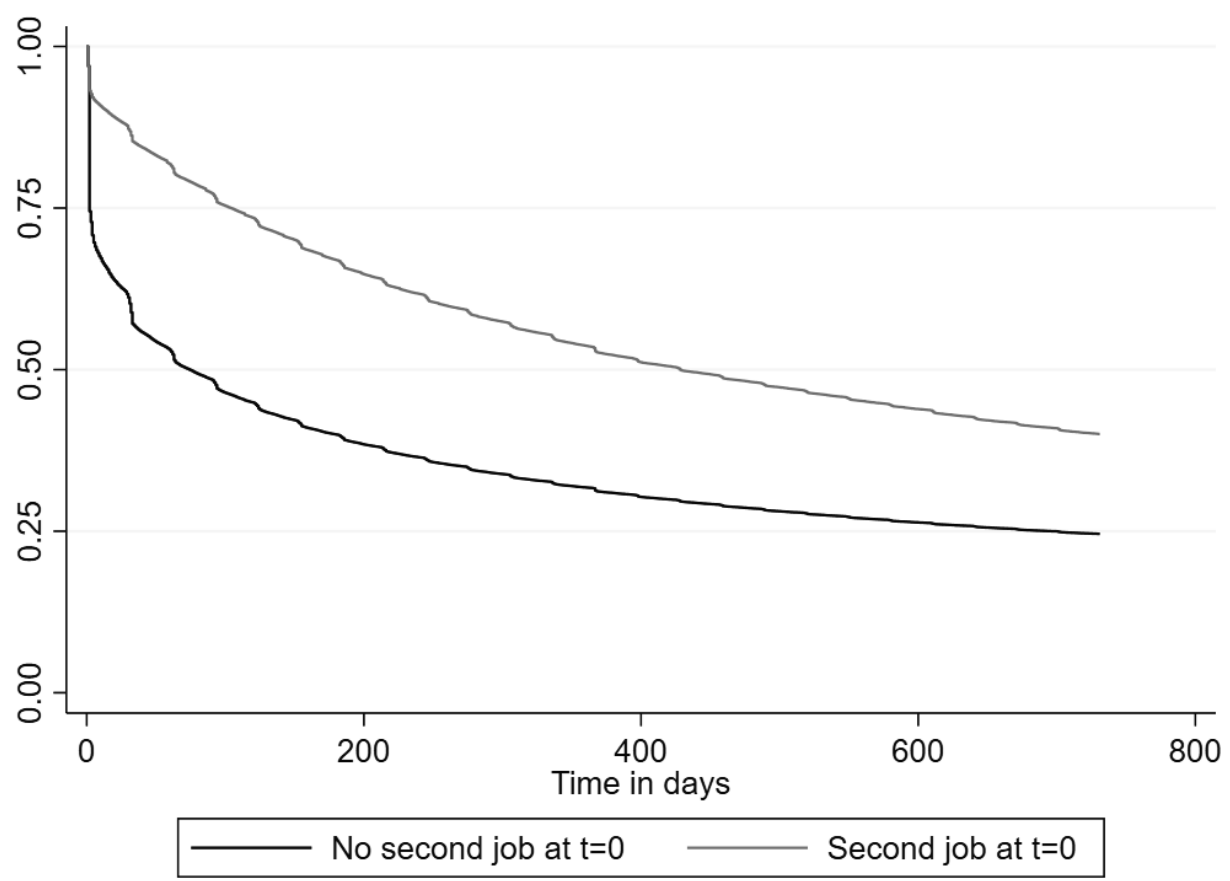


Appendix A |

Figure 3.A8 Kaplan-Meier survival curve of starting a new job by migration background

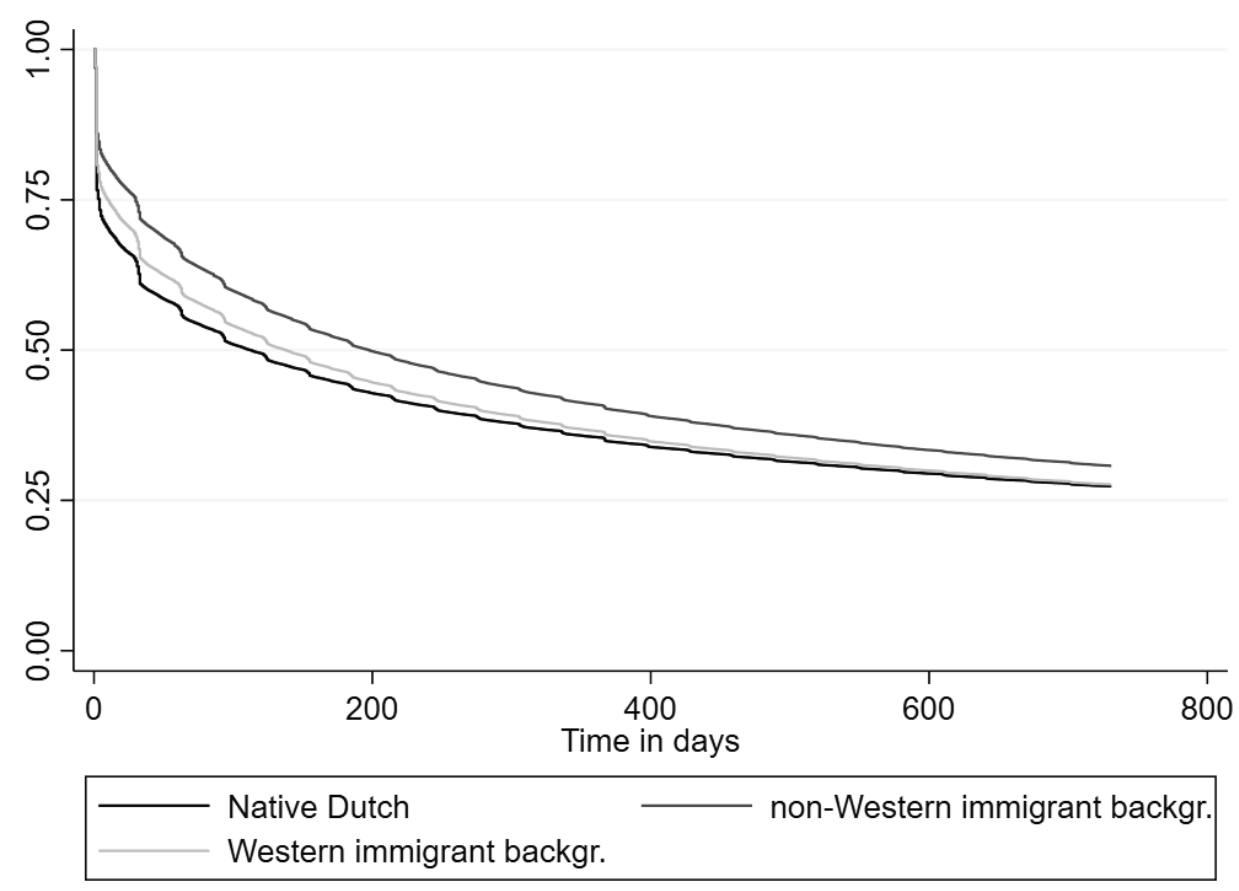


Figure 3.A9 Kaplan-Meier survival curve of starting a new job by gender

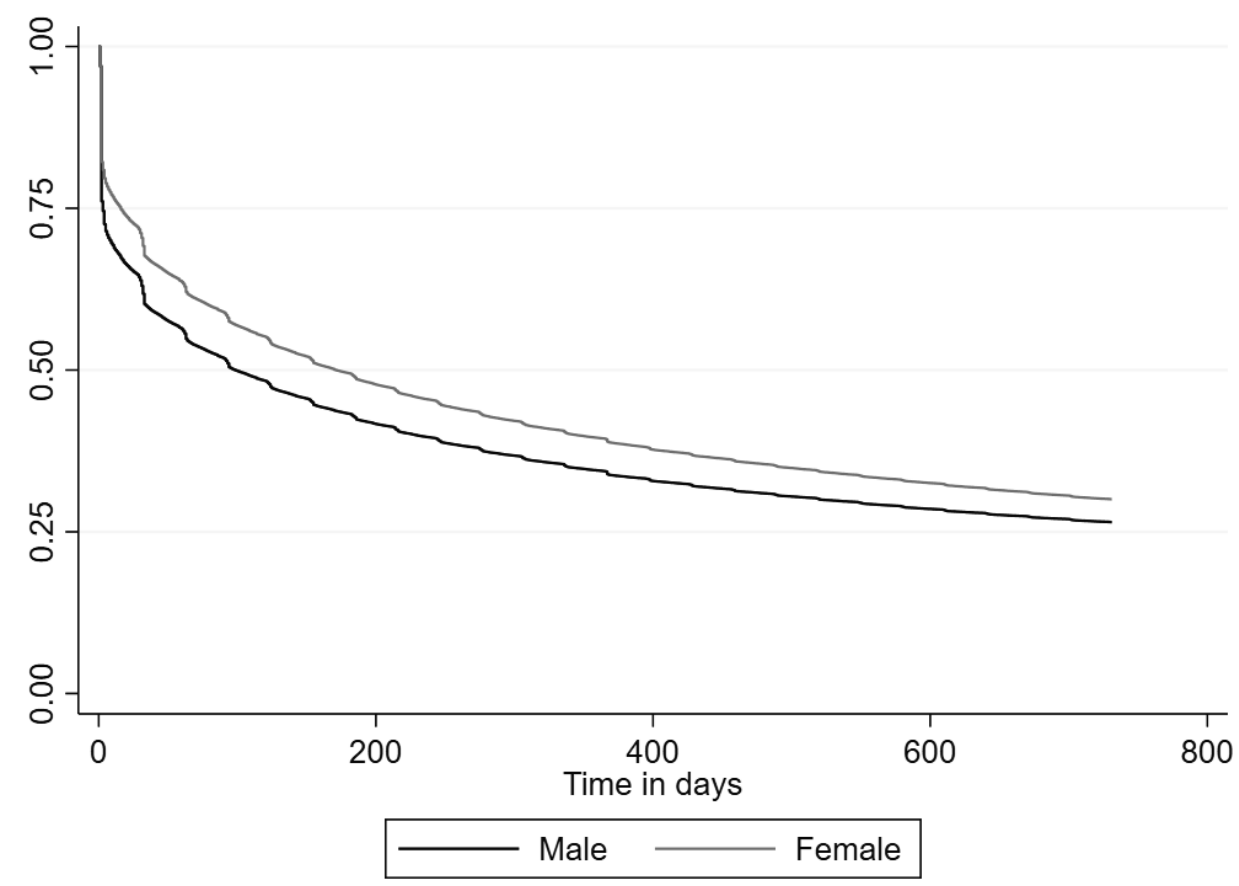


Figure 3.A10 Scaled Schoenfeld residual plot showing the deviation of the average Schoenfeld residuals from zero for the variable enterprise size

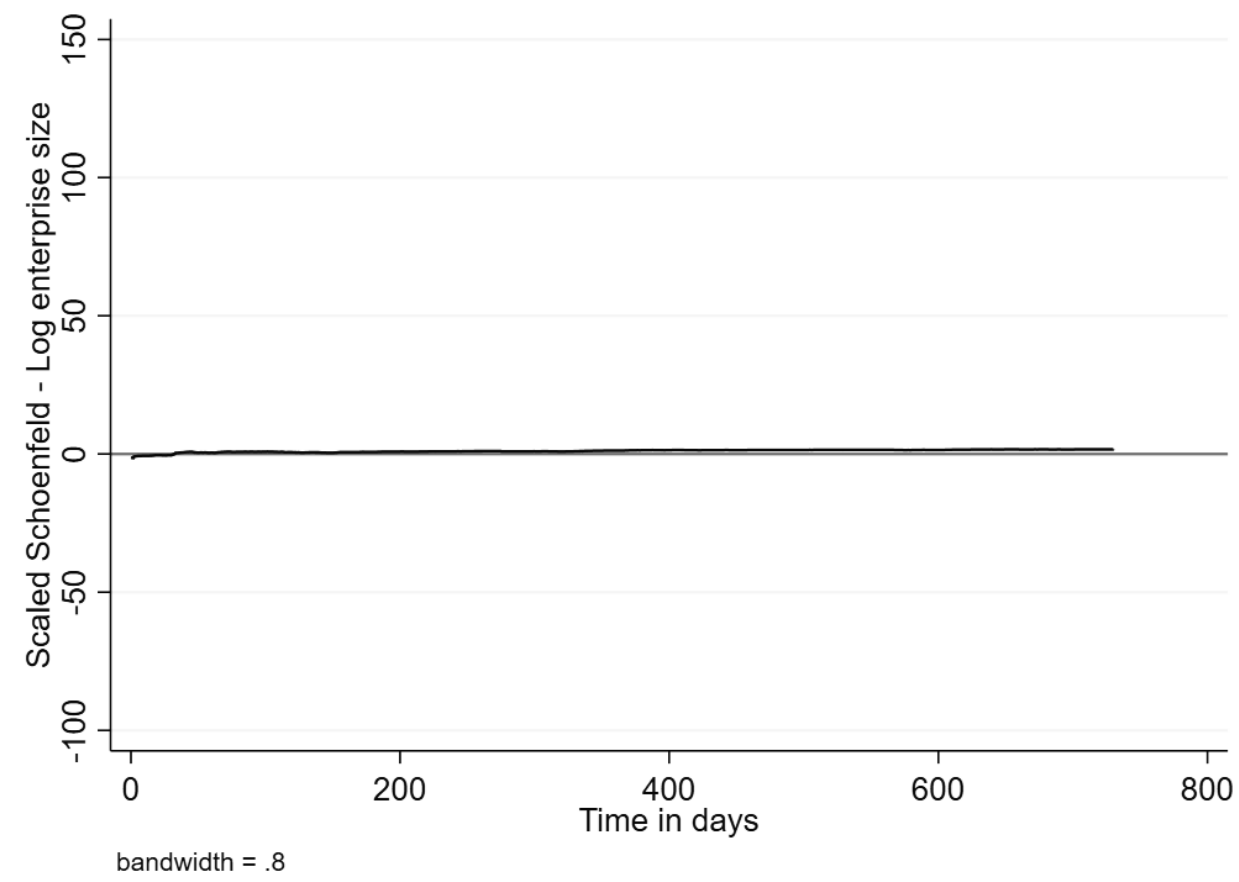

Due to the identifiability protocols of the Dutch Central Bureau of Statistics the plotted residuals cannot be shown 
Figure 3.A11 Kaplan-Meier survival curve of starting a new job by organizational innovation

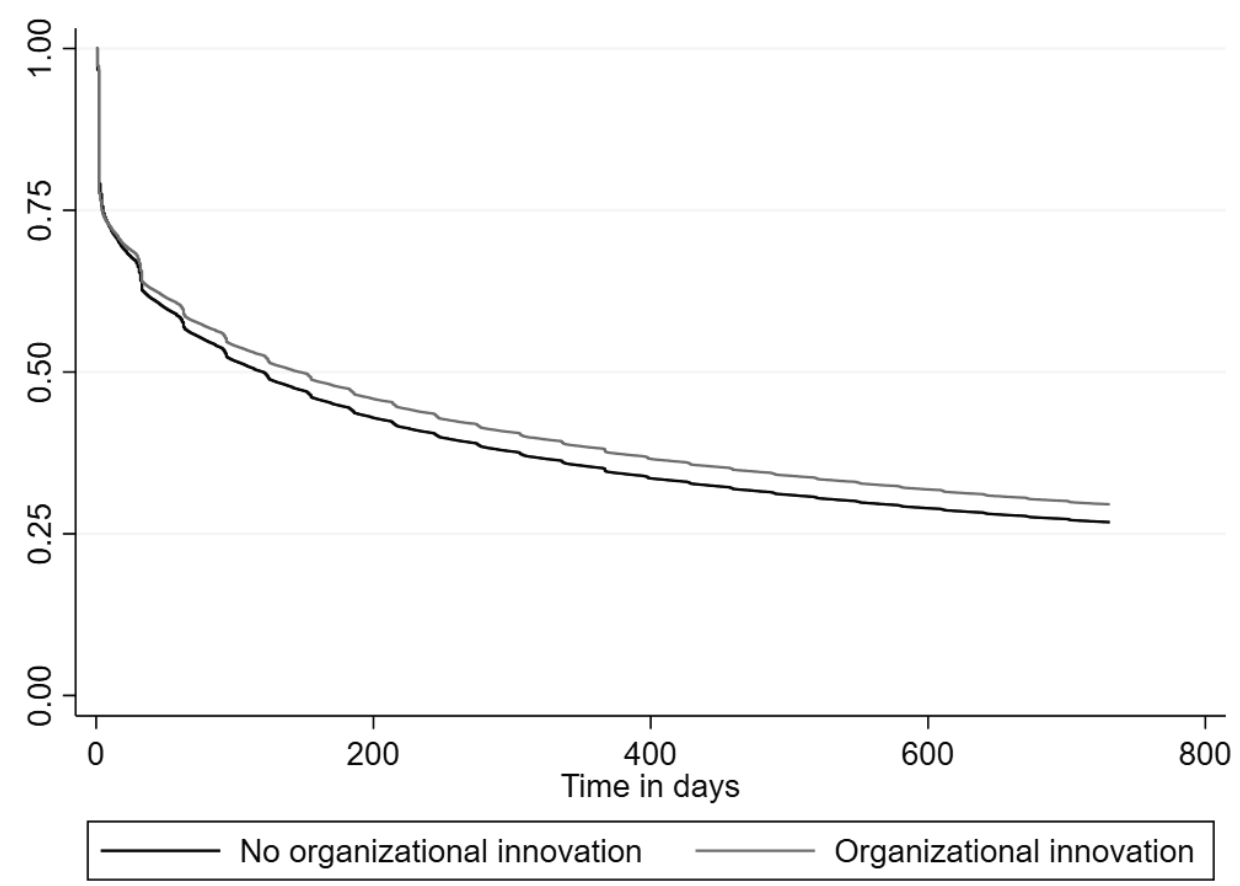


Figure 3.A12 Scaled Schoenfeld residual plot showing the deviation of the average Schoenfeld residuals from zero for the variable unemployment

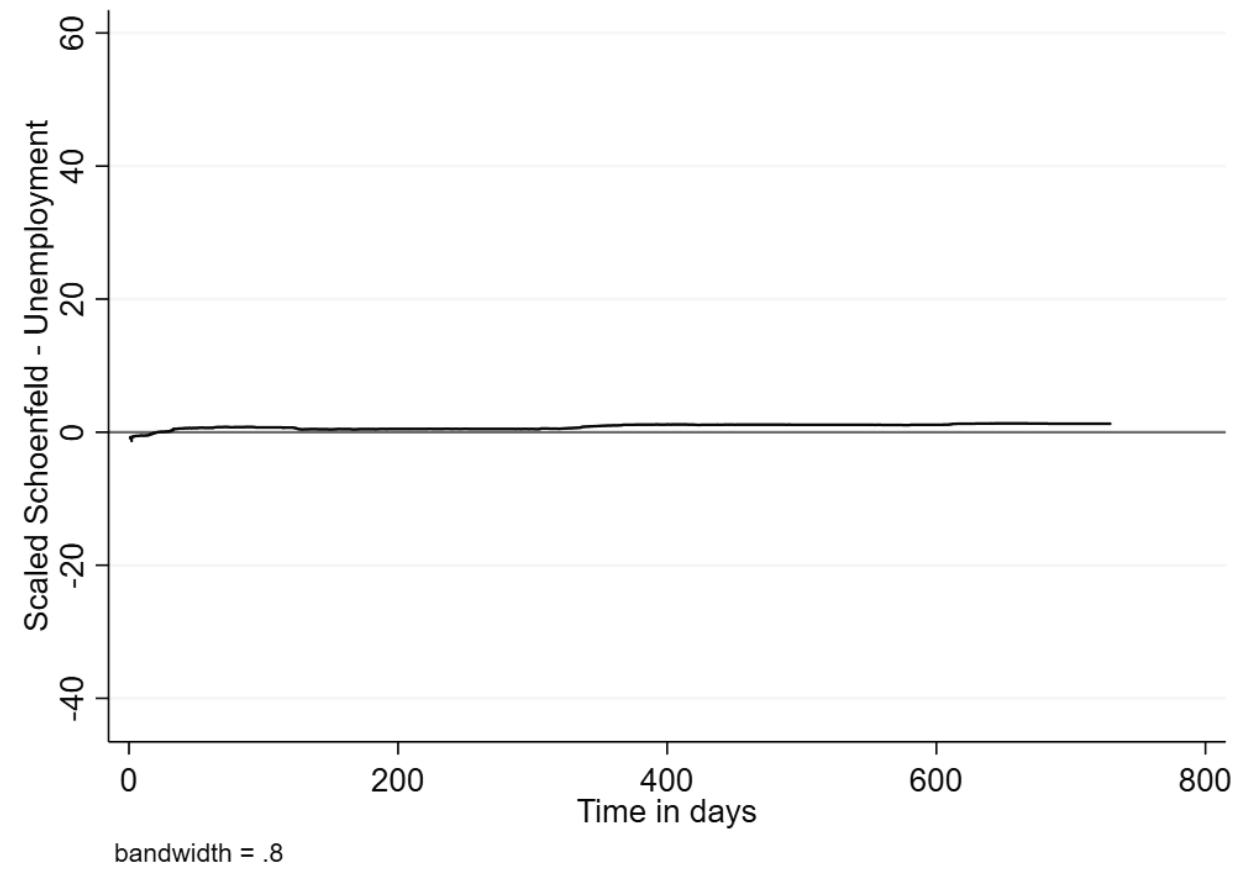

Due to the identifiability protocols of the Dutch Central Bureau of Statistics the plotted residuals cannot be shown 
| Appendix A 
Table 4.A1 Multilevel random effects models of technology implementation on the likelihood of job ending divided between observation periods and including fixed effects for enterprises

\begin{tabular}{|c|c|c|c|}
\hline & $\begin{array}{c}\text { Model } 9 \\
\text { Period 2001- } \\
2005\end{array}$ & $\begin{array}{c}\text { Model 10 } \\
\text { Period 2006- } \\
2010\end{array}$ & $\begin{array}{c}\text { Model 11 } \\
\text { Period 2011- } \\
2014\end{array}$ \\
\hline Technology & $\begin{array}{c}-0.027^{* * * *} \\
(0.001)\end{array}$ & $\begin{array}{c}-0.008^{* * *} \\
(0.001)\end{array}$ & $\begin{array}{c}-0.009^{* * * *} \\
(0.001)\end{array}$ \\
\hline (Ref: native Dutch) Non-Western & -0.000 & $0.002^{*}$ & $0.023^{* * * *}$ \\
\hline immigrant background & $(0.001)$ & $(0.001)$ & $(0.001)$ \\
\hline Non-Western immigrant background* & $0.014^{* * *}$ & -0.000 & $0.016^{* * * *}$ \\
\hline Technology & $(0.001)$ & $(0.001)$ & $(0.002)$ \\
\hline (Ref: lower education) Middle & $-0.010^{* * * *}$ & $-0.006^{* * *}$ & $0.006^{* * *}$ \\
\hline education & $(0.001)$ & $(0.001)$ & $(0.001)$ \\
\hline Higher education & $\begin{array}{c}0.001 \\
(0.001)\end{array}$ & $\begin{array}{c}-0.009^{* * * *} \\
(0.001)\end{array}$ & $\begin{array}{l}0.009^{* * * *} \\
(0.001)\end{array}$ \\
\hline Organizational tenure & $\begin{array}{c}-0.006^{* * * *} \\
(0.000)\end{array}$ & $\begin{array}{c}-0.005^{* * *} \\
(0.000)\end{array}$ & $\begin{array}{c}-0.004^{* * * *} \\
(0.000)\end{array}$ \\
\hline Age & $\begin{array}{c}-0.003^{* * * *} \\
(0.000)\end{array}$ & $\begin{array}{c}-0.002^{* * * *} \\
(0.000)\end{array}$ & $\begin{array}{c}-0.003^{* * * *} \\
(0.000)\end{array}$ \\
\hline (Ref: male) Gender & $\begin{array}{c}0.003^{* * *} \\
(0.001)\end{array}$ & $\begin{array}{c}-0.015^{* * *} \\
(0.000)\end{array}$ & $\begin{array}{c}-0.030^{* * * *} \\
(0.001)\end{array}$ \\
\hline Part-time work & $\begin{array}{c}0.111^{* * *} \\
(0.001)\end{array}$ & $\begin{array}{c}0.267^{* * * *} \\
(0.001)\end{array}$ & $\begin{array}{c}0.328^{* * * *} \\
(0.001)\end{array}$ \\
\hline Fixed-term contract & $\begin{array}{c}0.012^{* * *} \\
(0.001)\end{array}$ & $\begin{array}{c}0.037^{* * *} \\
(0.001)\end{array}$ & $\begin{array}{c}0.040^{* * * *} \\
(0.002)\end{array}$ \\
\hline Percentage Western immigrant & $\begin{array}{c}-0.002^{* * * *} \\
(0.000)\end{array}$ & $\begin{array}{c}0.002^{* * *} \\
(0.000)\end{array}$ & $\begin{array}{c}0.001^{\text {**** }} \\
(0.000)\end{array}$ \\
\hline Log enterprise size & $\begin{array}{c}0.015^{* * *} \\
(0.001)\end{array}$ & $\begin{array}{c}0.047^{* * * *} \\
(0.001)\end{array}$ & $\begin{array}{c}-0.028^{* * * *} \\
(0.002)\end{array}$ \\
\hline Percentage part-time workers & $\begin{array}{c}0.002^{* * *} \\
(0.000)\end{array}$ & $\begin{array}{c}0.000^{* * *} \\
(0.000)\end{array}$ & $\begin{array}{c}0.000 \\
(0.000)\end{array}$ \\
\hline Organizational innovation & $\begin{array}{c}0.012^{* * *} \\
(0.001)\end{array}$ & $\begin{array}{c}-0.006^{* * *} \\
(0.001)\end{array}$ & $\begin{array}{c}-0.007^{* * * *} \\
(0.001)\end{array}$ \\
\hline Unemployment & $\begin{array}{c}0.003^{* * *} \\
(0.000)\end{array}$ & $\begin{array}{c}0.018^{* * *} \\
(0.000)\end{array}$ & $\begin{array}{c}0.013^{* * *} \\
(0.000)\end{array}$ \\
\hline Constant & $\begin{array}{c}0.051^{* * *} \\
(0.000)\end{array}$ & $\begin{array}{c}0.061^{* * *} \\
(0.000)\end{array}$ & $\begin{array}{c}0.028^{* * *} \\
(0.001)\end{array}$ \\
\hline Constant individual level & $\begin{array}{c}0.006 \\
(0.000)\end{array}$ & $\begin{array}{c}0.003 \\
(0.000)\end{array}$ & $\begin{array}{c}0.001 \\
(0.000)\end{array}$ \\
\hline Residual variance & $\begin{array}{c}0.186 \\
(0.000)\end{array}$ & $\begin{array}{c}0.187 \\
(0.000)\end{array}$ & $\begin{array}{c}0.160 \\
(0.000)\end{array}$ \\
\hline $\begin{array}{l}\text { Observations } \\
\text { Enterprises }\end{array}$ & $\begin{array}{c}3,515,929 \\
3,836\end{array}$ & $\begin{array}{c}4,346,678 \\
4,830\end{array}$ & $\begin{array}{c}1.463 .652 \\
2,611\end{array}$ \\
\hline
\end{tabular}

Standard errors in parentheses

${ }^{*} p<0.05,{ }^{* *} p<0.01,{ }^{* * *} p<0.001$ 


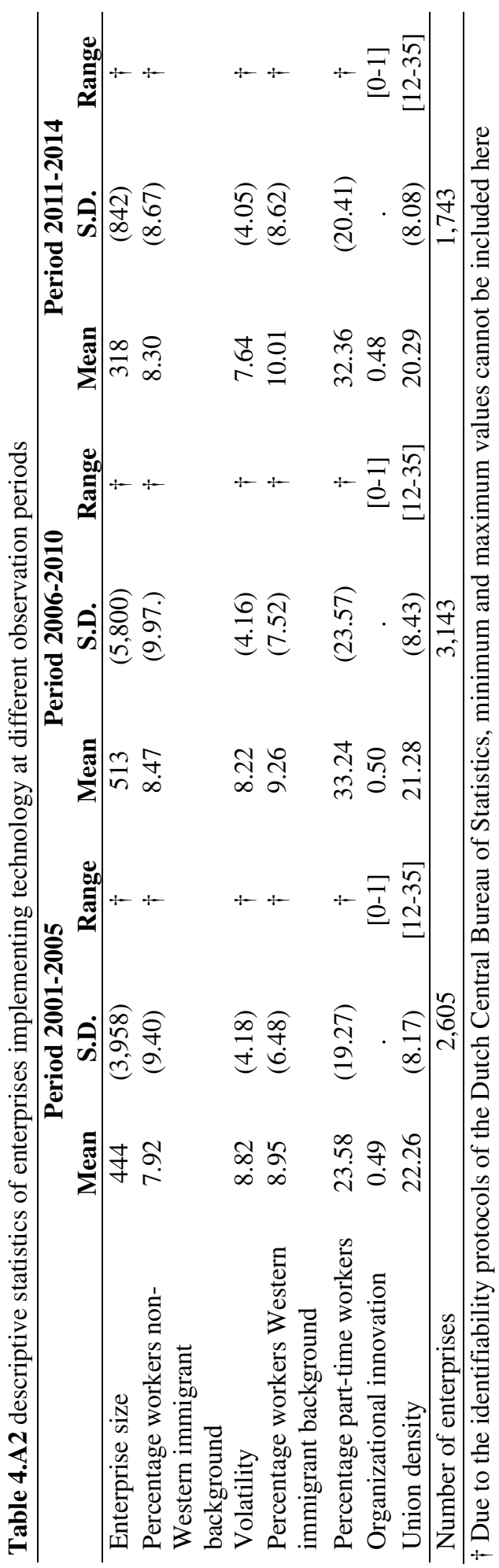


Table 4.A3 Fixed effects regression of technology implementation on the likelihood of job ending with human capital variables and fixed effects for enterprises

\begin{tabular}{|c|c|c|c|c|}
\hline & $\begin{array}{c}\text { Model } 12 \\
\text { Non- } \\
\text { Western } \\
\text { immigrant } \\
\text { background } \\
\end{array}$ & $\begin{array}{c}\text { Model } 13 \\
\text { Non- } \\
\text { Western } \\
\text { immigrant } \\
\text { generation }\end{array}$ & $\begin{array}{l}\text { Model } 14 \\
\text { Non- } \\
\text { Western } \\
\text { Dutch } \\
\text { language }\end{array}$ & $\begin{array}{c}\text { Model 15 } \\
\text { Immigrant } \\
\text { generation* } \\
\text { Dutch } \\
\text { language }\end{array}$ \\
\hline Technology & $\begin{array}{c}-0.014^{* * *} \\
(0.000)\end{array}$ & $\begin{array}{c}-0.014^{* * *} \\
(0.000)\end{array}$ & $\begin{array}{l}-0.014^{* * *} \\
(0.000)\end{array}$ & $\begin{array}{c}-0.014^{* * * *} \\
(0.000)\end{array}$ \\
\hline $\begin{array}{l}\text { (Ref: native Dutch) Non- } \\
\text { Western immigrant }\end{array}$ & $\begin{array}{l}0.006^{* * *} \\
(0.001)\end{array}$ & & & \\
\hline $\begin{array}{l}\text { Non-Western immigrant } \\
\text { background* Technology } \\
\text { Non-Western groups } \\
\text { decomposed into: }\end{array}$ & $\begin{array}{l}0.007^{* * * *} \\
(0.001)\end{array}$ & & & \\
\hline Second generation & & $\begin{array}{l}0.020^{* * *} \\
(0.001)\end{array}$ & & \\
\hline Second generation* Technology & & $\begin{array}{l}-0.002 \\
(0.001)\end{array}$ & & \\
\hline First generation & & $\begin{array}{c}-0.003^{* * *} \\
(0.001)\end{array}$ & & \\
\hline First generation* Technology & & $\begin{array}{l}0.011^{* * * *} \\
(0.001)\end{array}$ & & \\
\hline $\begin{array}{l}\text { Dutch speaking } \\
\text { (Surinamese/Antillean) }\end{array}$ & & & $\begin{array}{c}0.013^{* * *} \\
(0.001)\end{array}$ & \\
\hline Dutch speaking* Technology & & & $\begin{array}{c}0.001 \\
(0.001)\end{array}$ & \\
\hline Non-Dutch speaking (Rest) & & & $\begin{array}{l}0.002^{* *} \\
(0.001)\end{array}$ & \\
\hline $\begin{array}{l}\text { Non-Dutch speaking* } \\
\text { Technology }\end{array}$ & & & $\begin{array}{l}0.009^{* * *} \\
(0.001)\end{array}$ & \\
\hline $\begin{array}{l}\text { Second generation \& Dutch } \\
\text { speaking }\end{array}$ & & & & $\begin{array}{l}0.019^{* * *} \\
(0.001)\end{array}$ \\
\hline $\begin{array}{l}\text { Second generation \& Dutch } \\
\text { speaking* Technology }\end{array}$ & & & & $\begin{array}{l}-0.001 \\
(0.002)\end{array}$ \\
\hline $\begin{array}{l}\text { Second generation \& Non- } \\
\text { Dutch speaking }\end{array}$ & & & & $\begin{array}{c}0.020^{* * *} \\
(0.001)\end{array}$ \\
\hline $\begin{array}{l}\text { Second generation \& Non - } \\
\text { Dutch speaking* Technology }\end{array}$ & & & & $\begin{array}{l}-0.002 \\
(0.001)\end{array}$ \\
\hline $\begin{array}{l}\text { First generation \& Dutch } \\
\text { speaking }\end{array}$ & & & & $\begin{array}{c}0.008^{* * *} \\
(0.001)\end{array}$ \\
\hline $\begin{array}{l}\text { First generation \& Dutch } \\
\text { speaking* Technology }\end{array}$ & & & & $\begin{array}{c}0.003 \\
(0.002)\end{array}$ \\
\hline $\begin{array}{l}\text { First generation \& Non-Dutch } \\
\text { speaking }\end{array}$ & & & & $\begin{array}{c}-0.008^{* * *} \\
(0.001)\end{array}$ \\
\hline $\begin{array}{l}\text { First generation \& Non-Dutch } \\
\text { speaking* Technology }\end{array}$ & & & & $\begin{array}{l}0.015^{* * * *} \\
(0.001)\end{array}$ \\
\hline $\begin{array}{l}\text { (Ref: lower education) Middle } \\
\text { education }\end{array}$ & $\begin{array}{l}-0.006^{* * * *} \\
(0.000)\end{array}$ & $\begin{array}{c}-0.006^{* * *} \\
(0.000)\end{array}$ & $\begin{array}{c}-0.006^{* * *} \\
(0.000)\end{array}$ & $\begin{array}{c}-0.006^{* * *} \\
(0.000)\end{array}$ \\
\hline
\end{tabular}




\begin{tabular}{lcccc} 
Higher education & $-0.006^{* * *}$ & $-0.007^{* * * *}$ & $-0.006^{* * *}$ & $-0.007^{* * * *}$ \\
Organizational tenure & $(0.000)$ & $(0.000)$ & $(0.000)$ & $(0.000)$ \\
& $-0.005^{* * *}$ & $-0.005^{* * *}$ & $-0.005^{* * *}$ & $-0.005^{* * *}$ \\
Age & $(0.000)$ & $(0.000)$ & $(0.000)$ & $(0.000)$ \\
& $-0.002^{* * *}$ & $-0.002^{* * *}$ & $-0.002^{* * *}$ & $-0.002^{* * *}$ \\
(Ref: male) Gender & $(0.000)$ & $(0.000)$ & $(0.000)$ & $(0.000)$ \\
& $-0.011^{* * *}$ & $-0.011^{* * * *}$ & $-0.011^{* * *}$ & $-0.011^{* * * *}$ \\
Part-time work & $(0.000)$ & $(0.000)$ & $(0.000)$ & $(0.000)$ \\
& $0.217^{* * *}$ & $0.216^{* * *}$ & $0.217^{* * *}$ & $0.216^{* * *}$ \\
Fixed-term contract & $(0.001)$ & $(0.001)$ & $(0.001)$ & $(0.001)$ \\
& $0.033^{* * *}$ & $0.033^{* * *}$ & $0.033^{* * *}$ & $0.033^{* * *}$ \\
Percentage Western immigrant & $(0.001)$ & $(0.001)$ & $(0.001)$ & $(0.001)$ \\
& $0.000^{* *}$ & $0.000^{* *}$ & $0.000^{* *}$ & $0.000^{* *}$ \\
Log enterprise size & $(0.000)$ & $(0.000)$ & $(0.000)$ & $(0.000)$ \\
& $0.008^{* * *}$ & $0.008^{* * *}$ & $0.008^{* * *}$ & $0.008^{* * *}$ \\
Percentage part-time workers & $(0.001)$ & $(0.001)$ & $(0.001)$ & $(0.001)$ \\
& $0.001^{* * *}$ & $0.001^{* * *}$ & $0.001^{* * *}$ & $0.001^{* * *}$ \\
Organizational innovation & $(0.000)$ & $(0.000)$ & $(0.000)$ & $(0.000)$ \\
& $-0.002^{* * *}$ & $-0.002^{* * *}$ & $-0.002^{* * *}$ & $-0.002^{* * *}$ \\
Unemployment & $(0.000)$ & $(0.000)$ & $(0.000)$ & $(0.000)$ \\
Constant & $0.006^{* * *}$ & $0.006^{* * *}$ & $0.006^{* * *}$ & $0.006^{* * *}$ \\
& $(0.000)$ & $(0.000)$ & $(0.000)$ & $(0.000)$ \\
\hline Observations & $0.285^{* * * *}$ & $0.285^{* * *}$ & $0.285^{* * * *}$ & $0.285^{* * *}$ \\
Enterprises & $(0.007)$ & $(0.007)$ & $(0.007)$ & $(0.007)$ \\
\hline Standard & $9,843,454$ & $9,843,454$ & $9,843,454$ & $9,843,454$ \\
& 5,145 & 5,145 & 5,145 & 5,145 \\
\hline & & & &
\end{tabular}

Standard errors in parentheses

${ }^{*} p<0.05,{ }^{* *} p<0.01,{ }^{* * *} p<0.001$ 


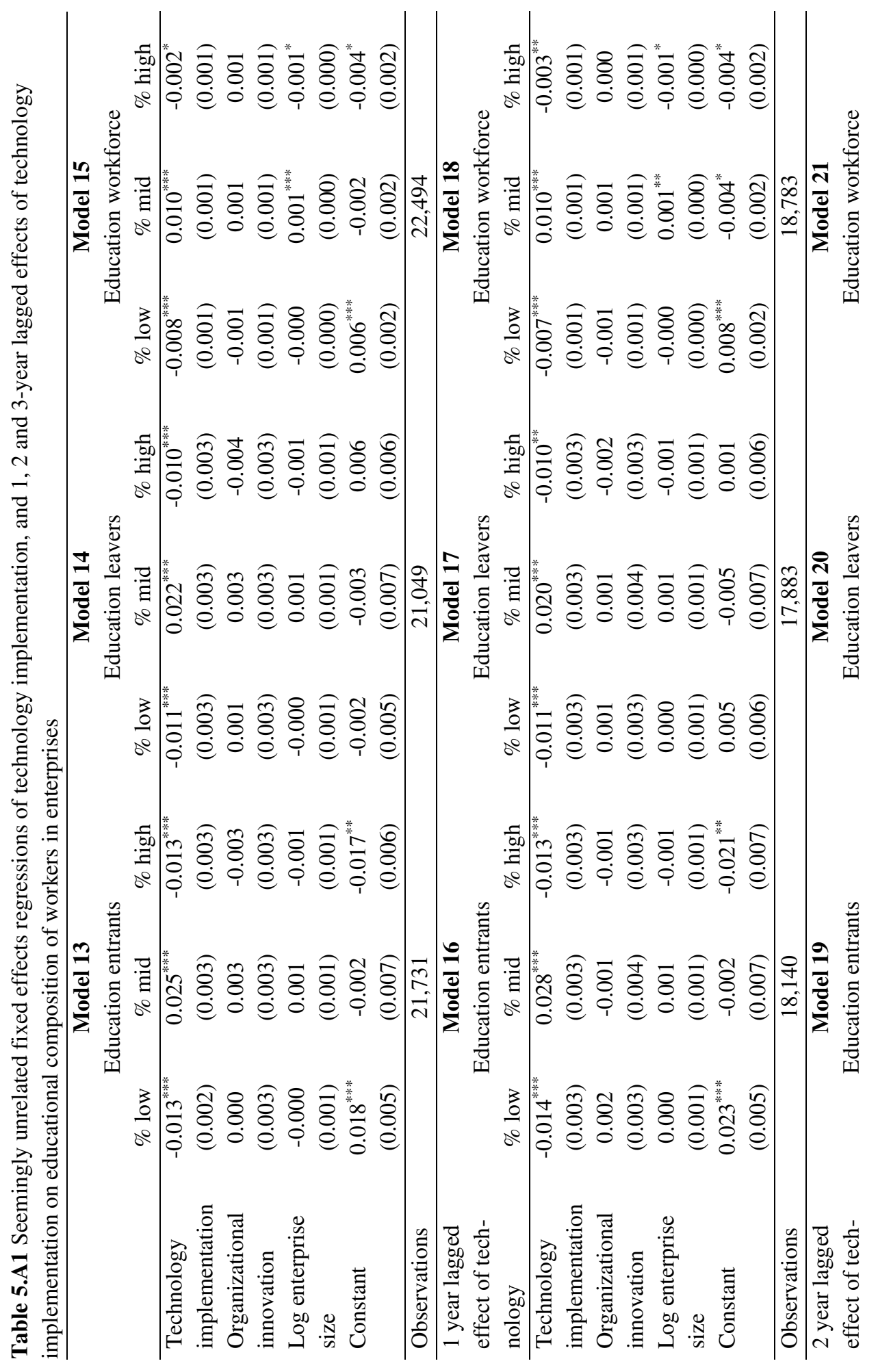




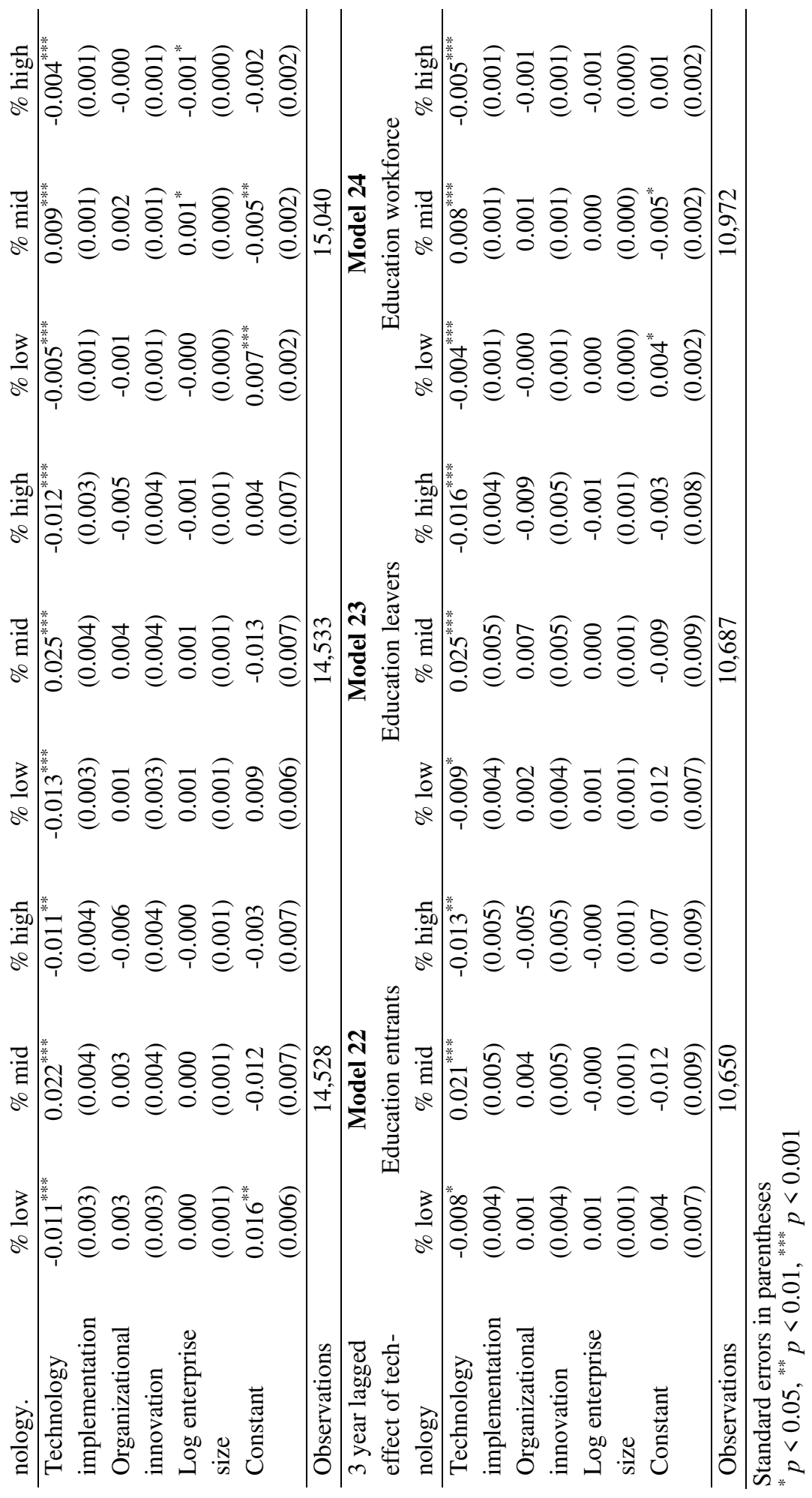




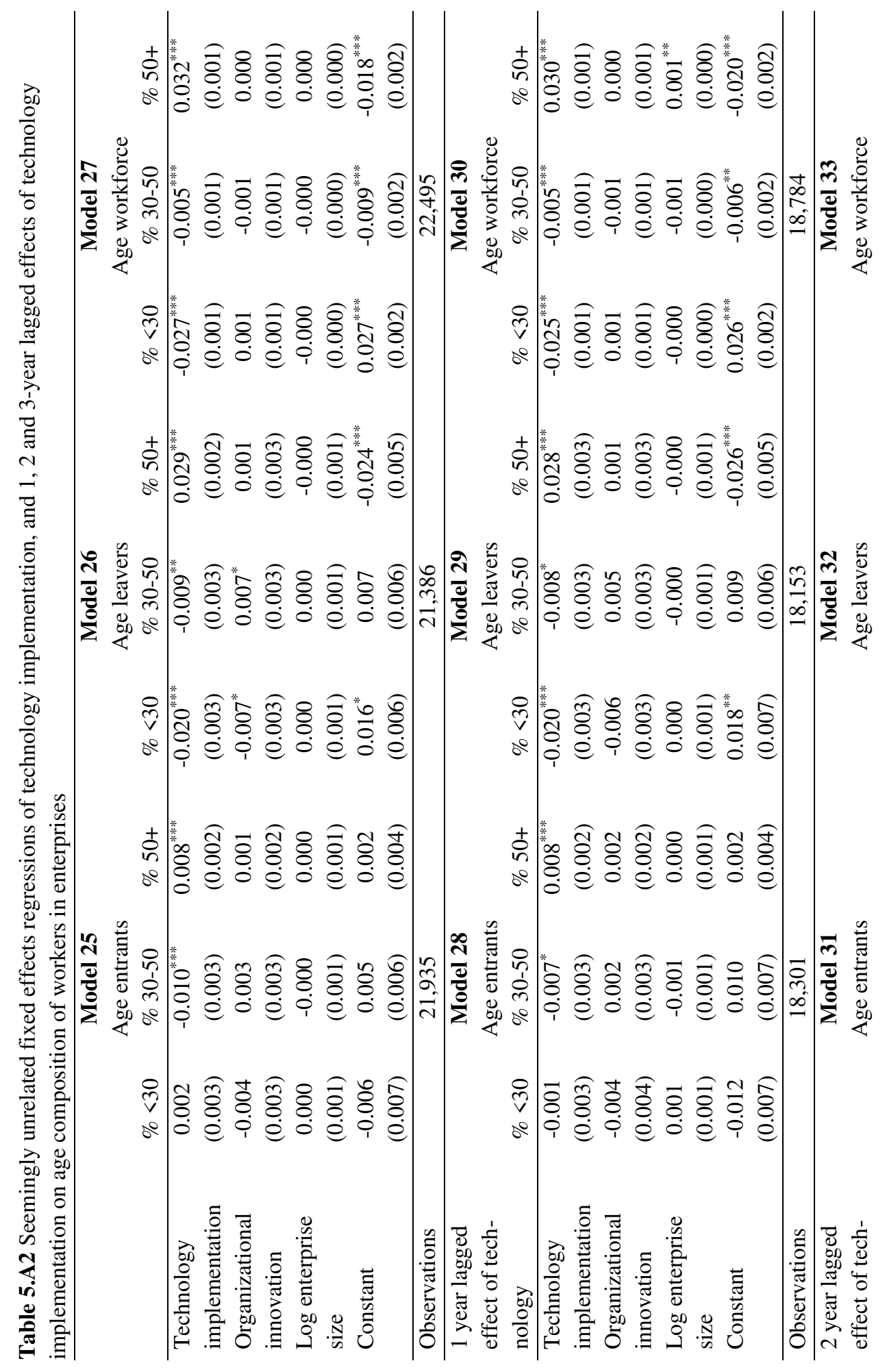




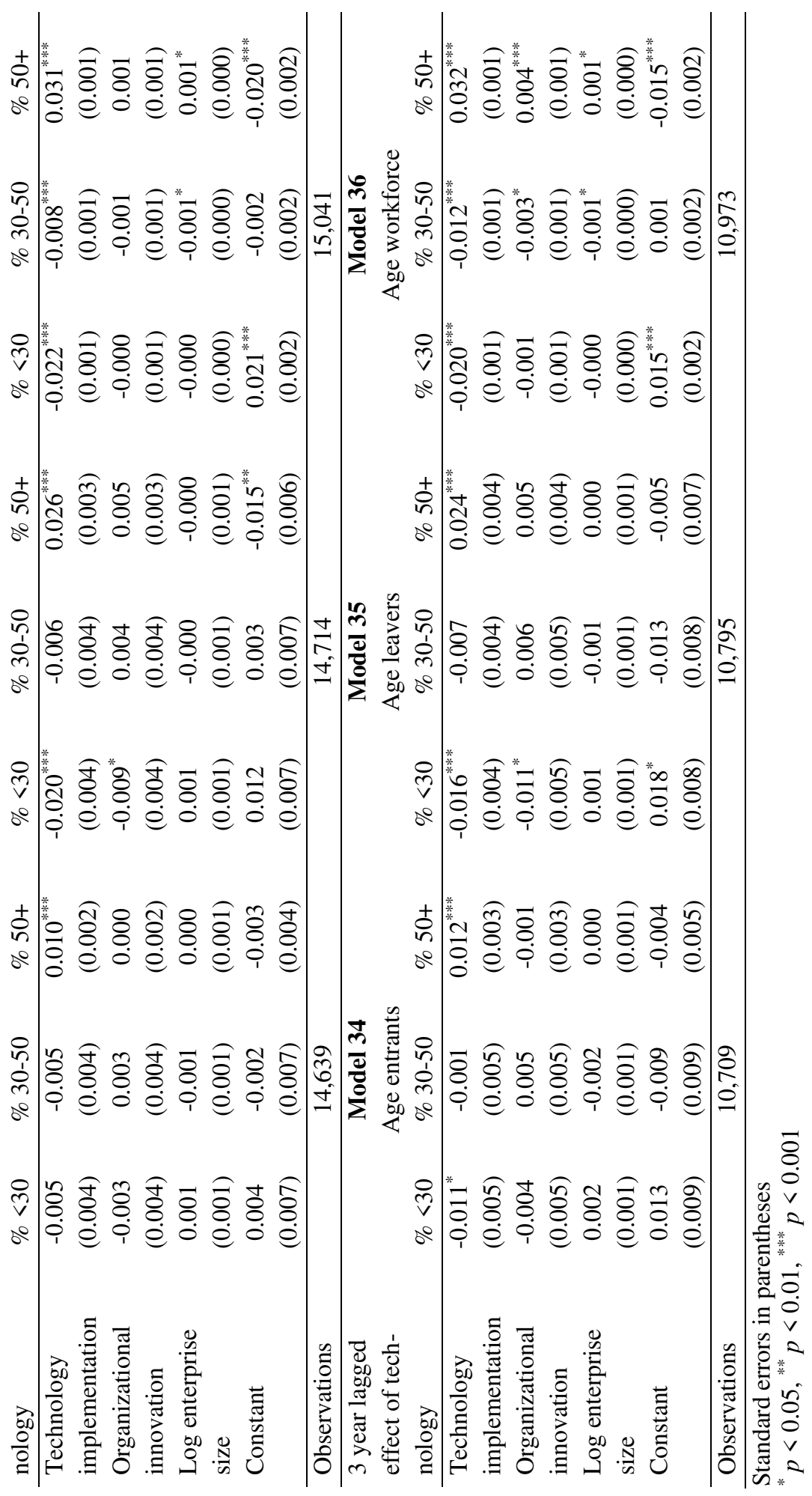



Appendix B 
The following section provides an elaboration of the main analyses of the dissertation. First, we provide an example regression clarifying the sometimes-confusing terms fixed and random effects. The example regression is closely related to most of the presented models. Furthermore, we provide examples of Stata syntax used to conduct the main analyses of the empirical chapters.

\section{Example regression for Table 2.2 Model 2 (with education interaction only)}

$\mathrm{Y}_{\mathrm{ijt}}=\alpha+\beta^{1} \times \mathrm{T}_{\mathrm{jt}}+\beta^{2} \times \mathrm{E}^{1}{ }_{\mathrm{it}}+\beta^{3} \times \mathrm{E}^{2}{ }_{\mathrm{it}}+\beta^{4} \mathrm{x}\left(\mathrm{E}_{\mathrm{it}}^{1} \mathrm{x} \mathrm{T}_{\mathrm{jt}}\right)+\beta^{5} \mathrm{x}\left(\mathrm{E}^{2}{ }_{\mathrm{it}} \times \mathrm{T}_{\mathrm{jt}}\right)+\boldsymbol{\beta}^{6 \ldots \mathrm{k}} \times \mathbf{C}_{\mathrm{ijt}}+\gamma^{1 \ldots \mathrm{j}} \mathrm{x}$ $\mathrm{O}_{\mathrm{j}}+\mu_{\mathrm{i}}+\mathrm{e}_{\mathrm{ijt}}$

Indices:

$\mathrm{i}$ - individuals

$\mathrm{j}$ - organisations

$\mathrm{t}$ - time

Model terms:

$\mathrm{Y}_{\mathrm{ijt}}-$ dependent variable job loss at time $t(0 / 1)$

$\alpha$ - intercept

$\mathrm{T}_{\mathrm{jt}}$ - technology implementation indicator $(0 / 1)$

$\beta^{1}$ - regression coefficient technology implementation

$\mathrm{E}^{1}{ }_{\text {it }}$ - indicator middle education ( $\mathrm{ref}=$ lower education)

$\mathrm{E}^{2}{ }_{\text {it }}$ - indicator higher education ( $\mathrm{ref}=$ lower education)

$\beta^{2}$ and $\beta^{3}$ - regression coefficients education

$\beta^{4}$ and $\beta^{5}$-regression coefficients interaction education-technology implementation

$\mathrm{C}_{\mathrm{ijt}}$ - covariates

$\mathbf{B}^{6} \ldots$...k - regression coefficients of $k$ model covariates

$\mathrm{O}_{\mathrm{j}}$-indicator variable for each of the $j$ organizations

$\gamma^{1 \ldots \mathrm{j}}$ - regression coefficients per indicator variable for each of the $j$ organizations

$\mu_{\mathrm{i}}-$ random intercept varying across $i$

$\mathrm{e}_{\mathrm{ijt}}$ - error term

In this example we include dummies for organizations to account for time invariant characteristics of organizations (fixed effects). At the individual level we include random intercepts (random effect). Because estimating the regression with $30.000+$ dummies is unfeasible we fixed the enterprise effects 'by hand'. This was achieved by subtracting the mean of each covariate at the enterprise level (over all time points) from the covariate at the individual level. These demeaned covariates were used to estimate the regression coefficients:

Stata syntax:

mixed mend c.mrmacvsall c.mISCEDhml2 c.mISCEDhml3 c.mrmacISCEDhml2 c.mrmacISCEDhml3 c.mgbageslacht c.methn2 c.methn3 c.mlogentsize c.minorg c.munemployment $\|$ rinpersoon: if ISCED2011! =. \& soortbaanid== "9"

$($ end $=$ job ending $)$ 
( rmac $=$ technological change $)$.

(ISCED = level of education $)$.

$(||$ rinpersoon $=$ random intercept at the individual level $)$

(please note that we estimated a slightly more parsimonious model to estimate the marginal effects (for technical reasons) as is indicated in the chapter. In this model we do not include a random intercept at the individual level. The fe command demeans the variable, the \#\# are used to create interaction effects, which was both done by hand in the above example).

\section{Stata syntax:}

xtreg jobend i.rmacvsall i.ISCEDhml2\#\#c.rmacvsall i.ISCEDhml3\#\#c.rmacvsall i.gbageslacht i.ethn i.inorg c.unemployment if ISCED2011! =. \& soortbaanid== "9", fe

\section{Examples of Stata syntax used to produce the main results of the empirical chapters}

\section{Chapter 2}

\section{Table $2.2 \mid$ model 5}

- Stata syntax

- distinct be_id

- local $d f=r($ ndistinct $)-1 / / d f$ due to be_id, minus 1

- mixed mend c.mrmacvsall c.mISCEDhml2 c.mrmacISCEDhml2 c.mISCEDhml3 c.mrmacISCEDhml3 c.mc_jobtenure c.mrmacjobtenure c.mage c.mrmacage c.mgbageslacht c.methn2 c.methn3 c.minorg c.munemployment || rinpersoon: if ISCED2011!=. \& soortbaanid $==" 9 "$

- est store mix 5

- mat $b=e(b)$

- scalar vadj $=(e(N)-2) /\left(e(N)-1-\left(' d f^{\prime}+1\right)\right)$

- matrix $V=v_{a d j} * e(V)$

- ereturn post $b V$

- ereturn display

\section{Table 2.3 | model 10}

- distinct be_id

- local $d f=r$ (ndistinct) $-1 / / d f$ due to be_id, minus 1

- mixed mend c.mrmacvsall c.vakb1993 mrmacvakb1993 c.mISCEDhml2 c.mrmacISCEDhml2 mvakbISCEDhml2 mtechvakbISCEDhml2 c.mISCEDhml3 c.mrmacISCEDhml3 mvakbISCEDhml3 mtechvakbISCEDhml3 mc_jobtenure mrmacjobtenure mvakbjobtenure mtechvakbjobtenure mage mrmacage mvakbage mtechvakbage c.mgbageslacht c.methn2 c.methn3 c.minorg c.munemployment \| rinpersoon: if ISCED2011!=. \& soortbaanid $==" 9 "$

- est store mix10

- $\operatorname{mat} b=e(b)$

- scalar vadj $=(e(N)-2) /\left(e(N)-1-\left(' d f^{\prime}+1\right)\right)$

- matrix $V=v_{a d j} *(V)$

- ereturn post $b V$ 
- ereturn display

Table 2.A1 | model 15

- xtreg end i.rmacvsall i.ISCEDhml2\#\#i.rmacvsall i.ISCEDhml3\#\#i.rmacvsall c.c_jobtenure\#\#i.rmacvsall c.c_age\#\#i.rmacvsall i.gbageslacht i.ethn i.inorg c.unemployment if ISCED2011! =. \& soortbaanid== "9", fe

- est store fe5

\section{Figure 2.1}

- est rfe5

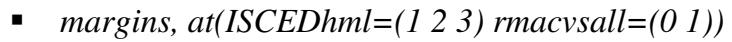

- marginsplot, noci

\section{Chapter 3}

\section{Table 3.2 $\mid$ model 6}

- stcox ISCEDhml\#\#i.rmacvsall c.c_jobtenure\#\#i.rmacvsall c.c_age2\#\#i.rmacvsall c.vakb1993\#\#i.rmacvsall c.deeltijd i.tweedebaan i.ethn i.gbageslacht i.inorg c.logentsize c.unemployment if soortbaanid=="9" \& ISCEDhml!=. \& vakb1993!=. , vce (cluster beid)

- est store cox7ioay

\section{Figure 3.1}

- est restore cox7ioay

- margins, at(c_age2=(-12.66(10)27.34) rmacvsall=(l0 1) $)$

- marginsplot

\section{Table 3.A1}

- stcox ISCEDhml\#\#i.rmacvsall c.c_jobtenure\#\#i.rmacvsall c.c_age2\#\#i.rmacvsall c.vakb1993\#\#i.rmacvsall c.deeltijd i.tweedebaan i.ethn i.gbageslacht i.inorg c.logentsize c.unemployment if soortbaanid=="9" \& ISCEDhml!=. \& vakb1993!=. \& age $>29 \&$ age $<68$, schoenfeld $\left(\mathrm{sch}^{*}\right)$ scaledsch $\left(\mathrm{sca}^{*}\right)$ vce(cluster beid) stphtest, detail

\section{Chapter 4}

\section{Table $4.2 \mid$ model 4}

- distinct be_id

- $\quad$ local $\mathrm{df}=\mathrm{r}$ (ndistinct) -1

- mixed mend c.mrmacvsall mgenlangm2 mrmacgenlangm2 mgenlangm4 mrmacgenlangm4 mgenlangm 3 mrmacgenlangm3 mgenlangm5 mrmacgenlangm5 c.mISCEDhml 2 c.mISCEDhml3 c.mc_jobtenure c.mage c.mgbageslacht c.mdeeltijd c.mvastflex c.mwestimmigr c.mlogentsize c.mparttime c.minorg c.munemployment $\|$ rinpersoon:

- est store mix 1

- mat $b=e(b)$

- $\quad$ scalar vadj $=(\mathrm{e}(\mathrm{N})-2) /\left(\mathrm{e}(\mathrm{N})-1-\left(\mathrm{Cdf}^{\prime}+1\right)\right)$ 
- matrix $\mathrm{V}=\operatorname{vadj}^{*} \mathrm{e}(\mathrm{V})$

- ereturn post b V

- ereturn display

\section{Table 4.3 | model 8}

- distinct be_id

- $\quad$ local $\mathrm{df}=\mathrm{r}$ (ndistinct) -1

- mixed mend c.mrmacvsall c.mnatnonwest c.mrmacnatnonwest c.mdevpercnonwest c.mrmacpercnonwest c.mpercnwnonwest c.mtechpercnwnonwest c.mrmacc_volatility2 c.mvolatnonwest c.mtechvolatnonwest c.mrmacvakb1993t c.mvakbnonwestt c.mtechvakbnonwestt c.mISCEDhml2 c.mISCEDhml3 c.mc_jobtenure c.mage c.mgbageslacht c.mdeeltijd c.mvastflex c.mwestimmigr c.mlogentsize c.mparttime c.minorg c.munemployment $\|$ rinpersoon:

- est store mix 1

- mat $b=e(b)$

- $\quad$ scalar vadj $=(\mathrm{e}(\mathrm{N})-2) /\left(\mathrm{e}(\mathrm{N})-1-\left(\mathrm{ddf}^{\prime}+1\right)\right)$

- matrix $\mathrm{V}=\operatorname{vadj}^{*} \mathrm{e}(\mathrm{V})$

- ereturn post b V

- ereturn display

\section{Table 4.A3 | model 15}

- \#delimit ; global contrvar "c.ISCEDhml2 c.ISCEDhml3 c.c_jobtenure c.c_age gbageslacht deeltijd vastflex westimmigr logentsize parttime inorg unemployment" ; \#delimit cr

- xtreg end i.rmacvsall\#\#i.genlang \$contrvar if ISCED2011!=., fe

\section{Figure 4.1}

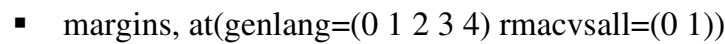

- marginsplot

\section{Chapter 5}

\section{Table $5.2 \mid \operatorname{model} 3$}

- distinct be_id

- $\quad$ local $\mathrm{df}=\mathrm{r}$ (ndistinct) -1

- sureg (pfixedenterlow fixedrmac fixedinorg logentsize i.year)(pfixedenterhigh fixedrmac fixedinorg logentsize i.year) [aweight=combweight]

- mat $b=e(b)$

- $\quad$ scalar vadj $=(\mathrm{e}(\mathrm{N})-2) /\left(\mathrm{e}(\mathrm{N})-1\right.$ - $\left.\left(1+\mathrm{`df}^{\prime}\right)\right)$

- matrix $\mathrm{V}=$ vadj*e(V)

- ereturn post b V

- ereturn display //--------------------------

- distinct be_id

- $\quad$ local $\mathrm{df}=\mathrm{r}($ ndistinct $)-1$ 
- quietly: sureg (pfixedentermid fixedrmac fixedinorg logentsize i.year)(pfixedenterhigh fixedrmac fixedinorg logentsize i.year) [aweight=combweight]

- mat $b=e(b)$

- $\quad$ scalar vadj $=(e(N)-2) /\left(e(N)-1-\left(1+` d f^{\prime}\right)\right)$

- matrix $\mathrm{V}=\operatorname{vadj}^{*} \mathrm{e}(\mathrm{V})$

- ereturn post b V

- ereturn display

\section{Table $5.4 \mid$ model 9}

- distinct be_id

- $\quad$ local $\mathrm{df}=\mathrm{r}$ (ndistinct) -1

- sureg (pfixedenterlow fixedrmac c.fixedrmac\#i.unionindus fixedinorg logentsize i.year)(pfixedenterhigh fixedrmac c.fixedrmac\#i.unionindus fixedinorg logentsize i.year) [aweight $=$ combweight]

- mat $b=e(b)$

- $\quad$ scalar vadj $=(\mathrm{e}(\mathrm{N})-2) /\left(\mathrm{e}(\mathrm{N})-1-\left(1+{ }^{`} \mathrm{df} \mathrm{f}^{\prime}\right)\right)$

- matrix $\mathrm{V}=\operatorname{vadj}^{*} \mathrm{e}(\mathrm{V})$

- ereturn post b V

- ereturn display //----------------------------

- distinct be_id

- $\quad$ local $\mathrm{df}=\mathrm{r}$ (ndistinct) -1

- quietly: sureg (pfixedentermid fixedrmac c.fixedrmac\#i.unionindus fixedinorg logentsize i.year)(pfixedenterhigh fixedrmac c.fixedrmac\#i.unionindus fixedinorg logentsize i.year) [aweight=combweight]

- mat $b=e(b)$

- $\quad$ scalar vadj $=(\mathrm{e}(\mathrm{N})-2) /\left(\mathrm{e}(\mathrm{N})-1\right.$ - $\left.\left(1+{ }^{-} \mathrm{df} \mathrm{f}^{\prime}\right)\right)$

- matrix $\mathrm{V}=\operatorname{vadj} * \mathrm{e}(\mathrm{V})$

- ereturn post b V

- ereturn display 


\section{Nederlandse samenvatting}

(Dutch summary) 


\section{Introductie}

De laatste jaren kende een toename aan zorgen over de druk die technologische vooruitgang uitoefent op de banen en het werk van werknemers. Deze zorgen zijn aangewakkerd door speculaties over de dreiging van een baanloze toekomst door toedoen van versnellingen in de ontwikkeling van robotica en artificiële intelligentie. Daarnaast worden deze speculaties gesterkt door studies die de vervangbaarheid van huidig werk door deze technologieën bestuderen. Deze studies voorspellen dat tussen een tiende en de helft van de banen in de nabije toekomst geautomatiseerd zullen kunnen worden.

De meeste studies naar de effecten van technologische verandering bestuderen arbeidsmarkten. Er is weinig onderzoek wat zich richt op hoe werknemers en hun werk beïnvloed worden door technologie. De vraag hoe werknemers op microniveau geraakt worden wanneer nieuwe technologieën in de organisatie worden geïntroduceerd blijft hierdoor grotendeels onbeantwoord. Dit is opmerkelijk gezien veel berichtgeving in de media gaat over de effecten van technologie op het werk en de baankansen van mensen in plaats van arbeidsmarkten. Is het bijvoorbeeld zo dat de introductie van nieuwe technologieën binnen organisaties gepaard gaat met het vertrek van werknemers? En als dit zo is, vinden deze werknemers dan makkelijk een nieuwe baan? Automatisering kan werknemers vervangen en verdringen. Tegelijkertijd kan technologie ook nieuwe baankansen genereren, aangezien technologie ook nieuwe banen en taken genereert. De huidige literatuur laat de vraag hoe het werk van werknemers geraakt wordt door technologische verandering grotendeels onbeantwoord. In deze dissertatie zetten we een stap in het beantwoorden van deze vragen door de relatie tussen de implementatie van technologie binnen organisaties en baanveranderingen van werknemers te onderzoeken.

Een centrale vraag is of technologisering ongelijkheid tussen werknemers vergroot. Onderzoek benadrukt dat technologie bovenal kapitaalbezitters en hoger opgeleiden ten goede komt, terwijl automatisering vooral het werk van lager en middel opgeleide werknemers raakt. Deze twee processen zouden zodoende bijdragen aan polarisering van de arbeidsmarkt en een afzwakking van de middenklasse. Verder kan technologisering de vraag naar nieuwe vaardigheden die technologie complementeren versterken. Dit is zorgelijk aangezien mensen steeds langer blijven werken. Voor oudere werknemers kan de versnelling van technologische verandering een extra uitdaging zijn om productief te blijven in een almaar langer durend werkend leven. Bovendien kan technologische verandering de productiviteit van jongere, technisch onderlegde werknemers vergroten ten opzichte van meer ervaren, maar minder technologisch vaardige werknemers. Ten slotte kunnen de kansen en uitdagingen die technologie met zich meebrengt competitie over banen tussen werknemers vergroten. Dit kan vijandigheid tussen groepen werknemers vergroten en kan leiden tot het afschermen van banen en kansen door dominante groepen.

Sommige werknemers lijken te kunnen profiteren van technologische verandering terwijl voor anderen het veiligstellen van een baan steeds moeilijker wordt. Bovendien lijkt technologie bestaande ongelijkheid tussen groepen werknemers te kunnen versterken. Ondanks deze mogelijke ongewenste effecten van technologie hebben we verassend weinig kennis over hoe het werk van verschillende werknemers wordt beïnvloed door technologische verandering. Deze dissertatie heeft als doel om ons begrip van hoe technologische verandering de arbeidskansen van werknemers beïnvloedt te vergroten. Dit doen we door te onderzoeken hoe 
de relatie tussen de implementatie van nieuwe technologie binnen organisaties en baanveranderingen van werknemers afhankelijk is van het opleidingsniveau, de werkervaring binnen de organisatie, de leeftijd en de migratieachtergrond van werknemers. Daarnaast onderzoeken we of de opleidings- en leeftijdssamenstelling van organisaties verandert wanneer er nieuwe technologie wordt geïmplementeerd in de organisatie.

Ten slotte gebeuren deze technologische veranderingen in een tijd waarin de macht van kapitaal toeneemt ten opzichte van de macht van werknemers. De toegenomen invloed van de financiële sector, neoliberale politiek, de groei van precair werk, en de afname van vakbondslidmaatschap en de dekkingsgraad van collectieve arbeidsovereenkomsten zouden bijgedragen hebben aan een verzwakking van de onderhandelingskracht van werknemers. Wanneer technologische veranderingen plaatsvinden wordt het belang van onderhandelingsprocessen waarschijnlijk sterker. Technologische veranderingen kunnen leiden tot een herverdeling van banen, taken, lonen en trainingen binnen de organisatie. Deze herverdeling komt werknemers die lager geplaatst zijn binnen de organisatie waarschijnlijk meer ten goede wanneer zij een sterkere onderhandelingspositie hebben.

Hoe onderhandelingskracht binnen organisaties is verdeeld hangt af van de organisatie en institutionele context. Werknemers hebben waarschijnlijk een betere onderhandelingspositie in organisaties en institutionele contexten waarin zij zich beter kunnen organiseren. Door deze vergrote onderhandelingskracht zijn werknemers mogelijk beter in staat om op te komen voor hun eigen belangen wanneer technologische veranderingen plaatsvinden. Een tweede doel van deze dissertatie is om de rol van de organisatie en institutionele context te verhelderen door te onderzoeken of en hoe de effecten van de implementatie van technologie op baanveranderingen van werknemers afhankelijk zijn van de organisatie en institutionele context.

De overkoepelende onderzoeksvraag van de dissertatie is: Hoe hangt het effect van technologie implementatie op baanveranderingen van werknemers af van eigenschappen van werknemers, organisaties en instituties?

\section{Theoretische bouwstenen}

In de studies maken we gebruiken van verschillende theoretische perspectieven. Deze theoretische perspectieven gebruiken we om argumenten mee te ontwikkelen en om hypothesen af te leiden. Soms leiden deze perspectieven tot tegengestelde hypothesen en soms zijn de verwachtingen die we afleiden in overeenstemming met elkaar. Hieronder worden kort de verschillende theorieën uiteengezet die de basis vormen van de studies in de dissertatie.

De Skill Biased Technological Change hypothese is een van de meest gebruikte theorieën in onderzoek naar de effecten van technologische verandering. Volgens deze theorie verhoogt technologie met name de productiviteit van vaardige, hoger opgeleide werknemers zoals programmeurs, wetenschappers, analisten, consultants en ingenieurs. Dit komt omdat hoger opgeleide werknemers meer vaardigheden hebben die technologie complementeren zoals probleemoplossend vermogen, analytische vaardigheden, intuïtie en communicatie vaardigheden. De theorie is veel gebruikt om groeiende inkomensongelijkheid op de arbeidsmarkt, met name in de $20^{\mathrm{e}}$ eeuw, begin $21^{\mathrm{e}}$ eeuw, te verklaren. De verhoogde vraag naar hoger opgeleiden door technologische verandering en vice versa zorgen ervoor dat de inkomens van hoger opgeleiden stijgen ten opzichte van lager opgeleiden. In de dissertatie gebruiken we 
de theorie om verwachtingen te formuleren over hoe de effecten van technologie implementatie op baanveranderingen van werknemers verschillen tussen hoger en lager opgeleiden.

De Routine Biased Technological Change hypothese bouwt voort op de Skill Biased Technological Change hypothese door te stellen dat technologie vooral routinematige banen in het middensegment vervangt. Binnen deze theorie wordt er gekeken naar de taken die bij een baan horen, en in hoeverre deze taken een vast patroon of routine hebben. Omdat routinematige taken voorspelbaar zijn en een vast patroon hebben zijn deze taken beter programmeerbaar in programmeertaal of in machinesequenties. De hypothese stelt hierom dat technologie vooral routinematige banen vervangt. De theorie wordt veelal gebruikt als mogelijke verklaring waarom we in de $21^{\mathrm{e}}$ eeuw een polarisatie van de arbeidsmarkt zien. Het segment van banen van middeninkomens wordt hierin kleiner. Als mogelijke verklaring wordt gegeven dat de meeste routinematige banen, met name kantoorbanen en productiebanen, in het middensegment zitten. Automatisering van routinematige banen raakt zodoende vooral het werk van deze werknemers in het middensegment. Deze werknemers wijken uit naar banen in het lage segment, veelal handmatige niet-routinematige banen, en naar banen in het hoge segment, veelal cognitieve niet-routinematige banen. Het gevolg is een polarisering van de arbeidsmarkt. In de dissertatie gebruiken we de theorie om verwachtingen te formuleren over welke groepen werknemers banen met veel routinematige taken hebben, en om te beargumenteren welke groepen werknemers hierdoor harder geraakt worden door automatisering.

De menselijk kapitaal theorie stelt dat de vaardigheden en kennis die mensen opdoen bepalend zijn voor de productiviteit van werknemers, het werk dat mensen kunnen doen en de mate waarin werknemers economische waarde generen. Investeringen in menselijk kapitaal doormiddel van scholing en training verhogen de productiviteit werknemers. De theorie wordt veel gebruikt om inkomensverschillen te verklaren. De centrale these is dat mensen met meer menselijk kapitaal productiever zijn en meer economische waarde creëren wat zich vertaalt in hoger inkomen. In de dissertatie verbinden we menselijk kapitaal met technologie omdat nieuwe technologie kan veranderen welke vaardigheden en kennis werknemers nodig hebben om productief te zijn. Vaardigheden en kennis die verbonden zijn aan oude technologie of oude productieprocessen kunnen in waarde verminderen. Omdat technologie de vraag naar vaardigheden kan veranderen wordt technologische verandering vaak in verband gebracht met de behoefte aan omscholing of training, zodat werknemers zich aan kunnen passen. In de dissertatie wordt de menselijk kapitaal theorie vooral gebruikt om verwachtingen te formuleren voor welke werknemers technologische verandering de sterkste waardevermindering van vaardigheden en kennis betekent, en voor welke werknemers het aanpassen van vaardigheden en kennis aan technologie de grootste uitdaging zal zijn.

Bovenstaande theorieën gaan vooral over de complementariteit tussen technologie en vaardigheden van werknemers, en over welke banen veel taken bevatten die een hoog risico lopen geautomatiseerd te worden. Wat ontbreekt is theorie over sociale relaties. In deze dissertatie bestuderen we technologische veranderingen binnen organisaties en de invloed hiervan op baanveranderingen van werknemers. De sociale relaties tussen werknemers, en werkgever en werknemer binnen organisaties zijn bepalend voor hoe veranderingen, zoals 
technologisering, verschillende werknemers beïnvloedt. Relational Inequality Theory stelt dat machtsverschillen in de positie tussen groepen werknemers bepalend zijn voor welke werknemers middelen binnen de organisatie, zoals banen, lonen of training voor zichzelf kunnen claimen. In de dissertatie verbinden we deze theorie aan technologische verandering door verwachtingen te formuleren over welke groepen werknemers binnen organisaties meer en welke groepen minder macht hebben. We verwachten dat groepen werknemers die een sterkere positie hebben binnen de organisatie meer invloed kunnen uitoefenen op hoe technologische verandering er uit ziet binnen de organisatie, en zodoende beter hun voordeel kunnen doen met de mogelijkheden die technologisering brengt. Daarentegen verwachten we dat minder machtige groepen werknemers minder invloed kunnen uitoefenen op technologische verandering en dat de kans dat technologie negatief uitpakt voor hun baankansen hierdoor groter is.

Ten slotte gebruiken we in de dissertatie theorie over de rol van de organisatie en institutionele context waarin technologische veranderingen plaatsvinden. We relateren de organisatie context aan de mate waarin technologische verandering gepaard gaat met een verscherping van groepsverschillen en de mate waarin werknemers het gevoel hebben dat hun positie binnen de organisatie bedreigd wordt door andere groepen werknemers. We beargumenteren dat technologische verandering gepaard gaat met een zekere mate van herverdeling van middelen binnen de organisatie, zoals banen, taken, lonen of training. We stellen hierbij de verwachting op dat in organisaties waar meer baanonzekerheid heerst en waar de ervaren dreiging tussen groepen sterker is, dominante groepen werknemers de mogelijkheden die geschept worden door technologie sterker zullen afschermen. De institutionele context relateren we aan de mate waarin werknemers beschermd en gesterkt worden, en de mate waarin werkgevers beperkt worden om hun werknemersbestand aan te passen aan technologie, bijvoorbeeld door middel van ontslag. In de studies gaan we met name in op de rol van vakbonden, en de mate van vakbondslidmaatschap binnen de sector waarin een bedrijf actief is. We beargumenteren dat sterkere vakbonden de positie van minder machtige groepen werknemers beschermt, waardoor de effecten van technologie op de banen van deze werknemers minder sterk zullen zijn. Daarnaast verwachten we dat een sterkere onderhandelingspositie van werknemers ervoor zorgt dat werkgevers minder makkelijk gebruik kunnen maken van baan beëindiging als manier om het werknemersbestand aan te passen aan technologie.

\section{Contributies}

In de huidige literatuur over technologische verandering is er vooral veel onderzoek naar de relatie tussen technologische verandering en de consequenties hiervan voor de distributie van banen en inkomens op arbeidsmarktniveau. Ondanks dat deze veranderingen grote invloed kunnen hebben op de werkende levens van individuen is hier weinig onderzoek naar gedaan.

Een eerste contributie van deze dissertatie is dat we onderzoeken wat voor impact technologische verandering heeft op de banen van werknemers. We bestuderen hoe de implementatie van nieuwe technologie binnen organisaties in Nederland is gerelateerd aan baan beëindigingen onder werknemers, aan de duur van het zoeken naar een nieuwe baan, en aan 
veranderingen in de samenstelling van werknemers binnen organisaties. We complementeren de schaarse literatuur die kijkt naar de effecten van technologische veranderingen binnen organisaties op het werk van werknemers. We bouwen voort op deze studies door de rol van categorische verschillen te onderzoeken tussen werknemers die verbonden zijn met macht binnen organisaties, zoals bijvoorbeeld migratieachtergrond.

Een tweede contributie is dat we een empirische en theoretische uitwerking bieden hoe de impact van technologische verandering verschillend is tussen werknemers. Waarschijnlijk zullen niet alle werknemers hetzelfde reageren en zijn er verschillen in aanpassingsvermogen tussen werknemers wanneer nieuwe technologieën geïmplementeerd worden in de organisatie. Sommigen vinden het makkelijk om te leren, of bezitten al de benodigde vaardigheden om met nieuwe technologieën te werken, terwijl anderen het mogelijk lastiger vinden om zich aan te passen aan nieuwe technologie. Er is echter een gebrek aan onderzoek dat systematisch evalueert hoe de effecten van technologische verandering op werk afhangt van karakteristieken van individuen. Is het bijvoorbeeld zo dat vooral lager opgeleiden hun baan kwijtraken? En als dat zo is, kunnen deze werknemers vervolgens gemakkelijk een nieuwe baan vinden? Deze dissertatie vult de bestaande literatuur aan door te testen of de effecten van technologie implementatie binnen organisaties op baanveranderingen en de kans op het vinden van een nieuwe baan afhankelijk zijn van het opleidingsniveau van werknemers.

In het onderzoek belichten we de rol van menselijk kapitaal echter van meer kanten dan alleen die van opleidingsniveau. Werknemers bezitten ook ervaring en vaardigheden die verworven zijn tijdens het werken binnen de organisatie. Daarnaast zitten er verschillen in de mate waarin werknemers van verschillende leeftijden zich kunnen aanpassen aan veranderingen in de vraag naar werkvaardigheden. Voor werknemers met veel werkervaring binnen de organisatie kan technologisering betekenen dat veel van de waarde van hun vaardigheden samen met oude manieren van werken verloren gaat. Tegelijkertijd kan technologie het belang van aanpassingsvermogen en het vermogen om te leren vergroten, wat een uitdaging kan zijn voor oudere werknemers of werknemers met een taalachterstand. In deze dissertatie verhelderen we hoe werknemers met verschillende karakteristieken gerelateerd aan menselijk kapitaal verschillend worden geraakt door technologische veranderingen op de werkvloer. Hiervoor bestuderen we de rol van opleidingsniveau, jaren werkervaring binnen de organisatie, leeftijd en migratieachtergrond van werknemers.

Een derde contributie van de dissertatie is dat we karakteristieken van werknemers en organisaties bestuderen die gerelateerd zijn aan machtsongelijkheid tussen werknemers. Er is een gebrek aan onderzoek naar de rol van sociale processen die te maken hebben met verschillen in onderhandelingsposities van werknemers en de rol van sociale stereotypen in tijden van technologische veranderingen. Technologische veranderingen binnen organisaties kunnen leiden tot een herverdeling van middelen zoals banen, taken en training. Deze herverdeling kan de competitie tussen werknemers vergroten. Bijvoorbeeld over wie welke baan krijgt of wie er promotie maakt, of wie de negatieve gevolgen, zoals ontslag, zal dragen. Een toename in competitie binnen de organisatie kan gepaard gaan met een verscherping en versterking van groepsverschillen en groepscategorisaties zoals jong-oud, man-vrouw of tussen etnische groepen. Zulke categorische scheidingen tussen groepen beïnvloeden hoe middelen binnen de 
organisatie verdeeld worden. Groepen werknemers met meer macht binnen de organisatie kunnen waarschijnlijk meer voordeel halen uit technologische veranderingen.

De rol die de machtspositie van verschillende werknemers speelt wordt verder gecompliceerd doordat besluitvormers binnen organisaties voor een groot deel bepalend zijn voor de verdeling van middelen binnen organisaties. De macht van werknemers om middelen binnen de organisatie voor zichzelf te claimen zal deels afhankelijk zijn van of besluitvormers binnen de organisatie deze claims als gelegitimeerd zien afgaande op verwachtte productiviteit en de waarde van een werknemer voor de organisatie. Deze verwachtte productiviteit, wanneer verbonden aan sociale categorieën, zoals leeftijd of etniciteit, vormt een sociaal stereotiep die besluitvorming beïnvloedt. Bijvoorbeeld over wie aangenomen wordt of wie training krijgt. Bovendien beïnvloeden stereotypen over groepen werknemers besluitvorming zelfs wanneer deze niet stroken met de werkelijke productiviteit van deze werknemers.

Het onderzoeken van de rol van de macht van werknemers en stereotypen kan ons begrip vergroten van hoe technologie werknemers verschillend beïnvloedt. Bijvoorbeeld, wanneer we vertrekken vanuit een menselijk kapitaal perspectief kunnen we verwachten dat oudere werknemers en werknemers met meer jaren werkervaring binnen de organisatie negatiever beïnvloed worden door technologie omdat de waardevermindering van vaardigheden en ervaring onder deze groepen sterker is. Een alternatieve verklaring is echter dat eerder dan een daadwerkelijke daling in productiviteit onder oudere werknemers, het vooral negatieve sociale stereotypen over de vaardigheden van oudere werknemers zijn die de baankansen van oudere werknemers doen dalen. Bovendien zouden we voor werknemers met meer jaren werkervaring binnen de organisatie een tegenovergestelde hypothese kunnen formuleren. Namelijk dat werknemers die al meerdere jaren in de organisatie werken werknemers zijn met meer macht binnen de organisatie. Dit zou kunnen betekenen dat juist de baankansen van meer recentelijk aangenomen werknemers geraakt worden door technologische verandering.

Ondanks de mogelijke meerwaarde van een aanpak die de rol van sociale relaties binnen organisaties in acht neemt in onderzoek naar de effecten van technologisering op werk bestaat hier bijna geen theoretische of empirische uitwerking van. In deze dissertatie zetten we hierin een stap door hypothesen op te stellen over hoe verschillen in machtsposities tussen werknemers gerelateerd aan het opleidingsniveau, jaren ervaring binnen de organisatie, leeftijd en migratieachtergrond van werknemers, de effecten van technologische veranderingen op baantransities van werknemers beïnvloeden.

Daarnaast bestuderen we hoe het belang van sociale groepsverschillen tussen werknemers verschilt afhankelijk van organisatie en institutionele karakteristieken. Dit doen we door te onderzoeken hoe patronen van baan beëindiging van werknemers met een nietWesterse migratieachtergrond verschillen en afhankelijk zijn van het percentage werknemers met een niet-Westerse migratieachtergrond binnen de organisatie, de stabiliteit, gemeten als de gemiddelde duur van banen binnen de organisatie, en van de dichtheid van vakbondslidmaatschap binnen de sector waarin de organisatie actief is.

Een vierde contributie is dat we de rol van de institutionele context waarin technologische verandering gebeurt onderzoeken. Het proces van technologische verandering is in de eerste plaats een fenomeen dat plaatsvindt binnen organisaties. Hoe de implementatie van technologie werknemers beïnvloedt zal afhankelijk zijn van de institutionele context waarin 
de organisatie actief is en van hoe besluitvorming binnen de organisatie gevormd wordt door instituties.

In de literatuur over de polarisering van de arbeidsmarkt wordt naast technologisering door meerdere auteurs gewezen op het belang van instituties en institutionele veranderingen, o.a. betreffend minimumlonen, vakbondsvorming en de regulering van arbeidscontracten, als belangrijke oorzaken van arbeidsmarktpolarisatie. In deze dissertatie beargumenteren we dat instituties niet enkel afzonderlijke factoren zijn die naast technologisering bijdragen aan arbeidsmarktveranderingen. We beargumenteren dat instituties ook bepalend zijn voor welk effect technologisering heeft op werk. De Nederlandse politieke economie wordt gekenmerkt door een hoge mate van samenwerking, coördinatie en overleg tussen organisaties, vakbondsverenigingen, werkgeversverenigingen en de nationale, regionale en lokale overheden. Binnen deze corporatistische institutionele structuur is er een hoge mate van georganiseerd overleg over socio-economisch beleid zoals wetgeving, en sociale bescherming. Deze institutionele structuur geeft werknemers de mogelijkheid en onderhandelingskracht om besluitvorming binnen organisaties te beïnvloeden.

Veel onderzoek over de (toekomstige) effecten van technologische veranderingen gaan over de VS. Binnen deze liberale markteconomie genieten werknemers een stuk minder institutionele bescherming. De effecten van technologisering zijn waarschijnlijk sterker in de VS, waar werknemers een minder sterke onderhandelingspositie hebben tegenover werkgevers dan in institutionele omgevingen die de positie van werknemers versterken. Via instituties kunnen werknemers onderhandelen over maatregelen die de kans op baanbehoud of baantransitie, bijvoorbeeld door omscholing, vergroten. Ondanks dat het effect van technologisering waarschijnlijk afhangt van de institutionele context is er weinig variatie of aandacht voor instituties in de literatuur over technologische verandering.

Door Nederland te bestuderen krijgen we inzicht in de effecten van technologisering in een institutionele setting die contrasteert met de VS door de hoge mate van institutionele werknemersbescherming. Wanneer werkgevers in Nederland hun werknemersbestand willen reorganiseren, bijvoorbeeld doordat er nieuwe technologie geïmplementeerd wordt, zijn zij verplicht om dit te overleggen met een werknemersvereniging en dienen zij met maatregelen te komen om negatieve consequenties voor werknemers te verzachten. Hoewel werkgevers niet verplicht zijn om met vakbonden te overleggen wordt dit in praktijk vaak wel gedaan omdat unilaterale overeenkomsten vaak gezien worden als minder legitiem in het geval dat er arbitrage plaatsvindt. Overeenkomsten met vakbonden legitimeren de beslissingen van werkgevers naar externe partijen en geven werknemers de kans om mee te beslissen over welke maatregelen en tegemoetkomingen opgenomen worden in de overeenkomst. Voorbeelden van zulke maatregelen zijn de reallocatie van werknemers binnen de organisatie, omscholing, het aanbieden van trainingen, of hulp bij het vinden van een nieuwe baan. Binnen deze institutionele context kunnen sterke vakbonden er mogelijk voor zorgen dat de macht die werknemers hebben om de effecten van technologische veranderingen te beïnvloeden wordt vergroot. De studies in deze dissertatie dragen bij aan ons begrip van de rol van instituties door te onderzoeken in welke mate de effecten van technologische verandering op werk van werknemers afhankelijk zijn van de sterkte van vakbonden binnen de sector waarin de organisatie actief is. 
Een vijfde en laatste contributie van de dissertatie is de data die gebruikt worden om technologische verandering te bestuderen. We gebruiken data afkomstig van een grootschalige enquête over (technologische) innovatie binnen Nederlandse bedrijven in de private sector (exclusief bedrijven in de landbouw). De bedrijven uit de survey koppelen we aan register data afkomstig van het Centraal Bureau voor de Statistiek, waarmee we een dataset krijgen van gekoppelde werkgevers-werknemers met hierin meer dan 35.000 bedrijven, meer dan 4 miljoen werknemers en bijna 7 miljoen banen in de periode 2000-2014. De data bevatten gemiddeld ongeveer 2.5 miljoen werkende individuen per jaar. Dit is meer dan de helft van de populatie werkenden in de private sector (landbouw niet meegeteld), welke tussen de 3.5 tot 4 miljoen werkenden lag in de periode 2000-2014. De data maken het mogelijk om de effecten van technologische veranderingen te testen aan de hand van een representatieve dataset die bijna alle private sectoren bevat en meer dan een decennium beslaat. Naar ons weten is het, op Bessen et al. (2019) na, de enige test van het effect van technologische verandering die gebruik maakt van gekoppelde werkgever-werknemer data met een zulke veelzijdigheid aan bedrijven over zo een lange periode.

De data bevatten een meting van technologische verandering op bedrijfsniveau. Dit betekent dat we de impact van technologisering kunnen observeren daar waar technologische verandering in hoofdzaak plaatsvindt, binnen de organisatie. Een beperking van veel onderzoek naar de effecten van technologisering is dat het effect van technologisering vaak wordt afgeleid van veranderingen in opleidingssamenstellingen en het aandeel routinematige banen binnen arbeidsmarkten. Als gevolg daarvan ontbreekt er direct empirisch bewijs van het effect van technologische verandering op het niveau van werknemers. Technologie is slechts een van de vele factoren naast bijvoorbeeld offshoring en outsourcing die arbeidsmarktveranderingen teweegbrengt. Door data over de implementatie van nieuwe technologie binnen Nederlandse bedrijven te koppelen aan data over individuele werknemers kunnen we direct meten hoe technologische veranderingen binnen organisaties relateren aan baanveranderingen en veranderingen in werknemersbestanden van bedrijven. Daarnaast kunnen we inzicht krijgen in de rol van karakteristieken van werknemers en de organisatie en institutionele context binnen deze relaties. Ten slotte kunnen we door het gebruik van register data werknemers en hun banen door de tijd heen volgen. Hierdoor kunnen we onderzoek doen naar hoe succesvol werknemers zijn in het vinden van een nieuwe baan wanneer baan beëindiging plaatsvindt in tijden van technologische verandering binnen het bedrijf.

\section{Samenvatting van de empirische hoofdstukken}

Deze dissertatie bestaat uit vier empirische hoofdstukken. De belangrijkste bevindingen en conclusies worden hieronder samengevat. Hoofdstuk 2 gaat over het effect van technologie implementatie op baan beëindiging onder werknemers, en de rol van opleidingsniveau, jaren werkervaring binnen de organisatie, leeftijd en vakbonden binnen deze relatie. Hoofdstuk 3 bouwt voort op het voorgaande hoofdstuk door te onderzoeken of werknemers die de organisatie verlaten wanneer technologie wordt geïmplementeerd er langer over doen om een nieuwe baan te vinden, en of deze relatie afhankelijk is van opleidingsniveau, jaren werkervaring binnen de organisatie, leeftijd en de mate van vakbondslidmaatschap binnen de sector. Hoofdstuk 4 richt zich wederom op de relatie tussen technologie implementatie en baan beëindiging maar bekijkt nu of deze relatie verschillend is voor werknemers met een niet- 
Westerse migratieachtergrond en Nederlandse werknemers. Daarnaast wordt in dit hoofdstuk onderzocht of dit effect afhangt van het percentage werknemers met een niet-Westerse achtergrond en de volatiliteit van banen binnen de organisatie, en de sterkte van vakbondslidmaatschap binnen de sector. Ten slotte onderzoeken we in hoofdstuk 5 hoe de samenstelling van werknemers wat betreft opleidingsniveau en leeftijd binnen organisaties verandert wanneer nieuwe technologie wordt geïmplementeerd, en of deze relatie anders is in sectoren met sterkere en zwakkere vakbonden.

\section{Hoofdstuk 2: Technologie implementatie in organisaties en baan beëindiging onder werknemers. Een studie naar de rol van opleidingsniveau, ervaring binnen de organisatie, leeftijd en vakbonden.}

De hypothese die we opstellen in de studie is dat middelhoog opgeleiden, werknemers die langer binnen de organisatie werken en oudere werknemers menselijk kapitaal hebben waarvan de waarde minder wordt door technologische verandering, en dat zij hierom een verhoogde kans op baan beëindiging hebben. Deels contrasterend met deze verwachting stellen we daarnaast de hypothese op dat hoger opgeleide werknemers, werknemers met meer ervaring binnen de organisatie en oudere werknemers meer onderhandelingsmacht hebben binnen de organisatie, en dat hierdoor de kans op baanverlies voor hen lager is. Daarnaast bestuderen we of deze relaties afhankelijk zijn van de mate van vakbondslidmaatschap in de sector waarin de organisatie actief is. Voor de analyses gebruiken we regressiemodellen met fixed effects op het bedrijfsniveau en random effects op het individu niveau. Met deze modellen analyseren we grootschalige longitudinale werkgever-werknemer data over technologie implementatie binnen Nederlandse bedrijven.

We vinden dat de implementatie van technologie samenhangt met een algemene verlaging van de kans dat werknemers het bedrijf verlaten. Verder vinden we dat de kans op baan beëindiging voor lager opgeleiden groter wordt ten opzichte van middel- en hoger opgeleiden. Deze bevinding wekt de suggestie dat technologie vooral de vraag naar werknemers met een hogere opleiding vergroot. In lijn met de hypothesen over menselijk kapitaal vinden we dat oudere werknemers (rond 50+) en werknemers met meer jaren ervaring binnen de organisatie (15+) een hogere kans hebben op baan beëindiging wanneer technologie wordt geïmplementeerd. Ten slotte vinden we niet dat de effecten van technologie implementatie afhangt van de mate van vakbondslidmaatschap binnen de sector waarin het bedrijf actief is.

\section{Hoofdstuk 3: Leidt technologische verandering ertoe dat werknemers wiens baan eindigt minder makkelijk een nieuwe baan vinden?}

Het derde hoofdstuk gaat in op de vraag hoe de implementatie van technologie de duur van het zoeken naar een baan beïnvloedt onder werknemers die het bedrijf verlaten. De kans op baanverlies kan groter worden voor werknemers met een baan die een hoger risico loopt om geautomatiseerd te worden. Echter, de kans dat deze werknemers ergens anders aan een baan komen wordt mogelijk ook kleiner, aangezien vergelijkbare technologische veranderingen zich waarschijnlijk ook binnen andere organisaties voordoen. De hypothese die we toetsen is dat werknemers die een bedrijf verlaten dat technologische veranderingen doorvoert er langer over doen om een nieuwe baan te vinden dan werknemers die een bedrijf verlaten dat geen technologische veranderingen doorvoert. Hiernaast onderzoeken we of werknemers die meer 
risico lopen om geraakt te worden door automatisering en werknemers waarvan we verwachten dat deze minder makkelijk hun vaardigheden kunnen aanpassen aan technologische veranderingen, namelijk middel en lager opgeleiden, werknemers die een langere tijd binnen het bedrijf werken en oudere werknemers, minder makkelijk een nieuwe baan vinden. Ten slotte toetsen we of deze effecten minder sterk zijn in sectoren waar de mate van vakbondslidmaatschap hoger is.

We gebruiken survival analyse om meer dan een miljoen baantransities te analyseren. In lijn met onze verwachtingen vinden we dat de kans op het vinden van een nieuwe baan lager is onder werknemers die een bedrijf verlaten waar nieuwe technologieën geïmplementeerd worden. Het lijkt erop dat werknemers wiens baan geraakt wordt door technologische verandering ook moeilijker aan een nieuwe baan komen. Deze bevinding lijkt het belang van initiatieven die gericht zijn op het vergroten van de competitiviteit en arbeidsgeschiktheid van werknemers, zoals omscholing, training en hulp bij baantransitie te ondersteunen.

Ook vinden we dat oudere werknemers die een bedrijf verlaten waar technologische veranderingen plaatsvinden minder makkelijk een nieuwe baan vinden dan jongere werknemers. Dit komt mogelijk doordat trainings- en opleidingsmogelijkheden schaarser zijn en het vermogen om vaardigheden aan te passen minder zijn onder oudere werknemers. Daarnaast is het mogelijk dat oudere werknemers die een baan zoeken in tijden van technologische verandering benadeeld worden door negatieve stereotypen over de technologische vaardigheden en het aanpassingsvermogen aan technologie van oudere werknemers.

Een andere interessante bevinding is dat de negatieve associatie tussen technologie implementatie en de kans op het vinden van een nieuwe baan kleiner is in sectoren waar vakbondslidmaatschap hoger is. Dit zou kunnen betekenen dat vakbonden de positie om te onderhandelen over omscholing, training en hulp bij het vinden van een nieuwe baan versterken.

Ten slotte vinden we niet dat opleidingsniveau of werkervaring binnen het bedrijf samenhangen met de kans op het vinden van een nieuwe baan wanneer technologische veranderingen plaatsvinden.

\section{Hoofdstuk 4: Technologie raakt immigranten: Het effect van technologie implementatie op het werk van Nederlandse werknemers en werknemers met een niet-Westerse migratieachtergrond.}

In dit hoofdstuk onderzoeken we of en hoe technologie een ander effect heeft op de banen van werknemers met een niet-Westerse migratieachtergrond ten opzichte van Nederlandse werknemers. Gebruikmakend van de Routine Biased Technological Change hypothese en theorie over menselijk kapitaal beargumenteren we dat werknemers met een migratieachtergrond vaker banen hebben die een groter risico lopen geautomatiseerd te worden. We complementeren de RBTC-hypothese en de menselijk kapitaal benadering met een Relational Inequality perspectief. We argumenteren dat in de sociale relaties binnen bedrijven tussen Nederlandse werknemers en werknemers met een migratieachtergrond er machtsongelijkheid bestaat in het voordeel van Nederlandse werknemers. Gebaseerd op deze twee argumenten formuleren we de hypothese dat technologisering de kansen op baan 
beëindiging onder werknemers met een migratieachtergrond vergroot ten opzichte van Nederlandse werknemers.

Een tweede doel is om te bestuderen hoe het effect van technologie implementatie afhankelijk is van de organisatie en institutionele context. We verwachten dat een hoger percentage werknemers met een niet-Westerse achtergrond binnen een bedrijf gepaard gaat met een sterker gevoel van dreiging en competitie door dominante groepen werknemers. Gevoelens van bedreiging verscherpen scheidslijnen tussen groepen en versterken sociale categorisering en discriminatie. Een mogelijk gevolg is dat gevoelens van dreiging ervoor zorgen dat dominante groepen baankansen en voorzieningen binnen de organisatie afschermen en binnen de eigen groep proberen te houden. Op een vergelijkbare manier verwachten we dat in organisaties waar banen instabieler zijn en werknemers sneller van baan wisselen gevoelens van dreiging sterker zijn, groepsverschillen van meer betekenis zijn, en het voortrekken van de eigen groep sterker is. De hypothese die we opstellen is dat naarmate het aandeel werknemers met een niet-Westerse migratieachtergrond toeneemt, en wanneer banen instabieler zijn de kans op baan beëindiging onder werknemers met een niet-Westerse migratieachtergrond toeneemt ten opzichte van Nederlandse werknemers. Ten slotte verwachten we dat de onderhandelingsmacht van minderheidsgroepen sterker wordt, en particularisme en sociale uitsluiting door dominante groepen werknemers afneemt wanneer er in een sector sterke vakbonden zijn, en dat hierdoor de relatie tussen technologisering en baan beëindiging onder werknemers met een niet-Westerse migratieachtergrond wordt afgezwakt.

We gebruiken regressie analyses met fixed effects op bedrijfsniveau en random effects op het niveau van werknemers. We vinden net als in hoofdstuk 2 dat technologisering gepaard gaat met een daling in de kans op baan beëindiging onder werknemers. We vinden echter dat deze daling kleiner is onder werknemers met een niet-Westerse migratieachtergrond dan onder Nederlandse werknemers. Verder zien we dat dit effect het sterkst is onder eerste generatie migranten uit niet-Westerse landen waar geen Nederlands gesproken wordt. Voor deze groep zien we dat technologie implementatie niet gepaard gaat met een daling in de kans op baan beëindiging. Wel is er meer onderzoek nodig om te ontrafelen of een gebrek aan menselijk kapitaal, selectie op banen met een hoog automatiseringsrisico of mechanismen van sociale uitsluiting de hoofdoorzaak is van dit effect. We vinden geen bewijs dat het effect van technologie implementatie afhankelijk is van het aandeel werknemers met een niet-Westerse migratieachtergrond of de instabiliteit van banen binnen organisaties of de mate van vakbondslidmaatschap in de sector. Zodoende lijkt het effect van technologie implementatie ook te bestaan in bedrijven waar interetnische competitie naar verwachting lager is en in institutionele contexten waarin werknemers meer bescherming en onderhandelingsmacht hebben.

\section{Hoofdstuk 5: Technologie implementatie binnen bedrijven en veranderingen in de opleidings- en leeftijdssamenstelling van bedrijven}

Het vijfde hoofdstuk gaat over hoe de samenstelling van werknemers binnen organisaties verandert naar aanleiding van technologische veranderingen. De implementatie van nieuwe technologie gaat gepaard met een verandering in productieprocessen en de organisatie van werk. Deze veranderingen hebben waarschijnlijk ook invloed op wat de ideale samenstelling van werknemers is binnen het bedrijf. We verwachten dat technologie de vraag naar hoger 
opgeleide werknemers met vaardigheden die complementair zijn aan technologie vergroot. Verder verwachten we dat de vraag naar middel en, in mindere mate, lager opgeleide werknemers afneemt omdat zij over gerepresenteerd zijn in routinematige banen die een hoger risico lopen vervangen te worden door technologie. Daarnaast verwachten we dat organisaties die technologische veranderingen doorvoeren vraag hebben naar technisch-vaardige jongere werknemers terwijl de vraag naar oudere werknemers met ervaring die gebonden is aan oude productieprocessen binnen de organisatie afneemt.

Een tweede doel van de studie is om te onderzoeken in welke mate het effect van technologie implementatie afhankelijk is van de mate van vakbondslidmaatschap in de sector. We verwachten dat sterkere vakbonden de positie van werknemers om te onderhandelen over baanbehoud, omscholing of training versterkt, terwijl werkgevers minder makkelijk werknemers kunnen ontslaan om de organisatie aan te passen aan nieuwe technologie.

In tegenstelling tot onze verwachtingen vinden we dat het aandeel middelhoog opgeleiden binnen organisaties eerder groter wordt dan kleiner. Hoewel we wel vinden dat het aandeel middelhoog opgeleiden dat vertrekt uit het bedrijf groter wordt, zien we dat het aandeel middelhoog opgeleiden dat aangetrokken wordt eveneens groter wordt. Verder vinden we niet dat het aandeel hoger opgeleiden binnen bedrijven groter wordt. Een mogelijke verklaring is dat omscholingsinitiatieven en het beroepsgeoriënteerde onderwijs in Nederland erg effectief is in het aanleren van vaardigheden die het voor middelhoog opgeleiden mogelijk maken om met nieuwe technologieën te werken.

Een ander resultaat is dat het aandeel werknemers van 50+ jaar toeneemt wanneer er nieuwe technologieën worden geïmplementeerd. Zoals we verwachtten vinden we dat het percentage 50+'ers wat het bedrijf verlaat toeneemt. Echter, wat we niet verwacht hadden is dat ook het aandeel 50+'ers wat aangenomen wordt toeneemt. Deze bevindingen lijken aan de ene kant te impliceren dat het aanpassen aan nieuwe technologie lastiger is voor oudere werknemers. Maar aan de andere kant dat er in tijden van technologische verandering ook behoeft is aan ervaring en kennis.

De bevindingen over de rol van vakbonden zijn divers en laten niet eenduidig zien dat de effecten van technologie kleiner zijn in sectoren met een hogere mate van vakbondslidmaatschap. We vinden dat het aandeel lager opgeleiden dat organisaties verlaat lager is in sectoren met sterkere vakbonden. Daarnaast vinden we een groter aandeel 50+'ers wat de organisatie verlaat, wat zou kunnen duiden op een groter gebruik van regelingen voor vervroegd pensioen.

\section{Conclusie}

Deze dissertatie heeft als doel meer inzicht te krijgen in de invloed van technologische verandering binnen organisaties op banen van werknemers. Om dit te bereiken hebben we onderzocht hoe de implementatie van technologie samenhangt met het vertrekken van werknemers, de duur van het zoeken naar een nieuwe baan, en de samenstellingen van werknemers binnen organisaties. De dissertatie spitst zich toe op twee perspectieven die onderbelicht zijn binnen de literatuur over technologische verandering. Ten eerste, het idee dat het effect van technologische verandering op werknemers afhankelijk is van verschillende karakteristieken van werknemers. En ten tweede, dat de invloed van technologische 
verandering afhangt van de organisatie en institutionele context waarin technologische verandering plaatsvindt.

Een eerste hoofdbevinding van de studies is dat de effecten van technologische verandering op het werk van werknemers binnen bedrijven aanwezig maar klein zijn. We zien niet dat technologie implementatie gepaard gaat met massa ontslag en baanverlies. In plaats daarvan vinden we dat technologische verandering binnen bedrijven de kans op baanverlies onder werknemers vermindert met ongeveer 1.7 procent. Onder werknemers wiens baan eindigt tijdens de implementatie van nieuwe technologie binnen de organisatie lijkt het iets langer te duren voordat zij ergens anders een nieuwe baan vinden. Dit effect is echter ook maar klein. We vinden dat de kans om binnen twee jaar een nieuwe baan te vinden 1.18 procent lager is wanneer nieuwe technologie geïmplementeerd wordt in vergelijking met wanneer er geen nieuwe technologie geïmplementeerd wordt in het bedrijf.

Afgaande op deze resultaten lijken zorgen over de druk die technologische verandering uitoefent op de houdbaarheid en de toekomst van werk overdreven. Voor een klein deel werknemers lijkt het aanpassen aan nieuwe technologie een uitdaging die ten koste gaat van hun inzetbaarheid en baankansen. Over het algemeen genomen lijkt de overgrote meerderheid, ten minste in de Nederlandse context, hun baan te kunnen behouden of ergens anders nieuw werk te vinden.

Een tweede hoofdbevinding van de studies is dat de effecten van technologische verandering ten dele afhankelijk zijn van karakteristieken van werknemers. In zoverre dat technologie de baanperspectieven van werknemers beïnvloedt, lijkt het er op dat technologie al bestaande ongelijkheid tussen werknemers versterkt.

Ten eerste lijken lager opgeleide werknemers meer van de negatieve consequenties van technologische verandering te dragen dan hoger opgeleide werknemers. We zien de kans op baan beëindiging onder lager opgeleiden groter worden ten opzichte van hoger opgeleide werknemers. Dit komt overeen met een van de meest gehoorde argumenten binnen de literatuur; dat technologische verandering van groter voordeel is voor hoger opgeleiden dan voor lager opgeleiden. Technologisering lijkt zodoende bij te dragen aan ongelijkheid tussen hoger en lager opgeleide werknemers.

Ten tweede lijkt technologisering de uitdaging voor oudere werknemers om werk te vinden en werk te behouden te vergroten. Moeilijkheden met het leren van nieuwe (technologische) vaardigheden en negatieve stereotypen over oudere werknemers dragen waarschijnlijk bij aan dit probleem. Verder vinden we dat werknemers die al langer binnen de organisatie werken een hogere kans hebben om te vertrekken wanneer er nieuwe technologie wordt geïmplementeerd. Dit is in lijn met het idee dat technologie de waardevermindering van vaardigheden kan versnellen, en lijkt een bevestiging van theorie over het belang van menselijk kapitaal. De bevindingen lijken de waarde van initiatieven gericht op een leven-lang-leren die als doel hebben om werknemers nieuwe vaardigheden aan te leren en om te scholen te bevestigen.

Ten slotte lijkt technologie implementatie ongelijkheid tussen Nederlandse werknemers en werknemers met een niet-Westerse migratieachtergrond te vergroten. Dit zien we met name voor eerste generatie migranten uit niet-Nederlands spekende landen. Technologische 
verandering vergroot het belang van vaardigheden die moeilijker zijn te automatiseren, zoals soft-skills, en vaardigheden die nodig zijn bij face-to-face interactie en in dienstverlenende beroepen. Deze verschuiving kan vooral een uitdaging zijn voor werknemers met een taalachterstand en werknemers die te maken hebben met discriminatie. Aangezien deze problemen vaker voorkomen onder werknemers met een niet-Westerse migratieachtergrond is het mogelijk dat technologie de baankansen onder deze werknemers verslechterd.

Een derde hoofdbevinding van de dissertatie is dat de effecten van technologie maar in zeer geringe mate afhankelijk lijken te zijn van de mate van vakbondslidmaatschap in de sector waarin het bedrijf actief is. Het is lastig een eenduidige interpretatie van de resultaten te geven. Aan de ene kant lijkt deze bevinding een bevestiging van studies die aangeven dat de invloed die vakbonden kunnen uitoefenen steeds kleiner wordt. Vakbonden zouden maar geringe mogelijkheden kunnen hebben om de effecten van technologisering te beïnvloeden. In het licht van een structurele verschuiving van macht in het voordeel van werkgevers en kapitaal kan het zijn dat de onderhandelingskracht van vakbonden dusdanig is afgezwakt dat verschillen in vakbondslidmaatschap er weinig toe doen.

We zien echter wel dat de positieve associatie tussen technologie implementatie en de duur van het zoeken naar een nieuwe baan iets minder sterk is in sectoren met meer vakbondslidmaatschap. Dit zou kunnen betekenen dat vakbonden een rol spelen bij het bevorderen van baantransities van werknemers wanneer technologische verandering plaatsvindt. Verder zou de bevinding dat we slechts kleine effecten van technologisering op de kans op baan beëindiging zien bewijs kunnen zijn dat institutionele bescherming van werknemers in Nederland sterk is. Binnen het corporatistische Nederlandse poldermodel zijn veel van de manieren waarop vakbonden de belangen van werknemers behartigen geformaliseerd en gecoördineerd. Hierdoor is de invloed van vakbonden waarschijnlijk minder afhankelijk van de mate van vakbondslidmaatschap in vergelijking met landen waar de rol van vakbonden meer activistisch en lokaal is. Het feit dat collectieve arbeidsovereenkomsten van toepassing zijn op veel meer werknemers (79\%) dan alleen vakbondsleden (17\%) wijst op een vakbondsinvloed die gekanaliseerd wordt door vertegenwoordigers. Wat de resultaten van deze dissertatie ons mogelijk vertellen is dat het institutionaliseren van de rol en de invloed van werknemersverenigingen helpt de onderhandelingspositie van werknemers te behouden, ondanks het teruglopen van vakbondslidmaatschap.

\section{Beleidsaanbevelingen}

De resultaten van de studies laten zien dat technologische veranderingen, tot nu toe, samenhangen met aanpassingsuitdagingen voor sommige werknemers, maar dat de effecten op banen van werknemers over het algemeen klein zijn. In overeenstemming met deze bevindingen beargumenteren Goos et al. (2019) dat de herstructurering van banen door technologie op dit moment een grotere uitdaging is dan een vermindering van de algehele werkgelegenheid. Ze benadrukken dat Europees beleid gericht op het bevorderen van een leven-lang-leren en werknaar-werk transities cruciaal is voor een goede voorbereiding op komende technologische veranderingen. Met name voor lager opgeleiden en oudere werknemers. Onze bevindingen bevestigen deze beleidsstrategie. 
Verder zouden maatregelen gericht op het verminderen van ongelijkheden die voortkomen uit verschillen in machtsposities en sociale categorisatie het huidige beleid, wat met name inzet op investeringen in menselijk kapitaal, mogelijk kunnen versterken. Investeringen in het trainen van oudere werknemers helpen waarschijnlijk, maar als deze werknemers last blijven houden van negatieve stereotypen en zij werkgevers niet kunnen overtuigen van hun nieuwverworven vaardigheden kan dit de effectiviteit van beleid verminderen. Een mogelijke manier voorwaarts is dat overheden, scholingsinstituten en organisaties toewerken naar standaardisering van certificaten die behaald zijn tijdens trainingen en opleidingstrajecten op latere leeftijd zodat de signaalfunctie van deze trajecten meer vergelijkbaar worden met formele opleidingen. Over het algemeen genomen zou organisatiebeleid over technologie en de toekomst van werk mogelijk kunnen profiteren van de inzichten en praktijken uit organisatiebeleid over inclusiviteit op de arbeidsmarkt en binnen organisaties. Bijvoorbeeld het gebruik van inclusieve vacatures, selectie van werknemers gebaseerd op kennis en vaardigheden, het gebruik van diverse selectiecomités, en het maken en communiceren van organisatiebeleid gericht op gelijkheid van behandeling en kansen.

Een ander onderwerp van Europees beleid gaat over de aansluiting tussen opleiding en werk. Het monitoren en voorspellen van de vaardigheden die bedrijven nodig gaan hebben helpt opleidingen om tijdig in te spelen op een door technologie veranderende vraag vanuit de praktijk. Een belangrijke manier om de aansluiting tussen scholing en de praktijk te bevorderen is het ontwikkelen van praktijkopleidingen, het gebruik van stages binnen opleidingen en het combineren van deze twee binnen duale-opleidingssystemen. Hoewel het laten aansluiten van opleidingen aan de behoeften vanuit het bedrijfsleven van grote waarde kan zijn, zit er een mogelijke valkuil in een beleidsstrategie die opleidingen verbindt aan technologie. Nieuwe technologie vervangt vaak oude technologie. Vaardigheden en ervaring die sterk verbonden zijn aan oude technologieën hebben waarschijnlijk het meeste last van waardevermindering wanneer nieuwe technologie oude technologie vervangt binnen een organisatie. Als gevolg daarvan is het mogelijk dat het toespitsen van opleidingen op de vraag aan vaardigheden vanuit het bedrijfsleven op de korte termijn de transitie van opleiding naar de arbeidsmarkt verbetert. Echter, op de lange termijn kan een tweede golf van technologische veranderingen juist een uitdaging vormen voor deze groep werknemers, waarmee het belang van meer continue investeringen in omscholing en training door werknemers en werkgevers mogelijk toeneemt. 


\section{References}


Acemoglu, D. (2002). Technical change, inequality, and the labor market. Journal of Economic Literature, 40(1), 7-72.

Acemoglu, D., Aghion, P., \& Violante, G. L. (2001, December). Deunionization, technical change and inequality. In Carnegie-Rochester conference series on public policy (Vol. 55, No. 1, pp. 229-264). North-Holland.

Acemoglu, D., \& Autor, D. (2011). Skills, tasks and technologies: Implications for employment and earnings. Handbook of Labor Economics, 4, 1043-1171.

Adner, R., \& Kapoor, R. (2016). Innovation ecosystems and the pace of substitution: Reexamining technology S-curves. Strategic Management Journal, 37(4), 625-648.

Aghion, P., Antonin, C., Bunel, S., \& Jaravel, X. (2020) What Are the Labor and Product Market Effects of Automation? New Evidence from France. Retrieved from https://scholar.harvard.edu/aghion/publications/what-are-labor-and-product-market effects-automation-new-evidence-france

Allport, W. Gordon. (1954). The Nature of Prejudice. Oxford, Addison-Wesley.

Althauser, R. P., \& Kalleberg, A. L. (1981). Firms, occupations, and the structure of labor markets: A conceptual analysis. Sociological Perspectives on Labor Markets, 8, 119-149.

Andriessen, I., Nievers, E., Dagevos, J., \& Faulk, L. (2012). Ethnic discrimination in the Dutch labor market: Its relationship with job characteristics and multiple group membership. Work and Occupations, 39(3), 237-269.

Arntz, M., Gregory, T., Lehmer, F., Matthes, B., \& Zierahn, U. (2017, October). Technology and jobs in the fourth industrial revolution. In IZA Workshop: Labor Productivity and the Digital Economy (Vol. 6).

Arntz, M., Gregory, T., \& Zierahn, U. (2017). Revisiting the risk of automation. Economics Letters, 159, 157-160.

Arulampalam, W., Booth, A. L., \& Bryan, M. L. (2004). Training in europe. Journal of the European Economic Association, 2(2-3), 346-360.

Åslund, O., \& Skans, O. N. (2010). Will I see you at work? Ethnic workplace segregation in Sweden, 1985-2002. ILR Review, 63(3), 471-493.

Autor, D. H. (2015). Why Are There Still So Many Jobs? The History and Future of Workplace Automation. Journal of Economic Perspectives, 29 (3): 3-30.

Autor, D. H., \& Dorn, D. (2013). The growth of low-skill service jobs and the polarization of the US labor market. American Economic Review, 103(5), 1553-97.

Autor, D. H., Katz, L. F., \& Kearney, M. S. (2006). The polarization of the US labor market. The American Economic Review, 96(2), 189-194.

Autor, D. H., Katz, L. F., \& Kearney, M. S. (2008). Trends in US wage inequality: Revising the revisionists. The Review of Economics and Statistics, 90(2), 300-323.

Autor, D. H., Katz, L. F., \& Krueger, A. B. (1998). Computing inequality: have computers changed the labor market?. The Quarterly Journal of Economics, 113(4), 1169-1213.

Autor, D. H., Levy, F., \& Murnane, R. J. (2003). The skill content of recent technological change: An empirical exploration. The Quarterly journal of economics, 118(4), 1279-1333.

Avent-Holt, D., \& Tomaskovic-Devey, D. (2010). The relational basis of inequality: Generic and contingent wage distribution processes. Work and Occupations, 37(2), 162-193. 
Avent-Holt, D., \& Tomaskovic-Devey, D. (2012). Relational inequality: Gender earnings inequality in US and Japanese manufacturing plants in the early 1980s. Social Forces, 91(1), 157-180.

Avent-Holt, D., \& Tomaskovic-Devey, D. (2014). A relational theory of earnings inequality. American Behavioral Scientist, 58(3), 379-399.

Baccaro, L., \& Howell, C. (2011). A common neoliberal trajectory: The transformation of industrial relations in advanced capitalism. Politics \& Society, 39(4), 521-563.

Bacolod, M., \& Rangel, M. A. (2017). Economic assimilation and skill acquisition: Evidence from the occupational sorting of childhood immigrants. Demography, 54(2), 571-602.

Baron, J. N., \& Bielby, W. T. (1980). Bringing the firms back in: Stratification, segmentation, and the organization of work. American sociological review, 737-765.

Bartel, A. P., \& Lichtenberg, F. R. (1987). The comparative advantage of educated workers in implementing new technology. The Review of Economics and Statistics, 69(1), 1-11.

Bartel, A. P., \& Sicherman, N. (1993). Technological change and retirement decisions of older workers. Journal of Labor Economics, 11(1), 162-183.

Bauer, T. K., \& Bender, S. (2004). Technological change, organizational change, and job turnover. Labour Economics, 11(3), 265-291.

Baumol, W. J., \& Wolff, E. N. (1998). Side effects of progress: How technological change increases the duration of unemployment (No. 41). Public Policy Brief.

BBC (2015), Will a robot take your job? Retrieved from: https://www.bbc.com/news/technology-34066941

Beaudry, P., Green, D. A., \& Sand, B. M. (2016). The great reversal in the demand for skill and cognitive tasks. Journal of Labor Economics, 34(S1), S199-S247.

Becker, G. S. (1993). Human capital: A theoretical and empirical analysis with special reference to education. Chicago: The University of Chicago Press. http://dx.doi.org/10.7208/chicago/9780226041223.001.0001

Becker, G. S. (2009). Human capital: A theoretical and empirical analysis, with special reference to education. University of Chicago press.

Beckmann, M. (2007). Age-biased technological and organizational change: Firm-level evidence and Management Implications. WWZ Discussion Paper No. 05/07.

Behaghel, L., \& Greenan, N. (2005). Training and age-biased technical change: evidence from French micro data. Mimeo, CREST-INSEE.

Berman, E., Bound, J., \& Griliches, Z. (1994). Changes in the demand for skilled labor within US manufacturing: evidence from the annual survey of manufactures. The Quarterly Journal of Economics, 109(2), 367-397.

Berman, E., Bound, J., \& Machin, S. (1998). Implications of skill-biased technological change: international evidence. The Quarterly Journal of Economics, 113(4), 1245-1279.

Bessen, J. E. (2016). How computer automation affects occupations: Technology, jobs, and skills. Boston University School of Law, Law and Economics Research Paper, (15-49).

Bessen, J. E., Goos, M., Salomons, A., \& Van den Berge, W. (2019). Automatic Reaction-What Happens to Workers at Firms that Automate?. Boston University School of Law, Law and Economics Research Paper.

Bessen, J. E., Goos, M., Salomons, A., \& Van den Berge, W. (2020). Automation: A Guide for Policymakers. 
Bessen, J. E., \& Righi, C. (2019). Shocking Technology: What Happens When Firms Make Large IT Investments?. Boston Univ. School of Law, Law and Economics Research Paper, (19-6).

Bidwell, M. J. (2013). What happened to long-term employment? The role of worker power and environmental turbulence in explaining declines in worker tenure. Organization Science, 24(4), 1061-1082.

Bielby, W. T., \& Baron, J. N. (1986). Men and women at work: Sex segregation and statistical discrimination. American Journal of Sociology, 91(4), 759-799.

Black, S. E., \& Spitz-Oener, A. (2010). Explaining women's success: technological change and the skill content of women's work. The Review of Economics and Statistics, 92(1), $187-$ 194.

Blechinger, D., \& Pfeiffer, F. (1996). Technological change and skill obsolescence: the case of German apprenticeship training (No. 96-15). ZEW Discussion Papers.

Bobo, L. (1988). Group conflict, prejudice, and the paradox of contemporary racial attitudes. In Eliminating racism (85-114). Springer, Boston, MA.

Böckerman, P., Skedinger, P., \& Uusitalo, R. (2018). Seniority rules, worker mobility and wages: Evidence from multi-country linked employer-employee data. Labour Economics, 51, 48-62.

Boeri, T., Brugiavini, A., \& Calmfors, L. (Eds.). (2001). The role of unions in the twenty-first century: a report for the Fondazione Rodolfo Debenedetti. OUP Oxford.

Bonfiglioli, A., R. Crinò, H. Fadinger, and G. Gancia. (2020). Robot Imports and Firm Level Outcomes. Retrieved from: https://repec.cepr.org/repec/cpr/ceprdp/DP14593.pdf

Bresnahan, T. F., Brynjolfsson, E., \& Hitt, L. M. (2002). Information technology, workplace organization, and the demand for skilled labor: Firm-level evidence. The Quarterly Journal of Economics, 117(1), 339-376.

Brewer, M. B. (1979). In-group bias in the minimal intergroup situation: A cognitivemotivational analysis. Psychological bulletin, 86(2), 307.

Brown, J. N. (1989). Why do wages increase with tenure? on-the-job training and life-cycle wage growth observed within firms. The American Economic Review, 79(5), 971-991.

Brynjolfsson, E., \& McAfee, A. (2014). The second machine age: Work, progress, and prosperity in a time of brilliant technologies. WW Norton \& Company.

Bryson, A., \& White, M. (2006). Unions, within-workplace job cuts and job security guarantees (No. 733). Centre for Economic Performance, London School of Economics and Political Science.

Brzeski, C., \& Burk, I. (2015). Die Roboter kommen. Folgen der Automatisierung für den deutschen Arbeitsmarkt. INGDiBa Economic Research, 30.

Buchanan, D., \& Badham, R. (2008). Power, politics, and organizational change: Winning the turf game. Sage.

Burkhardt, M. E., \& Brass, D. J. (1990). Changing patterns or patterns of change: The effects of a change in technology on social network structure and power. Administrative Science Quarterly, 104-127.

Card, D., \& DiNardo, J. E. (2002). Skill-biased technological change and rising wage inequality: Some problems and puzzles. Journal of Labor Economics, 20(4), 733-783. 
Carmichael, F., \& Ercolani, M. G. (2014). Age-training gaps in the European Union. Ageing \& Society, 34(1), 129-156.

Chan, S., \& Huff Stevens, A. (2001). Job loss and employment patterns of older workers. Journal of Labor Economics, 19(2), 484-521.

Chiswick, B. R., Le, A. T., \& Miller, P. W. (2008). How immigrants fare across the earnings distribution in Australia and the United States. ILR Review, 61(3), 353-373.

Choi, S., Leiter, J., \& Tomaskovic-Devey, D. (2008). Contingent autonomy: Technology, bureaucracy, and relative power in the labor process. Work and Occupations, 35(4), 422455.

CNBC (2019) These American workers are most afraid of A.I. taking over their jobs. Retrieved from: https://www.cnbc.com/2019/11/07/these-american-workers-are-the-most-afraid-ofai-taking-their-jobs.html

Coenders, M., \& Scheepers, P. (1998). Support for ethnic discrimination in the Netherlands 1979-1993: Effects of period, cohort, and individual characteristics. European Sociological Review, 14(4), 405-422.

Cornell University, INSEAD, \& WIPO (2015). The Global Innovation Index 2015: Effective Innovation Policies for Development, Fontainebleau, Ithaca, and Geneva.

Cortes, G. M., Jaimovich, N., \& Siu, H. E. (2017). Disappearing routine jobs: Who, how, and why?. Journal of Monetary Economics, 91, 69-87.

Cortes, G. M., \& Salvatori, A. (2016). Delving into the Demand Side: Changes in Workplace Specialization and Job Polarization. IZA Discussion Papers, No.10120, Institute for the Study of Labor (IZA), Bonn.

Cotter, D. A., Hermsen, J. M., \& Vanneman, R. (1999). Systems of gender, race, and class inequality: Multilevel analyses. Social Forces, 78(2), 433-460.

Crook, T. R., Todd, S. Y., Combs, J. G., Woehr, D. J., \& Ketchen Jr, D. J. (2011). Does human capital matter? A meta-analysis of the relationship between human capital and firm performance. Journal of Applied Psychology, 96(3), 443.

De Beer, P., \& Berntsen, L. (2019). Vakbondslidmaatschap onder druk in Nederland, maar niet in België. Tijdschrift voor Arbeidsvraagstukken, 35, 3.

De Beer, P. \& Keune, M. (2017). Dutch unions in a time of crisis. In: Lehndorff, S., Dribbusch. H. and Schulten, T. (eds.). Rough waters: European trade unions in a time of crisis. Brussels: ETUI.

De Koning, J., \& Gelderblom, A. (2006). ICT and older workers: No unwrinkled relationship. International Journal of Manpower, 27(5), 467-490.

De Hek, P., \& Van Vuuren, D. (2011). Are older workers overpaid? A literature review. International Tax and Public Finance, 18(4), 436-460.

Dearden, L., Reed, H., \& Van Reenen, J. (2006). The impact of training on productivity and wages: Evidence from British panel data. Oxford Bulletin of Economics and Statistics, 68(4), 397-421.

Dekker, F., Salomons, A., \& Waal, J. V. D. (2017). Fear of robots at work: the role of economic self-interest. Socio-Economic Review, 15(3), 539-562.

Desjardins, R., \& Warnke, A. J. (2012). Ageing and skills: a review and analysis of skill gain and skill loss over the lifespan and over time. OECD Education Working Papers No. 72. 
DiMaggio, P. J., \& Powell, W. W. (1983). The iron cage revisited: Institutional isomorphism and collective rationality in organizational fields. American sociological review, 147-160.

Dismissal. (2011, 18 December). Retrieved from https://www.government.nl/documents/leaflets/2011/12/18/dismissal

Diversiteit in Bedrijf (2018, 19 March) Divers werven en selecteren. Kennisdocument. Retrieved from https://diversiteitinbedrijf.nl/wp-content/uploads/2018/04/DiB-Kennisdocument-Diverswerven-en-selecteren-maart-2018.pdf

Dolfing, M., \& Van Tubergen, F. (2005). Bensaidi of Veenstra. Sociologie, 1, 407-422.

Domina, T., Penner, A., \& Penner, E. (2017). Categorical inequality: Schools as sorting machines. Annual Review of Sociology, 43, 311-330.

Dustmann, C., \& Schönberg, U. (2009). Training and union wages. The Review of Economics and Statistics, 91(2), 363-376.

Dutch Ministry of Social Affairs and Employment (2020, 5 July) Hoe word ik een verderkijker? Retrieved from: https://www.verderkijkers.nl/onderwerpen/hoe-word-ik-een-verderkijker

Dwyer, R. E. (2013). The care economy? Gender, economic restructuring, and job polarization in the US labor market. American Sociological Review, 78(3), 390-416.

Elvira, M. M., \& Graham, M. E. (2002). Not just a formality: Pay system formalization and sex-related earnings effects. Organization Science, 13(6), 601-617.

Elvira, M. M., \& Zatzick, C. D. (2002). Who's displaced first? The role of race in layoff decisions. Industrial Relations: A Journal of Economy and Society, 41(2), 329-361.

Esser, H. (2006). Migration, language, and integration. AKI Research Review 4. Berlin: Programme on Intercultural Conflicts and Societal Integration (AKI), Social Science Research Center. Retrieved 21 December 2007 from http://www.wzb.eu/zkd/aki/files/aki_research_review_4

European Commission (2019) Employment and social developments in Europe. Sustainable growth for all: choices for the future of Social Europe. Annual review 2019. Retrieved from

https://op.europa.eu/en/publication-detail/-/publication/747fefa1-d085-11e9-b4bf01aa75ed71a1

European Commission (2016) A new skills agenda for Europe. Working together to strengthen human capital, employability, and competitiveness. Retrieved from https://eur-lex.europa.eu/legal-content/en/TXT/?uri=CELEX:52016DC0381

European Commission, Eurostat (no date). Community Innovation Survey 2008 synthesis quality report. Retrieved from https://ec.europa.eu/eurostat/cache/metadata/Annexes/inn_cis2_esms_an3.pdf

European Commission, Eurostat (no date). Community Innovation Survey 2012 synthesis quality report. Retrieved from https://ec.europa.eu/eurostat/cache/metadata/Annexes/inn_cis8_esms_an6.pdf

European Commission, Eurostat (no date). Community Innovation Survey 2014 synthesis quality report. Retrieved from https://ec.europa.eu/eurostat/cache/metadata/Annexes/inn_cis9_esms_an6.pdf

Fernandez, R. M. (2001). Skill-Biased technological change and wage inequality: Evidence from a plant retooling. American Journal of Sociology, 107(2), 273-320. 
Fernández-Macías, E. (2012). Job polarization in Europe? Changes in the employment structure and job quality, 1995-2007. Work and Occupations, 39(2), 157-182.

Fernández-Macías, E., \& Hurley, J. (2017). Routine-biased technical change and job polarization in Europe. Socio-Economic Review, 15(3), 563-585.

Fibbi, R., Lerch, M., \& Wanner, P. (2006). Unemployment and discrimination against youth of immigrant origin in Switzerland: When the name makes the difference. Journal of International Migration and Integration/Revue de l'integration et de la migration internationale, 7(3), 351-366.

Ford, M. (2015). Rise of the Robots: Technology and the Threat of a Jobless Future. Basic Books, New York.

Freeman, R. B., \& Medoff, J. L. (1984). What do unions do. Indus. \& Lab. Rel. Rev., 38, 244.

Frey, C. B., \& Osborne, M. A. (2017). The future of employment: how susceptible are jobs to computerisation?. Technological Forecasting and Social Change, 114, 254-280.

Fullerton, A. S., \& Wallace, M. (2007). Traversing the flexible turn: US workers' perceptions of job security, 1977-2002. Social Science Research, 36(1), 201-221.

Gathmann, C., \& Schönberg, U. (2010). How general is human capital? A Task-Based approach. Journal of Labor Economics, 28(1), 1-49.

Goldin, C. D., \& Katz, L. F. (1998). The origins of technology-skill complementarity. The Quarterly Journal of Economics, 113(3), 693-732.

Goldin, C. D., \& Katz, L. F. (2009). The race between education and technology. Harvard university press.

Goos, M., Arntz, M., Zierahn, U., Gregory, T., Gomez, S. C., Vazquez, I. G., \& Jonkers, K. (2019). The Impact of Technological Innovation on the Future of Work (No. 2019/03). JRC Working Papers Series on Labour, Education and Technology.

Goos, M., \& Manning, A. (2007). Lousy and lovely jobs: The rising polarization of work in Britain. The Review of Economics and Statistics, 89(1), 118-133.

Goos, M., Manning, A., \& Salomons, A. (2009). Job polarization in europe. The American Economic Review, 99(2), 58-63.

Goos, M., Manning, A., \& Salomons, A. (2014). Explaining job polarization: Routine-biased technological change and offshoring. The American Economic Review, 104(8), 2509-2526.

Goos, M., Rademakers, E., Salomons, A., \& Willekens, B. (2019). Markets for jobs and their task overlap. Labour Economics, 61, 101750.

Granovetter, M. (2018). Getting a job: A study of contacts and careers. University of Chicago press.

Gregory, T., Salomons, A. M., \& Zierahn, U. (2016). Racing With or Against the Machine? Evidence from Europe. ZEW - Centre for European Economic Research Discussion Paper No. 16-053.

Guerrazzi, M. (2014). Workforce ageing and the training propensity of Italian firms: crosssectional evidence from the INDACO survey. European Journal of Training and Development, 38(9), 803-821.

Hall, B. H., \& Khan, B. (2003). Adoption of new technology (No. w9730). National bureau of economic research.

Hall, P. A., \& Soskice, D. (Eds.). (2001). Varieties of capitalism: The institutional foundations of comparative advantage. OUP Oxford. 
Hall, R., \& Lansbury, R. D. (2006). Skills in Australia: Towards workforce development and sustainable skill ecosystems. Journal of Industrial Relations, 48(5), 575-592.

Hanley, C. (2014). Putting the bias in skill-biased technological change? A relational perspective on white-collar automation at General Electric. American Behavioral Scientist, $58(3), 400-415$.

Hartog, J., Leuven, E., \& Teulings, C. (2002). Wages and the bargaining regime in a corporatist setting: the Netherlands. European Journal of Political Economy, 18(2), 317-331.

Heath, A. F., Rothon, C., \& Kilpi, E. (2008). The second generation in Western Europe: Education, unemployment, and occupational attainment. Annual Review of Sociology, 34, 211-235.

Hedström, P. (1991). Organizational differentiation and earnings dispersion. American Journal of Sociology, 97(1), 96-113.

Holzer, H. J. (1988). Search method use by unemployed youth. Journal of Labor Economics, 6(1), 1-20.

Holzer, H. J. (2015). Job market polarization and US worker skills: A tale of two middles. Economic Studies, The Brookings Institution.

Huffman, M. L., \& Cohen, P. N. (2004). Racial wage inequality: Job segregation and devaluation across US labor markets. American Journal of Sociology, 109(4), 902-936.

Imai, S., Stacey, D., \& Warman, C. (2019). From engineer to taxi driver? Language proficiency and the occupational skills of immigrants. Canadian Journal of Economics/Revue canadienne d'économique, 52(3), 914-953.

In, J., \& Lee, D. K. (2019). Survival analysis: part II-applied clinical data analysis. Korean Journal of Anesthesiology, 72(5), 441.

Josten, E., \& Schalk, R. (2010). The effects of demotion on older and younger employees. Personnel Review, 39(2), 195-209.

Jovanovic, B. (1979). Job matching and the theory of turnover. Journal of Political Economy, 87(5, Part 1), 972-990.

Jung, J., Lippényi, Z., \& Mun, E. (2020) Workplace volatility and gender inequality: A comparison of the Netherlands and South Korea. Manuscript submitted for publication.

Kalev, A., Dobbin, F., \& Kelly, E. (2006). Best practices or best guesses? Assessing the efficacy of corporate affirmative action and diversity policies. American Sociological Review, 71(4), 589-617.

Kalleberg, A. L. (2000). Nonstandard employment relations: Part-time, temporary and contract work. Annual Review of Sociology, 26(1), 341-365.

Kalleberg, A. L. (2009). Precarious work, insecure workers: Employment relations in transition. American sociological review, 74(1), 1-22.

Kalleberg, A. L. (2011). Good jobs, bad jobs: The rise of polarized and precarious employment systems in the United States, 1970s-2000s. Russell Sage Foundation.

Kalleberg, A. L., \& Van Buren, M. E. (1996). Is bigger better? Explaining the relationship between organization size and job rewards. American sociological review, 47-66.

Kalleberg, A. L., Wallace, M., \& Althauser, R. P. (1981). Economic segmentation, worker power, and income inequality. American Journal of Sociology, 87(3), 651-683.

Kanas, A., \& Van Tubergen, F. (2009). The impact of origin and host country schooling on the economic performance of immigrants. Social Forces, 88(2), 893-915. 
Kanas, A., Van Tubergen, F., \& Van der Lippe, T. (2011). The role of social contacts in the employment status of immigrants: A panel study of immigrants in Germany. International Sociology, 26(1), 95-122.

Katz, L. F. (1999). Changes in the wage structure and earnings inequality. In Handbook of Labor Economics (Vol. 3, pp. 1463-1555). Elsevier.

Katz, L. F., \& Murphy, K. M. (1992). Changes in relative wages, 1963-1987: supply and demand factors. The Quarterly Journal of Economics, 107(1), 35-78.

Keune, M. (Ed.). (2016). Nog steeds een mirakel? De legitimiteit van het poldermodel in de eenentwintigste eeuw. Amsterdam: Amsterdam University Press.

King, J., Reichelt, M., \& Huffman, M. L. (2017). Computerization and wage inequality between and within German work establishments. Research in Social Stratification and Mobility, 47, 67-77.

Koch, M., Manuylov, I., \& Smolka, M. (2020). Microeconomic implications of robot adoption: A firm level perspective. Retrieved from https://www.dropbox.com/s/7wd4sz2lr9f1qv7/KMS_manuscript_r.pdf?dl=0

Kollmeyer, C. (2018). Trade union decline, deindustrialization, and rising income inequality in the United States, 1947 to 2015. Research in Social Stratification and Mobility, 57, 1-10.

Kollmeyer, C., \& Peters, J. (2019). Financialization and the Decline of Organized Labor: A Study of 18 Advanced Capitalist Countries, 1970-2012. Social Forces, 98(1), 1-30.

Kristal, T. (2013). The capitalist machine: Computerization, workers' power, and the decline in labor's share within US industries. American Sociological Review, 78(3), 361-389.

Kristal, T., \& Cohen, Y. (2017). The causes of rising wage inequality: the race between institutions and technology. Socio-Economic Review, 15(1), 187-212.

Krueger, A. B. (1993). How computers have changed the wage structure: evidence from microdata, 1984-1989. The Quarterly Journal of Economics, 108(1), 33-60.

Lancee, B., \& Bol, T. (2017). The transferability of skills and degrees: Why the place of education affects immigrant earnings. Social Forces, 96(2), 691-716.

Lazear, E. P. (2009). Firm-specific human capital: A skill-weights approach. Journal of Political Economy, 117(5), 914-940.

Lee, D. S. (1999). Wage inequality in the United States during the 1980s: Rising dispersion or falling minimum wage?. The Quarterly Journal of Economics, 114(3), 977-1023.

Lehndorff, S., Dribbusch, H., \& Schulten, T. (Eds.). (2018). Rough waters: European trade unions in a time of crises. European Trade Union Institute.

Lindbeck, A. (1994). The welfare state and the employment problem. The American Economic Review, 84(2), 71-75.

Lössbroek, J., Lancee, B., Van der Lippe, T., \& Schippers, J. (2019). Understanding old-age adaptation policies in Europe: The influence of profit, principles and pressures. Ageing and Society, 39(5), 924-950.

Machin, S., \& Van Reenen, J. (1998). Technology and changes in skill structure: evidence from seven OECD countries. The Quarterly Journal of Economics, 113(4), 1215-1244.

Manyika, J., Chui, M., \& Miremadi, M. (2017). A future that works: AI, automation, employment, and productivity. McKinsey Global Institute Research, Tech. Rep, 60. 
Manyika, J., Chui, M., Miremadi, M., Bughin, J., George, K., Willmott, P., \& Dewhurst, M. (2017). A future that works: Automation, employment, and productivity. McKinsey Global Institute, New York, NY.

Marini, M. M., \& Fan, P. L. (1997). The gender gap in earnings at career entry. American Sociological Review, 588-604.

Marino, S., Penninx, R., \& Roosblad, J. (2015). Trade unions, immigration and immigrants in Europe revisited: Unions' attitudes and actions under new conditions. Comparative Migration Studies, 3(1), 1.

Melzer, S. M., Tomaskovic-Devey, D., Schunck, R., \& Jacobebbinghaus, P. (2018). A relational inequality approach to first-and second-generation immigrant earnings in German workplaces. Social Forces, 97(1), 91-128.

Meyer, B. (2019). Financialization, technological change, and trade union decline. SocioEconomic Review, 17(3), 477-502.

Meyer, J. (2011). Workforce age and technology adoption in small and medium-sized service firms. Small Business Economics, 37(3), 305-324.

Michaels, G., Natraj, A., \& Van Reenen, J. (2014). Has ICT polarized skill demand? evidence from eleven countries over twenty-five years. Review of Economics and Statistics, 96(1), 60-77.

Mishel, L., Schmitt, J., \& Shierholz, H. (2013). Assessing the job polarization explanation of growing wage inequality. Economic Policy Institute. Working Paper.

Mortensen, P. S., \& Bloch, C. W. (2005). Oslo manual-guidelines for collecting and interpreting innovation data. Organisation for Economic Cooporation and Development, OECD.

Mouw, T. (2003). Social capital and finding a job: do contacts matter?. American Sociological Review, 868-898.

Mueller, A. I., Spinnewijn, J., \& Topa, G. (2018). Job Seekers' Perceptions and Employment Prospects: Heterogeneity, Duration Dependence and Bias (No. w25294). National Bureau of Economic Research.

Nedelkoska, L. (2013). Occupations at risk: Job tasks, job security, and wages. Industrial and Corporate Change, 22(6), 1587-1628.

OECD (2016) International Migration Outlook. OECD Publishing, Paris, https://doi.org/10.1787/migr_outlook-2016-en

OECD (2018) OECD stat, Trade union membership and trade union density. https://stats.oecd.org/Index.aspx?DataSetCode $=$ CBCC (Accessed 29 April 2018)

OECD (2019), Working Better with Age, Ageing and Employment Policies, OECD Publishing, Paris, https://doi.org/10.1787/c4d4f66a-en.

OECD (2020a), OECD stat, Strictness of employment protection. https://stats.oecd.org/Index.aspx?DataSetCode=EPL_OV (Accessed 20 January, 2020)

OECD (2020b), Part-time employment rate (indicator). doi: 10.1787/f2ad596c-en (Accessed on 27 February 2020)

OECD/Eurostat/UNESCO Institute for Statistics (2015), ISCED 2011 Operational Manual: Guidelines for Classifying National Education Programmes and Related Qualifications, OECD Publishing, Paris. DOI: http://dx.doi.org/10.1787/9789264228368-en 
Orlikowski, W. J., \& Barley, S. R. (2001). Technology and institutions: What can research on information technology and research on organizations learn from each other?. MIS Quarterly, 25(2), 145-165.

Pajarinen, M., \& Rouvinen, P. (2014). Computerization threatens one third of Finnish employment. Etla Brief, 22(13.1), 2014.

Petersen, T., \& Saporta, I. (2004). The opportunity structure for discrimination. American Journal of Sociology, 109(4), 852-901.

Pettigrew, T. F., \& Tropp, L. R. (2006). A meta-analytic test of intergroup contact theory. Journal of Personality and Social Psychology, 90(5), 751.

Pfeffer, J., \& Cohen, Y. (1984). Determinants of internal labor markets in organizations. Administrative Science Quarterly, 550-572.

Picchio, M., \& van Ours, J. C. (2013). Retaining through training even for older workers. Economics of Education Review, 32, 29-48.

Posthuma, R. A., \& Campion, M. A. (2009). Age stereotypes in the workplace: Common stereotypes, moderators, and future research directions. Journal of Management, 35(1), $158-188$.

Quillian, L. (1995). Prejudice as a response to perceived group threat: Population composition and anti-immigrant and racial prejudice in Europe. American Sociological Review, 586611.

Raymo, J. M., Warren, J. R., Sweeney, M. M., Hauser, R. M., \& Ho, J. H. (2011). Precarious employment, bad jobs, labor unions, and early retirement. Journals of Gerontology Series B: Psychological Sciences and Social Sciences, 66(2), 249-259.

Reyneri, E., \& Fullin, G. (2011). Labour market penalties of new immigrants in new and old receiving West European countries. International Migration, 49(1), 31-57.

Roosblad, J. (2002). Vakbonden en immigranten in Nederland (1960-1997). Amsterdam: Aksant.

Roscigno, V. J., Garcia, L. M., \& Bobbitt-Zeher, D. (2007). Social closure and processes of race/sex employment discrimination. The Annals of the American Academy of Political and Social Science, 609(1), 16-48.

Rosholm, M., Scott, K., \& Husted, L. (2001). The Times they are A-Changin': Organizational Change and Immigrant Employment Opportunities in Scandinavia. International Migration Review 40 (2): 318-347.

Scheepers, P., Gijsberts, M., \& Coenders, M. (2002). Ethnic exclusionism in European countries. Public opposition to civil rights for legal migrants as a response to perceived ethnic threat. European Sociological Review, 18(1), 17-34.

Schlueter, E., \& Scheepers, P. (2010). The relationship between outgroup size and antioutgroup attitudes: A theoretical synthesis and empirical test of group threat-and intergroup contact theory. Social Science Research, 39(2), 285-295.

Scott, W.R. (2014). Institutions and organizations. Ideas, interests, and identities. Sage (4th edition).

Scott, W. R., \& Davis, G. F. (2015). Organizations and organizing: Rational, natural and open systems perspectives. Routledge. 
Siegel, D. S. (1998). The impact of technological change on employment: evidence from a firmlevel survey of Long Island manufacturers. Economics of Innovation and New Technology, 5(2-4), 227-246.

Slegers, K., Van Boxtel, M. P., \& Jolles, J. (2009). The efficiency of using everyday technological devices by older adults: the role of cognitive functions. Ageing \& Society, 29(2), 309-325.

Shin, T. (2009). Earnings inequality within organizations. Social Science Research, 38(1), 225238.

Shore, L. M., \& Goldberg, C. B. (2005). Age discrimination in the workplace. Discrimination at work: The psychological and organizational bases, 203-225.

Spitz-Oener, A. (2006). Technical change, job tasks, and rising educational demands: Looking outside the wage structure. Journal of Labor Economics, 24(2), 235-270.

Stainback, K., \& Tomaskovic-Devey, D. (2012). Documenting desegregation: Racial and gender segregation in private sector employment since the Civil Rights Act. Russell Sage Foundation.

Statistics Netherlands (2012, May 31). Organisatiegraad van werknemers 1995-2011. Retrieved from https://www.cbs.nl/nl-nl/maatwerk/2012/22/organisatiegraad-van-werknemers-19952011

Statistics Netherlands (2016, Nov 21). Jaarrapport integratie 2016. Retrieved from https://www.cbs.nl/nl-nl/publicatie/2016/47/jaarrapport-integratie-2016

Statistics Netherlands (2017, February 6). Ontslagen via rechter of UWV dalen met een kwart. Retrieved from https://www.cbs.nl/nl-nl/nieuws/2017/06/ontslagen-via-rechter-of-uwv-dalen-met-een kwart

Statistics Netherlands (2020). Banen van werknemers in december; economische activiteit (SBI2008). Retrieved from https://opendata.cbs.nl/statline/\#/CBS/nl/dataset/83582NED/table?dl=3E6C7

Svensson, S. (2011). Flexible working conditions and decreasing levels of trust. Employee Relations 34 (2): 126-137.

Sverke, M., Hellgren, J., \& Näswall, K. (2006). Job insecurity: A literature review. Stockholm: National Institute for Working Life.

Tajfel, H., Turner, J. C., Austin, W. G., \& Worchel, S. (1979). An integrative theory of intergroup conflict. Organizational identity: A reader, 56, 65.

Taylor, P., \& Urwin, P. (2001). Age and participation in vocational education and training. Work, Employment \& Society, 15(4), 763-779.

Ten Berge, J., Lippényi, Z., Van der Lippe, T., \& Goos, M. (2020). Technology implementation within enterprises and job ending among employees. A study of the role of educational attainment, organizational tenure, age and unionization. Research in Social Stratification and Mobility, 100548.

Thelen, K. (2014). Varieties of liberalization and the new politics of social solidarity. Cambridge University Press. 
Tholen, G. (2017). Symbolic closure: Towards a renewed sociological perspective on the relationship between higher education, credentials and the graduate labour market. Sociology, 51(5), 1067-1083.

Tilly, C. (1998). Durable inequality. University of California Press.

Tinbergen, J. (1974). Substitution of graduate by other labour. Kyklos: International Review for Social Sciences.

Tinbergen, J. (1975). Income Differences: Recent Research. Amsterdam: North Holland

Tomaskovic-Devey, D. (1993). Gender \& racial inequality at work: The sources and consequences of job segregation (No. 27). Cornell University Press.

Tomaskovic-Devey, D. (2014). The relational generation of workplace inequalities. Social Currents, 1(1), 51-73.

Tomaskovic-Devey, D., \& Avent-Holt, D. (2019). Relational inequalities: An organizational approach. Oxford University Press, USA.

Tomaskovic-Devey, D., Avent-Holt, D., Zimmer, C., \& Harding, S. (2009). The categorical generation of organizational inequality: A comparative test of Tilly's durable inequality. Research in Social Stratification and Mobility, 27(3), 128-142.

Tomaskovic-Devey, D., Hällsten, M., \& Avent-Holt, D. (2015). Where do immigrants fare worse? Modeling workplace wage gap variation with longitudinal employer-employee data. American Journal of Sociology, 120(4), 1095-1143.

Tomaskovic-Devey, D., \& Lin, K. H. (2011). Income dynamics, economic rents, and the financialization of the US economy. American Sociological Review, 76(4), 538-559.

Tomaskovic-Devey, D., \& Skaggs, S. (1999). An establishment-level test of the statistical discrimination hypothesis. Work and Occupations, 26(4), 422-445.

Tomaskovic-Devey, D., \& Skaggs, S. (2002). Sex segregation, labor process organization, and gender earnings inequality. American Journal of Sociology, 108(1), 102-128.

Tomaskovic-Devey, D., Zimmer, C., Stainback, K., Robinson, C., Taylor, T., \& McTague, T. (2006). Documenting desegregation: Segregation in American workplaces by race, ethnicity, and sex, 1966-2003. American Sociological Review, 71(4), 565-588.

Topel, R. (1991). Specific capital, mobility, and wages: Wages rise with job seniority. Journal of Political Economy, 99(1), 145-176.

Touwen, J. (2006) Varieties of Capitalism en de Nederlandse Economie in de Periode 1950 2000. Tijdschrift voor Sociale en Economische Geschiedenis, 3(1), 73-104.

Tracy, J.S. (1986) Seniority rules and the gains from union organization. (NBER Working Paper 2039).

Vallas, S. P. (2006). Empowerment redux: Structure, agency, and the remaking of managerial authority. American Journal of Sociology, 111(6), 1677-1717.

Van den Broek, A., Bronneman-Helmers, R., \& Veldheer, V. (2010). Wisseling van de wacht: generaties in Nederland, Sociaal en Cultureel Rapport 2010. Sociaal en Cultureel Planbureau (SCP). Den Haag, 2010-32.

Van der Lippe, T., \& Lippényi, Z. (Eds.). (2019). Investments in a Sustainable Workforce in Europe. Routledge.

Van Tubergen, F., \& Van de Werfhorst, H. (2007). Postimmigration investments in education: a study of immigrants in the Netherlands. Demography, 44(4), 883-898. 
Vasileva, K. (2012). Nearly two-thirds of the foreigners living in EU Member States are citizens of countries outside the EU-27. Eurostat Statistics in focus, 31, 2012.

Visser, J. (2002). The first part-time economy in the world: a model to be followed?. Journal of European Social Policy, 12(1), 23-42.

Von Below, D., \& Thoursie, P. S. (2010). Last in, first out?: Estimating the effect of seniority rules in Sweden. Labour Economics, 17(6), 987-997.

Wagner, U., Christ, O., Pettigrew, T. F., Stellmacher, J., \& Wolf, C. (2006). Prejudice and minority proportion: Contact instead of threat effects. Social Psychology Quarterly, 69(4), 380-390.

Warman, C., \& Worswick, C. (2015). Technological change, occupational tasks and declining immigrant outcomes: Implications for earnings and income inequality in Canada. Canadian Journal of Economics/Revue canadienne d'économique, 48(2), 736-772.

Weber, S. (2014). Human capital depreciation and education level. International Journal of Manpower, 35(5), 613-642.

Weeden, K. A. (2002). Why do some occupations pay more than others? Social closure and earnings inequality in the United States. American Journal of Sociology, 108(1), 55-101.

Weinberg, B. A. (2004). Experience and Technology Adoption. IZA Discussion paper series No. 1051

Westerman, S. J., \& Davies, D. R. (2000). Acquisition and application of new technology skills: the influence of age. Occupational Medicine, 50(7), 478-482.

World Bank. (2016). World Development Report 2016: Digital Dividends. Washington, DC: World Bank. doi:10.1596/978-1-4648-0671-1. License: Creative Commons Attribution CC BY 3.0 IGO

Yerkes, M. (2009). Part-time work in the Dutch welfare state: the ideal combination of work and care? Policy \& Politics, 37(4), 535-552.

Yerkes, M., \& Visser, J. (2006). Women's preferences or delineated policies? The development of part-time work in the Netherlands, Germany and the United Kingdom. Decent working time, 235. 
Dankwoord

(Acknowledgements) 
$\mathrm{Na}$ de master, vijf en een half jaar geleden dacht dat ik de deur van het Sjoerd Groenman voorgoed achter me had gesloten. Ik zat ernaast. Het bericht dat een van ons mogelijk een eigen onderzoeksvoorstel mocht gaan uitwerken zag ik als een unieke kans. Ik prijs mijzelf gelukkig dat ik niet de enige was die technologische verandering een studiewaardig onderwerp vond. Dat er nu een proefschrift ligt wat bij gratie van de leescommissie het daglicht mag zien, daar ben ik iedereen die hier direct en indirect aan heeft bijgedragen dankbaar voor.

Graag wil ik in het bijzonder de volgende mensen bedanken.

Allereerst mijn dagelijkse begeleider Zoltán. Heel veel dank voor al je inzet en bereidheid om te overleggen, uit te leggen, af te spreken, feedback te geven of anderszins hulp te bieden. De bevlogenheid waarmee je je vak uitoefent is zowel inspirerend als bewonderenswaardig. Ik kan niet ontkennen dat de hoeveelheid in rood verbeterd waar deze ijver regelmatig in resulteerde wel eens wat overweldigend is geweest. Gelukkig werd dit altijd begeleid door een aanstekelijke opgewektheid en positiviteit met een uitnodigende werking. Ik heb genoten van onze samenwerking. Ik waardeer je openheid en persoonlijke benadering zeer. Dank voor alles wat je me geleerd hebt.

Ook mijn begeleiders Tanja en Maarten wil ik bedanken. Tanja, dank voor alle sessies en bemoedigende woorden. Dank ook voor het tonen van begrip in tijden van twijfel en het geven van ruimte om het $\mathrm{PhD}$ werk aan te vullen met nevenactiviteiten. Je hulp bij het knopen doorhakken en het project in goede banen leiden hebben erg geholpen om alles tot een goed einde te brengen. Maarten, dank voor het delen van al je inzichten tijdens onze bijeenkomsten. Met name de bijeenkomsten waarin we op conceptueel niveau konden sparren over ideeën vond ik erg leuk. Achteraf heb ik het gevoel dat we wellicht meer samen hadden kunnen werken. Desalniettemin ben ik blij dat je bereid was om ons team te ondersteunen. Hopelijk treffen we elkaar nog eens in de toekomst.

Verder wil ik de leden van de leescommissie: Ellen Hamaker, Cok Vrooman, Paul de Beer, Frank van Tubergen en Fabian Dekker graag bedanken voor alle tijd en moeite die zij gestoken hebben in het lezen en beoordelen van het proefschrift.

Furthermore, I would like to thank prof. Donald Tomaskovic-Devey for welcoming me as a visiting scholar at UMass Amherst. I really enjoyed the open and informative discussions we had while writing our paper. I want to thank you and your wife Barbara for the nice drinks and dinners that we enjoyed together in Amherst. It was a really special and memorable time. Thanks also to James McAllister for being such a welcoming host, as well as to all the other nice people that I met and who welcomed me during my stay.

I would also like to thank all COIN members for the interesting and fun meetings at Prague and Copenhagen. May your efforts be fruitful!

Verder wil ik mijn jaar- en kamergenoten Marcus en Joris heel graag bedanken. Zonder hen had ik het niet voor elkaar gekregen. Het is vreemd om te bedenken dat je per toeval bij elkaar komt en dat het vervolgens zo goed klikt. Marcus, ik denk dat ik voor ons beiden spreek als ik zeg dat we elkaar er vanaf de master doorheen hebben gesleept. Bedankt voor je bereidheid om ten alle tijde te hulp te schieten als ik ergens niet uitkwam. Je vermogen om te leren is zowel intimiderend als inspirerend. Niet alleen op academisch vlak. Je besloot Nederlands te leren en 
twee jaar later was je vloeiend. Dat dit gepaard ging met het te pas en te onpas quoten van Jiskefet maakte het samenwerken natuurlijk alleen maar mooier. Het is vrij zeker dat je zonder twee kleuters op je kamer je proefschrift eerder af had gehad. Toch hebben we het naar mijn idee super naar ons zin gehad. Daarover gesproken, Joris, dankjewel voor alle potjes kantoorvoetbal die we gespeeld hebben. Het mag een klein wonder heten dat er behalve onze geloofwaardigheid als serieuze $\mathrm{PhD}$ studenten nooit iets anders is gesneuveld. Welgemeende excuses aan onze buren en kamergenoten voor dit exces. Joris, je humor en inzet als initiator en gastheer hebben de afgelopen jaren naar een hoger niveau getild. Dank daarvoor. Ook dank voor alle keren dat je bereid was om vanuit je plek tussen de wolken van mathematische sociologie, natuurkunde en complexity science neer te dalen om met ons, minder ontwikkelde levensvormen de meer mondaine en obscene onderwerpen van het leven te bespreken. Wel jammer dat je nooit de moeite hebt genomen om even een middagje op te offeren om Stata te leren zodat je me daarmee kon helpen. $\mathrm{Nu}$ was Marcus altijd de klos. Maar goed, dat is je vergeven. Jorans, wederom, zonder jullie was het niet gelukt. We hebben veel memorabele dingen meegemaakt samen. Van het doorbrengen van enkele nachten in een houten hutje ergens in een besneeuwd niemandsland in Noorwegen tot het versieren van het kantoorleven met perfect gesynchroniseerde koffiemomenten. Het was er allemaal. Dat er nog veel mag volgen.

Siyang, Judith, Eva en Mathijs, dat we jullie als buren kregen was niet alleen gunstig vanwege jullie tolerantie voor herrie. Wat een geluk heb ik gehad met jullie. (Sorry Siyang, ik had dit natuurlijk in het Engels moeten schrijven, maar ik weet dat je stiekem gewoon Nederlands kan). De hoeveelheid positieve energie die jullie elke dag mee brachten hebben het werk zoveel leuker gemaakt. Siyang, ik heb er erg van genoten hoe verassend goed onze humor klikte. Of, misschien beter gezegd, hoe gracieus je deze tolereerde. Ik wil nog steeds graag zien waar je bent opgegroeid. Al kan ik ook begrijpen dat je ons liever niet introduceert aan je ouders. Ik hoop dat je in Nederland blijft, en anders komen we je opzoeken. Hoe het ook zij, een ding is zeker; hoe minder je werkt, hoe minder er binnenkomt! Judtih, hoewel je helemaal uit Wageningen naar Utrecht kwam duurde het niet lang om het ijs te breken. Ik herinner me nog een verjaardagsfeestje, zo rond 11 Oktober 2016. Sindsdien ben je me blijven verassen. Je hebt de afgelopen jaren letterlijk en figuurlijk een stuk kleurrijker gemaakt. Dankjewel. Eva, hoewel ik me wel eens sceptisch heb uitgelaten over het bestaan van 'Brabantse gezelligheid' ben jij het levende bewijs. Ik denk niet dat ik een grotere gangmaker ken dan jij. Rupsje Nooitgenoeg onder de feestgangers. Ik bewonder je positieve instelling en de manier waarop je voor je idealen staat. Het is meer dan eens een effectief middel tegen cynisme geweest. Keep it going! Mathijs, dat je het voor elkaar hebt gekregen om in drie jaar je proefschrift te schrijven blijft moeilijk te geloven. Zeker gezien de omgeving waarin je dit hebt klaargespeeld. Nou gaat 'cool' blijven je ook opvallend goed af. Het was mooi om samen tot bijna verdrinken aan toe afgemat te worden door Kees. Hopelijk volgen er nog vele sport, feest, jam en chill sessies, maar daar heb ik wel vertrouwen in. Lieve buren, jullie hebben met de ontelbare weekendtripjes, fuifjes, etentjes, schapen- en tuinbezoekjes en koffiepauzes de afgelopen jaren tot een waar feest gemaakt.

Ik begrijp dat ik zojuist iemand te kort heb gedaan. Nikki, natuurlijk denk ik bij ambassadeurs van Brabantse gezelligheid ook aan jou. Jij en Heiko hebben op DTRH als veteranen laten zien hoe je een meerdaags festival doorkomt. Volgens mij ben ik nog steeds aan het bijkomen. En dan hebben we het nog niet eens over je promotiefeest $\mathrm{x}_{-} \mathrm{x}$. Daarover, de prijs voor meest imago schadende foto's gaat naar het promotiefeest van Leonie. Proficiat! Nikki, Leonie, Müge, 
Jelle, Lex, Sara (ik heb nog steeds een tenniswedstrijd en een biertje van je tegoed ;) Bas, Manja, Maaike, Hendrik, Tara, Rita, Philipp, Kasper, Anne, Kim, Sanjana, Nick, Ece, Christian en Ana, beste mede promovendi, dank voor alle gezelligheid. Dank ook aan de rest van de afdeling Sociologie voor alle ondersteuning en voor alle lunches en inspirerende bijeenkomsten. Jullie hebben de afgelopen jaren voor een fijne werkplek gezorgd.

Sanne. Dat je het met ons op de kamer hebt uitgehouden is een klein wonder. Ik heb erg genoten van je droge humor, je bereidheid om op ieder moment van de dag hedendaagse politiek te bespreken, en je stoïsche houding als je weer eens midden in een storm van loze kreten, kantoorvoetbal en youtube filmpjes terecht kwam. We komen elkaar vast nog eens tegen.

Antonie, Ineke en Kim. Samen gaven we het vak leeronderzoek. Bedankt voor de fijne samenwerking. Ik vond het leuk om het vak samen met jullie te geven. Ik heb er zelf een hoop van geleerd, en volgens mij hebben we de studenten ook een hoop kunnen leren. Dank ook aan alle studenten. Ik vond het leuk om jullie docent te zijn. Hopelijk vonden jullie dat ook.

Ook wil ik graag Daphne en iedereen van de SMO Promovendi groep bedanken. Via Joris hoorde ik van een project waarin een groep $\mathrm{PhD}$ studenten samen de krachten bundelen om maatschappelijke uitdagingen aan te pakken. Dit kwam voor mij precies op een moment waarop ik op zoek was naar een plek om meer teamgericht en meer praktijkgericht werk te doen. Uit eindelijk is daar een heel mooi project over technologische innovatie in de zorg uitgekomen. Daphne, supertof dat je dit hebt opgezet. Het is een hele waardevolle ervaring geweest. Na onze maandelijkse meeting ging ik altijd met heel veel zin en energie naar huis. Ik kan iedereen die graag zijn of haar PhD skills wil gebruiken en aanvullen met ondernemingsvaardigheden aanraden om mee te doen. Ook wil ik Han en Juliëtte, die de geest van SMO nu voortzetten in THRIVE bedanken voor alle samenwerking en hulp.

Joris en Mathijs. Bedankt voor alle tijd die we hebben gestoken in ons geesteskindje Bureau KBB (S/O naar SMO en THRIVE). Hoewel deze recentelijk een winterslaap is gestart sluit ik niet uit dat we uiteindelijk de Big Four van hun troon zullen stoten. Het feit dat we een paar kleine opdrachten hebben kunnen doen vind ik al heel tof. Superleuk om samen gedaan te hebben. We hebben nog steeds een goed diner te goed! Zodra het weer kan gaan we daar werk van maken.

Verder wil ik al mijn (oud) huisgenoten van de Burgemeester Reigerstraat 79 bedanken. Jullie hebben indirect het hele proces, door hoog en laag, mogen meemaken. Jullie zijn een onmisbare uitlaatklep geweest. Zeker het afgelopen jaar, waarin we door COVID veel op elkaar aangewezen zijn geweest, is jullie gezelschap bijzonder waardevol geweest. Waarde Reigers, de ontelbare feestjes, huisweekenden, kerstdiners, datediners, huisfeesten, zwarte-pistes, huisavonden, barbecues, zomeravonden, spelletjesavonden, gym-sessies, jac-sessies! en uitjes die we samen beleefd hebben zal ik nooit vergeten. Laten we elkaar blijven zien, ook wanneer we allemaal al lang en breed verhuisd zijn!

Ook wil ik Jan Jaap, Thom, Bas, de 'ouwe rotten' en de andere oud IBB'ers bedanken voor alle good-times, toen en nu. Jullie hebben het woord studententijd betekenis en inhoud gegeven. Ik beloof dat ik jullie blijf opzoeken, ook als weer ik in Rotterdam woon. 
Edu en Jori. We verhuisden ooit samen naar Utrecht. De tijd die we hadden in Overvecht is onvergetelijk en is het begin geweest van veel meer moois. Nu kom ik jullie achterna naar Rotterdam. Dat is leuk, want dan kan ik jullie weer vaker zien. Jamsessies en Rotiland, here we come! Umeu, als u dan ook eindelijk weer eens terugkeert uit Vietnam dan wordt het misschien nog gezellig ook! Tot die tijd skypen we gewoon verder.

Natuurlijk zouden de afgelopen jaren, net als Spanje, Italië, Marokko, Frankrijk, België en Nederland niet hetzelfde zijn zonder Anne-Vera, Nadia, Carmen, Michelle, Sarah \& Sarah, Pim, Orfeo, Eduard, Jop, Erwin, Sjoerd, Sander, David en TIIIIIIM! Er zijn niet veel dingen welkomer geweest dan onze Nieuwjaars en Paas uitstapjes naar de zon. Ongegeneerd lui, vraatzuchtig en gulzig zijn, gecombineerd met culturele hoogstandjes en bonte-avondjes heeft nu eenmaal het type aantrekkingskracht waardoor je terug blijft komen. Ik zie het huidige roet in het eten dan ook als niets meer dan een reden om het volgend jaar nog overdadiger dan gebruikelijk over te doen. De onuitputtelijke hoeveelheid initiatieven die voortkomt uit deze groep heeft al tot zo veel mooie dagen en avonden geleid. Laten we dit vooral blijven doen. Ik kan alleen maar zeggen, to be continued...

Lieve pa en ma. Lieve broer en schoonzus. Lieve familie. Volgens mij hebben jullie je meer dan eens afgevraagd waarom ik mezelf heb opgezadeld met het schrijven van zoiets moeilijks als een proefschrift. Natuurlijk kregen jullie het te horen als het even niet meezat. Maar ik kan jullie met een gerust hart vertellen dat ik een superleuke tijd heb gehad. Vooral door toedoen van hiervoor genoemde mensen. Ik prijs mezelf gelukkig met zulke fijne familie. In de afgelopen jaren is daar een lief klein neefje bijgekomen. Supergezellig. Bedankt voor alle fijne momenten samen.

Dank ook aan mijn lieve schoonfamilie. Ik heb me altijd welkom gevoeld. Ik vind het mooi om te zien hoe jullie met elkaar omgaan, hoe hecht jullie zijn en hoe jullie het leven omarmen. Bedankt voor alle warmte.

Ten slotte wil ik jou bedanken Sarah. Je bent de liefste persoon die ik ken. Ik waardeer je steun en hulp enorm. Maar belangrijker zijn nog wel alle leuke dingen die we samen meemaken en hebben meegemaakt. Bij Barbara en haar familie op bezoek in Ghana. In onze sneak-camper in Californië. In de jungle van Peru, tussen de krokodillen en piranha's. En in Noord-Spanje, wildkamperen op de kliffen, of in de krater op Tenerife. Maar ook gewoon thuis, uit eten of tijdens een wandelingetje. We hebben het altijd makkelijk fijn samen. Binnenkort gaan we in Rotterdam samen aan een nieuw hoofdstuk beginnen. Je gaat dan aan een nog drukkere baan beginnen. Ik vind het ontzettend knap hoe je het allemaal doet en dat je het voor elkaar hebt gekregen om in opleiding te komen. Het zal af en toe nog wel zwaar worden, maar daar komen we samen wel uit. Als alles een beetje mee zit ben je tegen die tijd ook klaar met je proefschrift. Wat een bevrijding zal dat zijn. Dat gaan we vieren. Lief, ik zie er naar uit om samen een fijn thuis te maken in ons nieuwe huisje. Tot die tijd kamperen we gezellig verder. Liefs, Jannes. 

About the author 
Jannes ten Berge was born in Rotterdam, the Netherlands, on Oktober 11, 1989. He obtained his bachelor's degree in Interdisciplinary Social Science at Utrecht University (2012). After working as a junior researcher at the Bureau of Research and Statistics of the local government of Amsterdam, he continued in the research master Sociology and Social Research. He completed this master in 2015. In September 2015 he started working as a PhD candidate at the Interuniversity Center for Social Science Theory and Methodology (ICS) in Utrecht and wrote this dissertation under the supervision of dr. Zoltán Lippényi, prof. Tanja van der Lippe and prof. Maarten Goos. As part of his PhD project, he visited prof. Donald Tomaskovic-Devey at the University of Massachusetts (UMass Amherst). Chapter 4 is the result of this collaboration. During his $\mathrm{PhD}$ he taught in the bachelor course Research Project: Social Stratification and Family Sociology and supervised bachelor theses. Furthermore, he participated in the SMO Promovendi programme (now THRIVE PhD Acadamy), resulting in a co-authored publication on technological innovation in healthcare. His work has appeared in European Sociological Review, Research in Social Stratification and Mobility, and in the edited book Investments in a Sustainable Workforce in Europe. 
ICS dissertation series 
The ICS series presents dissertations of the Interuniversity Center for Social Science Theory and Methodology. Each of these studies aims at integrating explicit theory formation with state of the art empirical research or at the development of advanced methods for empirical research. The ICS was founded in 1986 as a cooperative effort of the universities of Groningen and Utrecht. Since 1992, the ICS expanded to the University of Nijmegen and since 2017 to the University of Amsterdam (UvA). Most of the projects are financed by the participating universities or by the Netherlands Organization for Scientific Research (NWO). The international composition of the ICS graduate students is mirrored in the increasing international orientation of the projects and thus of the ICS series itself.

1. Kees van Liere (1990), "Lastige Leerlingen. Een empirisch onderzoek naar sociale oorzaken van probleemgedrag op basisscholen.” Amsterdam: Thesis Publishers

2. Marco van Leeuwen (1990), "Bijstand in Amsterdam, ca. 1800 - 1850. Armenzorg als beheersings en overlevingsstrategie.” ICS-dissertation, Utrecht

3. Ineke Maas (1990), "Deelname aan podiumkunsten via de podia, de media en actieve beoefening. Substitutie of leereffecten?” Amsterdam: Thesis Publishers

4. Marjolein Broese van Groenou (1991), "Gescheiden Netwerken. De relaties met vrienden en verwanten na echtscheiding” Amsterdam: Thesis Publishers

5. Jan van den Bos (1991), "Dutch EC Policy Making. A Model Guided Approach to Coordination and Negotiation.” Amsterdam: Thesis Publishers

6. Karin Sanders (1991), "Vrouwelijke Pioniers. Vrouwen en mannen met een 'mannelijke' hogere beroepsopleiding aan het begin van hun loopbaan.” Amsterdam: Thesis Publishers

7. Sjerp de Vries (1991), “Egoism, Altruism, and Social Justice. Theory and Experiments on Cooperation in Social Dilemmas." Amsterdam: Thesis Publishers

8. Ronald Batenburg (1991), "Automatisering in bedrijf." Amsterdam: Thesis Publishers

9. Rudi Wielers (1991), "Selectie en allocatie op de arbeidsmarkt. Een uitwerking voor de informele en geïnstitutionaliseerde kinderopvang.” Amsterdam: Thesis Publishers

10. Gert Westert (1991), "Verschillen in ziekenhuisgebruik." ICS-dissertation, Groningen

11. Hanneke Hermsen (1992), "Votes and Policy Preferences. Equilibria in Party Systems." Amsterdam: Thesis Publishers

12. Cora Maas (1992), "Probleemleerlingen in het basisonderwijs" Amsterdam: Thesis Publis $\neg$ hers

13. Ed Boxman (1992), "Contacten en carrière. Een empirisch theoretisch onderzoek naar de relatie tussen sociale netwerken en arbeidsmarktposities" Amsterdam: Thesis Publishers

14. Conny Taes (1992), "Kijken naar banen. Een onderzoek naar de inschatting van arbeidsmarktkansen bij schoolverlaters uit het middelbaar beroepsonderwijs." Amsterdam: Thesis Publishers

15. Peter van Roozendaal (1992), "Cabinets in Multi Party Democracies. The Effect of Dominant and Central Parties on Cabinet Composition and Durability." Amsterdam: Thesis Publishers

16. Marcel van Dam (1992), "Regio zonder regie. Verschillen in en effectiviteit van gemeentelijk arbeidsmarktbeleid.” Amsterdam: Thesis Publishers 
17. Tanja van der Lippe (1993), “Arbeidsverdeling tussen mannen en vrouwen.” Amsterdam: Thesis Publishers

18. Marc Jacobs (1993), "Software: Kopen of Kopiëren? Een sociaal wetenschappelijk onderzoek onder PC gebruikers." Amsterdam: Thesis Publishers

19. Peter van der Meer (1993), "Verdringing op de Nederlandse arbeidsmarkt. Sector- en sekseverschillen.” Amsterdam: Thesis Publishers

20. Gerbert Kraaykamp (1993), “Over lezen gesproken. Een studie naar sociale differentiatie in leesgedrag." Amsterdam: Thesis Publishers

21. Evelien Zeggelink (1993), "Strangers into Friends. The Evolution of Friendship Networks Using an Individual Oriented Modeling Approach.” Amsterdam: Thesis Publishers

22. Jaco Berveling (1994), "Het stempel op de besluitvorming. Macht, invloed en besluitvorming op twee Amsterdamse beleidsterreinen.” Amsterdam: Thesis Publishers

23. Wim Bernasco (1994), "Coupled Careers. The Effects of Spouse's Resources on Success at Work." Amsterdam: Thesis Publishers

24. Liset van Dijk (1994), "Choices in Child Care. The Distribution of Child Care Among Mothers, Fathers and Non Parental Care Providers." Amsterdam: Thesis Publishers

25. Jos de Haan (1994), "Research Groups in Dutch Sociology." Amsterdam: Thesis Publishers

26. Kwasi Boahene (1995), "Innovation Adoption as a Socio Economic Process. The Case of the Ghanaian Cocoa Industry.” Amsterdam: Thesis Publishers

27. Paul Ligthart (1995), "Solidarity in Economic Transactions. An Experimental Study of Framing Effects in Bargaining and Contracting." Amsterdam: Thesis Publishers

28. Roger Leenders (1995), "Structure and Influence. Statistical Models for the Dynamics of Actor Attributes, Network Structure, and their Interdependence." Amsterdam: Thesis Publishers

29. Beate Volker (1995), "Should Auld Acquaintance Be Forgot...? Institutions of Communism, the Transition to Capitalism and Personal Networks: the Case of East Germany." Amsterdam: Thesis Publishers

30. Anneke Cancrinus-Matthijsse (1995), “Tussen hulpverlening en ondernemerschap. Beroepsuitoefening en taakopvattingen van openbare apothekers in een aantal West Europese landen." Amsterdam: Thesis Publishers

31. Nardi Steverink (1996), "Zo lang mogelijk zelfstandig. Naar een verklaring van verschillen in oriëntatie ten aanzien van opname in een verzorgingstehuis onder fysiek kwetsbare ouderen." Amsterdam: Thesis Publishers

32. Ellen Lindeman (1996), "Participatie in vrijwilligerswerk." Amsterdam: Thesis Publishers

33. Chris Snijders (1996), "Trust and Commitments.” Amsterdam: Thesis Publishers

34. Koos Postma (1996), "Changing Prejudice in Hungary. A Study on the Collapse of State Socialism and Its Impact on Prejudice Against Gypsies and Jews.” Amsterdam: Thesis Publishers

35. Jooske van Busschbach (1996), "Uit het oog, uit het hart? Stabiliteit en verandering in persoonlijke relaties.” Amsterdam: Thesis Publishers 
36. René Torenvlied (1996), "Besluiten in uitvoering. Theorieën over beleidsuitvoering modelmatig getoetst op sociale vernieuwing in drie gemeenten." Amsterdam: Thesis Publishers

37. Andreas Flache (1996), "The Double Edge of Networks. An Analysis of the Effect of Informal Networks on Cooperation in Social Dilemmas." Amsterdam: Thesis Publishers

38. Kees van Veen (1997), "Inside an Internal Labor Market: Formal Rules, Flexibility and Career Lines in a Dutch Manufacturing Company." Amsterdam: Thesis Publishers

39. Lucienne van Eijk (1997), "Activity and Well being in the Elderly.” Amsterdam: Thesis Publishers

40. Róbert Gál (1997), “Unreliability. Contract Discipline and Contract Governance under Economic Transition.” Amsterdam: Thesis Publishers

41. Anne-Geerte van de Goor (1997), “Effects of Regulation on Disability Duration.” ICSdissertation, Utrecht

42. Boris Blumberg (1997), "Das Management von Technologiekooperationen. Partnersuche und Verhandlungen mit dem Partner aus Empirisch Theoretischer Perspektive." ICSdissertation, Utrecht

43. Marijke von Bergh (1997), "Loopbanen van oudere werknemers.” Amsterdam: Thesis Publishers

44. Anna Petra Nieboer (1997), "Life Events and Well Being: A Prospective Study on Changes in Well Being of Elderly People Due to a Serious Illness Event or Death of the Spouse." Amsterdam: Thesis Publishers

45. Jacques Niehof (1997), "Resources and Social Reproduction: The Effects of Cultural and Material Resources on Educational and Occupational Careers in Industrial Nations at the End of the Twentieth Century." ICS-dissertation, Nijmegen

46. Ariana Need (1997), "The Kindred Vote. Individual and Family Effects of Social Class and Religion on Electoral Change in the Netherlands, 1956 1994." ICS-dissertation, Nijmegen

47. Jim Allen (1997), "Sector Composition and the Effect of Education on Wages: an International Comparison." Amsterdam: Thesis Publishers

48. Jack Hutten (1998), "Workload and Provision of Care in General Practice. An Empirical Study of the Relation Between Workload of Dutch General Practitioners and the Content and Quality of their Care." ICS-dissertation, Utrecht

49. Per Kropp (1998), "Berufserfolg im Transformationsprozeß. Eine theoretisch empirische Studie über die Gewinner und Verlierer der Wende in Ostdeutschland." ICS-dissertation, Utrecht

50. Maarten Wolbers (1998), "Diploma-inflatie en verdringing op de arbeidsmarkt. Een studie naar ontwikkelingen in de opbrengsten van diploma's in Nederland." ICSdissertation, Nijmegen

51. Wilma Smeenk (1998), “Opportunity and Marriage. The Impact of Individual Resources and Marriage Market Structure on First Marriage Timing and Partner Choice in the Netherlands." ICS-dissertation, Nijmegen

52. Marinus Spreen (1999), "Sampling Personal Network Structures: Statistical Inference in Ego-Graphs.” ICS-dissertation, Groningen

53. Vincent Buskens (1999), “Social Networks and Trust.” ICS-dissertation, Utrecht 
54. Susanne Rijken (1999), "Educational Expansion and Status Attainment. A Cross-National and Over-Time Comparison." ICS-dissertation, Utrecht

55. Mérove Gijsberts (1999), "The Legitimation of Inequality in State-Socialist and Market Societies, 1987-1996.” ICS-dissertation, Utrecht

56. Gerhard van de Bunt (1999), "Friends by Choice. An Actor-Oriented Statistical Network Model for Friendship Networks Through Time.” ICS-dissertation, Groningen

57. Robert Thomson (1999), "The Party Mandate: Election Pledges and Government Actions in the Netherlands, 1986 1998." Amsterdam: Thela Thesis

58. Corine Baarda (1999), "Politieke besluiten en boeren beslissingen. Het draagvlak van het mestbeleid tot 2000.” ICS-dissertation, Groningen

59. Rafael Wittek (1999), “Interdependence and Informal Control in Organizations.” ICSdissertation, Groningen

60. Diane Payne (1999), "Policy Making in the European Union: an Analysis of the Impact of the Reform of the Structural Funds in Ireland." ICS-dissertation, Groningen

61. René Veenstra (1999), "Leerlingen Klassen Scholen. Prestaties en vorderingen van leerlingen in het voortgezet onderwijs." Amsterdam, Thela Thesis

62. Marjolein Achterkamp (1999), "Influence Strategies in Collective Decision Making. A Comparison of Two Models." ICS-dissertation, Groningen

63. Peter Mühlau (2000), "The Governance of the Employment Relation. A Relational Signaling Perspective." ICS-dissertation, Groningen

64. Agnes Akkerman (2000), "Verdeelde vakbeweging en stakingen. Concurrentie om leden.” ICS-dissertation, Groningen

65. Sandra van Thiel (2000), “Quangocratization: Trends, Causes and Consequences.” ICSdissertation, Utrecht

66. Sylvia Peacock-Korupp (2000), “Mothers and the Process of Social Stratification.” ICSdissertation, Utrecht

67. Rudi Turksema (2000), “Supply of Day Care.” ICS-dissertation, Utrecht

68. Bernard Nijstad (2000), "How the Group Affects the Mind: Effects of Communication in Idea Generating Groups.” ICS-dissertation, Utrecht

69. Inge de Wolf (2000), "Opleidingsspecialisatie en arbeidsmarktsucces van sociale wetenschappers.” ICS-dissertation, Utrecht

70. Jan Kratzer (2001), “Communication and Performance: An Empirical Study in Innovation Teams.” ICS-dissertation, Groningen

71. Madelon Kroneman (2001), "Healthcare Systems and Hospital Bed Use." ICS/NIVELdissertation, Utrecht

72. Herman van de Werfhorst (2001), "Field of Study and Social Inequality. Four Types of Educational Resources in the Process of Stratification in the Netherlands." ICSdissertation, Nijmegen

73. Tamás Bartus (2001), "Social Capital and Earnings Inequalities. The Role of Informal Job Search in Hungary." ICS-dissertation Groningen

74. Hester Moerbeek (2001), "Friends and Foes in the Occupational Career. The Influence of Sweet and Sour Social Capital on the Labour Market.” ICS-dissertation, Nijmegen

75. Marcel van Assen (2001), "Essays on Actor Perspectives in Exchange Networks and Social Dilemmas.” ICS-dissertation, Groningen 
76. Inge Sieben (2001), "Sibling Similarities and Social Stratification. The Impact of Family Background across Countries and Cohorts." ICS-dissertation, Nijmegen

77. Alinda van Bruggen (2001), "Individual Production of Social Well Being. An Exploratory Study.” ICS-dissertation, Groningen

78. Marcel Coenders (2001), "Nationalistic Attitudes and Ethnic Exclusionism in a Comparative Perspective: An Empirical Study of Attitudes Toward the Country and Ethnic Immigrants in 22 Countries." ICS-dissertation, Nijmegen

79. Marcel Lubbers (2001), "Exclusionistic Electorates. Extreme Right Wing Voting in Western Europe.” ICS-dissertation, Nijmegen

80. Uwe Matzat (2001), "Social Networks and Cooperation in Electronic Communities. A theoretical-empirical Analysis of Academic Communication and Internet Discussion Groups.” ICS-dissertation, Groningen

81. Jacques Janssen (2002), “Do Opposites Attract Divorce? Dimensions of Mixed Marriage and the Risk of Divorce in the Netherlands. ” ICS-dissertation, Nijmegen

82. Miranda Jansen (2002), “Waardenoriëntaties en partnerrelaties. Een panelstudie naar wederzijdse invloeden.” ICS-dissertation, Utrecht

83. Anne-Rigt Poortman (2002), "Socioeconomic Causes and Consequences of Divorce." ICS-dissertation, Utrecht

84. Alexander Gattig (2002), “Intertemporal Decision Making.” ICS-dissertation, Groningen

85. Gerrit Rooks (2000), "Contract en Conflict: Strategisch Management van Inkooptransacties.” ICS-dissertation, Utrecht

86. Károly Takács (2002), "Social Networks and Intergroup Conflict.” ICS-dissertation, Groningen

87. Thomas Gautschi (2002), "Trust and Exchange, Effects of Temporal Embeddedness and Network Embeddedness on Providing and Dividing a Surplus. ” ICS-dissertation, Utrecht

88. Hilde Bras (2002), "Zeeuwse meiden. Dienen in de levensloop van vrouwen, ca. 1850 1950." Aksant Academic Publishers, Amsterdam

89. Merijn Rengers (2002), "Economic Lives of Artists. Studies into Careers and the Labour Market in the Cultural Sector." ICS-dissertation, Utrecht

90. Annelies Kassenberg (2002), "Wat scholieren bindt. Sociale gemeenschap in scholen." ICS-dissertation, Groningen

91. Marc Verboord (2003), "Moet de meester dalen of de leerling klimmen? De invloed van literatuuronderwijs en ouders op het lezen van boeken tussen 1975 en 2000." ICSdissertation, Utrecht

92. Marcel van Egmond (2003), "Rain Falls on All of Us (but Some Manage to Get More Wet than Others): Political Context and Electoral Participation.” ICS-dissertation, Nijmegen

93. Justine Horgan (2003), "High Performance Human Resource Management in Ireland and the Netherlands: Adoption and Effectiveness." ICS-dissertation, Groningen

94. Corine Hoeben (2003), "LETS' Be a Community. Community in Local Exchange Trading Systems." ICS-dissertation, Groningen

95. Christian Steglich (2003), "The Framing of Decision Situations. Automatic Goal Selection and Rational Goal Pursuit.” ICS-dissertation, Groningen

96. Johan van Wilsem (2003), "Crime and Context. The Impact of Individual, Neighborhood, City and Country Characteristics on Victimization.” ICS-dissertation, Nijmegen 
97. Christiaan Monden (2003), "Education, Inequality and Health. The Impact of Partners and Life Course." ICS-dissertation, Nijmegen

98. Evelyn Hello (2003), "Educational Attainment and Ethnic Attitudes. How to Explain their Relationship.” ICS-dissertation, Nijmegen

99. Marnix Croes en Peter Tammes (2004). Gif laten wij niet voortbestaan. Een onderzoek naar de overlevingskansen van joden in de Nederlandse gemeenten, 1940-1945. Aksant Academic Publishers, Amsterdam.

100. Ineke Nagel (2004), “Cultuurdeelname in de levensloop.” ICS-dissertation, Utrecht

101. Marieke van der Wal (2004), "Competencies to Participate in Life. Measurement and the Impact of School.” ICS-dissertation, Groningen

102. Vivian Meertens (2004), "Depressive Symptoms in the General Population: a Multifactorial Social Approach.” ICS-dissertation, Nijmegen

103. Hanneke Schuurmans (2004), "Promoting Well-Being in Frail Elderly People. Theory and Intervention." ICS-dissertation, Groningen

104. Javier Arregui Moreno (2004), “Negotiation in Legislative Decision-Making in the European Union." ICS-dissertation, Groningen

105. Tamar Fischer (2004), "Parental Divorce, Conflict and Resources. The Effects on Children's Behaviour Problems, Socioeconomic Attainment, and Transitions in the Demographic Career.” ICS-dissertation, Nijmegen

106. René Bekkers (2004), "Giving and Volunteering in the Netherlands: Sociological and Psychological Perspectives.” ICS-dissertation, Utrecht

107. Renée van der Hulst (2004), "Gender Differences in Workplace Authority: An Empirical Study on Social Networks.” ICS-dissertation, Groningen

108. Rita Smaniotto (2004), “'You Scratch My Back and I Scratch Yours' Versus 'Love Thy Neighbour'. Two Proximate Mechanisms of Reciprocal Altruism.” ICS-dissertation, Groningen

109. Maurice Gesthuizen (2004), "The Life-Course of the Low-Educated in the Netherlands: Social and Economic Risks." ICS-dissertation, Nijmegen

110. Carlijne Philips (2005), "Vakantiegemeenschappen. Kwalitatief en Kwantitatief Onderzoek naar Gelegenheid en Refreshergemeenschap tijdens de Vakantie." ICSdissertation, Groningen

111. Esther de Ruijter (2005), "Household Outsourcing.” ICS-dissertation, Utrecht

112. Frank van Tubergen (2005), "The Integration of Immigrants in Cross-National Perspective: Origin, Destination, and Community Effects." ICS-dissertation, Utrecht

113. Ferry Koster (2005), "For the Time Being. Accounting for Inconclusive Findings Concerning the Effects of Temporary Employment Relationships on Solidary Behavior of Employees." ICS-dissertation, Groningen

114. Carolien Klein Haarhuis (2005), "Promoting Anti-Corruption Reforms. Evaluating the Implementation of a World Bank Anti-Corruption Program in Seven African Countries (1999-2001)." ICS-dissertation, Utrecht

115. Martin van der Gaag (2005), “Measurement of Individual Social Capital.” ICSdissertation, Groningen

116. Johan Hansen (2005), "Shaping Careers of Men and Women in Organizational Contexts." ICS-dissertation, Utrecht 
117. Davide Barrera (2005), “Trust in Embedded Settings.” ICS-dissertation, Utrecht

118. Mattijs Lambooij (2005), "Promoting Cooperation. Studies into the Effects of Long-Term and Short-Term Rewards on Cooperation of Employees." ICS-dissertation, Utrecht

119. Lotte Vermeij (2006), “What's Cooking? Cultural Boundaries among Dutch Teenagers of Different Ethnic Origins in the Context of School.” ICS-dissertation, Utrecht

120. Mathilde Strating (2006), "Facing the Challenge of Rheumatoid Arthritis. A 13-year Prospective Study among Patients and Cross-Sectional Study among Their Partners." ICS-dissertation, Groningen

121. Jannes de Vries (2006), "Measurement Error in Family Background Variables: The Bias in the Intergenerational Transmission of Status, Cultural Consumption, Party Preference, and Religiosity." ICS-dissertation, Nijmegen

122. Stefan Thau (2006), "Workplace Deviance: Four Studies on Employee Motives and SelfRegulation." ICS-dissertation, Groningen

123. Mirjam Plantinga (2006), "Employee Motivation and Employee Performance in Child Care. The effects of the Introduction of Market Forces on Employees in the Dutch ChildCare Sector." ICS-dissertation, Groningen

124. Helga de Valk (2006), "Pathways into Adulthood. A Comparative Study on Family Life Transitions among Migrant and Dutch Youth.” ICS-dissertation, Utrecht

125. Henrike Elzen (2006), "Self-Management for Chronically Ill Older People." ICSDissertation, Groningen

126. Ayse Güveli (2007), "New Social Classes within the Service Class in the Netherlands and Britain. Adjusting the EGP Class Schema for the Technocrats and the Social and Cultural Specialists.” ICS-dissertation, Nijmegen

127. Willem-Jan Verhoeven (2007), “Income Attainment in Post-Communist Societies.” ICSdissertation, Utrecht

128. Marieke Voorpostel (2007), "Sibling support: The Exchange of Help among Brothers and Sisters in the Netherlands." ICS-dissertation, Utrecht

129. Jacob Dijkstra (2007), "The Effects of Externalities on Partner Choice and Payoffs in Exchange Networks." ICS-dissertation, Groningen

130. Patricia van Echtelt (2007), "Time-Greedy Employment Relationships: Four Studies on the Time Claims of Post-Fordist Work." ICS-dissertation, Groningen

131. Sonja Vogt (2007), "Heterogeneity in Social Dilemmas: The Case of Social Support." ICS-dissertation, Utrecht

132. Michael Schweinberger (2007), "Statistical Methods for Studying the Evolution of Networks and Behavior." ICS-dissertation, Groningen

133. István Henrik Back (2007), "Commitment and Evolution: Connecting Emotion and Reason in Long-term Relationships.” ICS-dissertation, Groningen

134. Ruben van Gaalen (2007), "Solidarity and Ambivalence in Parent-Child Relationships." ICS-dissertation, Utrecht

135. Jan Reitsma (2007), "Religiosity and Solidarity - Dimensions and Relationships Disentangled and Tested.” ICS-dissertation, Nijmegen

136. Jan Kornelis Dijkstra (2007), "Status and Affection among (Pre)Adolescents and Their Relation with Antisocial and Prosocial Behavior.” ICS-dissertation, Groningen 
137. Wouter van Gils (2007), "Full-time Working Couples in the Netherlands. Causes and Consequences." ICS-dissertation, Nijmegen

138. Djamila Schans (2007), “Ethnic Diversity in Intergenerational Solidarity.” ICSdissertation, Utrecht

139. Ruud van der Meulen (2007), "Brug over Woelig Water: Lidmaatschap van Sportverenigingen, Vriendschappen, Kennissenkringen en Veralgemeend Vertrouwen." ICS-dissertation, Nijmegen

140. Andrea Knecht (2008), “Friendship Selection and Friends' Influence. Dynamics of Networks and Actor Attributes in Early Adolescence." ICS-dissertation, Utrecht

141. Ingrid Doorten (2008), "The Division of Unpaid Work in the Household: A Stubborn Pattern?" ICS-dissertation, Utrecht

142. Stijn Ruiter (2008), "Association in Context and Association as Context: Causes and Consequences of Voluntary Association Involvement.” ICS-dissertation, Nijmegen

143. Janneke Joly (2008), "People on Our Minds: When Humanized Contexts Activate Social Norms.” ICS-dissertation, Groningen

144. Margreet Frieling (2008), “'Joint production' als motor voor actief burgerschap in de buurt.” ICS-dissertation, Groningen

145. Ellen Verbakel (2008), "The Partner as Resource or Restriction? Labour Market Careers of Husbands and Wives and the Consequences for Inequality Between Couples.” ICSdissertation, Nijmegen

146. Gijs van Houten (2008), "Beleidsuitvoering in gelaagde stelsels. De doorwerking van aanbevelingen van de Stichting van de Arbeid in het CAO-overleg." ICS-dissertation, Utrecht

147. Eva Jaspers (2008), “Intolerance over Time. Macro and Micro Level Questions on Attitudes Towards Euthanasia, Homosexuality and Ethnic Minorities.” ICS-dissertation, Nijmegen

148. Gijs Weijters (2008), "Youth Delinquency in Dutch Cities and Schools: A Multilevel Approach.” ICS-dissertation, Nijmegen

149. Jessica Nooij (2009), “The Self in Social Rejection.” ICS-dissertation, Groningen

150. Gerald Mollenhorst (2009), "Networks in Contexts. How Meeting Opportunities Affect Personal Relationships.” ICS-dissertation, Utrecht

151. Tom van der Meer (2009), "States of Freely Associating Citizens: Comparative Studies into the Impact of State Institutions on Social, Civic and Political Participation.” ICSdissertation, Nijmegen

152. Manuela Vieth (2009), "Commitments and Reciprocity in Trust Situations. Experimental Studies on Obligation, Indignation, and Self-Consistency.” ICS-dissertation, Utrecht

153. Rense Corten (2009), "Co-evolution of Social Networks and Behavior in Social Dilemmas: Theoretical and Empirical Perspectives.” ICS-dissertation, Utrecht

154. Arieke Rijken (2009), "Happy Families, High Fertility? Childbearing Choices in the Context of Family and Partner Relationships.” ICS-dissertation, Utrecht

155. Jochem Tolsma (2009), "Ethnic Hostility among Ethnic Majority and Minority Groups in the Netherlands. An Investigation into the Impact of Social Mobility Experiences, the Local Living Environment and Educational Attainment on Ethnic Hostility.” ICSdissertation, Nijmegen 
156. Freek Bucx (2009), “Linked Lives: Young Adults' Life Course and Relations With Parents." ICS-dissertation, Utrecht

157. Philip Wotschack (2009), "Household Governance and Time Allocation. Four studies on the combination of work and care." ICS-dissertation, Groningen

158. Nienke Moor (2009), “Explaining Worldwide Religious Diversity. The Relationship between Subsistence Technologies and Ideas about the Unknown in Pre-industrial and (Post-)industrial Societies.” ICS-dissertation, Nijmegen

159. Lieke ten Brummelhuis (2009), "Family Matters at Work. Depleting and Enriching Effects of Employees' Family lives on Work Outcomes.” ICS-dissertation, Utrecht

160. Renske Keizer (2010), "Remaining Childless. Causes and Consequences from a Life Course Perspective." ICS-dissertation, Utrecht

161. Miranda Sentse (2010), "Bridging Contexts: The interplay between Family, Child, and Peers in Explaining Problem Behavior in Early Adolescence." ICS-dissertation, Groningen

162. Nicole Tieben (2010), “Transitions, Tracks and Transformations. Social Inequality in Transitions into, through and out of Secondary Education in the Netherlands for Cohorts Born Between 1914 and 1985." ICS-dissertation, Nijmegen

163. Birgit Pauksztat (2010), "Speaking up in Organizations: Four Studies on Employee Voice.” ICS-dissertation, Groningen

164. Richard Zijdeman (2010), "Status Attainment in the Netherlands, 1811-1941. Spatial and Temporal Variation Before and During Industrialization.” ICS-dissertation, Utrecht

165. Rianne Kloosterman (2010), "Social Background and Children's Educational Careers. The Primary and Secondary Effects of Social Background over Transitions and over Time in the Netherlands." ICS-dissertation, Nijmegen

166. Olav Aarts (2010), "Religious Diversity and Religious Involvement. A Study of Religious Markets in Western Societies at the End of the Twentieth Century.” ICS-dissertation, Nijmegen

167. Stephanie Wiesmann (2010), “24/7 Negotiation in Couples Transition to Parenthood." ICS-dissertation, Utrecht

168. Borja Martinovic (2010), “Interethnic Contacts: A Dynamic Analysis of Interaction Between Immigrants and Natives in Western Countries.” ICS-dissertation, Utrecht

169. Anne Roeters (2010), "Family Life Under Pressure? Parents' Paid Work and the Quantity and Quality of Parent-Child and Family Time.” ICS-dissertation, Utrecht

170. Jelle Sijtsema (2010), “Adolescent Aggressive Behavior: Status and Stimulation Goals in Relation to the Peer Context." ICS-dissertation, Groningen

171. Kees Keizer (2010), “The Spreading of Disorder.” ICS-dissertation, Groningen

172. Michael Mäs (2010), “The Diversity Puzzle. Explaining Clustering and Polarization of Opinions.” ICS-dissertation, Groningen

173. Marie-Louise Damen (2010), "Cultuurdeelname en CKV. Studies naar effecten van kunsteducatie op de cultuurdeelname van leerlingen tijdens en na het voortgezet onderwijs." ICS-dissertation, Utrecht

174. Marieke van de Rakt (2011), "Two generations of Crime: The Intergenerational Transmission of Convictions over the Life Course.” ICS-dissertation, Nijmegen 
175. Willem Huijnk (2011), "Family Life and Ethnic Attitudes. The Role of the Family for Attitudes Towards Intermarriage and Acculturation Among Minority and Majority Groups.” ICS-dissertation, Utrecht

176. Tim Huijts (2011), "Social Ties and Health in Europe. Individual Associations, CrossNational Variations, and Contextual Explanations.” ICS-dissertation, Nijmegen

177. Wouter Steenbeek (2011), "Social and Physical Disorder. How Community, Business Presence and Entrepreneurs Influence Disorder in Dutch Neighborhoods." ICSdissertation, Utrecht

178. Miranda Vervoort (2011), "Living Together Apart? Ethnic Concentration in the Neighborhood and Ethnic Minorities' Social Contacts and Language Practices.” ICSdissertation, Utrecht

179. Agnieszka Kanas (2011), “The Economic Performance of Immigrants. The Role of Human and Social Capital.” ICS-dissertation, Utrecht

180. Lea Ellwardt (2011), “Gossip in Organizations. A Social Network Study.” ICSdissertation, Groningen

181. Annemarije Oosterwaal (2011), “The Gap between Decision and Implementation. Decision making, Delegation and Compliance in Governmental and Organizational Settings.” ICS-dissertation, Utrecht

182. Natascha Notten (2011), "Parents and the Media. Causes and Consequences of Parental Media Socialization.” ICS-dissertation, Nijmegen

183. Tobias Stark (2011), "Integration in Schools. A Process Perspective on Students' Interethnic Attitudes and Interpersonal Relationships.” ICS-dissertation, Groningen

184. Giedo Jansen (2011), "Social Cleavages and Political Choices. Large-scale Comparisons of Social Class, Religion and Voting Behavior in Western Democracies." ICSdissertation, Nijmegen

185. Ruud van der Horst (2011), "Network Effects on Treatment Results in a Closed Forensic Psychiatric Setting.” ICS-dissertation, Groningen

186. Mark Levels (2011), "Abortion Laws in European Countries between 1960 and 2010. Legislative Developments and Their Consequences for Women's Reproductive Decisionmaking." ICS-dissertation, Nijmegen

187. Marieke van Londen (2012), "Exclusion of ethnic minorities in the Netherlands. The effects of individual and situational characteristics on opposition to ethnic policy and ethnically mixed neighbourhoods. " ICS-dissertation, Nijmegen

188. Sigrid Mohnen (2012), "Neighborhood context and health: How neighborhood social capital affects individual health.” ICS-dissertation, Utrecht

189. Asya Zhelyazkova (2012), "Compliance under Controversy: Analysis of the Transposition of European Directives and their Provisions.” ICS-dissertation, Utrecht

190. Valeska Korff (2012), "Between Cause and Control: Management in a Humanitarian Organization.” ICS-dissertation, Groningen

191. Maike Gieling (2012), "Dealing with Diversity: adolescents' support for civil liberties and immigrant rights.” ICS-dissertation, Utrecht

192. Katya Ivanova (2012), "From Parents to Partners: The Impact of Family on Romantic Relationships in Adolescence and Emerging Adulthood.” ICS-dissertation, Groningen 
193. Jelmer Schalk (2012), "The Performance of Public Corporate Actors: Essays on Effects of Institutional and Network Embeddedness in Supranational, National, and Local Collaborative Contexts." ICS-dissertation, Utrecht

194. Alona Labun (2012), "Social Networks and Informal Power in Organizations." ICSdissertation, Groningen

195. Michal Bojanowski (2012), "Essays on Social Network Formation in Heterogeneous Populations: Models, Methods, and Empirical Analyses.” ICS-dissertation, Utrecht

196. Anca Minescu (2012), "Relative Group Position and Intergroup Attitudes in Russia." ICS-dissertation, Utrecht

197. Marieke van Schellen (2012), "Marriage and crime over the life course. The criminal careers of convicts and their spouses." ICS-dissertation, Utrecht

198. Mieke Maliepaard (2012), "Religious Trends and Social Integration: Muslim Minorities in the Netherlands." ICS-dissertation, Utrecht

199. Fransje Smits (2012), "Turks and Moroccans in the Low Countries around the year 2000: determinants of religiosity, trend in religiosity and determinants of the trend." ICSdissertation, Nijmegen

200. Roderick Sluiter (2012), “The Diffusion of Morality Policies among Western European Countries between 1960 and 2010. A Comparison of Temporal and Spatial Diffusion Patterns of Six Morality and Eleven Non-morality Policies.” ICS-dissertation, Nijmegen

201. Nicoletta Balbo (2012), "Family, Friends and Fertility." ICS-dissertation, Groningen

202. Anke Munniksma (2013), "Crossing ethnic boundaries: Parental resistance to and consequences of adolescents' cross-ethnic peer relations” ICS-dissertation, Groningen

203. Anja-Kristin Abendroth (2013), "Working Women in Europe. How the Country, Workplace, and Family Context Matter.” ICS-dissertation, Utrecht

204. Katia Begall (2013), "Occupational Hazard? The Relationship between Working Conditions and Fertility." ICS-dissertation, Groningen

205. Hidde Bekhuis (2013), "The Popularity of Domestic Cultural Products: Cross-national Differences and the Relation to Globalization." ICS-dissertation, Utrecht

206. Lieselotte Blommaert (2013), "Are Joris and Renske more employable than Rashid and Samira? A study on the prevalence and sources of ethnic discrimination in recruitment in the Netherlands using experimental and survey data." ICS-dissertation, Utrecht

207. Wiebke Schulz (2013), "Careers of Men and Women in the 19th and 20th Centuries." ICS-dissertation, Utrecht

208. Ozan Aksoy (2013), “Essays on Social Preferences and Beliefs in Non-embedded Social Dilemmas." ICS-dissertation, Utrecht

209. Dominik Morbitzer (2013), “Limited Farsightedness in Network Formation." ICSdissertation, Utrecht

210. Thomas de Vroome (2013), “Earning Your Place: The Relation Between Immigrants' Economic and Psychological Integration in the Netherlands.” ICS-dissertation, Utrecht

211. Marloes de Lange (2013), "Causes and Consequences of Employment Flexibility Among Young People. Recent Developments in the Netherlands and Europe.” ICS-dissertation, Nijmegen

212. Roza Meuleman (2014), "Consuming the Nation. Domestic cultural consumption: its stratification and relation with nationalist attitudes.” ICS-dissertation, Utrecht 
213. Esther Havekes (2014), "Putting interethnic attitudes in context. The relationship between neighbourhood characteristics, interethnic attitudes and residential behaviour." ICSdissertation, Utrecht

214. Zoltán Lippényi (2014), “Transitions toward an open society? Intergenerational occupational mobility in Hungary in the 19th and 20th centuries." ICS-dissertation, Utrecht

215. Anouk Smeekes (2014), “The presence of the past: Historical rooting of national identity and current group dynamics." ICS-dissertation, Utrecht

216. Michael Savelkoul (2014), "Ethnic Diversity and Social capital. Testing Underlying Explanations Derived from Conflict and Contact Theories in Europe and the United States." ICS-dissertation, Nijmegen

217. Martijn Hogerbrugge (2014), "Misfortune and family: How negative events, family ties, and lives are linked." ICS-dissertation, Utrecht

218. Gina-Felicia Potarca (2014), "Modern Love. Comparative Insights in Online Dating Preferences and Assortative Mating." ICS dissertation, Groningen

219. Mariska van der Horst (2014), “Gender, Aspirations, and Achievements: Relating work and family aspirations to occupational outcomes." ICS-dissertation, Utrecht

220. Gijs Huitsing (2014), “A Social network perspective on bullying” ICS dissertation, Groningen

221. Thomas Kowalewski (2015), "Personal growth in organizational contexts." ICSdissertation, Groningen

222. Manuel Muñoz-Herrera (2015), "The impact of individual differences on network relations: Social exclusion and inequality in productive exchange and coordination games." ICS-dissertation, Groningen

223. Tim Immerzeel (2015), "Voting for a change. The democratic lure of populist radical right parties in voting behavior." ICS-dissertation, Utrecht

224. Fernando Nieto Morales (2015), "The control imperative: Studies on reorganization in the public and private sectors." ICS-dissertation, Groningen

225. Jellie Sierksma (2015), "Bounded helping: How morality and intergroup relations shape children's reasoning about helping." ICS-dissertation, Utrecht

226. Tinka Veldhuis (2015), “Captivated by fear. An evaluation of terrorism detention policy." ICS-dissertation, Groningen

227. Miranda Visser (2015), "Loyality in humanity.Turnover among expatriate humanitarian aid workers." ICS-dissertation, Groningen

228. Sarah Westphal (2015), "Are the kids alright? Essays on postdivorce residence arrangements and children's well-being." ICS-dissertation, Utrecht

229. Britta Rüschoff (2015), "Peers in careers: Peer relationships in the transition from school to work." ICS dissertation, Groningen

230. Nynke van Miltenburg (2015), "Cooperation under peer sanctioning institutions: Collective decisions, noise, and endogenous implementation." ICS-dissertation, Utrecht

231. Antonie Knigge (2015), "Sources of sibling similarity. Status attainment in the Netherlands during modernization.” ICS-dissertation, Utrecht 
232. Sanne Smith (2015), "Ethnic segregation in friendship networks. Studies of its determinants in English, German, Dutch, and Swedish school classes.” ICS-dissertation, Utrecht

233. Patrick Präg (2015), "Social stratification and health. Four essays on social determinants of health and wellbeing." ICS dissertation, Groningen

234. Wike Been (2015), “European top managers' support for work-life arrangements" ICSdissertation, Utrecht

235. André Grow (2016), "Status differentiation: New insights from agent-based modeling and social network analysis" ICS-dissertation, Groningen

236. Jesper Rözer (2016), “Family and personal networks. How a partner and children affect social relationships" ICS-dissertation, Utrecht

237. Kim Pattiselanno (2016), “At your own risk: The importance of group dynamics and peer processes in adolescent peer groups for adolescents' involvement in risk behaviors” ICSdissertation, Groningen

238. Vincenz Frey (2016), "Network formation and trust” ICS-dissertation, Utrecht

239. Rozemarijn van der Ploeg (2016), "Be a buddy, not a bully? Four studies on social and emotional processes related to bullying, defending, and victimization” ICS-dissertation, Groningen

240. Tali Spiegel (2016), “Identity, career trajectories and wellbeing: A closer look at individuals with degenerative eye conditions" ICS- dissertation, Groningen

241. Felix Christian Tropf (2016), "Social Science Genetics and Fertility” ICS-dissertation, Groningen

242. Sara Geven (2016), "Adolescent problem behavior in school: the role of peer networks" ICS-dissertation, Utrecht

243. Josja Rokven (2016), “The victimization-offending relationship from a longitudinal perspective” ICS-dissertation, Nijmegen

244. Maja Djundeva (2016), "Healthy ageing in context: Family welfare state and the life course” ICS-dissertation, Groningen

245. Mark Visser (2017), "Inequality between older workers and older couples in the Netherlands. A dynamic life course perspective on educational and social class differences in the late career" ICS-dissertation, Nijmegen

246. Beau Oldenburg (2017), “Bullying in schools: The role of teachers and classmates” ICSdissertation, Groningen

247. Tatang Muttaqin (2017), "The education divide in Indonesia: Four essays on determinants of unequal access to and quality of education" ICS-dissertation, Groningen

248. Margriet van Hek (2017), "Gender inequality in educational attainment and reading performance. A contextual approach.” ICS-dissertation, Nijmegen

249. Melissa Verhoef-van Dorp (2017), “Work schedules, childcare and well-being. Essays on the associations between modern-day job characteristics, childcare arrangements and the well-being of parents and children" ICS-dissertation, Utrecht

250. Timo Septer (2017), "Goal priorities, cognition and conflict: Analyses of cognitive maps concerning organizational change” ICS-dissertation, Groningen

251. Bas Hofstra (2017), “Online Social Networks: Essays on Membership, Privacy, and Structure” ICS-dissertation, Utrecht 
252. Yassine Khoudja (2018), “Women's labor market participation across ethnic groups: The role of household conditions, gender role attitudes, and religiosity in different national contexts" ICS-dissertation, Utrecht

253. Joran Laméris (2018), "Living together in diversity. Whether, why and where ethnic diversity affects social cohesion” ICS-dissertation, Nijmegen

254. Maaike van der Vleuten (2018), "Gendered Choices. Fields of study of adolescents in the Netherlands" ICS-dissertation, Utrecht

255. Mala Sondang Silitonga (2018), “Corruption in Indonesia: The impact of institutional change, norms, and networks" ICS-dissertation, Groningen

256. Manja Coopmans (2018), "Rituals of the past in the context of the present. The role of Remembrance Day and Liberation Day in Dutch society" ICS-dissertation, Utrecht

257. Paul Hindriks (2018), "The Struggle for Power: Attitudes towards the political participation of ethnic minorities" ICS-dissertation, Utrecht

258. Nynke Niezink (2018), "Modeling the dynamics of networks and continuous behavior" ICS-dissertation, Groningen

259. Simon de Bruijn (2018), "Reaching agreement after divorce and separation. Essays on the effectiveness of parenting plans and divorce mediation" ICS-dissertation, Utrecht

260. Susanne van 't Hoff-de Goede (2018), "While you were locked up. An empirical study on the characteristics, social surroundings and wellbeing of partners of prisoners in The Netherlands" ICS-dissertation, Utrecht

261. Loes van Rijsewijk (2018), “Antecedents and Consequences of Helping among Adolescents" ICS-dissertation, Groningen

262. Mariola Gremmen (2018), "Social network processes and academic functioning. The role of peers in students' school well-being, academic engagement, and academic achievement” ICS-dissertation, Groningen

263. Jeanette Renema (2018), “Immigrants' support for welfare spending. The causes and consequences of welfare usage and welfare knowledgeability" ICS-dissertation, Nijmegen

264. Suwatin Miharti (2018), "Community health centers in Indonesia in the era of decentralization. The impact of structure, staff composition and management on health outcomes" ICS-dissertation, Groningen

265. Chaïm la Roi (2019), "Stigma and stress: Studies on attitudes towards sexual minority orientations and the association between sexual orientation and mental health" ICSdissertation, Groningen

266. Jelle Lössbroek (2019), "Turning grey into gold. Employer-employee interplay in an ageing workforce" ICS-dissertation, Utrecht

267. Nikki van Gerwen (2019), "Employee cooperation through training. A multi-method approach” ICS-dissertation, Utrecht

268. Paula Thijs (2019), "Trends in cultural conservatism: The role of educational expansion, secularisation, and changing national contexts" ICS-dissertation, Nijmegen

269. Renske Verweij (2019), "Understanding childlessness: Unravelling the link with genes and the socio-environment" ICS-dissertation, Groningen

270. Niels Blom (2019), "Partner relationship quality under pressing work conditions. Longitudinal and cross-national investigation” ICS-dissertation, Nijmegen 
271. Müge Simsek (2019), "The dynamics of religion among native and immigrant youth in Western Europe" ICS-dissertation, Utrecht

272. Leonie van Breeschoten (2019), "Combining a career and childcare: The use and usefulness of work-family policies in European organizations" ICS-dissertation, Utrecht

273. Roos van der Zwan (2019), "The political representation of ethnic minorities and their vote choice" ICS-dissertation, Nijmegen

274. Ashwin Rambaran (2019), "The classroom as context for bullying: A social network approach" ICS-dissertation, Groningen

275. Dieko Bakker (2019), "Cooperation and social control: Effects of preferences, institutions, and social structure” ICS-dissertation, Groningen

276. Femke van der Werf (2019), "Shadow of a rainbow? National and ethnic belonging in Mauritius" ICS-dissertation, Utrecht

277. Robert Krause (2019), “Multiple Imputation for Missing Network Data” ICS-dissertation, Groningen

278. Take Sipma (2020), “Economic insecurity and populist radical right voting” ICSdissertation, Nijmegen

279. Mathijs Kros (2020), "The nature of negative contact: studies on interethnic relations in western societies" ICS-dissertation, Utrecht

280. Lonneke van den Berg (2020), "Time to leave: Individual and contextual explanations for the timing of leaving home” ICS-dissertation, Amsterdam

281. Marianne Hooijsma (2020), “Clashrooms: Interethnic peer relationships in schools” ICSdissertation, Groningen

282. Marina Tulin (2020), "Blind Spots in Social Resource Theory: Essays on the Creation, Maintenance and Returns of Social Capital” ICS-dissertation, Amsterdam

283. Tessa Kaufman (2020), “Toward Tailored Interventions: Explaining, Assessing, and Preventing Persistent Victimization of Bullying” ICS-dissertation, Groningen

284. Lex Thijssen (2020), "Racial and Ethnic Discrimination in Western Labor Markets: Empirical Evidence from Field Experiments" ICS-dissertation, Utrecht

285. Lukas Norbutas (2020), “Trust on the Dark Web: An analysis of illegal online drug markets" ICS-dissertation, Utrecht

286. Tomáš Diviák (2020), “Criminal Networks: Actors, Mechanisms, and Structures” ICSdissertation, Groningen

287. Tery Setiawan (2020), "Support for Interreligious Conflict in Indonesia" ICS-dissertation, Nijmegen

288. Vera de Bel (2020), "The ripple effect in family networks. Relational structures and wellbeing in divorced and non-divorced families" ICS-dissertation, Groningen

289. Diego Palacios (2020), “How Context and the Perception of Peers' Behaviors Shape Relationships in Adolescence: A Multiplex Social Network Perspective” ICS-dissertation, Groningen

290. Saskia Glas (2020), “Where are the Muslim Feminists?: Religiosity and Support for Gender Equality in the Arab region" ICS-dissertation, Nijmegen

291. Tomas Turner-Zwinkels (2020), “A New Macro-Micro Approach to the Study of Political Careers: Theoretical, Methodological and Empirical Challenges and Solutions" ICSdissertation, Groningen 
292. Lotte Scheeren (2020), "Not on the Same Track? Tracking Age and Gender Inequality in Education" ICS-dissertation, Amsterdam

293. Joris Broere (2020), "Essays on how social network structure affects asymmetric coordination and trust" ICS-dissertation, Utrecht

294. Marcus Kristiansen (2021), “Contact with Benefits: How Social Networks affect Benefit Receipt Dynamics in the Netherlands" ICS-dissertation, Utrecht

295. Judith Kas (2021), "Trust and reputation in the peer-to-peer platform economy" ICSdissertation, Utrecht

296. Andrea Forster (2021), "Navigating Educational Institutions: Mechanisms of Educational Inequality and Social Mobility in Different Educational Systems" ICS-dissertation, Amsterdam

297. Jannes ten Berge (2021), "Technological change and work: The relation between technology implementation within organizations and changes in workers' employment” ICS-dissertation, Utrecht 

Despite concerns about the consequences of technological change for work, we have limited knowledge of how it impacts workers' employment in organizations. Ten Berge addresses this knowledge gap by studying how technology implementation within Dutch enterprises affects workers' job ending, the success of workers' job searches, and the organizational workforce's composition. Furthermore, he investigates how technology's consequences differ depending on the characteristics of workers, organizations, and the institutional context.

Results indicate that the effects of enterprises' technology implementation on employment are small. Technology seems to decrease rather than increase workers' chances of leaving the organization, but leavers engage in a somewhat more extended search for a new job. Insofar as technology affects employment, it appears to strengthen existing inequalities, disadvantaging lower educated and older employees and first-generation non-Western immigrant workers from non-Dutch speaking countries.

Jannes ten Berge obtained his Research Master's degree in Sociology and Social Research at Utrecht University. He conducted the PhD research presented in this book at the Interuniversity Center for Social Science and Methodology (ICS) and the Department of Sociology of Utrecht University. 